Copyright

by

Son Thanh Hoang

2013 
The Dissertation Committee for Son Thanh Hoang Certifies that this is the approved version of the following dissertation:

\section{Nanostructured Materials for Solar Energy Conversion}

\section{Committee:}

Charles Buddie Mullins, Supervisor

Allen J. Bard

Brian A. Korgel

Gyeong S. Hwang

Keith J. Stevenson 


\title{
Nanostructured Materials for Solar Energy Conversion
}

$$
\text { by }
$$

\section{Son Thanh Hoang, B. Chemistry}

\author{
Dissertation \\ Presented to the Faculty of the Graduate School of \\ The University of Texas at Austin \\ in Partial Fulfillment \\ of the Requirements \\ for the Degree of \\ Doctor of Philosophy
}

The University of Texas at Austin

May 2013 


\section{Dedication}

To Thanh and my parents for their loving support 


\section{Acknowledgements}

First, I would like to express my sincere appreciation to my advisor, Professor C. Buddie Mullins, for his guidance, encouragement, and patience over the last five years. I joined to Buddie's research group with very little experience. I have learned a lot from Buddie regarding work ethics, the design and maintenance of high quality instruments and experiments, and inspiration to become a better scientist, and for that I am thankful. I would like to thank Prof. Allen J. Bard for his invaluable comments and discussion.

I was also lucky to interact with a number of talented and friendly people in Buddie's group, especially photocatalyst subgroup. Sean Berglund has always been supportive, encouraging, and willing to listen when I have vented my frustration. Nathan Hahn made significant contributions to the work contained in chapter 2 and 3, and tolerated my 'silly' questions when I first switched to the new research area. I have always enjoyed talking with Hoang Dang, Alex Rettie, Will Chemelewski, Ting Yan, and Ming Pan. I also acknowledge several UT facility scientists and technical specialists, especially Danny, Butch Cunningham, Jim Smitherman, Dr. Dwight Romanovicz, and Dr. Hugo Celio, whose invaluable help with equipment fabrication and experimentation over the years made this work possible.

I would also like to express my gratitude to my friends outside of the lab who made my graduate school experience in the US memorable. I thank Hieu Le, Trang Dinh, Chi Hoang, Thong Ngo, Thuy Nguyen, Anh Nguyen, Khoa Do, and Tuyen Huynh for their friendship and encouragement.

Finally, I would like to express my deepest appreciation for Thanh, and my parents whose love, encouragement, and unfailing support made it possible to complete 
my grad school. I would not have been able to accomplish what I have today without your unconditional support. 


\title{
Nanostructured Materials for Solar Energy Conversion
}

\author{
Son Thanh Hoang, $\mathrm{PhD}$ \\ The University of Texas at Austin, 2013 \\ Supervisor: Charles Buddie Mullins
}

The energy requirements of our planet will continue to grow with increasing world population and the modernization of currently underdeveloped countries. This will force us to search for environmental friendly alternative energy resources. Solar energy by far provides the largest of all renewable energy resources with an average power of $120000 \mathrm{TW}$ irradiated from the sun which can be exploited through solar electricity, solar fuel, and biomass. Nanostructured materials have been the subject of extensive research as the building block for construction of solar energy conversion devices for the past decades. The nanostructured materials sometimes have peculiar electrical and optical properties that are often shape and size dependent and are not expected in the bulk phase. Recent research has focused on new strategies to control nanostructured morphologies and compositions of semiconductor materials to optimize their solar conversion efficiency. In this dissertation, we discuss the synthesis and characterizations of one dimensional nanostructured $\mathrm{TiO}_{2}$ based materials and their solar energy conversion applications.

We have developed a solvothermal synthesis method for growing densely packed, vertical, single crystalline $\mathrm{TiO}_{2}$ rutile nanowire arrays with unprecedented small feature sizes of $5 \mathrm{~nm}$ and lengths up to $4.4 \mu \mathrm{m}$. Because of $\mathrm{TiO}_{2}$ 's large band gap, the working spectrum of $\mathrm{TiO}_{2}$ is limited to the ultra violet region with photons shorter than $420 \mathrm{~nm}$. vii 
We demonstrate that the active spectrum of $\mathrm{TiO}_{2}$ can be shifted to $\sim 520 \mathrm{~nm}$ with incorporation of $\mathrm{N}$ via nitridation of $\mathrm{TiO}_{2}$ nanowires in $\mathrm{NH}_{3}$ flow. In addition, we demonstrate a synergistic effect involving hydrogenation and nitridation cotreatment of $\mathrm{TiO}_{2}$ nanowires that further redshift the active spectrum of $\mathrm{TiO}_{2}$ to $570 \mathrm{~nm}$. The Ta and $\mathrm{N}$ co-incorporated $\mathrm{TiO}_{2}$ nanowires were also prepared and showed significant enhancement in photoelectrochemical performance compared to mono-incorporation of $\mathrm{Ta}$ or $\mathrm{N}$. This enhancement is due to fewer recombination centers from charge compensation effects and suppression of the formation of an amorphous layer on the nanowires during the nitridation process. Finally, we have developed hydrothermal synthesis of single crystalline $\mathrm{TiO}_{2}$ nanoplatelet arrays on virtually all substrates and demonstrated their applications in water photo-oxidation and dye sensitized solar cells. 


\section{Table of Contents}

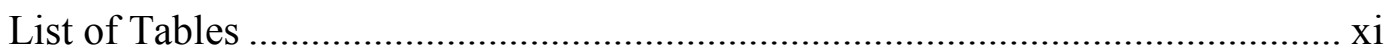

List of Figures .........................................................................................

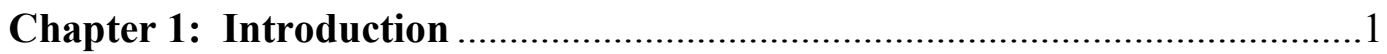

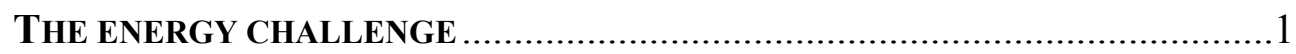

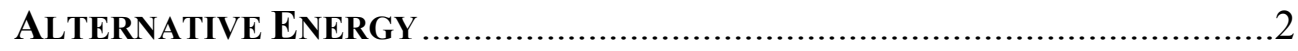

SOLAR HYDROGEN PRODUCTION FROM PHOTOELECTROCHEMICAL (PEC)

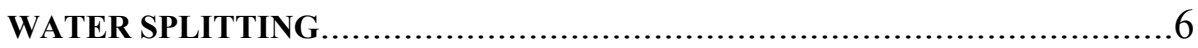

$\mathrm{TIO}_{2}$ AS THE PHOTOCATALYST FOR WATER SPLITTING …..........................

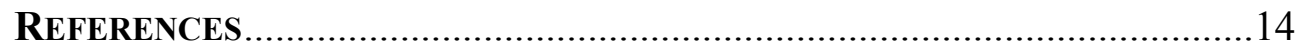

Chapter 2: Visible Light Driven Photoelectrochemical Water Oxidation on

Nitrogen-Modified TiO2 Nanowires .......................................................17

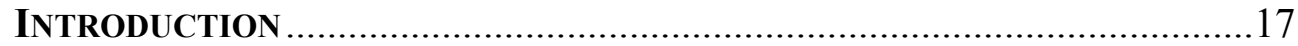

EXPERIMENTAL METHODS ………………………..............................19

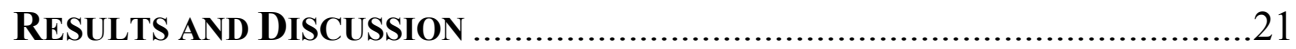

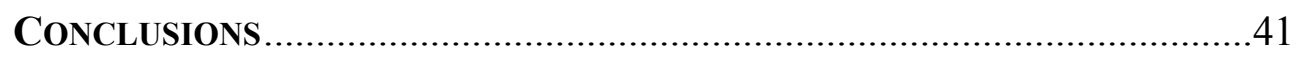

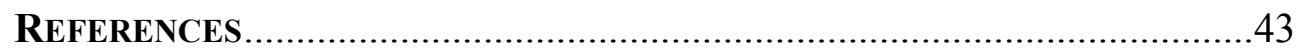

Chapter 3: Enhancing Visible Light Photo-Oxidation of Water with $\mathrm{TiO}_{2}$ Nanowire Arrays via Co-treatment with $\mathrm{H}_{2}$ and $\mathrm{NH}_{3}$ : Synergistic Effects

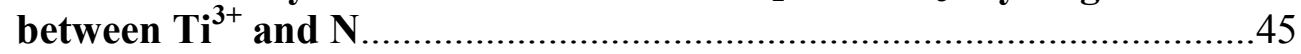

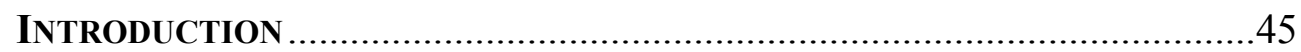

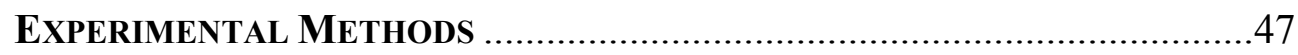

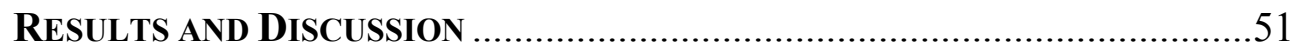

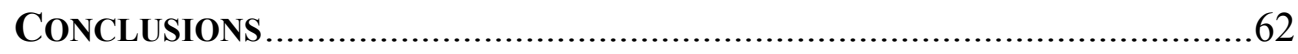

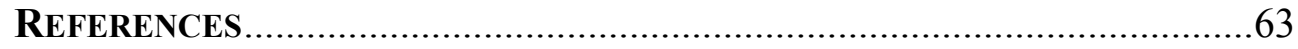

Chapter 4: Co-incorporation of $\mathrm{N}$ and $\mathrm{Ta}$ into $\mathrm{TiO}_{2}$ Nanowires for Visible-light Driven Photoelectrochemical Water Oxidation .....................................65

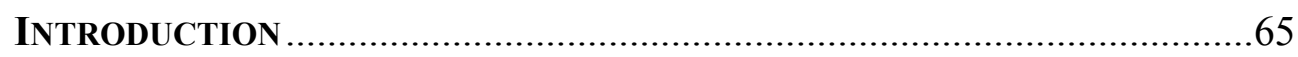

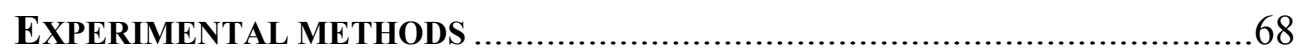




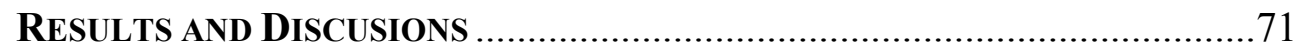

Synthesis and Characterization of Ta-incorporated $\mathrm{TiO}_{2}\left(\mathrm{Ta}_{\mathbf{T i O}}\right)$

Nanowire arrays....................................................................71

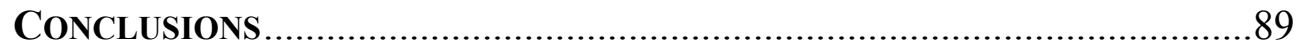

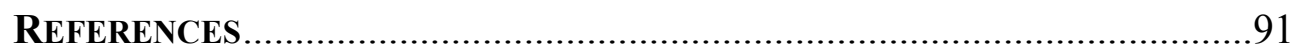

Chapter 5: Low Temperature Hydrothermal Synthesis of Vertically Aligned $\mathrm{TiO}_{2}$ Nanoplatelet Arrays for Solar Energy Conversion Applications..94

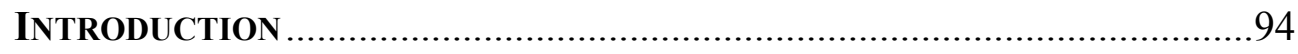

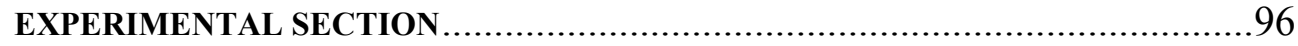

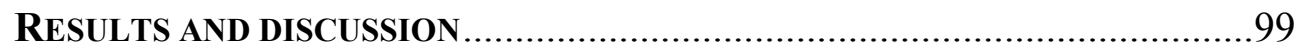

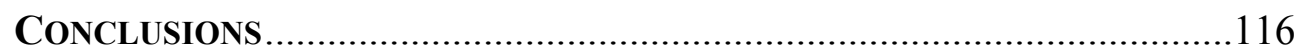

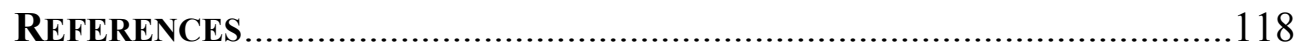

Chapter 6: Concluding Remarks and Future Research................................121

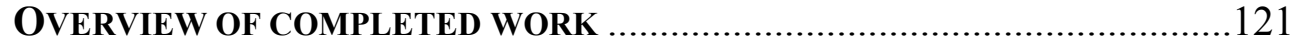

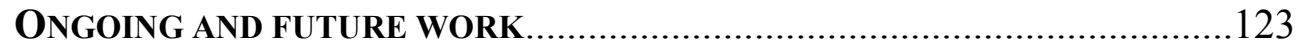

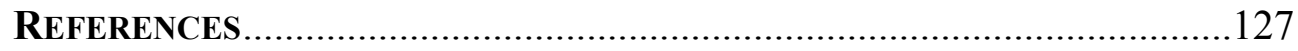

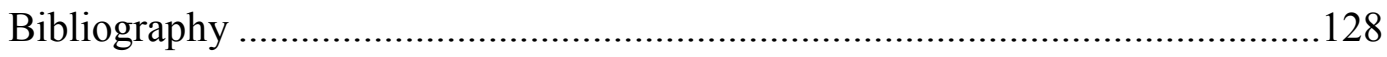

Vita 135 


\section{List of Tables}

Table 2.1. Thicknesses of some $\mathrm{TiO}_{2}$ nanowire arrays grown at $150{ }^{\circ} \mathrm{C}$ as a function of TTIP/n-hexane ratio, reaction time, and seeding layer.................25

Table 2.2. $\mathrm{N}$-dopant concentration in $\mathrm{TiO}_{2}$ nanowire films annealed at $500{ }^{\circ} \mathrm{C}$ in $\mathrm{NH}_{3}$ 


\section{List of Figures}

Figure 1.1. Energy consumption in the United States, China, and India, 1990-2035. ${ }^{1}$

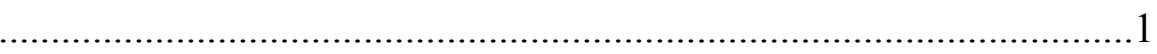

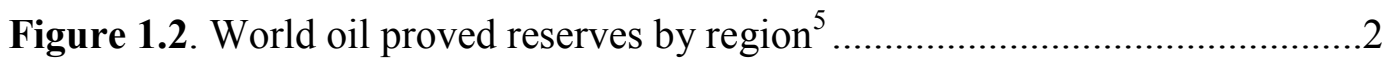

Figure 1.3. Reported timeline of solar cell energy conversion efficiencies...........4

Figure 1.4. A PEC cell for photo water splitting using an n-type semiconductor photoanode. ${ }^{10}$ .7

Figure 2.1. Vertically aligned single crystalline $\mathrm{TiO}_{2}$ rutile nanowire arrays on FTO glass: (a) cross-sectional and (b) top view SEM images, (c) HRTEM image, and (d) Grazing incidence angle x-ray diffraction (GIXRD) pattern

Figure 2.2. Morphology dependence of nanowire arrays on combinations of titanium precursors (i.e., titanium tetra-isopropoxide (TTIP) and titanium (IV) tetra-n-butoxide (TNBT)) and non-polar solvents (i.e., n-hexane and toluene). The scale bar applies to all the micrographs. 26

Figure 2.3. (a) Linear sweep voltammetry (LSV) measurements of $\mathrm{TiO}_{2}$ nanowire arrays $(1.6 \mu \mathrm{m})$ and the same film after cobalt treatment and (b) chronoamperometry measurement (at $1.23 \mathrm{~V}_{\mathrm{RHE}}$ ) of $\mathrm{TiO}_{2}$ nanowire arrays and the same film after cobalt treatment and silver treatment (cobalt treatment and silver treatment were performed on two different areas on the same $\mathrm{TiO}_{2}$ nanowire sample). All experiments were performed with $1 \mathrm{M} \mathrm{KOH}$ electrolyte $(\mathrm{pH}=13.5)$ and a $100 \mathrm{~W}$ Xenon lamp coupled with a UV/IR filter as the light source as described in the text. 
Figure 2.4. (a) Top-view SEM images of flower-like microparticles on top of the $\mathrm{TiO}_{2}$ nanowire arrays and (b) the nanostructure of the flower-like particles (zoom-in view of the dotted circle in S2-a) ......................30

Figure 2.5. Top-view SEM image of $\mathrm{TiO}_{2}$ nanowire arrays: as-synthesized film, film annealed in $\mathrm{NH}_{3}$ at $500{ }^{\circ} \mathrm{C}$ for 2 hours, film annealed in air at $500{ }^{\circ} \mathrm{C}$ for 0.5 hours, and film annealed in air at $500{ }^{\circ} \mathrm{C}$ for 0.5 hours, followed by nitridation at $500{ }^{\circ} \mathrm{C}$ for 2 hours. The scale bar applies for all micrographs. The insets show the digital images of the corresponding films on FTO substrates $(1.5 \mathrm{~cm} \times 1.5 \mathrm{~cm})$ 31

Figure 2.6. (a) Core $\mathrm{N}$ 1s XPS spectra of (1) anatase powder annealed in $\mathrm{NH}_{3}$ for two hours, (2) $\mathrm{TiO}_{2}$ nanowire film annealed in air for 30 minutes and then annealed in $\mathrm{NH}_{3}$ for two hours, (3) and (4) $\mathrm{TiO}_{2}$ nanowire films annealed in $\mathrm{NH}_{3}$ at $500{ }^{\circ} \mathrm{C}$ for one hour and two hours, respectively and (b) core $\mathrm{Ti} 2 \mathrm{p}$ XPS spectra of (1) as-synthesized $\mathrm{TiO}_{2}$ nanowire film and (2) a $\mathrm{TiO}_{2}$ nanowire film annealed in $\mathrm{NH}_{3}$ at $500{ }^{\circ} \mathrm{C}$ for two hours. 33

Figure 2.7. (a) Linear Sweep Voltammetry of the $\mathrm{TiO}_{1.988} \mathrm{~N}_{0.012}$ sample and the same electrode after cobalt treatment in darkness (dotted lines) and under illumination (solid lines), (b) IPCE spectra of $\mathrm{N}$-modified $\mathrm{TiO}_{2}$ films at 1.4 $\mathrm{V}_{\mathrm{RHE}}$ : blue curve and red curve are the corresponding IPCE spectra of the $\mathrm{TiO}_{1.988} \mathrm{~N}_{0.012}$ photoelectrode in figure $4 \mathrm{a}$, black curve is the IPCE of unmodified $\mathrm{TiO}_{2}$ sample after cobalt treatment, and green curve is the IPCE of the $\mathrm{TiO}_{1.957} \mathrm{~N}_{0.043}$ pretreated with cobalt, and (c) and (d) UV-vis absorbance spectra and UV-vis transmittance spectra of unmodified and $\mathrm{N}$-modified $\mathrm{TiO}_{2}$ nanowire samples, and an as-synthesized sample (black curve) was included as a reference 
Figure 2.8. (a) $\mathrm{XPS}$ valence band spectra of the $\mathrm{TiO}_{2}, \mathrm{TiO}_{1.988} \mathrm{~N}_{0.012}$, and

$\mathrm{TiO}_{1.957} \mathrm{~N}_{0.043}$ samples and (b) UPS spectra of the $\mathrm{TiO}_{2}$ and $\mathrm{TiO}_{1.957} \mathrm{~N}_{0.043}$ samples. The UPS spectra were calibrated versus the Fermi edge of a polycrystalline $\mathrm{Au}$ foil.

Figure 3.1. A typical incident light power density spectrum (from $320 \mathrm{~nm}-600 \mathrm{~nm}$ ) used for the IPCE measurements. The inset shows the incidence power density spectrum from $320 \mathrm{~nm}-350 \mathrm{~nm}$..........................................50

Figure 3.2. (a) Grazing incidence $\mathrm{XRD}$ patterns and (b) digital images of $\mathrm{TiO}_{2}, \mathrm{~N}-$ $\mathrm{TiO}_{2}, \mathrm{H}-\mathrm{TiO}_{2}$, and $\mathrm{H}, \mathrm{N}-\mathrm{TiO}_{2}$. .52

Figure 3.3. Scanning Electron Microscopy (SEM) images of (a) as-synthesized $\mathrm{TiO}_{2}$ (inset shows higher magnification view), and films annealed at $500{ }^{\circ} \mathrm{C}$ in (b) $\mathrm{NH}_{3}$, (c) $\mathrm{H}_{2}$, and (d) $\mathrm{H}_{2}$ and then $\mathrm{NH}_{3}$ 53

Figure 3.4. High resolution TEM images of (a) $\mathrm{H}, \mathrm{N}-\mathrm{TiO}_{2}$ and (b) $\mathrm{TiO}_{2}$ samples.54 Figure3.5. XPS spectra of the $\mathrm{TiO}_{2}, \mathrm{~N}-\mathrm{TiO}_{2}$, and $\mathrm{H}, \mathrm{N}-\mathrm{TiO}_{2} \mathrm{NW}$ arrays: (a) Core $\mathrm{N}$ $1 \mathrm{~s}$ and (b) Core Ti 2p. .54

Figure 3.6. EPR spectra recorded at $86 \mathrm{~K}$ for $\mathrm{TiO}_{2}, \mathrm{~N}-\mathrm{TiO}_{2}$ and $\mathrm{H}, \mathrm{N}-\mathrm{TiO}_{2}$ samples. The inset shows magnified view for the EPR spectra of the $\mathrm{TiO}_{2}$ and N$\mathrm{TiO}_{2}$ samples. .56 
Figure 3.7. (a) and (b) Linear Sweep Voltametry ( $5 \mathrm{mV} / \mathrm{s})$ and Chronoamperometry at $1.23 \mathrm{~V}_{\mathrm{RHE}}$ of the $\mathrm{H}, \mathrm{N}-\mathrm{TiO}_{2}$ sample, (c) IPCE spectra measured at 1.23 $\mathrm{V}_{\mathrm{RHE}}$, and (d) Normalized transmittance spectra. All PEC measurements were performed using a three-electrode electrochemical cell with a $\mathrm{Ag} / \mathrm{AgCl}$ reference electrode, a Pt wire counter electrode, and $1 \mathrm{M} \mathrm{KOH}$ electrolyte. A solar simulator (Oriel 96000) with an AM 1.5 G filter was used as the light source with light intensity of $100 \mathrm{~mW} / \mathrm{cm}^{2}$ measured by a thermopile detector (Newport, 818P-020-12). A UV filter that blocks all wavelengths $<420 \mathrm{~nm}$ was used for visible light experiments.

Figure 3.8. Chronoamperometry (CAM) measurement at $1.23 \mathrm{~V}_{\mathrm{RHE}}$ of the $\mathrm{H}, \mathrm{N}-\mathrm{TiO} 2$ sample. The measurement was performed using a three-electrode electrochemical cell with a $\mathrm{Ag} / \mathrm{AgCl}$ reference electrode, a Pt wire counter electrode, and $1 \mathrm{M} \mathrm{KOH}$ electrolyte. A solar simulator (Oriel 96000) coupling with an AM 1.5 G filter was used as the light source with light intensity of $100 \mathrm{~mW} / \mathrm{cm} 2$ measured by a thermopile detector (Newport, 818P-020-12). The measurement was performed in 3 sequential runs: run $\# 1$, run $\# 2$, and run \#3. After each run, we used a pipet to flush out bubbles forming on the $\mathrm{H}, \mathrm{N}-\mathrm{TiO}_{2}$ photoanode....58

Figure 3.9. Raw data of the UV-vis transmittance spectra of $\mathrm{FTO}$ substrate, $\mathrm{TiO}_{2}, \mathrm{H}$ $\mathrm{TiO}_{2}, \mathrm{~N}-\mathrm{TiO}_{2}$, and $\mathrm{H}, \mathrm{N}-\mathrm{TiO}_{2}$ samples 59

Figure 3.10. Proposed mechanism for the interaction between $\mathrm{Ti}^{3+}$ and substitutional N. 61

Figure 4.1. A typical incident light power density spectrum (from $320 \mathrm{~nm}-600 \mathrm{~nm}$ ) used for the IPCE measurements. 
Figure 4.2. Top-view Scanning Electron Microscopy (SEM) images of Ta: $\mathrm{TiO}_{2}$ nanowires synthesized with various amount of Ta precursor: (a) $0 \mathrm{~mL}$ (pristine $\mathrm{TiO}_{2}$ ), (b) $0.1 \mathrm{~mL}$, (c) $0.25 \mathrm{~mL}$, (d) $0.75 \mathrm{~mL}$, (e) $1.5 \mathrm{~mL}$, and (f) $2.5 \mathrm{~mL}$. The scale bar is applied for all the micrographs 72

Figure 4.3. SEM images of $\mathrm{TiO}_{2}$ nanowire arrays synthesized with addition of isopropanol (IPA): (a) $0 \mathrm{~mL}$, (b) $0.125 \mathrm{~mL}$, (c) $0.375 \mathrm{~mL}$, and (d) 1.25 $\mathrm{mL}$. The scale bar is applicable for all micrographs. .73

Figure 4.4. a) Core $\mathrm{Ta} 4 \mathrm{f} X P S$ spectra of $\mathrm{Ta}: \mathrm{TiO}_{2}$ nanowires synthesized with various amount of Ta precursor (1) $\mathrm{TiO}_{2},(2) \mathrm{Ta}: \mathrm{TiO}_{2}-075(0.75 \mathrm{~mL} \mathrm{Ta}$ precursor), and (3) $\mathrm{Ta}: \mathrm{TiO}_{2}-150(1.50 \mathrm{~mL}$ Ta precursor) and (b) atomic percentage of $\mathrm{Ta}$ in the $\mathrm{Ta}^{\mathrm{TiO}}{ }_{2}$ nanowires determined by XPS, the inset magnified the low Ta concentration region. 75

Figure 4.5. (a) Grazing incidence angle X-ray diffraction pattern of $\mathrm{Ta}^{\mathrm{TiO}} \mathrm{Ti}_{2}$ nanowires on $\mathrm{F}: \mathrm{SnO}_{2}$ coated substrates: $\mathrm{TiO}_{2}$ (black), Ta: $\mathrm{TiO}_{2}-025$ (blue), Ta: $\mathrm{TiO}_{2}-075$ (red), and $\mathrm{Ta}: \mathrm{TiO}_{2}-150$ (cyan) and HRTEM images of (b) $\mathrm{Ta}_{\mathrm{TiO}}-075$, (c) and (d) $\mathrm{Ta}_{2} \mathrm{TiO}_{2}-150$ .76

Figure 4.6. (a) SEM image of a chunk of Ta: $\mathrm{TiO}_{2}-150$ nanowire arrays, (b) EDX line scan profile acquired along the NW arrays shown in Figure 4.4a, (c) and (d) $\mathrm{Ti}$ and Ta elemental mapping of the $\mathrm{Ta}^{\mathrm{TiO}}{ }_{2}-150 \mathrm{NW}$ chunks shown in Figure 4.4a. 77 
Figure 4.7. (a) Photocurrent density at $1.23 \mathrm{~V}_{\mathrm{RHE}}$ of pristine $\mathrm{TiO}_{2} \mathrm{NW}$ sample and $\mathrm{Ta}: \mathrm{TiO}_{2} \mathrm{NW}$ samples with various amount of Ta precursor, (b) linear sweep voltammetry (LSV) (scan rate of $25 \mathrm{mV} / \mathrm{s}$ ) of $\mathrm{TiO}_{2}$ (black) and Ta:TiO $2-050$ (green) NW samples, (c) IPCE spectra measured at 1.23 $\mathrm{V}_{\mathrm{RHE}}$ and (d) UV-vis transmittance spectra of $\mathrm{TiO}_{2} \mathrm{NW}$ sample and Ta: $\mathrm{TiO}_{2}$ NW samples. All the PEC measurements were conducted using a three-electrode electrochemical cell with a $\mathrm{Ag} / \mathrm{AgCl}$ reference electrode, a Pt wire counter electrode, and $1 \mathrm{M} \mathrm{KOH}$ electrolyte. A solar simulator (Oriel 96000) with an AM 1.5 G filter with a light intensity of $100 \mathrm{~mW} / \mathrm{cm}^{2}$ was employed as the light source.

Figure 4.8. Digital images of $\mathrm{N}$, Ta-coincorporated $\mathrm{TiO}_{2}$ nanowire samples synthesized with various amount of Ta precursor (a) $0.25 \mathrm{~mL}$, (b) 0.75

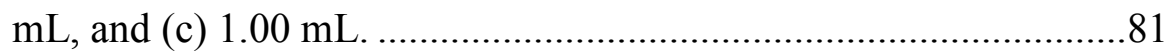

Figure 4.9. $\mathrm{XRD}$ of $\mathrm{N}: \mathrm{TiO}_{2}$ and $\mathrm{N}, \mathrm{Ta}: \mathrm{TiO}_{2}$ nanowire samples

Figure 4.10. SEM images of (a) $\mathrm{N}: \mathrm{TiO}_{2} \mathrm{NW}$ and (c) $\mathrm{N}, \mathrm{Ta}: \mathrm{TiO}_{2}-075 \mathrm{NW}$ and HRTEM images of (b) N:TiO 2 NW, and (d) N,Ta:TiO $2-075$ NW, (e) TEM images of N, Ta: $\mathrm{TiO}_{2}-250$ (NW) and (f) HRTEM images of N, $\mathrm{Ta}: \mathrm{TiO}_{2}-250 \mathrm{NW}$ (the area on the red box on figure 10e) 82

Figure 4.11. Top-view SEM images of $\mathrm{N}, \mathrm{Ta}: \mathrm{TiO}_{2}$ nanowires synthesized with various amount of Ta precursor: (a) $0 \mathrm{~mL}$ (pure $\mathrm{TiO}_{2}$ ), (b) $0.1 \mathrm{~mL}$, (c) $0.25 \mathrm{~mL}$, (d) $0.75 \mathrm{~mL}$, (e) $1.5 \mathrm{~mL}$, and (f) $2.5 \mathrm{~mL}$. The scale bar is applicable for all the micrographs .84

Figure 4.12. XPS spectra of core $\mathrm{N} 1 \mathrm{~s}$ for $\mathrm{TiO}_{2}$ (black), $\mathrm{N}: \mathrm{TiO}_{2}$ (red), $\mathrm{N}, \mathrm{Ta} \mathrm{TiO}_{2}-$ 050 (cyan), and $\mathrm{N}, \mathrm{Ta}: \mathrm{TiO}_{2}-075$ (blue). The feature at $\sim 400 \mathrm{eV}$ is assigned for $\mathrm{N}$ species absorbed on the surface. 
Figure 4.13. XPS spectra of (a) core $\mathrm{Ti} 2 \mathrm{p}$ and (b) core $\mathrm{O} 1 \mathrm{~s}$ for $\mathrm{TiO}_{2}$ (black), $\mathrm{N}: \mathrm{TiO}_{2}$ (red), N, Ta: $\mathrm{TiO}_{2}-050$ (cyan), and N, Ta: $\mathrm{TiO}_{2}-075$ (blue) .86

Figure 4.14. (a) Photocurrent density at $1.23 \mathrm{~V}_{\mathrm{RHE}}$ of $\mathrm{N}: \mathrm{TiO}_{2} \mathrm{NW}$ sample and N,Ta: $\mathrm{TiO}_{2} \mathrm{NW}$ samples with various amount of Ta precursor, (b) LSV (scan rate of $25 \mathrm{mV} / \mathrm{s}$ ) of $\mathrm{N}: \mathrm{TiO}_{2}$ (red) and N,Ta:TiO $2-075$ (blue) $\mathrm{NW}$ samples under AM 1.5 G (solid line) and visible light (> $420 \mathrm{~nm})($ dotted line), (c) IPCE spectra measured at $1.23 \mathrm{~V}_{\mathrm{RHE}}$ and (d) UV-vis transmittance spectra of $\mathrm{N}: \mathrm{TiO}_{2} \mathrm{NW}$ sample and $\mathrm{N}, \mathrm{Ta}: \mathrm{TiO}_{2}-075 \mathrm{NW}$ samples. All the PEC measurements were conducted using a threeelectrode electrochemical cell with a $\mathrm{Ag} / \mathrm{AgCl}$ reference electrode, a $\mathrm{Pt}$ wire counter electrode, and $1 \mathrm{M} \mathrm{KOH}$ electrolyte. A solar simulator (Oriel 96000) with an AM 1.5 G filter with a light intensity of 100 $\mathrm{mW} / \mathrm{cm}^{2}$ was employed as the light source. A UV filter blocking all wavelengths $<420 \mathrm{~nm}$ was used for visible light measurements. .....88

Figure 4.15. Mott-Schottky plots obtained at a frequency of $1 \mathrm{kHz}$ in the dark in $1 \mathrm{M}$ $\mathrm{KOH}$ electrolyte for the pristine $\mathrm{TiO}_{2}, \mathrm{Ta}: \mathrm{TiO}_{2}-075, \mathrm{~N}: \mathrm{TiO}_{2}$, and $\mathrm{N}$, $\mathrm{Ta}: \mathrm{TiO}_{2}-075$ nanowires. The inset enlarges the Mott-Schottky plot for the $\mathrm{N}, \mathrm{Ta}: \mathrm{TiO}_{2}-075$ nanowire samples........................................89

Figure 5.1. Typical light intensity for IPCE and EQE measurements .................98

Figure 5.2. Single crystalline rutile $\mathrm{TiO}_{2}$ nanoplatelet arrays on FTO glass: (a) crosssectional and (b) top view SEM images, (c) HRTEM image; the inset shows lattice resolved HRTEM image, and (d) X-ray diffraction (XRD) pattern. 100

Figure 5.3. XPS spectra of (a) core Ti $2 p$ and (b) core $\mathrm{O} 1 \mathrm{~s}$ and its fitting curves for $\mathrm{TiO}_{2}$ nanoplatelet arrays. 101 xviii 
Figure 5.4. Top-view $\mathrm{SEM}$ images of $\mathrm{TiO}_{2}$ films obtained at various $\mathrm{pH}$ of the precursor solution: (a) $\mathrm{pH}=1.2$, (b) $\mathrm{pH}=1.06$, (c) $\mathrm{pH}=0.71$, and (d) $\mathrm{pH}=0.66$. The scale bar applies to all micrographs. We note that there is no $\mathrm{TiO}_{2}$ film obtained when $\mathrm{pH}$ of the precursor solution is smaller than 0.6 or larger than 1.2 . 102

Figure 5.5. Top view SEM image of (a) FTO-coated glass substrate and timeevolution of $\mathrm{TiO}_{2}$ nanoplatelet growth: (b) after $135 \mathrm{~min}$, (c) after 150 min, and (d) after $165 \mathrm{~min}$. The scale bar applies for all micrograph. See Figure $5.1 \mathrm{~b}$ for the SEM image of the $\mathrm{TiO}_{2}$ film grown for $180 \mathrm{~min} .104$

Figure 5.6. (a) SEM image of micron-size powder aggregating on the bottom of the reactor and (b) Higher magnification image of the area in the red box 104

Figure 5.7. $\mathrm{SEM}$ images of $\mathrm{TiO}_{2}$ nanoplatelet grown on various substrates: (a) Ti foil, (b) glass, (c) Si wafer, and (d) polyethylene terephthalate (PET) plastic.

Figure 5.8. Top-view SEM images of $\mathrm{TiO}_{2}$ nanoplatelet arrays grown with various concentrations of $\mathrm{TiCl}_{3}$ solution: (a) $8 \mathrm{mM}$, (b) $12 \mathrm{mM}$, (c) $16 \mathrm{mM}$, (d) $24 \mathrm{mM}$, (e) $32 \mathrm{mM}$, and (f) $40 \mathrm{mM}$. The scale bar is applied for all micrographs. Note that the $\mathrm{pH}$ of the reaction solution is slightly changed with the addition of different amounts of $\mathrm{TiCl}_{3}$ solution..106

Figure 5.9. (a) UV-vis absorbance spectra of typical $\mathrm{TiO}_{2}$ nanoplatelet arrays. The inset shows the Tauc plot created for the absorbance values and (b) Photoluminescence emission spectrum (the black curve under the red curve which is the sum of the Gaussian fitted curves shown in green) from a typical $\mathrm{TiO}_{2}$ nanoplatelet film obtained at room temperature. The excitation wavelength is at $320 \mathrm{~nm}(3.88 \mathrm{eV})$. 108 
Figure 5.10. Mott-Schottky plot obtained in the dark in $1 \mathrm{M} \mathrm{KOH}$ electrolyte for a typical $\mathrm{TiO}_{2}$ nanoplatelet sample. 110

Figure 5.11. (a) Linear sweep voltammetry under intermittent AM $1.5 \mathrm{G}$ illumination and (b) IPCE spectrum at $1.2 \mathrm{~V}_{\mathrm{RHE}}$ for a typical $\mathrm{TiO}_{2}$ nanoplatelet film synthesized with a $16 \mathrm{mM} \mathrm{TiCl}_{3}$ precursor solution at $\mathrm{pH}$ of 0.71 . (c) PEC performance at $1.2 \mathrm{~V}_{\mathrm{RHE}}$ of $\mathrm{TiO}_{2}$ films synthesized at various $\mathrm{pH}$. All measurements were conducted using 3-electrode electrochemical cell with a $\mathrm{Ag} / \mathrm{AgCl}$ reference electrode, a Pt wire counter electrode, and 1 $\mathrm{M} \mathrm{KOH}$ electrolyte. 112

Figure 5.12. (a) Photocurrent density (solid line) and photoconversion efficiency (dotted line) of the DSSCs made of as-synthesized $\mathrm{TiO}_{2}$ nanoplatelets (red) and annealed $\mathrm{TiO}_{2}$ nanoplatelets (blue) under AM 1.5 G illumination $\left(100 \mathrm{~mW} / \mathrm{cm}^{2}\right)$; (b) External quantum efficiency of the DSSC made of annealed $\mathrm{TiO}_{2}$ nanoplatelets. 114

Figure 5.13. Electrical impedance spectroscopy (EIS) for DSSCs made of assynthesized (red line) and annealed (blue line) $\mathrm{TiO}_{2}$ nanoplatelets. The inset demonstrates the equivalent circuit of the cell consisting of the counter electrode $(\mathrm{CE}) /$ redox electrolyte interface and the $\mathrm{TiO}_{2} /$ dye/redox electrolyte interface, where $\mathrm{R} 1$ and $\mathrm{R} 2$ are the respective resistances, CPE1 and CPE2 are the respective constant phase elements, and Rs is the sheet resistance of FTO, Pt-coated FTO substrates and the resistance of electrolyte. 116

Figure 6.1. Various approaches for material design for water splitting application. 124 
Figure 6.2. (a) Scanning electron micrograph of a $\mathrm{Nb}$-incorporated $\mathrm{TiO}_{2}$ hierarchical microsphere (HS), (b) incident-photon-to-current conversion efficiency (IPCE) spectra of dye sensitized solar cells employing $\mathrm{TiO}_{2}$ anatase nanoparticles (cyan), $\mathrm{TiO}_{2} \mathrm{HS}$ (black) and $\mathrm{Nb}$-incorporated $\mathrm{TiO}_{2}$ materials (blue and red). 


\section{Chapter 1: Introduction}

\section{THE ENERGY CHALLENGE}

The world energy demand continues to increase due to population growth and industrialization and modernization of the developing countries. The energy use in China was estimated to surpass in 2009 and is projected to be $68 \%$ higher in 2035 than that for the United States (Figure 1.1). ${ }^{1}$

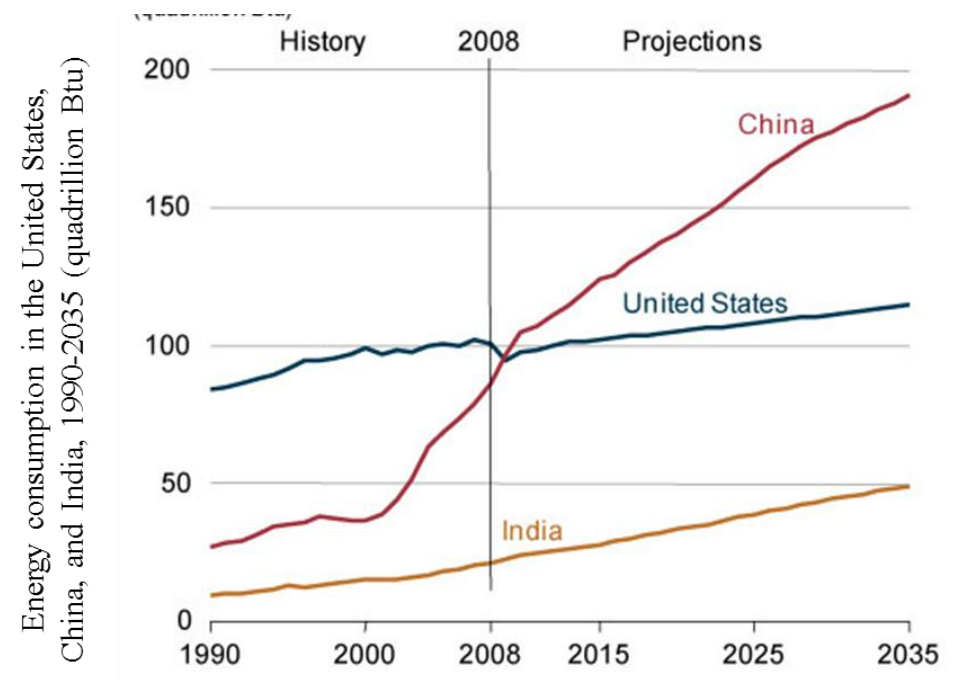

Figure 1.1. Energy consumption in the United States, China, and India, 1990-2035. ${ }^{1}$

In 2001, the global power consumption rate was 13 tetrawatts (TW), equivalent to $4.1 \times 10^{20}$ joules/year of which $86 \%$ comes from fossil fuels. ${ }^{2,3}$ The energy demand is projected to more than double (30 TW) by 2050 and more than triple (46 TW) by $2100 .^{3}$ In the short term, fossil fuels will still be extensively employed, but the production will attain the peak and decline eventually given a finite reserve. ${ }^{4}$ In addition to the increase in the scarcity of fossil fuels, the geographical distribution of fossil fuel reserves has become more and more apparent in global politics since the largest oil reserves are 
located in the politically unstable regions, such as the Middle East (Figure 1.2). Moreover, the over-consumption of fossil fuels leads to the emission of a number greenhouse gases and pollutants causing global climate changes. Finding alternative sustainable and environmental friendly energy resources to fill in the huge energy gap (17 TW by 2050 and 33 TW by 2100) is still the most daunting challenge for all human society.

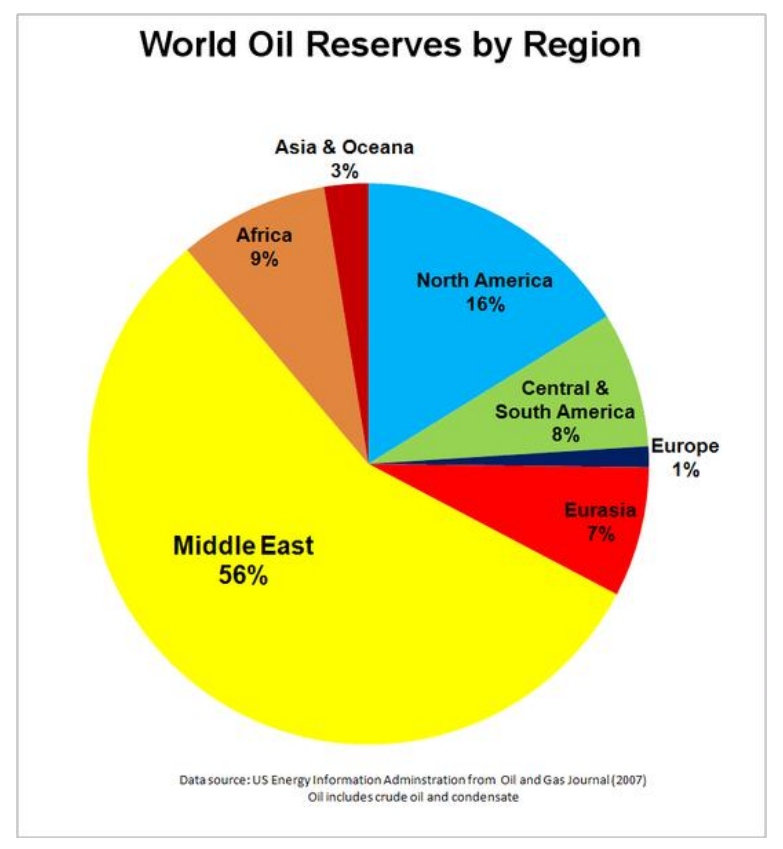

Figure 1.2. World oil proved reserves by region ${ }^{5}$

\section{Alternative Energy}

In order to maintain our current lifestyle, it is obvious that we will need to seek environmentally friendly alternative energy resources to fill the energy gap. A number of options exist such as carbon neutral energy, nuclear power, and renewable energy. Carbon neutral energy refers to technology that employs fossil fuels in conjunction with carbon sequestration to achieve a net zero carbon footprint or zero carbon emissions. The 
challenge now is not only doubling fossil fuel production (which is already at the peak) but also finding a secure storage for $\sim 30$ billion metric tons of $\mathrm{CO}_{2}$ produced annually to obtain the additional $13 \mathrm{TW}$ of energy. If nuclear power is entirely used to fill the energy gap, it will require construction of $\sim 13,0001 \mathrm{GW}$-electric nuclear power plans by 2050 , i.e. it will require construction of a new nuclear power plan every day for the next 50 years.

The renewable energy resources include hydroelectric resources $(0.5 \mathrm{TW})$, tides and ocean currents (2 TW), geothermal (12 TW), wind power (2-4 TW), and solar energy (120 $000 \mathrm{TW})$ which can be exploited through solar electricity, solar fuel, and biomass. Clearly, the potential capacity of solar energy outperforms other options although the contribution of energy produced from solar to the total energy demand is still quite modest. Solar electricity contributes less than $0.1 \%$ of the world electricity and biomass contributed less than $1.5 \%$ of the world's energy. 3,4

The sun irradiates the earth's surface with $\sim 120000 \mathrm{TW}$ of power, i.e. more energy from the sunlight striking the earth in one hour than the global energy consumed in one year. It means that by covering $0.16 \%$ of the earth surface with $10 \%$ solar conversion efficiency devices, we could generate $20 \mathrm{TW}$ to meet global demands for carbon-neutral energy in the second half of the $21^{\text {st }}$ century. ${ }^{3}$ The solar cell market is one of fastest growing markets with growing rate of 35-40\%. Providing a total capacity of 1200 MW reported for 2004, it would reach 20 TW in 2036 with a sustained $35 \%$ annual growth rate. ${ }^{6}$ In addition, solar energy is decentralized on a global scale, thus minimizing national security dependence.

Although solar energy is ideal to meet the projected demand, significant advances in science and technology are required to attain higher solar conversion efficiency and cheaper devices. Figure 1.3 shows the best solar cell (photovoltaic, PV) efficiency in 
research. The multi-junction cells demonstrate the highest efficiency, the most dominant direct solar conversion technology, however, is still the single-crystal silicon based photovoltaic devices which are commercially available with a $15 \%$ efficiency. ${ }^{3}$ However, these devices suffer from high cost of manufacturing and installation. Therefore extensive research is needed to develop more cost-effective strategies to convert solar energy. Thin film technology using polycrystalline semiconductors such as $\mathrm{CuInGaSe}_{2}, \mathrm{CdTe}, \mathrm{Si}$ or amorphous $\mathrm{Si}-\mathrm{H}$ can bring the cost down significantly due to smaller raw materials required for manufacturing. Dye sensitized solar cells have also gained considerable interest since their main compounds consisting of earth-abundant elements $\left(\mathrm{TiO}_{2}\right)$ which are necessary to enlarge installation scale to the TW-scale.

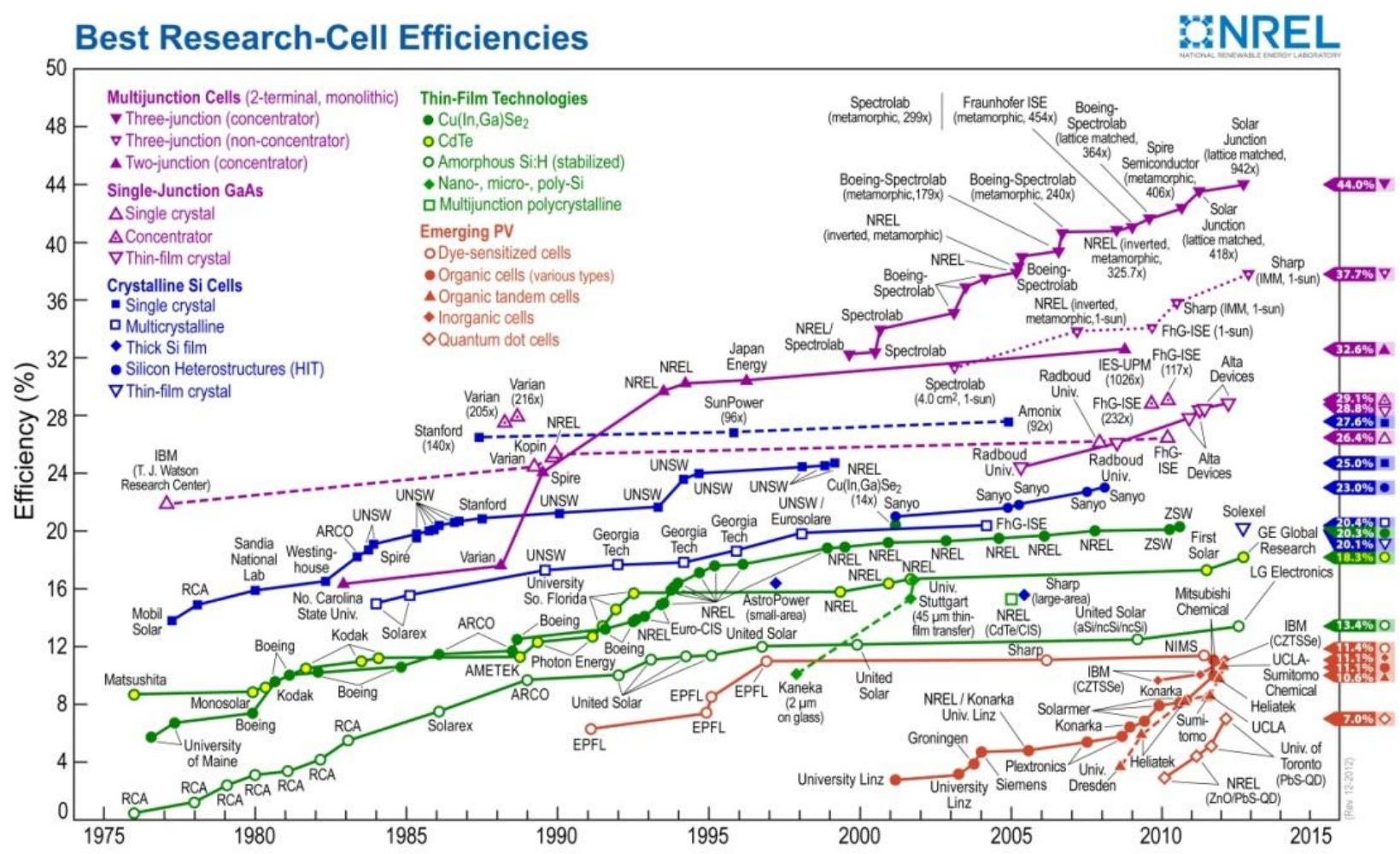

Figure 1.3. Reported timeline of solar cell energy conversion efficiencies 
One of the challenges for solar cells technology is the intermittent and time variant nature of sunlight. Local, seasonal, and diurnal weather patterns introduce difficulty in matching the electricity energy supply and demand. More importantly, the solar cell can only generate electricity during daytime. Therefore, efficient energy storage strategies are needed for solar energy utilization in large-scale. There are number of options existed such as electrochemical systems such as batteries, and chemical energy carriers, i.e. fuels such as hydrogen. Hydrogen is one of the most promising candidates due to its high energy and power densities and its flexibility regarding conversion to other forms of energy such as heat via combustion or electricity via fuel cells. In addition, consumption of $\mathrm{H}_{2}$ either via combustion or reaction in fuel cells produces only $\mathrm{H}_{2} \mathrm{O}$ which is harmfulness to the environment, therefore bringing up interest in the future prospect of a so-called "Hydrogen Economy" - a proposed system of delivering energy using hydrogen as the fuel. Numerous research efforts are currently focusing on developing strategies for the efficient production, storage, transportation, and utilization of hydrogen.

Hydrogen is also a valuable basic chemical feedstock itself, used with large quantities in ammonia synthesis (mostly for fertilizer market) and petroleum refining. The current primary source of hydrogen is the steam reforming of hydrocarbons (e.g. methane). This method requires consumption of fossil fuel feedstock associated with production of $\mathrm{CO}_{2}$ (5.5 tons of $\mathrm{CO}_{2}$ are made for every ton of $\mathrm{H}_{2}$ ), thus is not a sustainable strategy for long-term hydrogen production. Alternative $\mathrm{H}_{2}$ production methods exist such as electrolysis of water using electricity and water, biological production methods via fermentative conversion of organics to bio-hydrogen, and thermochemical water splitting etc. Beside steam reforming, electrolysis of water is still 
the most developed technology to produce hydrogen which contributes to roughly $4 \%$ of hydrogen produced in US despite the high cost of electricity (consuming approximately 50 kilowatt-hours of electricity per kilogram of hydrogen produced) and electrolyzer systems.

The straightforward method to utilize sunlight and water for sustainable production of $\mathrm{H}_{2}$ is by coupling solar cells with electrolyzer systems. However, a large current density of $\sim 1 \mathrm{~A} \mathrm{~m}^{-2}$, thus a high cell voltage $(1.9 \mathrm{~V})$ required for this system sets the limit of the electricity-to-hydrogen efficiency at around $65 \%$ since the thermodynamic potential required for water splitting is $1.23 \mathrm{eV}{ }^{6}$ The fusion of two systems, solar cells and electrolyzers, into a single device namely photo-electro-chemical cells is much more attractive since it reduces the capital costs and allows relatively low current densities and overpotentials for water splitting reaction, thus higher overall energy conversion efficiencies.

\section{SOLAR HYDROGEN PRODUCTION FROM PHOTOELECTROCHEMICAL (PEC) WATER SPLITTING}

Solar hydrogen production via the photoelectrolysis of water using semiconductors is considered as the "Holy Grail" of chemistry. ${ }^{7}$ The Gibbs free energy for the conversion of one mole of $\mathrm{H}_{2} \mathrm{O}$ (liquid) to 1 mole of $\mathrm{H}_{2}$ (gas) and $1 / 2$ mole of $\mathrm{O}_{2}$ (gas) is $237.2 \mathrm{~kJ}$, corresponding to $\Delta \mathrm{E}^{\mathrm{o}}=1.23 \mathrm{~V}$ per electron transferred. ${ }^{8}$ It means that for electrochemical decomposition of water, a potential difference of $1.23 \mathrm{~V}$ or more is thermodynamically required between anode and cathode. This potential difference is equivalent to the energy of photon with a wavelength of $1008 \mathrm{~nm}$ or shorter, indicating that water can be decomposed using visible light. Since water does not absorb visible light, water can only be decomposed directly under irradiation of wavelengths shorter 
than $190 \mathrm{~nm}$. In 1972, Fujishiima and Honda first reported electrochemical photolysis of water on $\mathrm{TiO}_{2}$ rutile photoanode under ultra violet irradiation. ${ }^{9}$

Figure 1.4 shows the operation principle for a photo-electrochemical water splitting cell using an n-type semiconductor as the photoanode and a metal cathode (usually $\mathrm{Pt}$ ). Upon absorption of a photon having energy equal or higher than the band gap energy, an electron is promoted from the valence band into the conduction band of the semiconductor, leaving a positive charge called "hole" in the valence band. The photogenerated electrons and holes are then separated by an electric field close to the interface between the semiconductor and the electrolyte. This electric field is formed during the formation of a Schottky-type contact between the semiconductor and the electrolyte. The photogenerated electrons travel to the back contact and are then transported to the counter electrode where they reduce water, forming hydrogen. The positive charge 'holes' migrate to the interface, where they oxide water to produce oxygen.

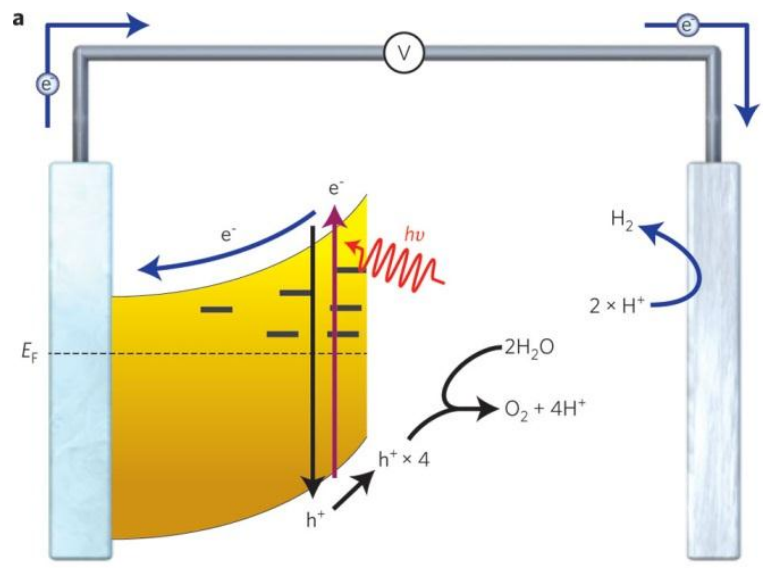

Figure 1.4. A PEC cell for photo water splitting using an n-type semiconductor photoanode. ${ }^{10}$ 
Solar-to-hydrogen (STH) efficiencies are determined as the chemical energy stored in hydrogen molecules divided by the solar energy input. In a PEC cell, assuming that all the current flows through the outer circuit corresponds to the water splitting reaction, the STH efficiency can be obtained using Equation (1): ${ }^{6,11}$

$$
\eta_{S T H}=\frac{j\left(V_{\text {redox }}-V_{B}\right)}{P_{\text {light }}}
$$

where $\mathrm{j}$ is the photocurrent density $\left(\mathrm{mA} \mathrm{cm}^{-2}\right), \mathrm{V}_{\text {redox }}$ is the potential required for water splitting $(1.23 \mathrm{~V}), \mathrm{V}_{\mathrm{B}}(\mathrm{V})$ is the bias voltage applied between the oxygen-evolving photoanode and the hydrogen-evolving photocathode, and $\mathrm{P}_{\text {light }}$ is the incident light intensity $\left(\mathrm{mW} \mathrm{cm}^{-2}\right)$.

In order to compete with the current industrial hydrogen production technology, the common target STH efficiency required for a PEC cell is $10 \%$ with a lifetime of at least 10 years. $^{7}$ The world-record STH efficiency of $12.4 \%$ cell using GaAs/GaInP2 photocathode wired to a Pt anode was reported by Turner et al. in $1998,{ }^{12}$ however, the materials were expensive and unstable in aqueous environments under illumination. Significant research efforts have focused on discovering and developing efficient photoactive materials. For efficient solar hydrogen production, the photoactive materials have to satisfy the following requirements:

1. Abundance and low-cost

2. High chemical stability in aqueous solution under illumination

3. Suitable band edge positions to enable reduction/oxidation of water: the conduction band minimum (CBM) and the valence band maximum (VBM) should straddle the oxygen and hydrogen evolution potentials.

4. High visible light absorption

5. Efficient charge transport

6. Low overpotentials for the reduction/oxidation reactions of water 
Despite enormous research effort during past 4 decades, there is still no known material that satisfies all the requirements mentioned above. Materials showing high activity tend to be not photo-stable in aqueous solution, such as materials used for solar cells. Vice versa, those demonstrating good stability tend to show poor solar conversion properties, such as $\mathrm{TiO}_{2}, \mathrm{a}-\mathrm{Fe}_{2} \mathrm{O}_{3}$, and $\mathrm{BiVO}_{4}$ etc. Besides discovering new materials, strategies to develop efficient PEC materials include improving solar conversion properties of stable materials and stabilizing active materials. In our research, we focus on optimizing PEC performance of $\mathrm{TiO}_{2}$ - a stable but wide band gap material via improving charge transport properties and visible light absorption properties.

\section{TIO $_{2}$ AS THE PHOTOCATALYST FOR WATER SPLITTING}

Since the first demonstration of its application in photoeletrolysis of water, $\mathrm{TiO}_{2}$ has been the subject of extensive research, which has led to not only PEC water splitting but also many other applications such as photo-assisted oxidation of oil and organics, gas sensors, catalyst supports, the Li-ion battery, etc. ${ }^{13-15}$ In fact, $\mathrm{TiO}_{2}$ is still the most studied material for water splitting application due to its abundance, photo-stability in aqueous solution, high photocatalytic activity, and electronic band structures with the band edges straddling the water redox potentials. ${ }^{13,16,17}$ However, due to its large band gap $(\sim 3.2$ eV), $\mathrm{TiO}_{2}$ can only utilize ultraviolet (UV) photons that contribute $\sim 5 \%$ of the total energy of the solar spectrum. ${ }^{18-21}$ There have been numerous investigations regarding the band structure engineering and band gap narrowing of $\mathrm{TiO}_{2}$ in order to shift its absorption spectrum to visible light, which represents a greater portion of the energy in the solar

spectrum. ${ }^{17,22-26}$ For spontaneous photoelectrochemical (PEC) splitting of water without an applied bias, the band edges of the semiconductors must straddle the thermodynamic water redox potentials. ${ }^{17,25}$ The band edge alignments of $\mathrm{TiO}_{2}$ satisfy this requirement in 
which the conduction band minimum $(\mathrm{CBM})$ is $\sim 0.3-0.4 \mathrm{eV}$ more negative than the hydrogen production potential, whereas the valence band maximum (VBM) is far below ( $\sim 1.6 \mathrm{eV}$ more positive) the oxygen production potential. ${ }^{17}$ Ideally, for efficient solar water splitting without bias, the $\mathrm{CBM}$ of $\mathrm{TiO}_{2}$ should remain as is or slightly shift closer to the vacuum level (more negative on the electrochemical scale) and the valence band maximum should also shift in the same direction so that the band gap reduces to $\sim 2 \mathrm{eV}$ accordingly. ${ }^{17,23,25}$

Monodoping $\mathrm{TiO}_{2}$ with $3 \mathrm{~d}$ transitional metals $\left(\mathrm{V}^{13,14}\right.$ and $\left.\mathrm{Cr}^{13}\right)$ has gained some success in extending the absorption spectrum to the visible region by introducing a donor level under the conduction band, ${ }^{27,28}$ however the decrease in carrier mobility due to the formation of strongly localized d states within the band gap and the existence of a carrier recombination center significantly reduce the photo-induced current. ${ }^{27-33}$ Monodoping with anions such as $\mathrm{N},{ }^{23,34} \mathrm{C},{ }^{35}$ and $\mathrm{S}^{36}$ has been of interest because the $\mathrm{p}$ states of incorporated anions $(\mathrm{N}, \mathrm{C}$, or $\mathrm{S}$ ) normally create an impurity band above the VBM or hybridization with $\mathrm{O} 2 \mathrm{p}$ states, thus narrowing the band gap and keeping the CBM the same. Coincorporation of both metal cations and non-metal anions into $\mathrm{TiO}_{2}$ has been proposed as a new approach for engineering the band structure. ${ }^{17,25,37-40}$ The neutralization of positive and negative charges in the $\mathrm{TiO}_{2}$ lattice created by coincorporation reduces the charge recombination centers, thus enhancing the photocatalytic activity. Moreover, co-incorporation of metal ions and nonmetal ions can help overcome solubility limits, improve material quality, and enhance optical absorption. $^{25}$

Besides engineering the band structure, it is also very important to enhance the charge transport characteristics of materials. Vertically oriented one dimensional (1D) nanostructures such as nanowires, nanorods, nanotubes etc., have been demonstrated to 
be advantageous over planar geometries because these 1D structures provide comparable penetration depth while still decreasing the diffusion distance of the minority charge carrier (holes for n-type and electrons for p-type semiconductors) to the electrolyte. ${ }^{6,41-44}$

This thesis is divided into six chapters. Chapter 1 provides general background regarding the motivation and strategies to develop solar energy conversion and storage solutions. Background on photoelectrochemical water splitting cell and $\mathrm{TiO}_{2}$ as one of the PEC materials is also discussed on this chapter. The following four chapters provide more details on studies regarding synthesis and characterizations of nanostructured $\mathrm{TiO}_{2}$ materials for the PEC energy conversion applications. These studies have been submitted to or published in peer-reviewed journals. In the final chapter, chapter 6, we present several conclusions from studies in chapter 2-5 and recommendations for future research along these lines.

In chapter 2, we present a solvothermal synthesis of single crystalline $\mathrm{TiO}_{2}$ nanowire arrays with unprecedented small feature sizes of $\sim 5 \mathrm{~nm}$ and lengths up to 4.4 $\mu \mathrm{m}$. A substantial amount of nitrogen (up to 1.08 atomic \%) can be incorporated into the $\mathrm{TiO}_{2}$ lattice via nitridation in $\mathrm{NH}_{3}$ flow at relatively low temperature $\left(500{ }^{\circ} \mathrm{C}\right)$ because of the small cross-section of the nanowires, leading to a significant redshift in the active spectra of $\mathrm{N}$-modified $\mathrm{TiO}_{2}$ with the low-energy threshold of the incident-photon to current efficiency located at $\sim 520 \mathrm{~nm}(2.4 \mathrm{eV})$. We also report a simple cobalt treatment for improving the PEC performance of our $\mathrm{N}$-modified $\mathrm{TiO}_{2}$ nanowire arrays.

In chapter 3, we demonstrate a strategy to further improve the PEC performance of our $\mathrm{TiO}_{2}$ materials under visible light illumination via a synergistic effect involving hydrogenation and nitridation co-treatment of $\mathrm{TiO}_{2}$ nanowire arrays. The active spectra of the cotreated- $\mathrm{TiO}_{2}$ nanowires extend to $570 \mathrm{~nm}$, compared to $\sim 550 \mathrm{~nm}$ for the $\mathrm{TiO}_{2}$ 
nanowires solely nitrided. We speculate that the interactions between substitutional $\mathrm{N}$ and $\mathrm{Ti}^{3+}$ are responsible for this enhancement.

In chapter 4, we demonstrate the synthesis of $\mathrm{N}$ and Ta-coincorporated $\mathrm{TiO}_{2}(\mathrm{~N}$, Ta: $\left.\mathrm{TiO}_{2}\right)$ and Ta-incorporated $\mathrm{TiO}_{2}\left(\mathrm{Ta}: \mathrm{TiO}_{2}\right)$ nanowire (NW) arrays and their application as photoanodes for water photo-oxidation. Tantalum is incorporated into $\mathrm{TiO}_{2}$ NWs with concentrations ranging from 0.11 to 3.47 atomic $\%$ by a simple solvothermal synthesis. $\mathrm{N}, \mathrm{Ta}: \mathrm{TiO}_{2}$ nanowires are prepared via nitridation of $\mathrm{Ta}: \mathrm{TiO}_{2}$ nanowires in $\mathrm{NH}_{3}$ flow at a relatively low temperature. $\mathrm{N}, \mathrm{Ta}: \mathrm{TiO}_{2} \mathrm{NWs}$ with the optimum Ta concentration of 0.29 at. $\%$ also demonstrate significant enhancement in PEC performance with the photocurrent reaching $0.52 \mathrm{~mA} / \mathrm{cm}^{2}$ and $0.18 \mathrm{~mA} / \mathrm{cm}^{2}$ under $\mathrm{AM}$ $1.5 \mathrm{G}$ and visible light $(>420 \mathrm{~nm})$ illumination, compared with $0.26 \mathrm{~mA} / \mathrm{cm}^{2}$ and 0.13 $\mathrm{mA} / \mathrm{cm}^{2}$ for that of $\mathrm{N}: \mathrm{TiO}_{2} \mathrm{NWs}$, although the active spectrum of the $\mathrm{N}, \mathrm{Ta}^{\mathrm{T}} \mathrm{TiO}_{2} \mathrm{NW}$ sample only extends to $\sim 520 \mathrm{~nm}(2.38 \mathrm{eV})$, compared to $\sim 540 \mathrm{~nm}(2.30 \mathrm{eV})$ for N:TiO 2 NWs. We believe that the enhancement shown by the N, Ta-coincorporated sample is due to less recombination centers from charge compensation effects and suppression of the formation of an amorphous layer on the nanowires during the nitridation process.

In chapter 5, we report a facile, scalable, low cost, and low temperature $\left(80{ }^{\circ} \mathrm{C}\right)$ hydrothermal synthesis of vertically aligned $\mathrm{TiO}_{2}$ nanoplatelet arrays on various substrates including fluorine-doped tin oxide coated glass substrates and their applications for PEC water splitting and dye sensitized solar cells. The $\mathrm{TiO}_{2}$ arrays consisting of single crystal rutile nanoplatelets with heights (film thicknesses) of up to 1 $\mu \mathrm{m}$, lengths of up to $130 \mathrm{~nm}$, and widths of $\sim 5 \mathrm{~nm}$ were grown via controlling oxidation and hydrolysis of $\mathrm{TiCl}_{3}$ at low $\mathrm{pH}(0.71-0.85)$ and low $\mathrm{TiCl}_{3}$ concentration $(8-40 \mathrm{mM})$. As a photoanode for water oxidation in a $\mathrm{PEC}$ water splitting cell, the $\mathrm{TiO}_{2}$ nanoplatelets show excellent charge separation characteristics with a saturated photocurrent in $1 \mathrm{M}$ 
$\mathrm{KOH}$ electrolyte under $\mathrm{AM} 1.5 \mathrm{G}$ illumination of $\sim 0.4 \mathrm{~mA} / \mathrm{cm}^{2}$ reached at an exceptionally low bias of $-0.6 \mathrm{~V}$ vs $\mathrm{Ag} / \mathrm{AgCl}(0.4 \mathrm{~V}$ vs. reversible hydrogen electrode). Dye sensitized solar cells assembled using N719 dye sensitized- $\mathrm{TiO}_{2}$ nanoplatelet arrays also show promising performance with photoconversion efficiencies of $1.28 \%$ for assynthesized (no thermal post-treatment) and $3.7 \%$ for annealed $\mathrm{TiO}_{2}$ nanoplatelets. 


\section{REFERENCES}

(1) US Energy Information Administration, International Energy Outlook 2011.

(2) Lewis, N. S.; Nocera, D. G. PNAS 2006, 103, 15729.

(3) Lewis, N. S.; Crabtree, G. W. "Basic Research Needs for Solar Energy Utilization: Report on the Basic Energy Sciences Workshop on Solar Energy Utilization,” 2005.

(4) Kamat, P. V. J. Phys. Chem. C 2007, 111, 2834.

(5) Administration, U. S. E. I. 2007.

(6) van de Krol, R.; Liang, Y. Q.; Schoonman, J. J. Mater. Chem. 2008, 18, 2311.

(7) Bard, A. J.; Fox, M. A. Acc. Chem. Res. 1995, 28, 141.

(8) Walter, M. G.; Warren, E. L.; McKone, J. R.; Boettcher, S. W.; Mi, Q.; Santori, E. A.; Lewis, N. S. Chem. Rev. 2010, 110, 6446.

(9) Fujishima, A.; Honda, K. Nature 1972, 238, 37.

(10) Tachibana, Y.; Vayssieres, L.; Durrant, J. R. Nature Photonics 2012, 6, 511.

(11) Chen, Z. B.; Jaramillo, T. F.; Deutsch, T. G.; Kleiman-Shwarsctein, A.; Forman, A. J.; Gaillard, N.; Garland, R.; Takanabe, K.; Heske, C.; Sunkara, M.; McFarland, E. W.; Domen, K.; Miller, E. L.; Turner, J. A.; Dinh, H. N. J. Mater. Res. 2010, 25, 3.

(12) Khaselev, O.; Turner, J. A. Science 1998, 280, 425.

(13) Chen, X.; Mao, S. S. Chem. Rev. 2007, 107, 2891.

(14) Pishko, M. V.; Cook, J. P.; Heller, E.; Schwitzgebel, J.; Gunawan, G.; Ekerdt, J. G.; Heller, A. Abstracts of Papers of the American Chemical Society 1994, 207, 208.

(15) Lin, Y.-M.; Abel, P. R.; Flaherty, D. W.; Wu, J.; Stevenson, K. J.; Heller, A.; Mullins, C. B. J. Phys. Chem. C 2011, 115, 2585.

(16) Leary, R.; Westwood, A. Carbon 2011, 49, 741.

(17) Gai, Y.; Li, J.; Li, S.-S.; Xia, J.-B.; Wei, S.-H. Phys. Rev. Lett. 2009, 102, 036402 .

(18) Linsebigler, A. L.; Lu, G.; Yates, J. T. Chem. Rev. 1995, 95, 735.

(19) Bolton, J. R. Solar Energy 1996, 57, 37.

(20) Bolton, J. R.; Strickler, S. J.; Connolly, J. S. Nature 1985, 316, 495. 
(21) Murphy, A. B.; Barnes, P. R. F.; Randeniya, L. K.; Plumb, I. C.; Grey, I. E.; Horne, M. D.; Glasscock, J. A. Int. J. Hydrogen Energy 2006, 31, 1999.

(22) Chen, X.; Liu, L.; Yu, P. Y.; Mao, S. S. Science 2011, 331, 746.

(23) Asahi, R.; Morikawa, T.; Ohwaki, T.; Aoki, K.; Taga, Y. Science 2001, 293, 269.

(24) Khan, S. U. M.; Al-Shahry, M.; Ingler, W. B. Science 2002, 297, 2243.

(25) Yin, W.-J.; Tang, H.; Wei, S.-H.; Al-Jassim, M. M.; Turner, J.; Yan, Y. Phys. Rev. B 2010, 82, 045106.

(26) Choi, J.; Park, H.; Hoffmann, M. R. J. Mater. Res. 2010, 25, 149.

(27) Umebayashi, T.; Yamaki, T.; Itoh, H.; Asai, K. J. Phys. Chem. Solids 2002, 63, 1909.

(28) Ohno, T.; Tanigawa, F.; Fujihara, K.; Izumi, S.; Matsumura, M. J. Photochem. Photobiol. 1998, 118, 41.

(29) Chen, X. B.; Lou, Y. B.; Dayal, S.; Qiu, X. F.; Krolicki, R.; Burda, C.; Zhao, C. F.; Becker, J. J. Nanosci. Nanotechnol. 2005, 5, 1408.

(30) Choi, W. Y.; Termin, A.; Hoffmann, M. R. J. Phys. Chem. 1994, 98, 13669.

(31) Janisch, R.; Gopal, P.; Spaldin, N. A. J. Phys.: Condens. Matter 2005, 17, R657.

(32) Litter, M. I.; Navio, J. A. J. Photochem. Photobiol. 1996, 98, 171.

(33) Dvoranova, D.; Brezova, V.; Mazur, M.; Malati, M. A. Appl. Cat. B 2002, 37,91 .

(34) Hoang, S.; Guo, S.; Hahn, N. T.; Bard, A. J.; Mullins, C. B. Nano Lett. 2012, 12, 26.

(35) Park, J. H.; Kim, S.; Bard, A. J. Nano Lett. 2005, 6, 24.

(36) Umebayashi, T.; Yamaki, T.; Itoh, H.; Asai, K. Appl. Phys. Lett. 2002, 81, 454.

(37) Long, R.; English, N. J. Chem. Phys. Lett. 2009, 478, 175.

(38) Zhu, W.; Qiu, X.; Iancu, V.; Chen, X.-Q.; Pan, H.; Wang, W.; Dimitrijevic, N. M.; Rajh, T.; Meyer, H. M.; Paranthaman, M. P.; Stocks, G. M.; Weitering, H. H.; Gu, B.; Eres, G.; Zhang, Z. Phys. Rev. Lett. 2009, 103, 226401.

(39) Breault, T. M.; Bartlett, B. M. J. Phys. Chem. C, 116, 5986.

(40) Gai, Y. Q.; Li, J. B.; Li, S. S.; Xia, J. B.; Yan, Y. F.; Wei, S. H. Phys. Rev. B 2009, 80, 153201. 
(41) Hahn, N. T.; Ye, H.; Flaherty, D. W.; Bard, A. J.; Mullins, C. B. ACS Nano 2010, 4, 1977.

(42) Mor, G. K.; Prakasam, H. E.; Varghese, O. K.; Shankar, K.; Grimes, C. A. Nano Lett. 2007, 7, 2356.

(43) Cho, I. S.; Chen, Z.; Forman, A. J.; Kim, D. R.; Rao, P. M.; Jaramillo, T. F.; Zheng, X. Nano Lett. 2011, 11, 4978.

(44) Feng, X.; Shankar, K.; Varghese, O. K.; Paulose, M.; Latempa, T. J.; Grimes, C. A. Nano Lett. 2008, 8, 3781. 


\section{Chapter 2: Visible Light Driven Photoelectrochemical Water Oxidation on Nitrogen-Modified TiO2 Nanowires}

\section{INTRODUCTION}

Titanium dioxide $\left(\mathrm{TiO}_{2}\right)$ is well known as a candidate for water photo-oxidation as it is abundant, stable in aqueous solution under irradiation, and it has strong photocatalytic activity. ${ }^{1,2}$ However, due to its large band gap $(\sim 3.0 \mathrm{eV}$ for rutile and 3.2 $\mathrm{eV}$ for anatase), $\mathrm{TiO}_{2}$ is only active in the ultraviolet (UV) region which contributes less than $5 \%$ of the total energy of the solar spectrum. ${ }^{3}$ Shifting the absorption of $\mathrm{TiO}_{2}$ to include visible light, which composes a greater portion of the solar spectrum $(45 \%)$, is one of the prerequisites to enhancing the solar energy conversion efficiency of titania. ${ }^{4-7}$ Another requirement of an effective photomaterial is good electron-hole separation characteristics, which can be improved by increasing charge transfer (normally via nanostructuring the morphology and doping with foreign ions) and increasing the kinetics of water oxidation by holes and water reduction by electrons (via loading of co-catalysts). $\mathrm{TiO}_{2}$ has short a hole diffusion length (about $10 \mathrm{~nm}$ for the rutile single crystal), ${ }^{8}$ therefore it is necessary to reduce the $\mathrm{TiO}_{2}$ characteristic size to decrease the diffusion pathway of photoholes to the electrode/electrolyte interface. Moreover, in a photoelectrochemical (PEC) cell, electrons generated in the $\mathrm{TiO}_{2}$ photoanode film have to travel within the $\mathrm{TiO}_{2}$ film to the back contact, and then transfer to the cathode. Therefore the optimum morphology is a one-dimensional single crystalline structure to enable electrons to travel to the back contact and holes to diffuse to the electrode/electrolyte interface in the easiest manner without scattering at a grain boundary. Co-catalysts such as $\mathrm{IrO}_{2},{ }^{9} \mathrm{Co}$ based materials, ${ }^{10}$ and $\mathrm{Co}-\mathrm{Pi}^{11}$ for water oxidation are also needed to increase the kinetics of the reactions, thus reducing the charge recombination rate. 
Incorporating nitrogen has been said to narrow the band gap of $\mathrm{TiO}_{2}$ for water splitting applications since substitutional $\mathrm{N} 2 \mathrm{p}$ states hybridize with $\mathrm{O} 2 \mathrm{p}$ states, upshifting the valence band edge while almost keeping the conduction band edge in the same position. ${ }^{4,12,13}$ However, there is an on-going debate regarding the red-shift of the absorption edge of $\mathrm{N}$-modified $\mathrm{TiO}_{2}$. Some researchers believe substitutional $\mathrm{N}$ forms isolated $\mathrm{N} 2 \mathrm{p}$ midgap states slightly above the top of the $\mathrm{O} 2 \mathrm{p}$ valence, instead of mixing with $\mathrm{O} 2 \mathrm{p}$ to form a continuous valence band as proposed above. ${ }^{14-16}$ In this case, photogenerated holes may be trapped in these localized states leading to a high recombination rate, thus decreasing the quantum yields of $\mathrm{N}$-modified $\mathrm{TiO}_{2}$. Some other researchers suggest that high doping of nitrogen in $\mathrm{TiO}_{2}$ produces color centers with a different local chemical composition and electronic structure. ${ }^{17,}{ }^{18}$ In this picture, the color centers, including $\mathrm{Ti}^{3+}$, are responsible for visible light absorption in the $\mathrm{N}$-modified $\mathrm{TiO}_{2}$ material.

Nitrogen incorporation can be accomplished by calcining $\mathrm{TiO}_{2}$ under $\mathrm{NH}_{3}$. However, due to the low solubility of $\mathrm{N}$ in the $\mathrm{TiO}_{2}$ lattice, the reactions normally have to be conducted at high temperatures (above $550{ }^{\circ} \mathrm{C}$ ) to yield sufficient $\mathrm{N}$-dopant incorporation for better visible light absorption. However, annealing in $\mathrm{NH}_{3}$ at such high temperatures leads to unwanted side-effects such as defect formation within the $\mathrm{TiO}_{2}$ lattice, degradation of the transparent conductive substrate (FTO), and sintering of the nanostructure.

In this letter, we report a simple hydrothermal synthesis route for growing densely packed, vertical, single crystalline $\mathrm{TiO}_{2}$ rutile nanowire arrays on FTO substrates of unprecedented small cross-section with a characteristic dimension of $\sim 5 \mathrm{~nm}$ and lengths up to $4.4 \mu \mathrm{m}$. A significant amount of nitrogen (up to 1.08 atomic \%) can be incorporated into the $\mathrm{TiO}_{2}$ by annealing the films under $\mathrm{NH}_{3}$ flow at a relatively low temperature $(500$ 
${ }^{\circ} \mathrm{C}$ ) because of the exceptionally small nanowire cross-section. Furthermore, we report a simple surface treatment employing cobalt as a co-catalyst that we believe has not been investigated previously with $\mathrm{TiO}_{2}$, in order to improve the water oxidation performance of $\mathrm{N}$-modified $\mathrm{TiO}_{2}$. N-modified $\mathrm{TiO}_{2}$ films without a cobalt co-catalyst yielded a lower photocurrent under a full spectrum and lower quantum yields in the UV region than similar unmodified $\mathrm{TiO}_{2}$ samples although the $\mathrm{N}$-modified samples had higher visible light photocurrents. A cobalt co-catalyst not only enhances the quantum yield in the visible light region but also restores the quantum yield in the UV region compared to the equivalent values of the unmodified samples.

\section{EXPERIMENTAL METHODS}

Material Characterization

Scanning electron microscopy (SEM) was performed on a Zeiss field-emission SEM using a $10 \mathrm{kV}$ focus voltage and on a Hitachi S-5500 scanning transmission electron microscope (STEM) using a $30 \mathrm{kV}$ focus voltage. Transmission electron microscopy (TEM) was performed on a JEOL 2010F field-emission TEM. The JEOL 2010F was also used to collect energy dispersive x-ray spectroscopy (EDX) spectra for elemental analysis. Grazing incidence X-ray diffraction (GIXRD) patterns were collected with a Bruker D8 diffractometer. UV-vis absorbance spectra were taken with a Cary 5000 spectrophotometer using a blank FTO substrate as a baseline standard. The transmittance spectra were collected using a Cary 500 UV-vis-NIR spectrophotometer attached to a Labsphere DRA-CA-5500 integrating sphere. X-ray photoelectron spectroscopy (XPS) was performed on a Kratos Axis X-ray photoelectron spectrometer. The binding energy was calibrated using the $\mathrm{C} 1 \mathrm{~s}$ photoelectron peak at $284.6 \mathrm{eV}$ as a reference. The elemental percentages were calculated from XPS spectra using the 
CasaXPS computer program with specific relative sensitivity factors for the Kratos Axis XPS (Ti 2p: 2.001, O 1s: 0.78, and N 1s: 0.47). CasaXPS was also used for peak fitting on XPS spectra. Ultraviolet photoemission spectroscopy (UPS) measurements were performed on the same Kratos Axis in XPS measurements. UPS spectra were collected using the $\mathrm{He}(\mathrm{I})$ line $(21.2 \mathrm{eV})$ with a negative bias voltage of $-8.7 \mathrm{~V}$ applied to the samples in order to shift the spectra from the spectrometer threshold. The UPS spectrum for each sample was scanned 5 times to ensure that the uncertainty is smaller than the scan resolution $(0.05 \mathrm{eV})$. The spectra were calibrated versus the Fermi edge of a polycrystalline Au foil.

\section{Electrochemical and Photoelectrochemical (PEC) Characterization}

The PEC measurements were performed using a three-electrode electrochemical cell with the FTO supported nanowire arrays as the working electrode, a $\mathrm{Ag} / \mathrm{AgCl}$ (saturated $\mathrm{KCl}$ ) reference electrode, a platinum wire counter electrode, and $1 \mathrm{M} \mathrm{KOH}$ electrolyte $(\mathrm{pH}=13.5)$. The working electrode with exposed area of $0.16 \mathrm{~cm}^{2}$ was illuminated from the back side (through the FTO substrate - $\mathrm{TiO}_{2}$ nanowire interface) by a $100 \mathrm{~W}$ xenon lamp (Newport) through a UV/IR filter (Schott, KG3) to remove infrared (>800 nm) and short wavelength UV light $(<300 \mathrm{~nm})$. Using a Scientech calorimeter (Model 38-0101), the light intensity of the spectrum from $400 \mathrm{~nm}$ to $1.2 \mu \mathrm{m}$ was measured as $37 \mathrm{~mW} / \mathrm{cm}^{2}$. The fraction of the total energy of the spectrum from $400 \mathrm{~nm}$ to $800 \mathrm{~nm}$ for our lamp is estimated to be $85 \%$ - $90 \%$ of the total light energy, therefore, we estimate the energy flux in our PEC measurements to be $\sim 41-43 \mathrm{~mW} / \mathrm{cm}^{2}$. A CHI 832 electrochemical station was used for linear sweep voltammetry (I-V) and amperometry (I-t) measurements. Incident photon to current conversion efficiencies (IPCEs) were calculated from amperometry measurements using a monochromator (Newport) in conjunction with a power meter and photodiode (Newport), given by: 
$I P C E=\frac{1240 \times j_{p h}}{\lambda \times I} \times 100 \%$

Where $\mathrm{j}_{\mathrm{ph}}$ is the steady-state photocurrent density at a specific wavelength, $\lambda$ is the wavelength of the incident light. $I$ is the light power intensity of the wavelength at the film surface, $I$ ranges from $80-300 \mu \mathrm{W} / \mathrm{cm}^{2}$ over the spectrum of wavelengths studied (320 nm-550 nm). .

The measured potentials $v s$. the $\mathrm{Ag} / \mathrm{AgCl}$ were converted to the reversible hydrogen electrode (RHE) scale via the Nernst equation

$$
\mathrm{E}_{\mathrm{RHE}}=\mathrm{E}_{\mathrm{Ag} / \mathrm{AgCl}}+0.059 \mathrm{pH}+\mathrm{E}_{\mathrm{Ag} / \mathrm{AgCl}}^{\mathrm{o}}
$$

where $\mathrm{E}_{\mathrm{RHE}}$ is the converted potential vs. $\mathrm{RHE}, \mathrm{E}_{\mathrm{Ag} / \mathrm{AgCl}}$ is the experimental potential measured against $\mathrm{Ag} / \mathrm{AgCl}$ reference electrode, and $\mathrm{E}_{\mathrm{Ag} / \mathrm{AgCl}}^{\mathrm{a}}$ is the standard potential of $\mathrm{Ag} / \mathrm{AgCl}$ at $25^{\circ} \mathrm{C}(0.1976 \mathrm{~V})$.

\section{RESULTS AND DISCUSSION}

\section{Synthesis of $\mathrm{TiO}_{2}$ nanowire arrays.}

FTO coated glass substrates were first cleaned by sonication in a mixture of ethanol and water for 30 minutes, subsequently rinsed by deionized (DI) water, and finally dried in an air stream. In order to enhance the sample integrity and shorten the growing time, FTO substrates were also seeded with a thin layer of $\mathrm{TiO}_{2}$ before growing the nanowire arrays. For seeding, clean FTO substrates were first soaked in $0.025 \mathrm{M} \mathrm{TiCl}_{4}$ in n-hexane for 30 minutes. They were then taken out, rinsed by ethanol, and finally annealed in air at $500{ }^{\circ} \mathrm{C}$ for 30 minutes. In a typical hydrothermal growth procedure, the seeded FTO substrates were placed on the bottom of a Teflon lined autoclave $(125 \mathrm{~mL}$, 
Parr Instrument), containing $50 \mathrm{~mL}$-hexane (Extra dry, 96+\%, Acros Organics), $5 \mathrm{~mL}$ $\mathrm{HCl}$ (ACS Reagent Grade 36.5-38\%, MP), and 2.5 - $5 \mathrm{~mL}$ of titanium (IV) isopropoxide (98+\%, Acros Organics). The hydrothermal synthesis was conducted at $150{ }^{\circ} \mathrm{C}$ for certain amount of time in a box oven. After the reaction was completed and the autoclave naturally cooled down to room temperature, the $\mathrm{TiO}_{2}$ nanowire films were taken out and cleaned by rinsing with copious amount of ethanol and water.

The hydrothermal growth of vertical $\mathrm{TiO}_{2}$ nanowire arrays on FTO with feature sizes of $\sim 20 \mathrm{~nm}$ via a nonpolar solvent/hydrophilic solid substrate interfacial reaction was first reported by Grimes and co-workers. ${ }^{19}$ Using a similar strategy, we developed the recipe (i.e., titanium precursors, nonpolar solvents) and hydrothermal reaction conditions (i.e., reaction time and temperature) described above that enable the synthesis of high quality rutile $\mathrm{TiO}_{2}$ single crystalline nanowire arrays with smaller feature sizes ( $5 \mathrm{~nm}$ ). As proposed by Grimes et al., ${ }^{19}$ at room temperature, titanium precursors (e.g., TTIP) and water (from hydrochloric acid solution) are separated since the precursors are soluble and water is immiscible in the nonpolar solvents (e.g., n-hexane). Under hydrothermal conditions, to minimize system energy, water diffuses to the hydrophilic FTO surface where it hydrolyzes with TTIP to form $\mathrm{TiO}_{2}$ nuclei on the FTO surface. As the newly-formed $\mathrm{TiO}_{2}$ nuclei are also hydrophilic, water continues to diffuse to the nuclei resulting in further hydrolysis and crystal growth. The $\mathrm{Cl}^{-}$ions play an important role in the hydrothermal growth as they promote anisotropic growth of one dimensional nanocrystals. The $\mathrm{Cl}^{-}$ions are inclined to absorb on the rutile (110) plane, thus retarding further growth of this plane. We did not observe nanowire array formations when $\mathrm{HCl}$ was replaced by $\mathrm{HNO}_{3}$ or $\mathrm{H}_{2} \mathrm{SO}_{4}$.

\section{Characterization of $\mathrm{TiO}_{2}$ nanowire arrays.}


Shown in figure 2.1a and $\mathrm{b}$ are cross-sectional-view and top-view scanning electron microscope (SEM) images of a typical as-synthesized (with no further heat treatment) nanowire film. The nanowire arrays consisting of vertically-aligned and tetragonal shaped nanowires are highly uniform and densely packed with exceptionally small feature sizes (average characteristic cross-sectional dimension is $\sim 5 \mathrm{~nm}$ ). The grazing incidence X-ray diffraction (GIXRD) pattern in figure 2.1d shows that the assynthesized nanowire arrays are rutile $\mathrm{TiO}_{2}$ with an enhancement in the (101) facet exposure relative to the standard rutile powder pattern (JCPDS \#88-1175). The high resolution transmission electron microscope (HRTEM) image in figure 2.1c further confirms that the nanowires are single crystalline with an interplanar d-spacing of 0.327 $\mathrm{nm}$, corresponding to (110) planes of rutile $\mathrm{TiO}_{2}$. The atomic ratio of $\mathrm{Ti}$ to $\mathrm{O}$ was found to be $\sim 1: 2$ using energy dispersive $\mathrm{x}$-ray analysis (EDX) (the expected stoichiometric values).

The length of the nanowire arrays is a function of the TTIP to n-hexane volume ratio, the reaction conditions (i.e., temperature and time), and seeding layer. The thicknesses of nanowire arrays versus reaction conditions, determined from crosssectional view SEM, are shown in table 1. We are able to grow nanowires with lengths varying from $\sim 500 \mathrm{~nm}$ up to $4.4 \mu \mathrm{m}$ with no significant change in feature sizes. Moreover, if the FTO substrates are coated with a thick $\mathrm{TiO}_{2}$ layer $(\sim 5 \mu \mathrm{m})$ prior to hydrothermal reaction, we can grow nanowire arrays with lengths up to $17 \mu \mathrm{m}$. Optimization of the thickness of a photoelectrode for PEC applications involves balancing the charge carrier mobility and the absorbance of photons. The photoanode should be as thin as possible to allow electrons to travel to the back contact in the shortest time while still being thick enough to absorb the majority of the photons from sunlight. In our study, the highest photocurrents were from samples with thicknesses of $\sim 1.5 \mu \mathrm{m}$. 
Therefore, we focused on the PEC characterization of $\mathrm{TiO}_{2}$ nanowire films with thicknesses of $1.59 \pm 0.26 \mu \mathrm{m}$ grown at $150{ }^{\circ} \mathrm{C}$ for 5 hours with TTIP/n-hexane ratios of $1 / 20$.

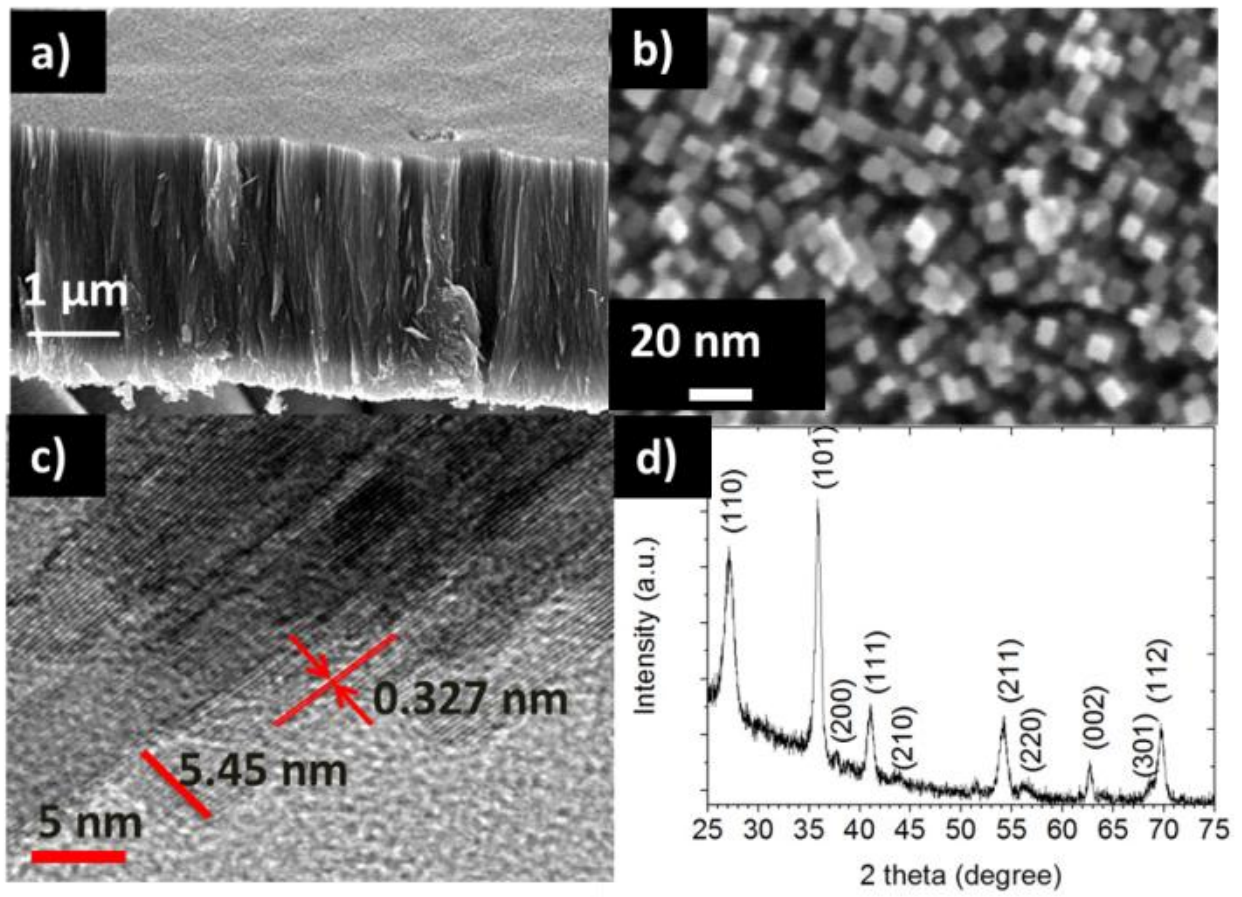

Figure 2.1. Vertically aligned single crystalline $\mathrm{TiO}_{2}$ rutile nanowire arrays on FTO glass: (a) cross-sectional and (b) top view SEM images, (c) HRTEM image, and (d) Grazing incidence angle x-ray diffraction (GIXRD) pattern

The seeding layer enhances both the nanowire arrays' adherence to the FTO substrate and the growth rate. For example, the thickness of $\mathrm{TiO}_{2}$ nanowire arrays grown with the ratio TTIP/n-hexane of $1 / 10$ at $150{ }^{\circ} \mathrm{C}$ for 5 hours with and without the seeding layer are $2.60 \pm 0.27 \mu \mathrm{m}$ and $1.2 \pm 0.15 \mu \mathrm{m}$, respectively. As mentioned above, when FTO was coated with a thick $\mathrm{TiO}_{2}$ seeding layer of $\sim 5 \mu \mathrm{m}$, the same reaction conditions resulted in a nanowire length of $\sim 17 \mu \mathrm{m}$. 
Table 2.1. Thicknesses of some $\mathrm{TiO}_{2}$ nanowire arrays grown at $150{ }^{\circ} \mathrm{C}$ as a function of $\mathrm{TTIP} / \mathrm{n}$-hexane ratio, reaction time, and seeding layer.

\begin{tabular}{|c|c|c|c|c|}
\hline $\begin{array}{c}\text { TTIP/n-hexane } \\
\text { volume ratio }\end{array}$ & $\begin{array}{c}\text { Reaction time } \\
\text { (hour) }\end{array}$ & Seeding & $\begin{array}{c}\text { Number of } \\
\text { sample(s) }\end{array}$ & $\begin{array}{c}\text { Length of } \\
\text { nanowires }\end{array}$ \\
\hline $1 / 20$ & 5 & No & 1 & $500 \mathrm{~nm}$ \\
\hline $1 / 20$ & 5 & Yes & 20 & $1.59 \pm 0.26 \mu \mathrm{m}$ \\
\hline $1 / 10$ & 5 & No & 4 & $1.2 \pm 0.26 \mu \mathrm{m}$ \\
\hline $1 / 10$ & 5 & Yes & 22 & $2.6 \pm 0.27 \mu \mathrm{m}$ \\
\hline $1 / 10$ & 10 & Yes & 4 & $4.4 \pm 0.27 \mu \mathrm{m}$ \\
\hline
\end{tabular}

We found that the combination of titanium precursor and nonpolar solvent strongly affects the morphology of the nanowire arrays. Using a combination of titanium (IV) tetra-n-butoxide (TNBT) $\left(\mathrm{Ti}^{4+}\right.$ precursor) and $\mathrm{n}$-hexane or a combination of TTIP and toluene (nonpolar solvent) resulted in un-oriented, wire bundle formation. We further investigated nanowire array growth using a combination of TNBT and toluene which resulted in oriented but shorter nanowire arrays $(\sim 1.3 \mu \mathrm{m})$ with bigger feature sizes $(\sim 15$ nm) (Figure 2.2). 


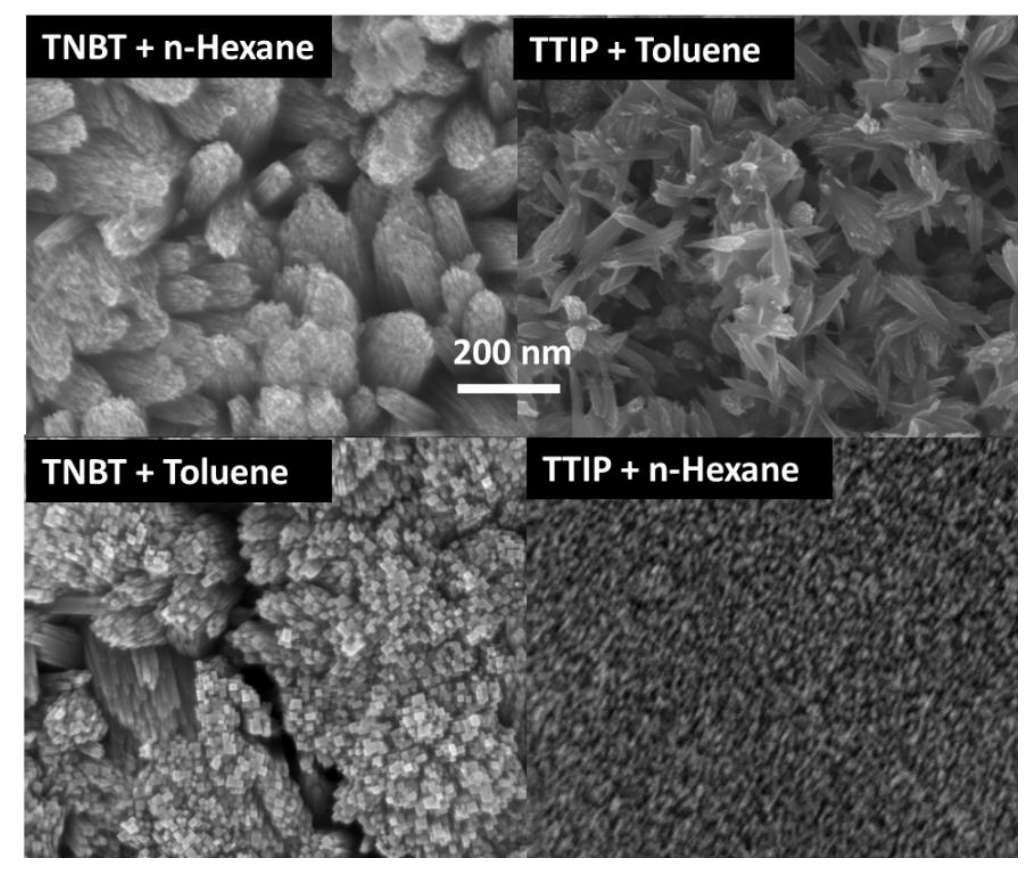

Figure 2.2. Morphology dependence of nanowire arrays on combinations of titanium precursors (i.e., titanium tetra-isopropoxide (TTIP) and titanium (IV) tetran-butoxide (TNBT)) and non-polar solvents (i.e., n-hexane and toluene). The scale bar applies to all the micrographs.

\section{PEC properties of $\mathrm{TiO}_{2}$ nanowire arrays.}

The PEC characterization of $\mathrm{TiO}_{2}$ nanowire samples was performed using a threeelectrode electrochemical cell with the FTO supported nanowire arrays as the working electrode, a $\mathrm{Ag} / \mathrm{AgCl}$ (saturated $\mathrm{KCl}$ ) reference electrode, a platinum wire counter electrode, and $1 \mathrm{M} \mathrm{KOH}$ electrolyte $(\mathrm{pH}=13.5)$. The working electrode with exposed area of $0.16 \mathrm{~cm}^{2}$ was illuminated from the back side (through the FTO substrate $-\mathrm{TiO}_{2}$ nanowire interface) by a $100 \mathrm{~W}$ xenon lamp (Newport) through a UV/IR filter (Schott, $\mathrm{KG} 3)$ to remove infrared $(>800 \mathrm{~nm})$ and short wavelength $\mathrm{UV}$ light $(<300 \mathrm{~nm})$. Using a Scientech calorimeter (Model 38-0101), the light intensity of the spectrum from $400 \mathrm{~nm}$ to $1.2 \mu \mathrm{m}$ was measured as $37 \mathrm{~mW} / \mathrm{cm}^{2}$. The fraction of the total energy of the spectrum from $400 \mathrm{~nm}$ to $800 \mathrm{~nm}$ for our lamp is estimated to be $85 \%-90 \%$ of the total light 
energy, therefore, we estimate the energy flux in our PEC measurements to be $\sim 41-43$ $\mathrm{mW} / \mathrm{cm}^{2}$. Incident photon to current conversion efficiencies (IPCEs) were calculated from amperometry measurements using a monochromator (Newport) with a bandwidth of $7.4 \mathrm{~nm}$ in conjunction with a power meter and photodiode (Newport), given by:

$$
I P C E=\frac{1240 \times j_{p h}}{\lambda \times I} \times 100 \%
$$

where $\mathrm{j}_{\mathrm{ph}}$ is the steady-state photocurrent density at a specific wavelength, and $\lambda$ is the wavelength of the incident light. $I$ is the light intensity for wavelength $\lambda$ at the film surface, $I$ ranges from $80-300 \mu \mathrm{W} / \mathrm{cm}^{2}$ over the spectrum of wavelengths studied (320 $\mathrm{nm}-550 \mathrm{~nm})$.

The measured potentials versus the $\mathrm{Ag} / \mathrm{AgCl}$ reference electrode were converted to the reversible hydrogen electrode (RHE) scale via the Nernst equation

$$
\mathrm{E}_{\mathrm{RHE}}=\mathrm{E}_{\mathrm{Ag} / \mathrm{AgCl}}+0.059 \mathrm{pH}+\mathrm{E}_{\mathrm{Ag} / \mathrm{AgCl}}^{\mathrm{o}} \text { (2) }
$$

where $\mathrm{E}_{\mathrm{RHE}}$ is the converted potential vs. RHE, $\mathrm{E}_{\mathrm{Ag} / \mathrm{AgCl}}$ is the experimental potential measured against the $\mathrm{Ag} / \mathrm{AgCl}$ reference electrode, and $\mathrm{E}_{\mathrm{Ag} / \mathrm{AgCl}}^{\mathrm{a}}$ is the standard potential of $\mathrm{Ag} / \mathrm{AgCl}$ at $25{ }^{\circ} \mathrm{C}(0.1976 \mathrm{~V})$. We also used the same testing conditions for other samples throughout this study. 

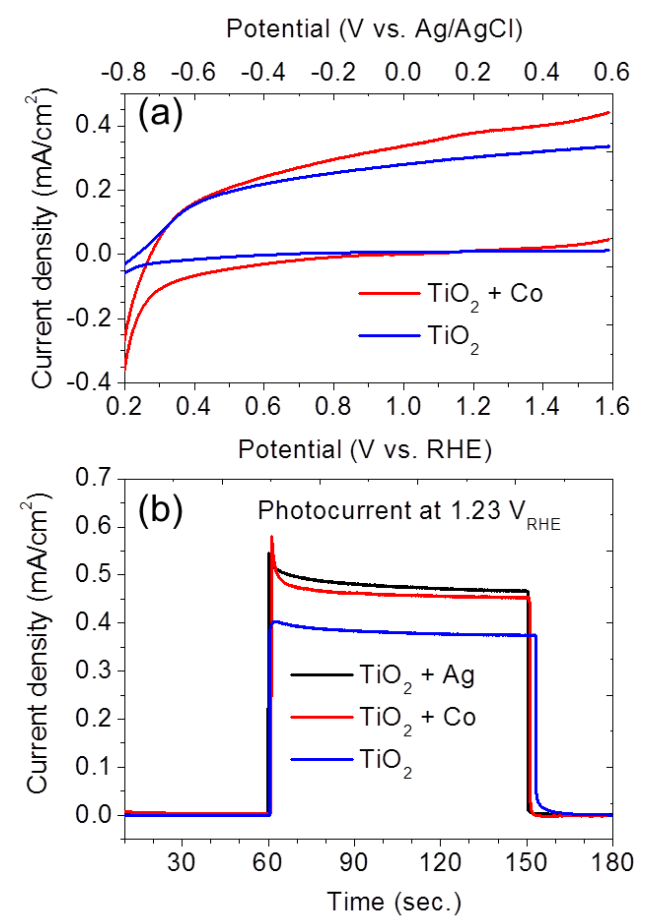

Figure 2.3. (a) Linear sweep voltammetry (LSV) measurements of $\mathrm{TiO}_{2}$ nanowire arrays $(1.6 \mu \mathrm{m})$ and the same film after cobalt treatment and (b) chronoamperometry measurement (at $1.23 \mathrm{~V}_{\mathrm{RHE}}$ ) of $\mathrm{TiO}_{2}$ nanowire arrays and the same film after cobalt treatment and silver treatment (cobalt treatment and silver treatment were performed on two different areas on the same $\mathrm{TiO}_{2}$ nanowire sample). All experiments were performed with $1 \mathrm{M}$ $\mathrm{KOH}$ electrolyte $(\mathrm{pH}=13.5)$ and a $100 \mathrm{~W}$ Xenon lamp coupled with a UV/IR filter as the light source as described in the text.

Before testing, the as-synthesized films were annealed in air at $500{ }^{\circ} \mathrm{C}$ for one hour to remove contaminants and increase the adherence of the $\mathrm{TiO}_{2}$ arrays to the $\mathrm{SnO}_{2}$ layer. Figure 2.3a shows the linear sweep voltammetry of the $\mathrm{TiO}_{2}$ nanowire sample. The onset potential of our $\mathrm{TiO}_{2}$ nanowire arrays is $\sim 0.2 \mathrm{~V}_{\mathrm{RHE}}$, around $0.2 \mathrm{~V}$ more negative compared to $\mathrm{TiO}_{2}$ nanotube sample. ${ }^{5}$ In order to improve the PEC performance, we also applied a cobalt treatment technique similar to that reported by Grätzel et al. ${ }^{10}$ in which the $\mathrm{TiO}_{2}$ nanowire arrays were soaked in $0.1 \mathrm{M} \mathrm{Co}\left(\mathrm{NO}_{3}\right)_{2}$ for one minute, followed by 
rinsing with a copious amount of water. The photocurrent measured at $1.23 \mathrm{~V}_{\mathrm{RHE}}$ was improved by $\sim 20 \%$ due to the cobalt treatment, from $0.38 \mathrm{~mA} / \mathrm{cm}^{2}$ [without treatment] to $0.46 \mathrm{~mA} / \mathrm{cm}^{2}$. Cobalt based materials such as Co-Pi are well-known catalysts for the water oxidation reaction. ${ }^{11}$ However, to our knowledge, there have not been any reports on PEC enhancement of $\mathrm{TiO}_{2}$ due to loading cobalt as a co-catalyst, probably due to the high intrinsic oxidative power of the holes photogenerated within the valence band of $\mathrm{TiO}_{2}$. We speculate that in this case the cobalt treatment improves the PEC performance mainly via the saturation of dangling bonds on the $\mathrm{TiO}_{2}$ surface, thus passivating the surface states which act as charge recombination centers. Employing a silver treatment (similar to cobalt treatment), in which $0.05 \mathrm{M} \mathrm{AgNO}_{3}$ replaced $0.1 \mathrm{M} \mathrm{Co}\left(\mathrm{NO}_{3}\right)_{2}$, leads to a similar improvement (figure 2.3b), supporting our speculation.

We have also noticed that the orientation of the FTO placed in the reactor, i.e., whether it 'faces up' or 'faces down' during the nanowire growth affects the PEC performance although it does not affect the growth rate of the nanowire arrays. The films grown with the FTO 'facing up' yielded a photocurrent $\sim 10-15 \%$ higher than films grown with the FTO 'facing down'. The samples grown with the FTO 'facing up' have some flower-like micro-size particles on top (Figure 2.4) which have been reported to enhance light harvesting, thus improving the PEC performance. ${ }^{20,21}$ 


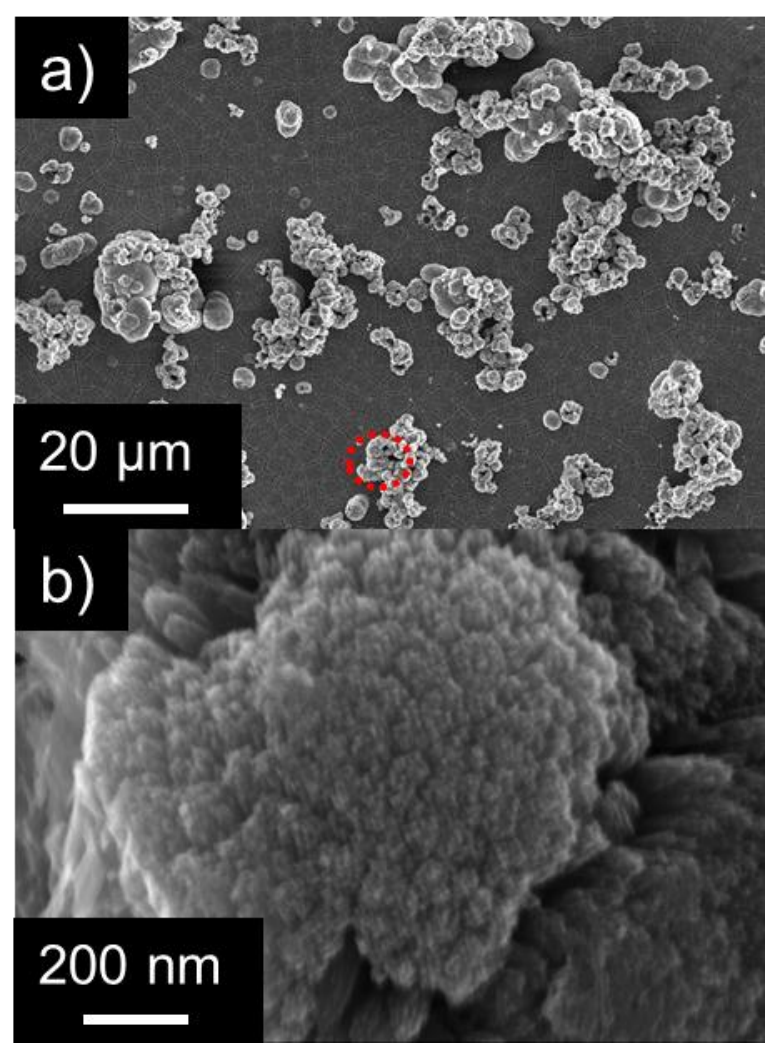

Figure 2.4. (a) Top-view SEM images of flower-like microparticles on top of the $\mathrm{TiO}_{2}$ nanowire arrays and (b) the nanostructure of the flower-like particles (zoomin view of the dotted circle in S2-a)

Synthesis of $\mathbf{N}$-modified $\mathrm{TiO}_{2}$ nanowire arrays. Nitrogen modified $\mathrm{TiO}_{2}$ films were prepared by annealing $\mathrm{TiO}_{2}$ nanowire films in an $\mathrm{NH}_{3}$ flow $(100 \mathrm{~mL} / \mathrm{min})$ at temperatures from $400{ }^{\circ} \mathrm{C}$ to $650{ }^{\circ} \mathrm{C}$. The color of all films changed from cloudy white to bright yellow, indicating successful $\mathrm{N}$ incorporation. The average feature size of $\mathrm{N}$ modified $\mathrm{TiO}_{2}$ nanowires is around $15 \mathrm{~nm}$, larger than that of the as-synthesized sample, probably due to sintering of the nanowires at elevated temperatures (Figure 2.5). At calcination temperatures higher than $500{ }^{\circ} \mathrm{C}$ (i.e., $550{ }^{\circ} \mathrm{C}, 600{ }^{\circ} \mathrm{C}$, and $650{ }^{\circ} \mathrm{C}$ ), FTO substrates were damaged and not electrically conductive. Wang et al. reported that at 
temperatures higher than $550{ }^{\circ} \mathrm{C}, \mathrm{NH}_{3}$ decomposes, releasing $\mathrm{H}_{2}$ and causing partial reduction of $\mathrm{TiO}_{2}{ }^{22}$ The appearance of $\mathrm{Sn}$ signals in the XRD patterns of these films suggests that the $\mathrm{SnO}_{2}$ layer was also reduced (data not shown). Compared with films annealed at lower temperatures (i.e., $400{ }^{\circ} \mathrm{C}$ and $450{ }^{\circ} \mathrm{C}$ ), films nitrided at $500{ }^{\circ} \mathrm{C}$ showed the highest photocurrent. Therefore, we focused on characterizing films annealed in $\mathrm{NH}_{3}$ at $500{ }^{\circ} \mathrm{C}$.

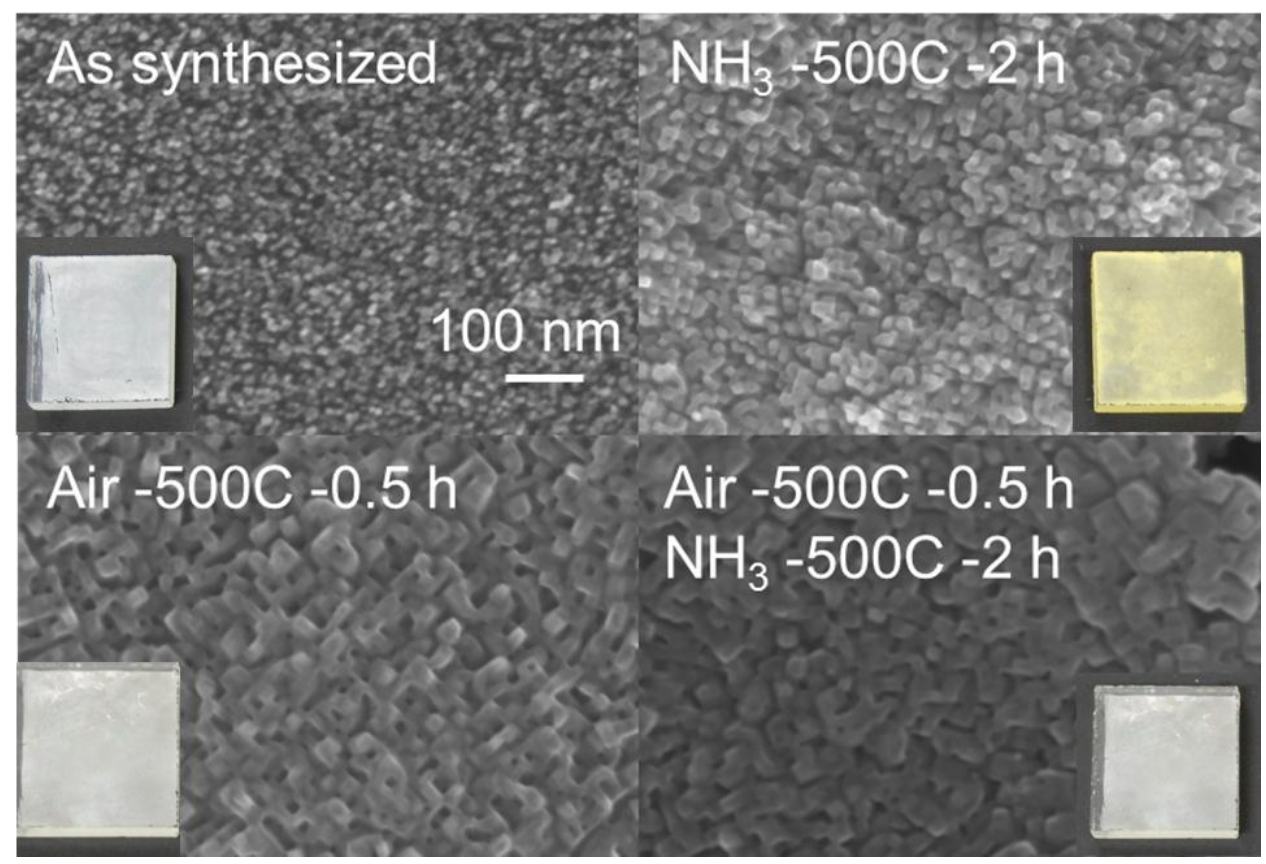

Figure 2.5. Top-view $\mathrm{SEM}$ image of $\mathrm{TiO}_{2}$ nanowire arrays: as-synthesized film, film annealed in $\mathrm{NH}_{3}$ at $500{ }^{\circ} \mathrm{C}$ for 2 hours, film annealed in air at $500{ }^{\circ} \mathrm{C}$ for 0.5 hours, and film annealed in air at $500{ }^{\circ} \mathrm{C}$ for 0.5 hours, followed by nitridation at $500{ }^{\circ} \mathrm{C}$ for 2 hours. The scale bar applies for all micrographs. The insets show the digital images of the corresponding films on FTO substrates $(1.5 \mathrm{~cm} \times 1.5 \mathrm{~cm})$. 
Chemical characterization of $\mathbf{N}$-modified $\mathrm{TiO}_{2}$ nanowire arrays. The $\mathrm{N} 1 \mathrm{~s}$ XPS spectra of $\mathrm{TiO}_{2}$ nanowire films annealed at $500{ }^{\circ} \mathrm{C}$ in $\mathrm{NH}_{3}$ flow both for 1 hour and 2 hours are shown in figure 2.6a-3 and figure 2.6a-4, respectively. Two N $1 \mathrm{~s}$ binding energy peaks around $400 \mathrm{eV}$ and $394 \mathrm{eV}$ in the films annealed in $\mathrm{NH}_{3}$ clearly indicate that $\mathrm{N}$ has been successfully incorporated into the $\mathrm{TiO}_{2}$ lattice. The $\mathrm{N} 1$ s peak at $\sim 400$ $\mathrm{eV}$ can be attributed to either interstitial $\mathrm{N}^{23,24}$ atoms or chemisorbed $\mathrm{N}$-containing gas such as $\mathrm{NH}_{3}$ or $\mathrm{N}_{2} \cdot{ }^{4,25,26}$ However, its origin and contribution to visible light absorption are still under debate. According to early XPS investigations on $\mathrm{N}$-modified $\mathrm{TiO}_{2},{ }^{12,22,24-}$ ${ }^{26}$ the $\mathrm{N} 1$ s peak at $392-396 \mathrm{eV}$ was assigned to $\beta-\mathrm{N}$ in the Ti-N bond or $\mathrm{N}$ substituted at oxygen sites (substitutional $\mathrm{N}$ ). There is no TiN formation indicated in the XRD and also no $\mathrm{Ti}^{3+}$ in the XPS spectra (a typical one is shown in figure 2.6b-2) of these films suggesting that the $\mathrm{N} 1$ s peak at $394 \mathrm{eV}$ in our $\mathrm{N}$-modified $\mathrm{TiO}_{2}$ samples may be assigned as substitutional $\mathrm{N}$, resulting in a composition that can be described as $\mathrm{TiO}_{2-\mathrm{x}} \mathrm{N}_{\mathrm{x}}$. The substitutional $\mathrm{N}$ species is commonly recognized as a contributor to visible light absortion and changes in photocatalytic activity. For example, Irie et al. ${ }^{25}$ reported a monotonic increase in visible light absorption, yet a monotonic decrease in photocatalytic activity with an increase in the substitutional $\mathrm{N}$ concentration. In addition, we did not observe formation of $\mathrm{Ti}^{3+}$ (figure 2.6b), one of the most important types of color centers. Therefore we believe that the substitutional $\mathrm{N}$ species found at $394 \mathrm{eV}$ is likely the main contributor to visible light absorption and changes in the water photo-oxidation performance in the $\mathrm{TiO}_{2}$ nanowire films as shown in the next section. 

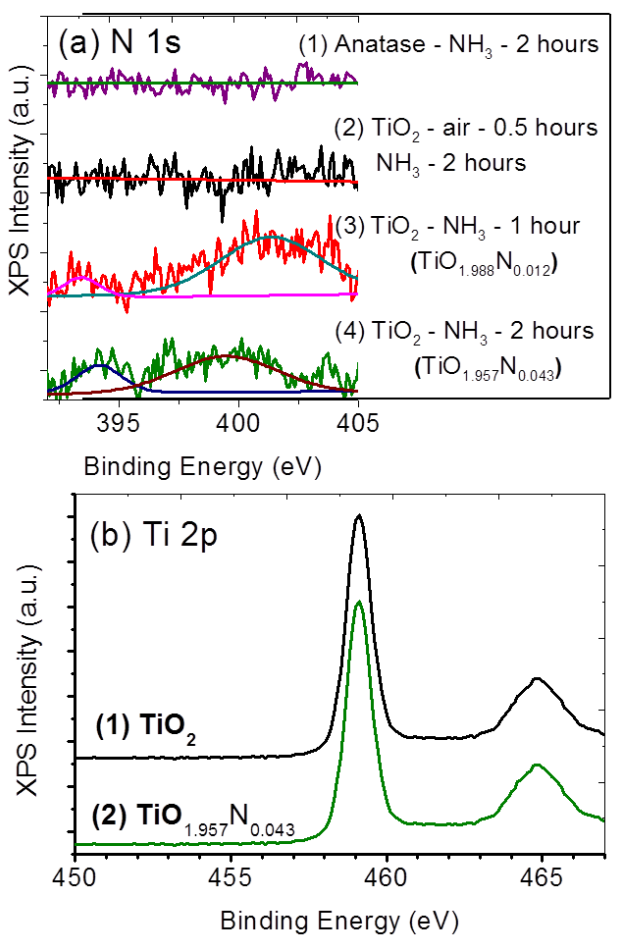

Figure 2.6. (a) Core $\mathrm{N}$ 1s XPS spectra of (1) anatase powder annealed in $\mathrm{NH}_{3}$ for two hours, (2) $\mathrm{TiO}_{2}$ nanowire film annealed in air for 30 minutes and then annealed in $\mathrm{NH}_{3}$ for two hours, (3) and (4) $\mathrm{TiO}_{2}$ nanowire films annealed in $\mathrm{NH}_{3}$ at $500{ }^{\circ} \mathrm{C}$ for one hour and two hours, respectively and (b) core Ti $2 \mathrm{p}$ XPS spectra of (1) as-synthesized $\mathrm{TiO}_{2}$ nanowire film and (2) $\mathrm{a} \mathrm{TiO}_{2}$ nanowire film annealed in $\mathrm{NH}_{3}$ at $500{ }^{\circ} \mathrm{C}$ for two hours.

Shown in table 2.2 are our XPS analysis with atomic percentages of substitutional $\mathrm{N}$ in films annealed for one hour and two hours of $0.35 \%$ and $1.08 \%$ respectively. Since the surface is rich in oxygen, probably due to the adsorption of oxygen-containing species on the surface, we calculate the values of $x$ in $\operatorname{TiO}_{2-x} \mathrm{~N}_{x}$ as $x=$ atomic percentage of $\mathrm{N}$ divided by the atomic percentage of $\mathrm{Ti}$, resulting in $\mathrm{x}$ value of 0.012 and 0.043 for samples annealed in $\mathrm{NH}_{3}$ for 1 hour and 2 hours, respectively. Compared with other $\mathrm{N}$-modified $\mathrm{TiO}_{2}$ materials synthesized via nitridation of $\mathrm{TiO}_{2}$ in $\mathrm{NH}_{3}$ such as a rutile $\mathrm{TiO}_{2}$ (110) single crystal, ${ }^{27}$ anatase powder, ${ }^{25}$ anatase films, ${ }^{28,}{ }^{29}$ and 
anatase nanobelts, ${ }^{22}$ the substitutional $\mathrm{N}$ concentrations in the present films are significantly higher despite lower nitridation temperatures and/or shorter times. We believe that the small feature size of the nanowire arrays allows better nitrogen diffusion into the $\mathrm{TiO}_{2}$ lattice and that this is likely the key to the enhancement in the Nincorporation level. We performed control tests in which a $\mathrm{TiO}_{2}$ nanowire sample with larger average characteristic size (of $\sim 25 \mathrm{~nm}$ ) prepared by pre-annealing the assynthesized $\mathrm{TiO}_{2}$ nanowire sample in air at $500{ }^{\circ} \mathrm{C}$ in 30 minutes (Figure 2.6a-2) and a commercial $\mathrm{TiO}_{2}$ anatase nanoparticle powder with average size of $32 \mathrm{~nm}$ (Alfa Aesar Figure 2.6a-1) were annealed in $\mathrm{NH}_{3}$ under the same conditions as our as-synthesized $\mathrm{TiO}_{2}$ nanowire films $\left(500{ }^{\circ} \mathrm{C}\right.$ for two hours). No $\mathrm{N}$ was detected in the XPS spectra, indicating the $\mathrm{N}$ uptake is very small - below the detection limit of the XPS instrument $(0.1 \%)$, thus supporting our hypothesis.

Table 2.2. N-dopant concentration in $\mathrm{TiO}_{2}$ nanowire films annealed at $500{ }^{\circ} \mathrm{C}$ in $\mathrm{NH}_{3}$

\begin{tabular}{|l|l|l|}
\hline \multirow{2}{*}{$\begin{array}{l}\text { Annealing } \\
\text { conditions }\end{array}$} & $\begin{array}{l}\text { N content/ } \\
\text { peak position } \\
\text { (atomic \%/eV) }\end{array}$ & $\begin{array}{l}\mathbf{x} \text { in } \\
\mathbf{T i O}_{2-\mathbf{x}} \mathbf{N}_{\mathbf{x}}\end{array}$ \\
\hline $500{ }^{\circ} \mathrm{C}-\mathrm{NH}_{3}-1$ hour & $0.35 \% / 393.4 \mathrm{eV}$ & \multirow{2}{*}{0.012} \\
\hline $500{ }^{\circ} \mathrm{C}-\mathrm{NH}_{3}-2$ hours & $3.41 \% / 401.3 \mathrm{eV}$ & \\
\hline
\end{tabular}


PEC Properties of $\mathbf{N}$-modified $\mathrm{TiO}_{2}$ nanowire films. Figure 2.7a shows currentvoltage characteristics in the dark (blue dotted line) and in white light (solid blue line) for the $\mathrm{TiO}_{1.988} \mathrm{~N}_{0.012}$ film. Compared with unmodified $\mathrm{TiO}_{2}$ films (Figure 2.3a), there is a positive shift in the onset potential, $\mathrm{E}_{\mathrm{on}}$ from $0.2 \mathrm{~V}_{\mathrm{RHE}}$ to $0.5 \mathrm{~V}_{\mathrm{RHE}}$. Indeed, the transient photocurrent onset potentials for the two samples are almost the same, at around -0.15 $\mathrm{V}_{\mathrm{RHE}}$, indicating that the flat-band potential does not shift with the inclution of $\mathrm{N}$. In this case, ${ }^{30}$ even if the band gap is reduced, the apparent photocurrent onset potential relative to the reference electrode (in a 3-electrode cell) should theoretically remain the same. We, therefore, believe that the shift in $\mathrm{E}_{\mathrm{on}}$ may be due to either a larger band banding requirement for separating electrons and holes because of the material's likely possession of poorer charge-transport properties than pure $\mathrm{TiO}_{2}$ or slower water oxidation kinetics at the surface of $\mathrm{N}$-modified $\mathrm{TiO}_{2}$ sample. Moreover, compared to an unmodified sample of the same thickness $(1.6 \mu \mathrm{m})$, the N-modified sample shows a noticeably lower photocurrent, reaching $0.23 \mathrm{~mA} / \mathrm{cm}^{2}$ at $1.23 \mathrm{~V}$ RHE, compared to $0.38 \mathrm{~mA} / \mathrm{cm}^{2}$ for the unmodified $\mathrm{TiO}_{2}$ nanowire film (Figure 2.3a). Although most authors report an enhancement in the visible light response for $\mathrm{N}$-modified $\mathrm{TiO}_{2}$ films, they also observe a significant decrease in quantum yields in the UV region that leads to poor PEC performance under whole spectrum (i.e., white light) illumination. ${ }^{13,15,25,31}$ Poor PEC performance has often been explained as being due to the formation of isolated $\mathrm{N} 2 \mathrm{p}$ states above the valence band edge, which act as electron-hole recombination centers. Using time-resolved absorption spectroscopy, Tang et al. reported two distinct photohole populations that are trapped at the nitrogen induced states. ${ }^{32}$ They also demonstrated that the lack of water oxidation is due to either rapid electron-hole recombination between charges trapped at the $\mathrm{N}$-incorporation induced states or the reduced oxidative power of the photoholes leading to a lack of thermodynamic driving force. Additionally, Chambers 
et al. reported that the hole trapping probability at the $\mathrm{N}$ induced states is crystallographically dependent. ${ }^{33}$ The hole trapping probability increases if the photogenerated holes diffuse along $<110>$ and $<001>$ directions and the detrapping probability increases if the holes diffuse along $<100>$ direction. As other authors have suggested, it could be that when incorporating $\mathrm{TiO}_{2}$ with $\mathrm{N}$, substitutional $\mathrm{N} 2 \mathrm{p}$ states hybridize with $\mathrm{O} 2 \mathrm{p}^{4,}{ }^{34}$ Since the N $2 \mathrm{p}$ state has a higher orbital energy than the $\mathrm{O} 2 \mathrm{p}$ state, the orbital hybridization shifts the valence band edge to more negative potentials, thus decreasing the oxidative power of photogenerated holes, which hinders hole transfer rates to oxidizable species on the film surface $\left(\mathrm{H}_{2} \mathrm{O}\right.$ or $\left.\mathrm{OH}^{-}\right)$. A water oxidation electrocatalyst (WOC), therefore, may be useful in lowering the overpotential for the reaction. In the next section, we present a simple cobalt co-catalyst treatment which improves the PEC performance of our $\mathrm{N}$-modified $\mathrm{TiO}_{2}$ films.

Water Oxidation Catalyst for $\mathrm{N}$-modified $\mathrm{TiO}_{2}$ Nanowire Films. In PEC water splitting, the water oxidation half reaction is normally more challenging than water reduction and is the rate limiting step since it involves removal of a total of four electrons and four protons from two water molecules to form one oxygen molecule. There have been numerous investigations of water oxidation catalysts for photoanode materials such as $\mathrm{Co}-\mathrm{Pi},{ }^{11} \mathrm{IrO}_{\mathrm{x}},{ }^{9} \mathrm{Pt}, \mathrm{Co}_{3} \mathrm{O}_{4}$, and $\mathrm{IrO}_{\mathrm{x}} \cdot{ }^{35}$ However, to our knowledge, there have not been any reports on water oxidation catalysts for $\mathrm{N}$-modified $\mathrm{TiO}_{2}$ photoanodes. We employed cobalt and silver treatments similar to that mentioned for the unmodified $\mathrm{TiO}_{2}$ nanowire films in the previous section in which our $\mathrm{N}$-modified $\mathrm{TiO}_{2}$ films were immersed in either $0.1 \mathrm{M} \mathrm{Co}\left(\mathrm{NO}_{3}\right)_{2}$ or $0.05 \mathrm{M} \mathrm{AgNO}_{3}$ solution for one minute followed by rinsing with a copious amount of water. 

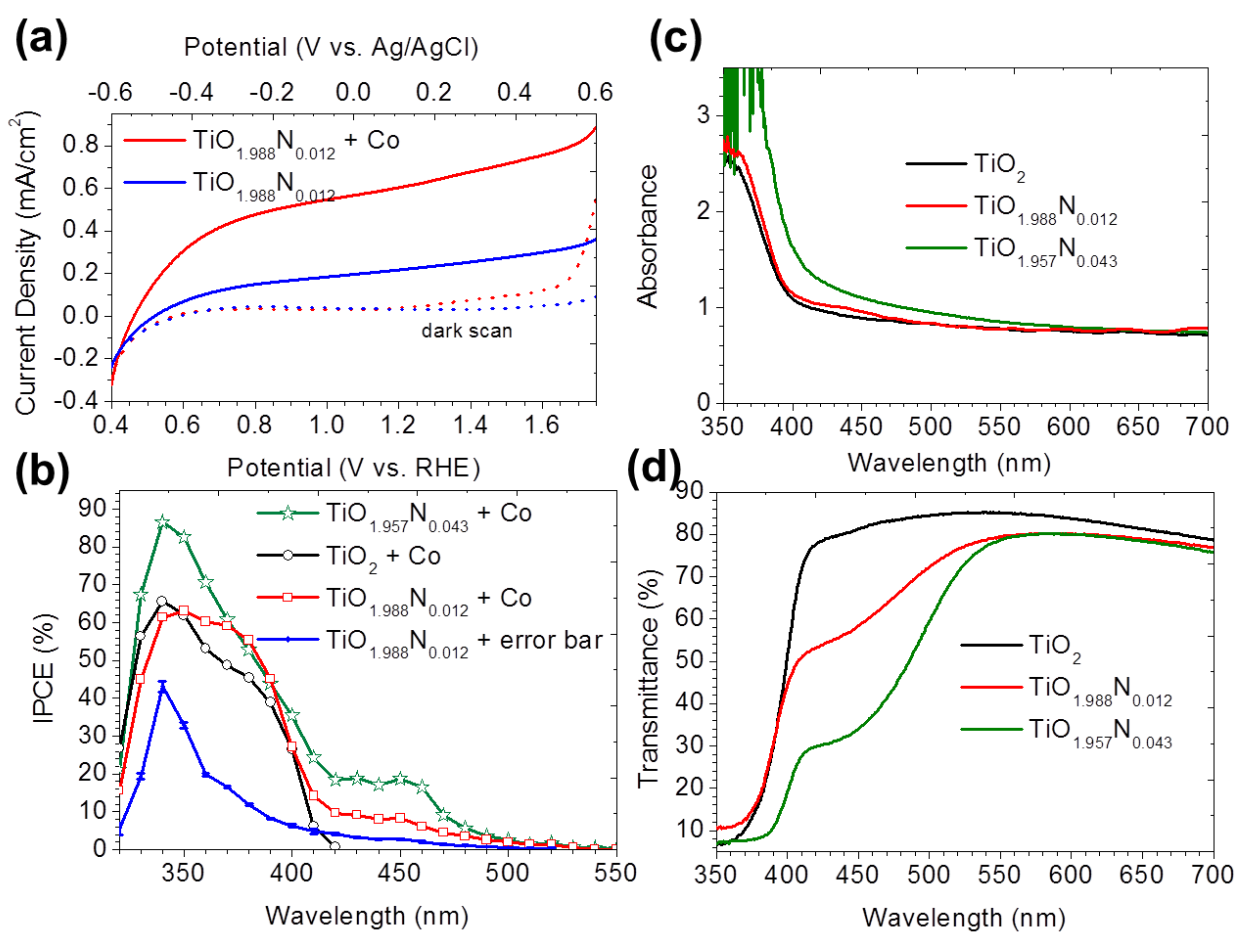

Figure 2.7. (a) Linear Sweep Voltammetry of the $\mathrm{TiO}_{1.988} \mathrm{~N}_{0.012}$ sample and the same electrode after cobalt treatment in darkness (dotted lines) and under illumination (solid lines), (b) IPCE spectra of $\mathrm{N}$-modified $\mathrm{TiO}_{2}$ films at 1.4 $\mathrm{V}_{\mathrm{RHE}}$ : blue curve and red curve are the corresponding IPCE spectra of the $\mathrm{TiO}_{1.988} \mathrm{~N}_{0.012}$ photoelectrode in figure $4 \mathrm{a}$, black curve is the IPCE of unmodified $\mathrm{TiO}_{2}$ sample after cobalt treatment, and green curve is the IPCE of the $\mathrm{TiO}_{1.957} \mathrm{~N}_{0.043}$ pretreated with cobalt, and (c) and (d) UV-vis absorbance spectra and UV-vis transmittance spectra of unmodified and Nmodified $\mathrm{TiO}_{2}$ nanowire samples, and an as-synthesized sample (black curve) was included as a reference

Figure 2.7a shows linear sweep voltammetry of the $\mathrm{TiO}_{1.988} \mathrm{~N}_{0.012}$ photoanode before and after cobalt treatment. After the cobalt treatment, the photocurrent density at $1.23 \mathrm{~V}_{\mathrm{RHE}}$ increases from $0.23 \mathrm{~mA} / \mathrm{cm}^{2}$ [without cobalt] to $0.61 \mathrm{~mA} / \mathrm{cm}^{2}(60 \%$ higher than the unmodified $\mathrm{TiO}_{2}$ sample shown in Figure 2.3a). Compared to an unmodified sample, the cobalt treatment has a much stronger effect on $\mathrm{N}$-modified $\mathrm{TiO}_{2}$ samples with 
around a 2.5 fold improvement in the photocurrent at $1.23 \mathrm{~V}_{\mathrm{RHE}}$. Silver treatment on the $\mathrm{N}$-modified $\mathrm{TiO}_{2}$ film only slightly improves the photocurrent of around $15 \%$ at 1.23 $\mathrm{V}_{\mathrm{RHE}}$ (data not shown), almost the same as for the pristine $\mathrm{TiO}_{2}$, probably because of the surface passivation effect (Ag is not known as a water oxidation co-catalyst). Therefore, we believe that in this case, the cobalt treatment plays dual roles: (1) to passivate surface states, thus increasing hole lifetime and (2) to form a cobalt-based water oxidation catalyst layer. The main PEC performance enhancement may be primarily from the water oxidation catalytic activity of the cobalt layer. We also performed a long chronoamperometry measurement which shows no significant change in the photocurrent during 10 minutes of illumination (data not shown), suggesting good stability of N-modified $\mathrm{TiO}_{2}$ nanowire arrays and the cobalt layer. Grätzel et al. proposed a mechanism for the electrocatalysis of water oxidation by cobalt on hematite surfaces which involves $\mathrm{Co}^{\mathrm{II}} / \mathrm{Co}^{\mathrm{III}}$ and $\mathrm{Co}{ }^{\mathrm{III}} / \mathrm{Co}^{\mathrm{IV}}$ couples. ${ }^{10} \mathrm{We}$ believe cobalt plays a similar role on N-modified $\mathrm{TiO}_{2}$ surfaces. Holes photogenerated within the valence band of $\mathrm{N}$-modified $\mathrm{TiO}_{2}$ have $\mathrm{N}^{3-} 2 \mathrm{p}$ character rather than $\mathrm{O}^{2-} 2 \mathrm{p}$ as in $\mathrm{TiO}_{2}$, thus having less positive potential which results in slower kinetics for water oxidation. On cobalt modified $\mathrm{N}$-modified $\mathrm{TiO}_{2}$ surfaces, water oxidation may follow a reaction pathway that does not require the formation of energetic intermediates such as $\mathrm{OH}$ radicals, thus lowering the activation barrier. The photoholes generated within the valence band of pristine $\mathrm{TiO}_{2}$ have a significant built-in overpotential for water oxidation $\left(\sim 1.6 \mathrm{~V}^{30}\right)$, therefore the use of cobalt as a co-catalyst is not necessary.

Photoconversion Efficiency of $\mathrm{N}$-modified $\mathrm{TiO}_{2}$ nanowire films. IPCE tests were performed in $1 \mathrm{M} \mathrm{KOH}$ at $1.4 \mathrm{~V}_{\mathrm{RHE}}$ to evaluate PEC water oxidation performance of cobalt-treated N-modified $\mathrm{TiO}_{2}$ films (Figure 2.7b). The IPCE spectra of N-modified $\mathrm{TiO}_{2}$ photoanodes have a low-energy threshold at a wavelength of $\sim 520 \mathrm{~nm}$, 
corresponding to $2.4 \mathrm{eV}$ (IPCE $\sim 1.7 \%$ at $520 \mathrm{~nm}$ for cobalt-treated $\mathrm{TiO}_{1.957} \mathrm{~N}_{0.043}$ ), although they weakly responded to photons with wavelengths up to $600 \mathrm{~nm}$ (typical calculated IPCEs in the region from $530 \mathrm{~nm}$ to $600 \mathrm{~nm}$ were from $0.6 \%$ to $\sim 0.05 \%$ ). For cobalt treated unmodified $\mathrm{TiO}_{2}$ (black curve), the PEC onset is located at around $420 \mathrm{~nm}$. We note that after the cobalt treatment, the IPCE performance of $\mathrm{N}$-modified $\mathrm{TiO}_{2}$ films (green and red curves) in the UV region is restored to that of the unmodified samples. This indicates that the low water oxidation quantum yields in the UV region due to $\mathrm{N}$ incorporation are likely due to the lower overpotential for water oxidation of photoholes at the $\mathrm{N}$-modified $\mathrm{TiO}_{2}$ valence band edge. This lower overpotential can apparently be made up by the use of an appropriate water oxidation co-catalyst.

The IPCE spectra fit the absorbance spectra and the transmittance spectra well (figure $2.7 \mathrm{c}$ and figure $2.7 \mathrm{~d}$ ), which suggest that there are no major relative differences in the oxidative power of the holes photogenerated by UV and visible-light photons. ${ }^{13}$ The conversion efficiency of visible photons appears to be limited by absorption depth. Moreover, the onset of the IPCE spectra located at $\sim 550 \mathrm{~nm}$ confirms that the long tail at longer wavelength in the UV-vis absorbance spectra for N-modified samples is not solely due to the light scattering of the nanostructure. The plateau in the IPCE spectrum from $420 \mathrm{~nm}$ to $460 \mathrm{~nm}$ is well matched up with the plateau in the transmittance spectrum indicating that the sample absorbs photons within this range with similar efficiency. It is also interesting that the IPCE spectrum in the visible light region (greater than $420 \mathrm{~nm}$ ) for cobalt treated $\mathrm{TiO}_{1.9570} \mathrm{~N}_{.043}$ (Figure $2.7 \mathrm{~b}$, green curve) is significantly higher than that of cobalt treated $\mathrm{TiO}_{1.988} \mathrm{~N}_{0.012}$ (Figure $2.7 \mathrm{~b}$, red curve). In the visible light region, the IPCE spectrum of the cobalt treated $\mathrm{TiO}_{1.957} \mathrm{~N}_{0.043}$ film plateaus from $420 \mathrm{~nm}$ to $460 \mathrm{~nm}$ at values of $\sim 18 \%$, before decaying to $\sim 0.2 \%$ at $550 \mathrm{~nm}$. The IPCE spectrum of the cobalt treated $\mathrm{TiO}_{1.988} \mathrm{~N}_{0.012}$ film has a similar shape, but with plateau values of $\sim 9 \%$ 
from $420 \mathrm{~nm}$ to $450 \mathrm{~nm}$. It is well established that more $\mathrm{N}$-dopant leads to better visible light absorbance, although unfortunately this has not always lead to better water oxidation performance and photocatalytic activity. ${ }^{13,22}$ However, it is clear that by using a water oxidation co-catalyst, the PEC performance of cobalt treated $\mathrm{N}$-modified $\mathrm{TiO}_{2}$ can be enhanced, resulting in more than $60 \%$ higher full-spectrum photocurrent compared to unmodified $\mathrm{TiO}_{2}$.

The UV-vis absorbance and transmittance spectra for untreated and Co-treated samples are almost identical, suggesting that the Co-catalyst does not affect the light absorption ability of the materials. Additionally, the IPCE of Co-treated $\mathrm{TiO}_{2}$ samples does not show response to wavelength $>420 \mathrm{~nm}$. Comparing with the pristine $\mathrm{TiO} 2$ nanowire arrays, we observed additional response from $420 \mathrm{~nm}-550 \mathrm{~nm}$ including the plateau from $\sim 420 \mathrm{~nm}$ to $\sim 460 \mathrm{~nm}$ in both of the IPCE spectra and the UV-vis transmittance spectra for all $\mathrm{N}$-modified samples, suggesting that additional $\mathrm{N}$-induced states are present in the range of $0-0.7 \mathrm{eV}$ above the valence band edge of $\mathrm{TiO}_{2}$ (or 3.0 $2.3 \mathrm{eV}$ below the conduction band edge). We believe that the density of these $\mathrm{N}$-induced states is almost constant from $0-0.3 \mathrm{eV}$ above the valence band edge. We, however, did not observe additional electronic states above the valence band edge in the valence band XPS spectra and the ultraviolet photoemission spectra (Figure 2.8) of the N-modified $\mathrm{TiO}_{2}$ samples. 

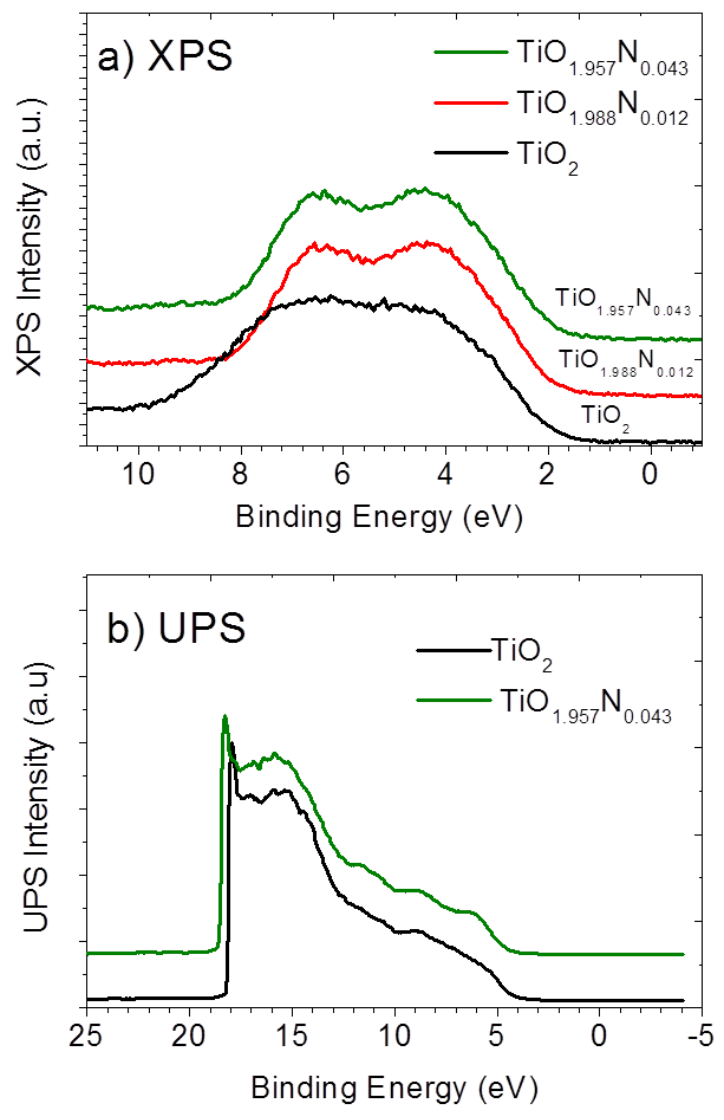

Figure 2.8. (a) XPS valence band spectra of the $\mathrm{TiO}_{2}, \mathrm{TiO}_{1.988} \mathrm{~N}_{0.012}$, and $\mathrm{TiO}_{1.957} \mathrm{~N}_{0.043}$ samples and (b) UPS spectra of the $\mathrm{TiO}_{2}$ and $\mathrm{TiO}_{1.957} \mathrm{~N}_{0.043}$ samples. The UPS spectra were calibrated versus the Fermi edge of a polycrystalline Au foil.

\section{CONCLUSIONS}

In summary, we report a hydrothermal synthesis route that allows direct growth of vertically aligned, densely packed, single crystalline rutile $\mathrm{TiO}_{2}$ nanowire arrays with exceptionally small feature sizes of $\sim 5 \mathrm{~nm}$ and lengths up to $4.4 \mu \mathrm{m}$ on top of FTO substrates. We also report the synthesis of visible-light-active nitrogen-modified $\mathrm{TiO}_{2}$ photoanodes via the nitridation of hydrothermally synthesized $\mathrm{TiO}_{2}$ nanowire arrays in $\mathrm{NH}_{3}$ at relatively low temperature. We also demonstrate that utilization of a cobalt cocatalyst can significantly enhance the PEC performance of our $\mathrm{N}$-modified $\mathrm{TiO}_{2}$ 
nanowire arrays. With a cobalt water oxidation co-catalyst, the quantum yields of our Nmodified $\mathrm{TiO}_{2}$ samples increase with increasing substitutional nitrogen concentration, and are higher than the quantum yields of unmodified $\mathrm{TiO}_{2}$ samples both in the $\mathrm{UV}$ and visible light regions. 


\section{REFERENCES}

1. Fujishima, A.; Honda, K. Nature 1972, 238, (5358), 37-38.

2. Linsebigler, A. L.; Lu, G.; Yates, J. T. Chem. Rev. 1995, 95, (3), 735-758.

3. Chen, X.; Mao, S. S. Chem. Rev. 2007, 107, (7), 2891-2959.

4. Asahi, R.; Morikawa, T.; Ohwaki, T.; Aoki, K.; Taga, Y. Science 2001, 293, (5528), 269-271.

5. Park, J. H.; Kim, S.; Bard, A. J. Nano Lett. 2005, 6, (1), 24-28.

6. Zhu, W.; Qiu, X.; Iancu, V.; Chen, X.-Q.; Pan, H.; Wang, W.; Dimitrijevic, N. M.; Rajh, T.; Meyer, H. M.; Paranthaman, M. P.; Stocks, G. M.; Weitering, H. H.; Gu, B.; Eres, G.; Zhang, Z. Phys. Rev. Lett. 2009, 103, (22), 226401.

7. Yin, W.-J.; Tang, H.; Wei, S.-H.; Al-Jassim, M. M.; Turner, J.; Yan, Y. Phys. Rev. B 2010, 82, (4), 045106.

8. Salvador, P. J. Appl. Phys. 1984, 55, (8), 2977-2985.

9. Abe, R.; Higashi, M.; Domen, K. J. Am. Chem. Soc. 2010, 132, (34), $11828-$ 11829.

10. Kay, A.; Cesar, I.; GrÃatzel, M. J. Am. Chem. Soc. 2006, 128, (49), 15714-15721.

11. Kanan, M. W.; Nocera, D. G. Science 2008, 321, (5892), 1072-1075.

12. Burda, C.; Lou, Y.; Chen, X.; Samia, A. C. S.; Stout, J.; Gole, J. L. Nano Lett. 2003, 3, (8), 1049-1051.

13. Beranek, R.; Neumann, B.; Sakthivel, S.; Janczarek, M.; Dittrich, T.; Tributsch, H.; Kisch, H. Chem. Phys. 2007, 339, (1-3), 11-19.

14. Nakamura, R.; Tanaka, T.; Nakato, Y. J. Phys. Chem. B 2004, 108, (30), 1061710620.

15. Torres, G. R.; Lindgren, T.; Lu, J.; Granqvist, C. G.; Lindquist, S. E. J J. Phys. Chem. B 2004, 108, (19), 5995-6003.

16. Batzill, M.; Morales, E. H.; Diebold, U. Phys. Rev. Lett. 2006, 96, (2), 026103.

17. Serpone, N. J. Phys. Chem. B 2006, 110, (48), 24287-24293.

18. Emeline, A. V.; Sheremetyeva, N. V.; Khomchenko, N. V.; Ryabchuk, V. K.; Serpone, N. J. Phys. Chem. C 2007, 111, (30), 11456-11462.

19. Feng, X.; Shankar, K.; Varghese, O. K.; Paulose, M.; Latempa, T. J.; Grimes, C. A. Nano Lett. 2008, 8, (11), 3781-3786.

20. Meinan, L.; Hongxia, W.; Cheng, Y.; Geoffrey, W.; John, B. Appl. Phys. Lett. 2011, 98, 133113. 
21. Shao, F.; Sun, J.; Gao, L.; Yang, S.; Luo, J. ACS Appl. Mater. Interfaces 2011, 3, (6), 2148-2153.

22. Wang, J.; Tafen, D. N.; Lewis, J. P.; Hong, Z.; Manivannan, A.; Zhi, M.; Li, M.; Wu, N. J. Am. Chem. Soc. 2009, 131, (34), 12290-12297.

23. Chen, X.; Burda, C. J. Am. Chem. Soc. 2008, 130, (15), 5018-5019.

24. Fujishima, A.; Zhang, X. T.; Tryk, D. A. Surf. Sci. Rep. 2008, 63, (12), 515-582.

25. Irie, H.; Watanabe, Y.; Hashimoto, K. J. Phys. Chem. B 2003, 107, (23), 54835486.

26. Takahashi, I.; Payne, D. J.; Palgrave, R. G.; Egdell, R. G. Chem. Phys. Lett. 2008, 454, (4-6), 314-317.

27. Diwald, O.; Thompson, T. L.; Zubkov, T.; Walck, S. D.; Yates, J. T. J. Phys. Chem. B 2004, 108, (19), 6004-6008.

28. Miyauchi, M.; Ikezawa, A.; Tobimatsu, H.; Irie, H.; Hashimoto, K. Phys. Chem. Chem. Phys. 2004, 6, (4), 865-870.

29. Irie, H.; Washizuka, S.; Yoshino, N.; Hashimoto, K. Chem. Commun. 2003, (11), 1298-1299.

30. Gai, Y.; Li, J.; Li, S.-S.; Xia, J.-B.; Wei, S.-H. Phys. Rev. Lett. 2009, 102, (3), 036402 .

31. Lindgren, T.; Lu, J.; Hoel, A.; Granqvist, C. G.; Torres, G. R.; Lindquist, S. E. Sol. Energy Mater. Sol. Cells 2004, 84, (1-4), 145-157.

32. Tang, J.; Cowan, A. J.; Durrant, J. R.; Klug, D. R. J. Phys. Chem. C 2011, 115, (7), 3143-3150.

33. Ohsawa, T.; Henderson, M. A.; Chambers, S. A. J. Phys. Chem. C 2010, 114, (14), 6595-6601.

34. Asahi, R.; Taga, Y.; Mannstadt, W.; Freeman, A. J. Phys. Rev. B 2000, 61, (11), 7459.

35. Ye, H.; Park, H. S.; Bard, A. J. J. Phys. Chem. C 2011, 115, (25), 12464-12470. 


\section{Chapter 3: Enhancing Visible Light Photo-Oxidation of Water with $\mathrm{TiO}_{2}$ Nanowire Arrays via Co-treatment with $\mathrm{H}_{2}$ and $\mathrm{NH}_{3}$ : Synergistic Effects between $\mathrm{Ti}^{3+}$ and $\mathrm{N}$}

\section{INTRODUCTION}

The search for cheap, efficient, and stable photocatalysts for solar hydrogen production from water splitting has been an increasingly active field since Honda and Fujishima's discovery of water photo-oxidation on a $\mathrm{TiO}_{2}$ photoanode under ultraviolet (UV) light. ${ }^{1}$ To date, $\mathrm{TiO}_{2}$ is still one of the most studied photocatalyst materials due to its abundance, low-cost, low-toxicity, superior photo-stability, and high intrinsic catalytic activity under UV illumination. ${ }^{2-5}$ However, the photo-conversion efficiency of $\mathrm{TiO}_{2}$ is limited to less than $2.2 \%$ under AM 1.5 global solar illumination due to its large band gap energy (3.0 $\mathrm{eV}$ for rutile and $3.2 \mathrm{eV}$ for anatase). ${ }^{6}$ The generally-accepted benchmark for solar-tohydrogen efficiency under AM 1.5 global illumination is $10 \%$ for practical implementation. ${ }^{7}$ Therefore, extending the working spectrum of $\mathrm{TiO}_{2}$-based materials to include more of the visible light region, which composes $\sim 45 \%$ of the total energy of the solar spectrum, has been of great interest.

Recent efforts have focused on modifying the valence band of $\mathrm{TiO}_{2}$ by incorporating nonmetal ions such as $\mathrm{C},{ }^{8} \mathrm{~S},{ }^{9}$ and $\mathrm{N}^{4,10}$. The $\mathrm{p}$ states of the nonmetal foreign ions $(\mathrm{N}, \mathrm{S}$, or C) normally form impurity states above the valence band or hybridize with $\mathrm{O} 2 \mathrm{p}$ states (composing most of the valence band for $\mathrm{TiO}_{2}$ ) thus upshifting the valence band edge of $\mathrm{TiO}_{2}{ }^{3}$ Among nonmetal elements, $\mathrm{N}$ doping has been widely investigated and some success has been achieved in extending the working spectrum of $\mathrm{TiO}_{2}$ toward the visible

light range. ${ }^{4}$ Modifying $\mathrm{TiO}_{2}$ by hydrogen has also received attention recently. ${ }^{11,12}$ Wang 
et al. demonstrated that annealing rutile $\mathrm{TiO}_{2} \mathrm{NW}$ arrays in an $\mathrm{H}_{2}$ atmosphere creates oxygen vacancy sites thus forming donor states below the conduction band. ${ }^{11}$ This improves light absorption and charge transport similar to n-type doping, thus enhancing water oxidation performance. Chen et al. reported a hydrogenation method to produce disorder in nanophase $\mathrm{TiO}_{2}$, which significantly enhances visible light absorption. ${ }^{12}$ Despite the interest in the effects of nitrogen doping and hydrogen modification, there are only a few studies on the synergistic effects of $\mathrm{H}$ and $\mathrm{N}$ co-doping on the photocatalytic activity of $\mathrm{TiO}_{2}$ materials. ${ }^{13-17}$ To our knowledge, there is no report on the enhancement of visible light water photo-oxidation of $\mathrm{TiO}_{2}$ due to the cotreatment with $\mathrm{H}_{2}$ and $\mathrm{NH}_{3}$ at high temperature. Diwald et al. prepared $\mathrm{H}, \mathrm{N}$-codoped $\mathrm{TiO}_{2}$ material that is photoactive for $\mathrm{Ag}$ deposition under irradiation by photons of $2.4 \mathrm{eV}$ by annealing rutile $\mathrm{TiO}_{2}(110)$ in $\mathrm{NH}_{3}$ at $870 \mathrm{~K}$. The treatment introduced two species of $\mathrm{N}$ into the $\mathrm{TiO}_{2}$ lattice: substituitonal and interstitial $\mathrm{N}$ species. ${ }^{17}$ The authors claimed that the co-doping effect between the interstitial species and hydrogen is responsible for the enhancement in the visible light activity. The authors, however, did not consider the effects of $\mathrm{Ti}^{3+}$ formation. In fact, under this nitridation condition, $\mathrm{Ti}^{3+}$ formation is expected and can be more readily detected using bulk characterization techniques such as EPR rather than by conventional surface characterization techniques such as X-ray Photoemission Spectroscopy (XPS) due to the instability of the surface $\mathrm{Ti}^{3+}$ in air or water.

In addition to enhancing optical absorption, it is equally important to optimize the photogenerated electron/hole separation characteristics. Vertically oriented nanocolumnar structures are considered to be very effective structures for 
photoelectrochemical (PEC) water splitting applications. ${ }^{18,19}$ These structures permit significant light absorption depths while still enhancing the charge separation by providing high electrode/electrolyte interface areas and shortening the minority charge carrier transport distance to the electrolyte. We have recently reported the hydrothermal synthesis of vertically-aligned ultrafine single crystalline rutile $\mathrm{TiO}_{2} \mathrm{NW}$ arrays with an average cross sectional dimension of $\sim 5 \mathrm{~nm} .{ }^{10}$ Upon nitridation in a $\mathrm{NH}_{3}$ flow at $500{ }^{\circ} \mathrm{C}$, the optical absorption and the PEC response spectrum extended from $\sim 420 \mathrm{~nm}$ to $\sim 550$ nm. In the present study, we demonstrate synergistic effects of hydrogenation and nitridation that further extend the active spectrum of the $\mathrm{TiO}_{2} \mathrm{NW}$ arrays to $\sim 570 \mathrm{~nm}$. To our knowledge, we are the first to demonstrate the enhancement of visible light water photo-oxidation reactivity of $\mathrm{TiO}_{2}$ material due to hydrogenation and nitridation cotreatment.

\section{EXPERIMENTAL METHODS}

Materials. All chemicals were purchased and used without further purification including titanium (IV) isopropoxide (TTIP) $(98+\%$, Acros Organics), $\mathrm{HCl}$ (ACS Reagent Grade 36.5-38\%, MP), n-hexane (Extra dry, 96+\%, Acros Organics), titanium (IV) chloride, (99.0+\%, Alfa Aesar), gas mixture of $\mathrm{H}_{2}$ and $\mathrm{Ar}\left(5 \% \mathrm{H}_{2}\right.$ in $\mathrm{Ar}$, Matheson Tri-gas), and ammonia (99.99\%, Matheson Tri-gas).

Hydrothermal Synthesis. Fluorine-doped Tin Oxide (FTO) coated glass substrates were first cleaned by sonication in a mixture of ethanol and water for 30 minutes, subsequently rinsed by deionized (DI) water, and finally dried in an air stream. The FTO substrates were then seeded with a thin layer of $\mathrm{TiO}_{2}$ before growing the 
nanowire arrays by soaking in $0.025 \mathrm{M} \mathrm{TiCl}_{4}$ in $\mathrm{n}$-hexane for 30 minutes. They were then taken out, rinsed by ethanol, and finally annealed in air at $500{ }^{\circ} \mathrm{C}$ for 30 minutes. The seeded FTO substrates were then placed on the bottom of a Teflon lined autoclave (125 $\mathrm{mL}$, Parr Instrument), containing $50 \mathrm{~mL}$-hexane, $5 \mathrm{~mL} \mathrm{HCl}$, and $5 \mathrm{~mL}$ of titanium (IV) isopropoxide. The hydrothermal synthesis was conducted at $150{ }^{\circ} \mathrm{C}$ for 5 hours. After the reaction was completed and the autoclave naturally cooled down to room temperature, the $\mathrm{TiO}_{2}$ nanowire films were taken out and cleaned by rinsing with copious amount of ethanol and water. The $\mathrm{TiO}_{2}$ nanowire array thickness was measured as $2.6 \mu \mathrm{m} \pm 0.27$ $\mu \mathrm{m}$ by Scanning Electron Microscopy.

Thermal treatments. To remove the contaminants and increase the crystallinity, the pristine $\mathrm{TiO}_{2}$ nanowire sample was prepared by annealing the as-hydrothermally synthesized sample in air at $500{ }^{\circ} \mathrm{C}$ for 1 hour in a box oven. The hydrogen treatment and nitridation process were performed using a tube furnace (MTI, OTF-1200x-80). The tube was first evacuated until the pressure inside the tube was below 1 Torr. The tube was then filled with desired gases $\left(\mathrm{H}_{2} / \mathrm{Ar}\right.$ or $\left.\mathrm{NH}_{3}\right)$ to atmospheric pressure. The flows of $\mathrm{H}_{2} / \mathrm{Ar}$ (100 mL/minute) and $\mathrm{NH}_{3}(100 \mathrm{~mL} /$ minute $)$ were controlled by gas flow controllers during annealing time. The exhaust line was bubbled through a cup of water (the exhaust line was kept $\sim 5 \mathrm{~cm}$ below the water surface). The hydrogen-treated sample (H-TiO2) and the nitrided sample $\left(\mathrm{N}-\mathrm{TiO}_{2}\right)$ were prepared by annealing the as-synthesized samples at $500{ }^{\circ} \mathrm{C}$ in $\mathrm{H}_{2} / \mathrm{Ar}$ for 1 hour and $\mathrm{NH}_{3}$ for 2 hours respectively. The co-treated sample $\left(\mathrm{H}, \mathrm{N}-\mathrm{TiO}_{2}\right)$ were prepared by first annealing in $\mathrm{H}_{2} / \mathrm{Ar}$ at $500{ }^{\circ} \mathrm{C}$ for 1 hour, following by annealing in $\mathrm{NH}_{3}$ at $500{ }^{\circ} \mathrm{C}$ for 2 hours.

Material Characterization. Scanning electron microscopy (SEM) was performed on a Zeiss field-emission SEM using a $10 \mathrm{kV}$ focus voltage. Transmission electron microscopy (TEM) was performed on a JEOL 2010F field-emission TEM using 
a $200 \mathrm{kV}$ focus voltage. Grazing incidence X-ray diffraction (GIXRD) patterns were collected with a Bruker D8 diffractometer. The transmittance spectra were collected using a Cary 500 UV-vis-NIR spectrophotometer attached to a Labsphere DRA-CA-5500 integrating sphere. X-ray photoelectron spectroscopy (XPS) was performed on a Kratos Axis x-ray photoelectron spectrometer with scanning step of $0.1 \mathrm{eV}$ and dwell time of 4 second/step. The binding energy was calibrated using the $\mathrm{C} 1 \mathrm{~s}$ photoelectron peak at $284.6 \mathrm{eV}$ as a reference. The elemental percentages were calculated from XPS spectra using the CasaXPS computer program with specific relative sensitivity factors for the Kratos Axis XPS (Ti 2p: 2.001, O 1s: 0.78, and N 1s: 0.48). The electron paramagnetic resonance (EPR) spectra were collected at $86 \mathrm{~K}$ using a Bruker EMX-CW EPR spectrometer operating at the X-band frequency. The samples were first loaded in quartz glass tubes covered by aluminum foil, then baked out in an oven at $60{ }^{\circ} \mathrm{C}$ for 24 hours before EPR measurements. Five (5) scans were added for each spectrum with following scan parameters: microwave frequency $=9.47 \mathrm{GHz}$; modulation amplitude $=1 \mathrm{G}$; modulation frequency $=100 \mathrm{kHz}$; and non-saturating microwave power $=20 \mathrm{~mW}$.

\section{Electrochemical and Photoelectrochemical (PEC) Characterizations.}

The PEC measurements were performed using a three-electrode electrochemical cell with the FTO supported nanowire arrays as the working electrode, a $\mathrm{Ag} / \mathrm{AgCl}$ (saturated $\mathrm{KCl}$ ) reference electrode, a platinum wire counter electrode, and $1 \mathrm{M} \mathrm{KOH}$ electrolyte $(\mathrm{pH}=13.5)$. The working electrode with exposed area of $0.205 \mathrm{~cm}^{2}$ was illuminated from the back side (through the FTO substrate - $\mathrm{TiO}_{2}$ nanowire interface) by a solar simulator (Newport, Model 9600, $150 \mathrm{~W}$ xenon lamp) equipped with an AM 1.5 G filter (Newport, Model 81094). The light intensity was measured as $100 \mathrm{~mW} / \mathrm{cm}^{2}$ using a thermopile detector with the spectrum response from 0.19 to $10.6 \mu \mathrm{m}$ (Newport, 818P- 
020-12). A CHI 660D electrochemical station was used for linear sweep voltammetry (IV) and chronoamperometry (I-t) measurements.

Incident photon to current conversion efficiencies (IPCEs) were calculated from chronoamperometry measurements using a motorized monochrometer (Oriel Cornerstone $1301 / 8 \mathrm{~m})$. The monochrometer slit size was adjusted to $0.75 \mathrm{~mm} \times 2 \mathrm{~mm}$ providing monochromatic wavelengths with a bandwidth of $\sim 5 \mathrm{~nm}$ and a power density which could be adjusted from 8 to $4000 \mu \mathrm{W} / \mathrm{cm}^{2}$ for wavelengths from 320 to $600 \mathrm{~nm}$. A typical light power density spectrum used for IPCE can be found in Figure 3.1.

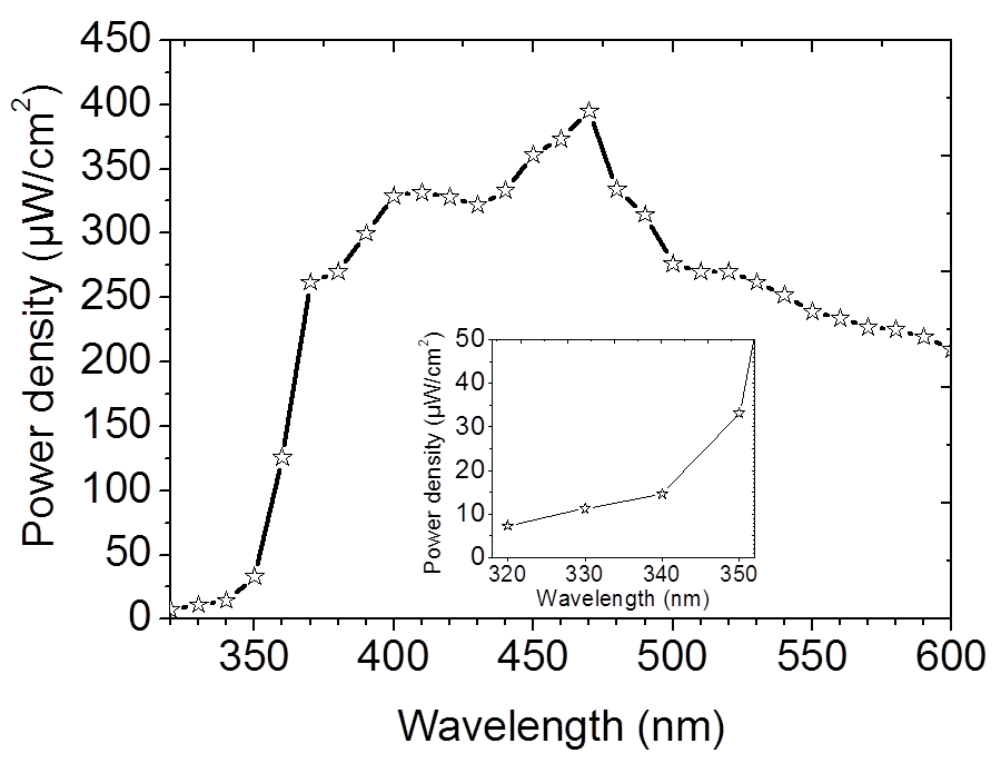

Figure 3.1. A typical incident light power density spectrum (from $320 \mathrm{~nm}-600 \mathrm{~nm}$ ) used for the IPCE measurements. The inset shows the incidence power density spectrum from $320 \mathrm{~nm}-350 \mathrm{~nm}$.

Light power was measured using a handheld optical power meter with a UV enhanced silicon photo-detector (Newport). IPCE values were calculated using the following equation: 


$$
\operatorname{IPCE}(\lambda)=\frac{1240 j_{p}(\lambda)}{\lambda E_{\lambda}(\lambda)}
$$

where $j_{p}(\lambda)$ is the measured photocurrent density $\left(\mathrm{mA} / \mathrm{cm}^{2}\right)$ and $E_{\lambda}(\lambda)$ is the incident light power density $\left(\mathrm{mW} / \mathrm{cm}^{2}\right)$ for each wavelength, $\lambda(\mathrm{nm})$.

The measured potentials vs. the $\mathrm{Ag} / \mathrm{AgCl}$ were converted to the reversible hydrogen electrode (RHE) scale via the Nernst equation

$$
\mathrm{E}_{\mathrm{RHE}}=\mathrm{E}_{\mathrm{Ag} / \mathrm{AgCl}}+0.059 \mathrm{pH}+\mathrm{E}_{\mathrm{Ag} / \mathrm{AgCl}}^{\mathrm{o}}(2)
$$

where $\mathrm{E}_{\mathrm{RHE}}$ is the converted potential vs. RHE, $\mathrm{E}_{\mathrm{Ag} / \mathrm{AgCl}}$ is the experimental potential measured against $\mathrm{Ag} / \mathrm{AgCl}$ reference electrode, and $\mathrm{E}_{\mathrm{Ag} / \mathrm{AgCl}}^{\mathrm{o}}=0.1976 \mathrm{~V}$ at 25 ${ }^{\circ} \mathrm{C}$.

\section{RESULTS AND DISCUSSION}

The $\mathrm{TiO}_{2}$ photoelectrodes were prepared via two steps: (1) hydrothermal synthesis followed by (2) thermal treatments. The single crystalline rutile $\mathrm{TiO}_{2} \mathrm{NW}$ arrays with a thickness of $2.60 \pm 0.27 \mu \mathrm{m}$ were hydrothermally prepared on Fluorine-doped Tin Oxide (FTO) substrates. The NW arrays were further modified by annealing at $500{ }^{\circ} \mathrm{C}$ (i) in air for 1 hour (denoted as $\left.\mathrm{TiO}_{2}\right)$, (ii) in $\mathrm{NH}_{3}$ for 2 hours $\left(\mathrm{N}-\mathrm{TiO}_{2}\right)$, (iii) in a mixture of $\mathrm{H}_{2}$ and $\operatorname{Ar}\left(5 \%\right.$ of $\left.\mathrm{H}_{2}\right)$ for 1 hour $\left(\mathrm{H}-\mathrm{TiO}_{2}\right)$, and (iv) in the a mixture of $\mathrm{H}_{2}$ and Ar for 1 hour followed by annealing in $\mathrm{NH}_{3}$ for 2 hours $\left(\mathrm{H}, \mathrm{N}-\mathrm{TiO}_{2}\right)$.

The X-ray diffraction data (XRD) (Figure 3.2a) confirms that all films are of rutile phase and no additional phase was detected upon thermal treatment. However, the thermal treatments have a profound effect on the visual appearance and morphology of the NW arrays. The white color of the pristine $\mathrm{TiO}_{2}$ film did not change after hydrogen 
treatment; however, it turned green after nitridation, and dark green after both treatments (Figure 3.2b).
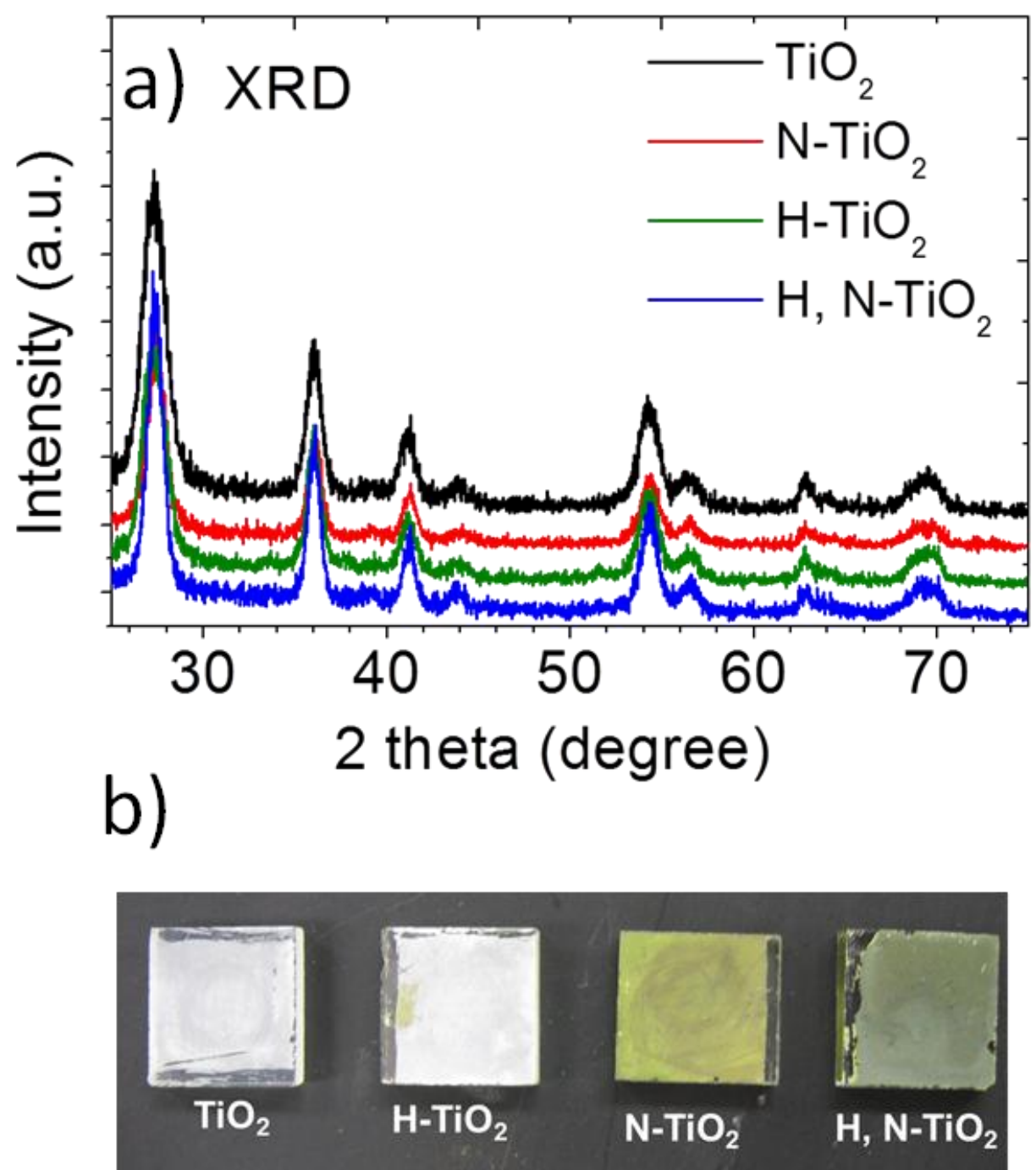

Figure 3.2. (a) Grazing incidence XRD patterns and (b) digital images of $\mathrm{TiO}_{2}, \mathrm{~N}-\mathrm{TiO}_{2}$, $\mathrm{H}-\mathrm{TiO}_{2}$, and $\mathrm{H}, \mathrm{N}-\mathrm{TiO}_{2}$.

In addition the shape and size of the nanowires changed with each treatment as can be seen by the SEM images in Figure 3.3. 


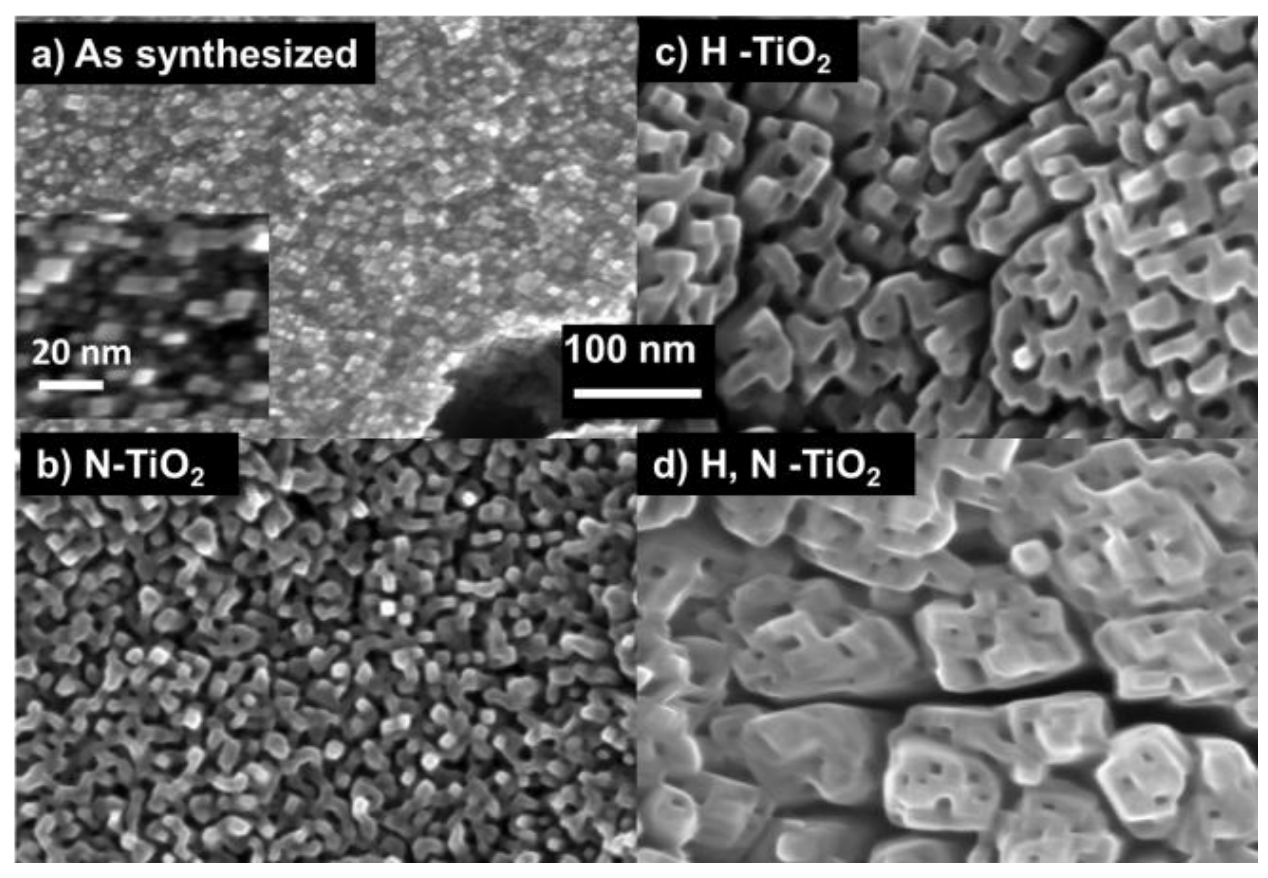

Figure 3.3. Scanning Electron Microscopy (SEM) images of (a) as-synthesized $\mathrm{TiO}_{2}$ (inset shows higher magnification view), and films annealed at $500{ }^{\circ} \mathrm{C}$ in (b) $\mathrm{NH}_{3}$, (c) $\mathrm{H}_{2}$, and (d) $\mathrm{H}_{2}$ and then $\mathrm{NH}_{3}$.

Upon treatment, the cross-section of the NW becomes larger due to the sintering of the small wires. Increases in the interplanar d-spacing for the (101) crystal plane due to co-treatment observed by Transmission Electron Microscopy (TEM) (Figure 3.4) indicate lattice expansion as a result of $\mathrm{N}$ incorporation. 


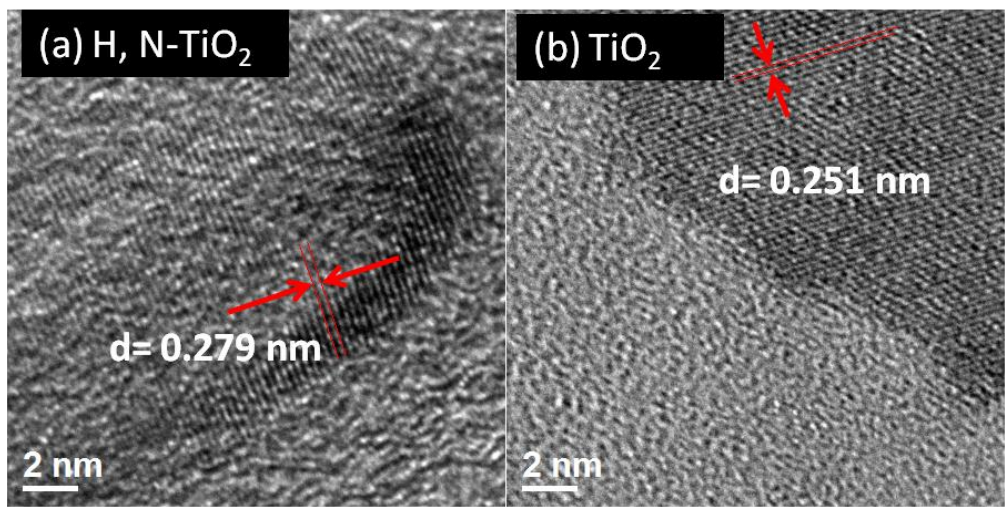

Figure 3.4. High resolution TEM images of (a) $\mathrm{H}, \mathrm{N}-\mathrm{TiO}_{2}$ and (b) $\mathrm{TiO}_{2}$ samples.

We employed X-ray Photoemission Spectroscopy (XPS) to investigate the chemical composition of the surface (Figure 3.5). The $\mathrm{N} 1 \mathrm{~s}$ peak at $399.8 \mathrm{eV}$ of the $\mathrm{TiO}_{2}$ sample is assigned to molecular $\mathrm{N}_{2}$ adsorbed on the surface. ${ }^{4}$
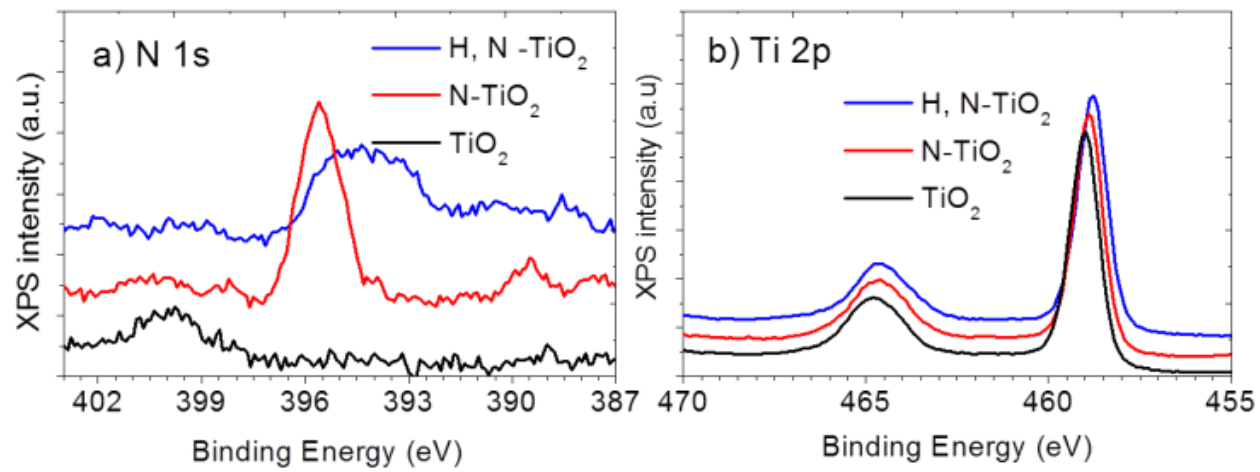

Figure3.5. XPS spectra of the $\mathrm{TiO}_{2}, \mathrm{~N}-\mathrm{TiO}_{2}$, and $\mathrm{H}, \mathrm{N}-\mathrm{TiO}_{2} \mathrm{NW}$ arrays: (a) Core $\mathrm{N} 1 \mathrm{~s}$ and (b) Core Ti 2p.

The $\mathrm{N} 1 \mathrm{~s}$ feature at $395.6 \mathrm{eV}$ of the $\mathrm{N}-\mathrm{TiO}_{2}$ sample and the feature at $394.4 \mathrm{eV}$ of the $\mathrm{H}, \mathrm{N}-\mathrm{TiO}_{2}$ sample are assigned to substitutional $\beta-\mathrm{N}\left(\mathrm{N}^{3-}\right)$ species which is considered 
responsible for enhancing the visible light activity of the $\mathrm{N}$-doped materials. ${ }^{4,20}$ It is interesting that the $\mathrm{N} 1 \mathrm{~s}$ feature of the $\mathrm{H}, \mathrm{N}-\mathrm{TiO}_{2}$ sample is broader and shifts to a lower binding energy compared with that of the $\mathrm{N}-\mathrm{TiO}_{2}$. We will discuss these phenomena in more detail later. The substitutional $\mathrm{N}$ concentrations are calculated as 5.6 atomic $\%$ for $\mathrm{N}-\mathrm{TiO}_{2}$ and 3.5 atomic $\%$ for $\mathrm{H}, \mathrm{N}-\mathrm{TiO}_{2}$, corresponding to $\mathrm{x}$ values of 0.20 and 0.12 ( $\mathrm{x}$ in $\mathrm{TiO}_{2-\mathrm{x}} \mathrm{N}_{\mathrm{x}}$ ), respectively. The substitutional $\mathrm{N}$ concentration in our $\mathrm{N}$-modified $\mathrm{TiO}_{2}$ nanowires is considerably higher compared to other $\mathrm{N}$-doped $\mathrm{TiO}_{2}$ materials prepared via nitridation of $\mathrm{TiO}_{2}$ at elevated temperature in $\mathrm{NH}_{3}$ flow. ${ }^{21}$ The unique morphology and the ultrafine cross-section of the NW may enhance $\mathrm{N}$ diffusion into the $\mathrm{TiO}_{2}$ lattice.

The Ti 2p3/2 XPS features are observed at $459.20 \mathrm{eV}, 458.76 \mathrm{eV}$, and $458.71 \mathrm{eV}$ for $\mathrm{TiO}_{2}, \mathrm{~N}-\mathrm{TiO}_{2}$, and $\mathrm{H}, \mathrm{N}-\mathrm{TiO}_{2}$ respectively. These features are all assigned to $\mathrm{Ti}^{4+}$, indicating no $\mathrm{Ti}^{3+}$ species exist on the surface (the XPS technique characterizes the top 1 $\mathrm{nm}-10 \mathrm{~nm}$ layer of the material). The presence of $\mathrm{Ti}^{3+}$ was further investigated by low temperature electron paramagnetic resonance (EPR) (Figure 3.6). No EPR features appear for a g-value of $\sim 2.02$ corresponding to $\mathrm{O}_{2}{ }^{-}$produced from the reduction of adsorbed $\mathrm{O}_{2}$ (from air) by surface $\mathrm{Ti}^{3+}$ further confirming the absence of surface $\mathrm{Ti}^{3+} \cdot{ }^{22}$ Surface $\mathrm{Ti}^{3+}$ is unstable under illumination in air or in electrolyte as it is easily oxidized by air or dissolved oxygen in water. ${ }^{23}$ The strong EPR signal for a g-value of 1.992 for the $\mathrm{H}, \mathrm{N}-\mathrm{TiO}_{2}$ sample indicates the presence of $\mathrm{Ti}^{3+}$ in the bulk. We also observed a trace amount of $\mathrm{Ti}^{3+}$ in the bulk of the $\mathrm{N}^{3}-\mathrm{TiO}_{2}$ sample. The intensity of the feature at g-value of 1.981 for the $\mathrm{N}-\mathrm{TiO}_{2}$ sample is two orders of magnitude smaller than the feature at a $\mathrm{g}$ of 1.992 for the $\mathrm{H}, \mathrm{N}-\mathrm{TiO}_{2}$ sample. 


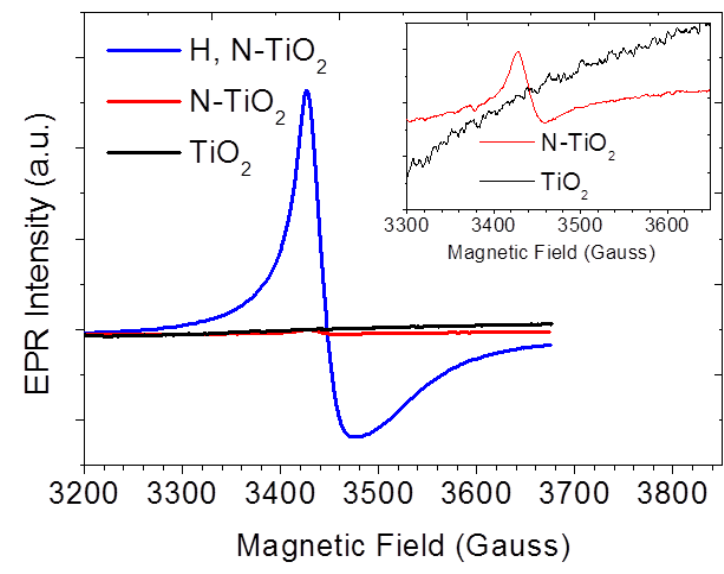

Figure 3.6. EPR spectra recorded at $86 \mathrm{~K}$ for $\mathrm{TiO}_{2}, \mathrm{~N}-\mathrm{TiO}_{2}$ and $\mathrm{H}, \mathrm{N}-\mathrm{TiO}_{2}$ samples. The inset shows magnified view for the EPR spectra of the $\mathrm{TiO}_{2}$ and $\mathrm{N}-\mathrm{TiO}_{2}$ samples.

Linear sweep voltammetry (scan rate of $5 \mathrm{mV} / \mathrm{s}$ ) results for the $\mathrm{H}, \mathrm{N}-\mathrm{TiO}_{2}$ nanowires are shown in Figure 3.7a. The onset potential for the $\mathrm{H}, \mathrm{N}-\mathrm{TiO}_{2}$ sample positively shifts to $0.6 \mathrm{~V}$ vs. reversible hydrogen electrode $\left(\mathrm{V}_{\mathrm{RHE}}\right)$ compared with $0.2 \mathrm{~V}_{\mathrm{RHE}}$ for the pristine $\mathrm{TiO}_{2}$ sample even though the photocurrent transient onset potentials for the two sample are almost the same, $\sim-0.15 \mathrm{~V}_{\mathrm{RHE}}$ (data not shown). The shift in the constant-illumination onset potential might be due to either a larger band banding requirement for separating electrons and holes because of the material's likely possession of poorer charge-transport properties than pure $\mathrm{TiO}_{2}$ or slower surface kinetics as a result of hydrogenation and nitridation co-treatment. ${ }^{10}$

The $\mathrm{H}, \mathrm{N}-\mathrm{TiO}_{2}$ sample shows remarkable visible light water oxidation performance. The visible light $(>420 \mathrm{~nm})$ current reaches $0.159 \mathrm{~mA} / \mathrm{cm}^{2}$ at $1.23 \mathrm{~V}$ vs. reversible hydrogen electrode $\left(\mathrm{V}_{\mathrm{RHE}}\right)$ and contributes $\sim 41 \%$ of the full AM $1.5 \mathrm{G}$ photocurrent. The chronoamperometry $(\mathrm{CAM})$ measurement at $1.23 \mathrm{~V}_{\mathrm{RHE}}$ (total time of $\sim 30$ minutes) in 
Figure $3.7 \mathrm{~b}$ indicates the material's high stability. After the test, we observed the formation of bubbles on the film, suggesting the oxygen production from water oxidation. We believe that the formation of oxygen bubbles decreases the electrode/electrolyte contact area, resulting in a slight decrease of $4.6 \%$ in the AM 1.5 G photocurrent after 15 minute

illumination.
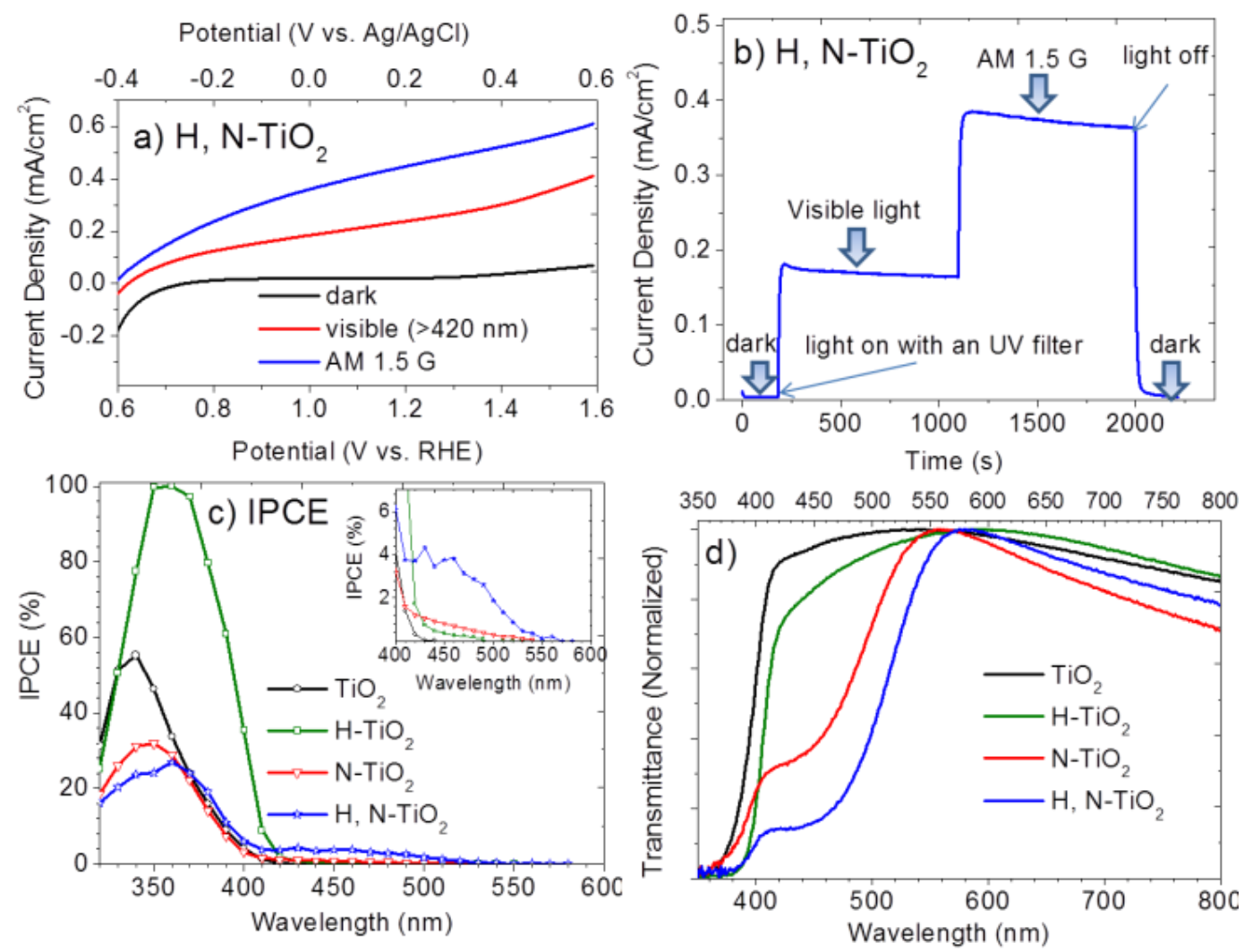

Figure 3.7. (a) and (b) Linear Sweep Voltametry $(5 \mathrm{mV} / \mathrm{s})$ and Chronoamperometry at $1.23 \mathrm{~V}_{\mathrm{RHE}}$ of the $\mathrm{H}, \mathrm{N}-\mathrm{TiO}_{2}$ sample, (c) IPCE spectra measured at 1.23 $\mathrm{V}_{\mathrm{RHE}}$, and (d) Normalized transmittance spectra. All PEC measurements were performed using a three-electrode electrochemical cell with a $\mathrm{Ag} / \mathrm{AgCl}$ reference electrode, a Pt wire counter electrode, and $1 \mathrm{M} \mathrm{KOH}$ electrolyte. A solar simulator (Oriel 96000) with an AM 1.5 G filter was used as the light source with light intensity of $100 \mathrm{~mW} / \mathrm{cm}^{2}$ measured by a thermopile detector (Newport, 818P-020-12). A UV filter that blocks all wavelengths $<$ $420 \mathrm{~nm}$ was used for visible light experiments. 


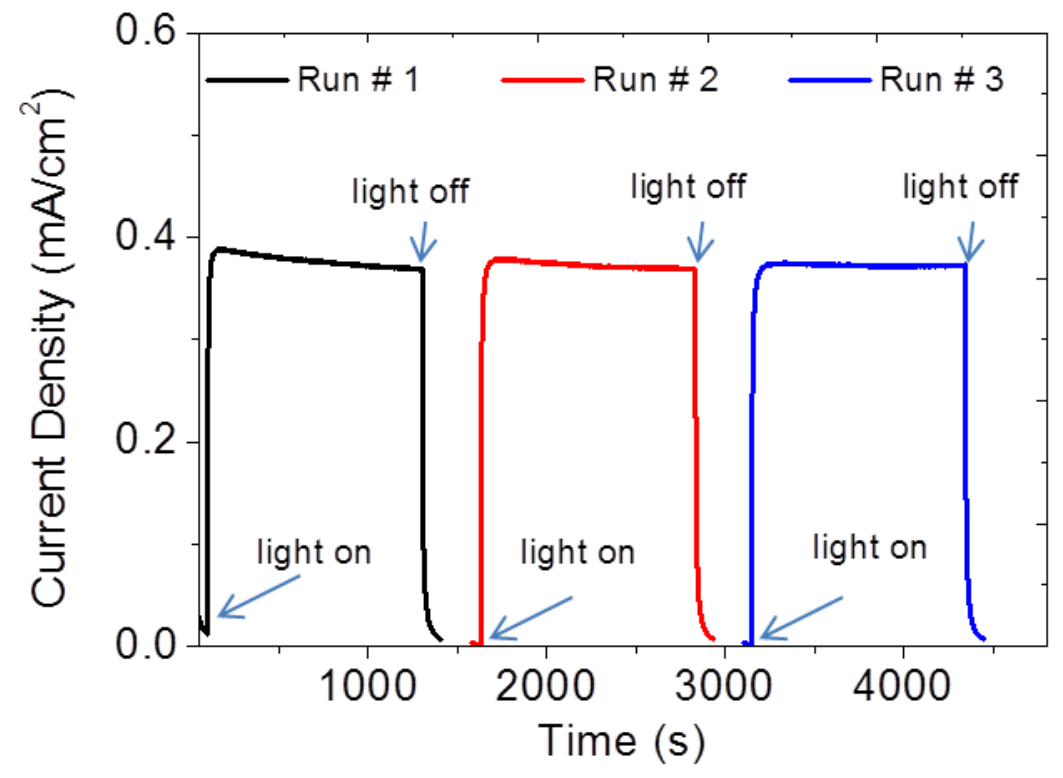

Figure 3.8. Chronoamperometry (CAM) measurement at $1.23 \mathrm{~V}_{\mathrm{RHE}}$ of the $\mathrm{H}, \mathrm{N}-\mathrm{TiO} 2$ sample. The measurement was performed using a three-electrode electrochemical cell with a $\mathrm{Ag} / \mathrm{AgCl}$ reference electrode, a Pt wire counter electrode, and $1 \mathrm{M} \mathrm{KOH}$ electrolyte. A solar simulator (Oriel 96000) coupling with an AM $1.5 \mathrm{G}$ filter was used as the light source with light intensity of $100 \mathrm{~mW} / \mathrm{cm} 2$ measured by a thermopile detector (Newport, 818P-020-12). The measurement was performed in 3 sequential runs: run $\# 1$, run $\# 2$, and run $\# 3$. After each run, we used a pipet to flush out bubbles forming on the $\mathrm{H}, \mathrm{N}-\mathrm{TiO}_{2}$ photoanode.

Figure 3.8 shows 3 runs of CAM measurement between which we used a pipet to flush out bubbles on the sample. The photocurrents were almost fully restored, thus supporting our hypothesis. In fact, after repeated testing for 5 months (the sample was stored in open air) the film still retains this performance.

Figures 3.7c and 3.7d show the incident photon-to-current efficiency (IPCE) spectra and the normalized UV-vis transmittance spectra (the raw data are included in Figure 
3.9). The absorption edge of the $\mathrm{H}, \mathrm{N}-\mathrm{TiO}_{2}$ sample shifts $\sim 20 \mathrm{~nm}$ to the longer wavelength region compared to the $\mathrm{N}$-doped $\mathrm{TiO}_{2} \mathrm{NW}$ sample. The decrease in the transmittance for all samples at larger wavelengths than $570 \mathrm{~nm}$ is due to the light absorption of FTO substrates in this region which is confirmed by the UV-vis transmittance of FTO in Figure 3.9.

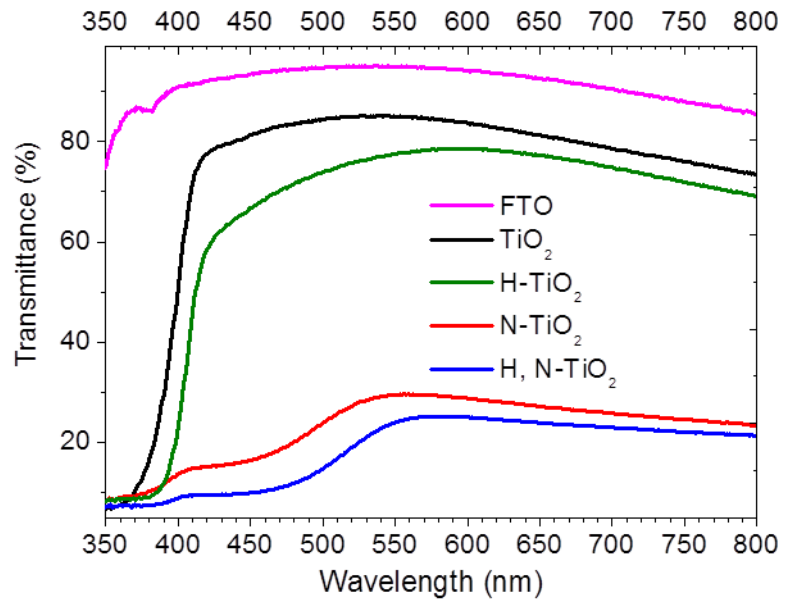

Figure 3.9. Raw data of the UV-vis transmittance spectra of $\mathrm{FTO}$ substrate, $\mathrm{TiO}_{2}, \mathrm{H}$ $\mathrm{TiO}_{2}, \mathrm{~N}-\mathrm{TiO}_{2}$, and $\mathrm{H}, \mathrm{N}-\mathrm{TiO}_{2}$ samples

The IPCE spectra fit well with the transmittance spectra, confirming that the active spectra of the $\mathrm{H}, \mathrm{N}-\mathrm{TiO}_{2}$ sample extends to $\sim 570 \mathrm{~nm}$. The photocurrent obtained by integrating the calculated IPCE multiplied by the AM 1.5 G solar energy flux ${ }^{24}$ over the range of $420 \mathrm{~nm}-570 \mathrm{~nm}$ is $0.159 \mathrm{~mA} / \mathrm{cm}^{2}$, contributing to $\sim 35 \%$ of the total integrated AM $1.5 \mathrm{G}$ photocurrent $\left(0.454 \mathrm{~mA} / \mathrm{cm}^{2}\right)$. The small discrepancy between the full AM 1.5 G photocurrent obtained by the CAM measurement $\left(0.388 \mathrm{~mA} / \mathrm{cm}^{2}\right)$ and the integration method $\left(0.454 \mathrm{~mA} / \mathrm{cm}^{2}\right)$ might be due to the difference between the simulated sunlight 
(Xenon lamp + AM 1.5 filter) and standard AM 1.5. The absence of a photo response in the IPCE of the untreated $\mathrm{TiO}_{2} \mathrm{NW}$ arrays indicates that the absorption tails from $420 \mathrm{~nm}$ - $500 \mathrm{~nm}$ in the transmittance spectra of the untreated $\mathrm{TiO}_{2}$ sample is due to light scattering from the nanostructures. The $\mathrm{H}-\mathrm{TiO}_{2}$ sample shows significant improvement in the PEC performance in the UV region due to the enhancement in the electron conductivity. ${ }^{11}$ Its IPCE spectrum, however, just shows a weak response from visible light (420 nm $-\sim 500 \mathrm{~nm}$ ), mainly due to the photoelectrochemically inactive transition from the valence band to hydrogenation-induced oxygen vacancy states. ${ }^{11}$

As mentioned in our previous study, incorporating $\mathrm{N}$ into the rutile $\mathrm{TiO}_{2} \mathrm{NW}$ arrays modifies the valence band structure, thus extending the working spectrum to $\sim 550 \mathrm{~nm}$. In the present study, we demonstrate that pre-hydrogenation significantly increases the bulk $\mathrm{Ti}^{3+}$ concentration and the interaction between $\mathrm{Ti}^{3+}$ and $\mathrm{N}$-doping increase the visible light absorption and shifts the absorption edge further to the longer wavelength region ( $570 \mathrm{~nm}$ ) compared to individual doping with $\mathrm{Ti}^{3+}$ or N. Employing EPR, Livraghi et al. detected paramagnetic bulk species of $\mathrm{N}\left(\mathrm{N}_{\mathrm{b}}{ }^{\circ}\right)$ at a g-value of 2.005, which formed localized states within the band gap of their $\mathrm{N}$-doped $\mathrm{TiO}_{2}{ }^{25}$ The authors proposed a reversible electron transfer between the $\mathrm{N}_{\mathrm{b}}{ }^{\cdot}$ and $\mathrm{Ti}^{3+}$ centers forming the diamagnectic bulk species of $\mathrm{N}\left(\mathrm{N}_{\mathrm{b}}{ }^{-}\right)$and $\mathrm{Ti}^{4+}$. A similar phenomenon is also observed by Napoli et al. when they exposed a pre-reduced $\mathrm{TiO}_{2}$ to a $\mathrm{N}$ plasma. ${ }^{26}$ The $\mathrm{N}$-induced states of $\mathrm{N}_{\mathrm{b}}{ }^{-}$ species are higher in energy than that of corresponding $\mathrm{N}_{\mathrm{b}}{ }^{\cdot}$ species due to greater Coulombic repulsion. Di Valentin et al. prepared $\mathrm{F}, \mathrm{N}$-codoped $\mathrm{TiO}_{2}$ samples and reported an increase in $\mathrm{Ti}^{3+}$ concentration with increasing $\mathrm{F}$ doping level. The authors 
also claimed that the formation of $\mathrm{N}_{\mathrm{b}}{ }^{-}$is more favorable with an increase in $\mathrm{Ti}^{3+}$ and that is the key for the improvement in the visible light photocatalytic activity. ${ }^{27}$ We did not detect any paramagnetic species other than $\mathrm{Ti}^{3+}$ in our $\mathrm{H}, \mathrm{N}-\mathrm{TiO}_{2}$ sample. We, however, can observe the interactions of $\mathrm{Ti}^{3+}$ and substitutional $\mathrm{N}$ in the $\mathrm{H}, \mathrm{N}-\mathrm{TiO}_{2}$ sample in the core N 1s XPS spectra (Figure 3.2a). The broadening and shift to the lower binding energy of the XPS N 1s feature compared with that of the $\mathrm{N}-\mathrm{TiO}_{2}$ sample indicates lower oxidation states of the substitutional $\mathrm{N}$ in the $\mathrm{H}, \mathrm{N}-\mathrm{TiO}_{2}$ sample which might be due to electron transfer from $\mathrm{Ti}^{3+}$. Due to the Columbic repulsion, the lower oxidation states of $\mathrm{N}$ in the $\mathrm{H}, \mathrm{N}-\mathrm{TiO}_{2}$ sample have higher energy than that of the $\mathrm{N}-\mathrm{TiO}_{2}$ sample, thus enabling excitation with photons of longer wavelengths. The proposed interaction between $\mathrm{Ti}^{3+}$ and $\mathrm{N}$ that modifies the electronic band structure of $\mathrm{TiO}_{2}$ is illustrated in Figure 3.10.

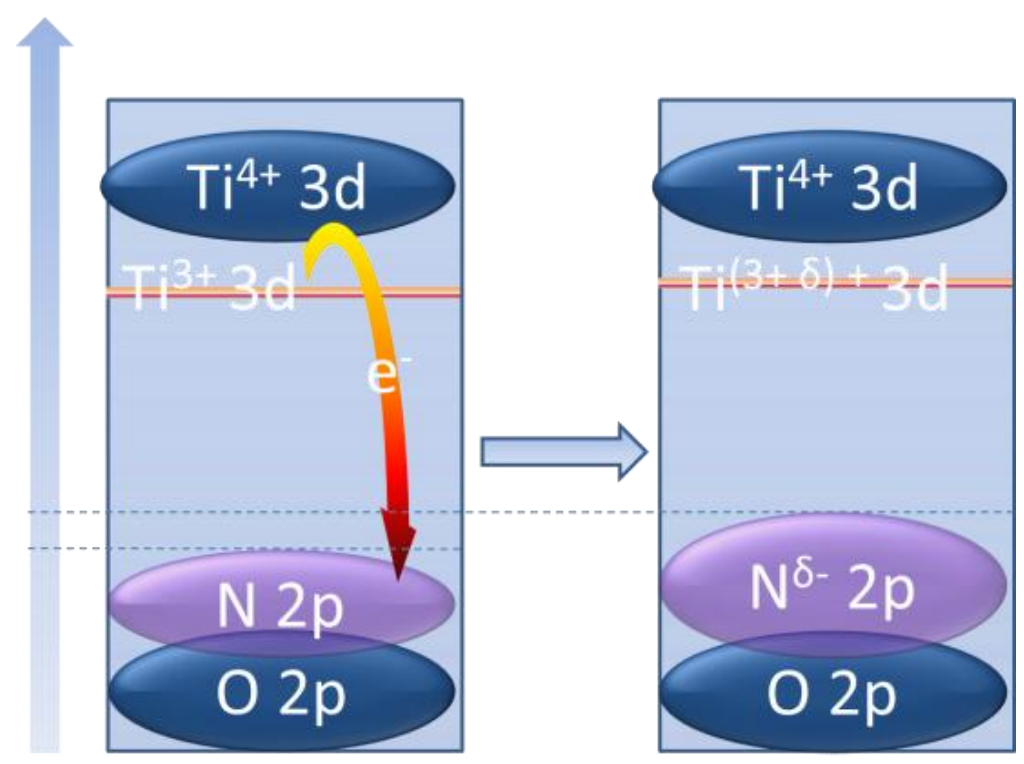

Figure 3.10. Proposed mechanism for the interaction between $\mathrm{Ti}^{3+}$ and substitutional $\mathrm{N}$. 


\section{Conclusions}

In summary, we report a synergistic effect between hydrogen and nitridation cotreatment that significantly enhances the water photo-oxidation of rutile $\mathrm{TiO}_{2} \mathrm{NW}$ arrays under visible light. The photocurrent of the $\mathrm{H}, \mathrm{N}-\mathrm{TiO}_{2}$ sample under visible light $(>420$ $\mathrm{nm})$ illumination contributes $\sim 41 \%$ of the simulated AM $1.5 \mathrm{G}$ photocurrent. The IPCE and UV-vis transmittance spectroscopy reveal that the working spectrum of the $\mathrm{H}, \mathrm{N}$ $\mathrm{TiO}_{2}$ sample extends to $\sim 570 \mathrm{~nm}$ compared with $\sim 550 \mathrm{~nm}$ for the $\mathrm{N}_{-1 i O}$ and $\sim 420 \mathrm{~nm}$ for pristine $\mathrm{TiO}_{2}$. The hydrogenation process increases the bulk $\mathrm{Ti}^{3+}$ concentration in $\mathrm{TiO}_{2}$. We speculate that the interactions between substitutional $\mathrm{N}$ and $\mathrm{Ti}^{3+}$ are responsible for the enhancement in the water oxidation performance under visible light illumination. 


\section{REFERENCES}

(1) Fujishima, A.; Honda, K. Nature 1972, 238, 37-38.

(2) Linsebigler, A. L.; Lu, G.; Yates, J. T. Chem. Rev. 1995, 95, 735-758.

(3) Chen, X.; Mao, S. S. Chem. Rev. 2007, 107, 2891-2959.

(4) Asahi, R.; Morikawa, T.; Ohwaki, T.; Aoki, K.; Taga, Y. Science 2001, 293, 269-271.

(5) Leary, R.; Westwood, A. Carbon 2011, 49, 741-772.

(6) Murphy, A. B.; Barnes, P. R. F.; Randeniya, L. K.; Plumb, I. C.; Grey, I. E.; Horne, M. D.; Glasscock, J. A. Int. J. Hydrogen Energy 2006, 31, 1999-2017.

(7) Bard, A. J.; Fox, M. A. Acc. Chem. Res. 1995, 28, 141-145.

(8) Park, J. H.; Kim, S.; Bard, A. J. Nano Lett. 2006, 6, 24-28.

(9) Umebayashi, T.; Yamaki, T.; Itoh, H.; Asai, K. Appl. Phys. Lett. 2002, 81, 454-456.

(10) Hoang, S.; Guo, S.; Hahn, N. T.; Bard, A. J.; Mullins, C. B. Nano Lett. 2012, 12, 2632.

(11) Wang, G.; Wang, H.; Ling, Y.; Tang, Y.; Yang, X.; Fitzmorris, R. C.; Wang, C.; Zhang, J. Z.; Li, Y. Nano Lett. 2011, 11, 3026-3033.

(12) Chen, X.; Liu, L.; Yu, P. Y.; Mao, S. S. Science 2011, 331, 746-750.

(13) Mi, L.; Zhang, Y.; Wang, P. N. Chem. Phys. Lett. 2008, 458, 341-345.

(14) Russo, S. P.; Grey, I. E.; Wilson, N. C. J. Phys. Chem. C 2008, 112, 7653-7664.

(15) Pan, H.; Zhang, Y.-W.; Shenoy, V. B.; Gao, H. J. Phys. Chem. C 2011, 115, 1222412231.

(16) Lan, M.; Peng, X.; Hong, S.; Pei-Nan, W.; Weidian, S. Applied Physics Letters 2007, 90, 171909 .

(17) Diwald, O.; Thompson, T. L.; Zubkov, T.; Walck, S. D.; Yates, J. T. J. Phys. Chem. $B$ 2004, 108, 6004-6008.

(18) Hahn, N. T.; Ye, H.; Flaherty, D. W.; Bard, A. J.; Mullins, C. B. ACS Nano 2010, 4, 1977-1986.

(19) van de Krol, R.; Liang, Y. Q.; Schoonman, J. J. Mat. Chem. 2008, 18, 2311-2320.

(20) Takahashi, I.; Payne, D. J.; Palgrave, R. G.; Egdell, R. G. Chem. Phys. Lett. 2008, 454, 314-317.

(21) Wang, J.; Tafen, D. N.; Lewis, J. P.; Hong, Z.; Manivannan, A.; Zhi, M.; Li, M.; Wu, N. J. Am. Chem. Soc. 2009, 131, 12290-12297.

(22) Anpo, M.; Che, M.; Fubini, B.; Garrone, E.; Giamello, E.; Paganini, M. Top. Catal. 1999, 8, 189-198. 
(23) Teleki, A.; Pratsinis, S. E. Phys. Chem. Chem. Phys. 2009, 11, 3742-3747.

(24) http://rredc.nrel.gov/solar/spectra/am1.5/

(25) Livraghi, S.; Paganini, M. C.; Giamello, E.; Selloni, A.; Di Valentin, C.; Pacchioni, G. J. Am. Chem. Soc. 2006, 128, 15666-15671.

(26) Napoli, F.; Chiesa, M.; Livraghi, S.; Giamello, E.; Agnoli, S.; Granozzi, G.; Pacchioni, G.; Di Valentin, C. Chem. Phys. Lett. 2009, 477, 135-138.

(27) Di Valentin, C.; Finazzi, E.; Pacchioni, G.; Selloni, A.; Livraghi, S.; Czoska, A. M.; Paganini, M. C.; Giamello, E. Chem. Mat. 2008, 20, 3706-3714. 


\section{Chapter 4: Co-incorporation of $\mathrm{N}$ and $\mathrm{Ta}$ into $\mathrm{TiO}_{2}$ Nanowires for Visible-light Driven Photoelectrochemical Water Oxidation}

\section{INTRODUCTION}

Titanium dioxide $\left(\mathrm{TiO}_{2}\right)$ is well known for PEC water splitting due to its abundance, photostability in aqueous solutions, and strong photocatalytic activity. ${ }^{1-6}$ However, due to its large band gap $(\sim 3.2 \mathrm{eV}), \mathrm{TiO}_{2}$ can only utilize ultraviolet (UV) photons that contribute $\sim 5 \%$ of the total energy of the solar spectrum. ${ }^{6-9}$ There have been numerous investigations regarding the band structure engineering and band gap narrowing of $\mathrm{TiO}_{2}$ in order to shift its absorption spectrum to visible light, which represents a greater portion of the energy in the solar spectrum. ${ }^{1,5,10-13}$ For spontaneous photoelectrochemical (PEC) splitting of water without an applied bias, the band edges of the semiconductors must straddle the thermodynamic water redox potentials. ${ }^{1,12}$ The band edge alignments of $\mathrm{TiO}_{2}$ satisfy this requirement in which the conduction band minimum $(\mathrm{CBM})$ is $\sim 0.3-0.4 \mathrm{eV}$ more negative than the hydrogen production potential, whereas the valence band maximum $(\mathrm{VBM})$ is far below $(\sim 1.6 \mathrm{eV}$ more positive) the oxygen production potential. ${ }^{1}$ Ideally, for efficient solar water splitting without bias, the CBM of $\mathrm{TiO}_{2}$ should remain as is or slightly shift closer to the vacuum level (more negative on the electrochemical scale) and the valence band maximum should also shift in the same direction so that the band gap reduces to $\sim 2 \mathrm{eV}$ accordingly. ${ }^{1,10,12}$

Monodoping $\mathrm{TiO}_{2}$ with $3 \mathrm{~d}$ transitional metals $\left(\mathrm{V}^{13,14}\right.$ and $\left.\mathrm{Cr}^{13}\right)$ has gained some success in extending the absorption spectrum to the visible region by introducing a donor level under the conduction band, ${ }^{14,15}$ however the decrease in carrier mobility due to the formation of strongly localized d states within the band gap and the existence of a carrier recombination center significantly reduce the photo-induced current. ${ }^{14-20}$ Monodoping with anions such as $\mathrm{N},{ }^{10,21} \mathrm{C},{ }^{22}$ and $\mathrm{S}^{23}$ has been of interest because the $\mathrm{p}$ states of 
incorporated anions ( $\mathrm{N}, \mathrm{C}$, or S) normally create an impurity band above the VBM or hybridization with $\mathrm{O} 2 \mathrm{p}$ states, thus narrowing the band gap and keeping the CBM the same. We have recently reported synthesis of $\mathrm{N}$-modified $\mathrm{TiO}_{2}$ rutile nanowire arrays with the water photo-oxidation spectrum extending to $\sim 520 \mathrm{~nm} .{ }^{21}$ We also demonstrated that thermal co-treatment of $\mathrm{H}_{2}$ and $\mathrm{NH}_{3}$ can further extending the working spectrum of the $\mathrm{TiO}_{2}$ nanowires to $570 \mathrm{~nm}$ due to the interaction of bulk $\mathrm{Ti}^{3+}$ and $\mathrm{N}$ dopants. ${ }^{24}$

Coincorporation of both metal cations and non-metal anions into $\mathrm{TiO}_{2}$ has been proposed as a new approach for engineering the band structure. ${ }^{1,12,25-28}$ The neutralization of positive and negative charges in the $\mathrm{TiO}_{2}$ lattice created by coincorporation reduces the charge recombination centers, thus enhancing the photocatalytic activity. Moreover, co-incorporation of metal ions and nonmetal ions can help overcome solubility limits, improve material quality, and enhance optical absorption. ${ }^{12}$ There are several theoretical studies demonstrating the enhancement in photocatalytic activity of a Ta and $\mathrm{N}$ coincorporation approach over monoincorporation of $\mathrm{Ta}$ or $\mathrm{N}$, however there is lack of support from experimental studies ${ }^{12,25,29-31}$ which is partly is due to the difficulty in preparing co-incorporated $\mathrm{TiO}_{2}$ materials. Obata et al. reported visible light active $\mathrm{Ta}, \mathrm{N}$ co-doped $\mathrm{TiO}_{2}$ thin films prepared via radio-frequency magnetron sputtering $\mathrm{Ti}$ and mixture of $\mathrm{TiO}_{2}$ and $\mathrm{Ta}_{2} \mathrm{O}_{5}$ target, however the quantum yields are quite low (smaller than $0.15 \%$ in the visible light spectrum $(420-500 \mathrm{~nm})$ ) and the enhancement in PEC performance due to codoping effects is not clear since PEC performance is compared between samples with different thicknesses (the Ta, $\mathrm{N}$ codoped samples are almost two times thicker than the undoped samples). ${ }^{30}$ Additionally, Wang et al. reported preparation of $\mathrm{N}, \mathrm{F}$, and $\mathrm{Ta}$ tri-doped $\mathrm{TiO}_{2}$ nanoparticle which are visible light active for photodegradation of Rhodamine B and phenol. ${ }^{32}$ 
Besides engineering the band structure, it is also very important to enhance the charge transport characteristics of materials. Vertically oriented one dimensional (1D) nanostructures such as nanowires, nanorods, nanotubes etc., have been demonstrated to be advantageous over planar geometries because these 1D structures provide comparable penetration depth while still decreasing the diffusion distance of the minority charge carrier (holes for n-type and electrons for p-type semiconductors) to the electrolyte. ${ }^{33-37}$

In the present study, we report the synthesis of Ta-incorporated and $\mathrm{N}$, Tacoincorporated rutile $\mathrm{TiO}_{2}$ nanowire arrays and their application for water photooxidation. Ta-incorporated $\mathrm{TiO}_{2}$ nanowire arrays with controllable $\mathrm{Ta}$ incorporation levels (from 0.11 to 3.5 atomic \%) were prepared via a facile solvothermal synthesis. The N, Ta-coincorporated $\mathrm{TiO}_{2} \mathrm{NWs}$ were prepared via nitridation of the $\mathrm{Ta}: \mathrm{TiO}_{2} \mathrm{NWs}$ under $\mathrm{NH}_{3}$ flow at a relatively low temperature $\left(500{ }^{\circ} \mathrm{C}\right) . \mathrm{N}, \mathrm{Ta}_{\mathrm{TiO}} \mathrm{TW}_{2} \mathrm{NWmples}$ with the optimum Ta concentration of 0.29 at. \% demonstrate significant enhancement in PEC performance with the photocurrent reaching $0.52 \mathrm{~mA} / \mathrm{cm}^{2}$ and $0.18 \mathrm{~mA} / \mathrm{cm}^{2}$ under $\mathrm{AM}$ $1.5 \mathrm{G}$ and visible light $(>420 \mathrm{~nm}$ ) illumination, respectively. This compares with 0.26 $\mathrm{mA} / \mathrm{cm}^{2}$ and $0.13 \mathrm{~mA} / \mathrm{cm}^{2}$ for that of $\mathrm{N}: \mathrm{TiO}_{2}$ nanowires, although the active spectrum of the N, $\mathrm{Ta}^{\mathrm{TiO}}{ }_{2} \mathrm{NW}$ sample only extends to $\sim 520 \mathrm{~nm}(2.38 \mathrm{eV})$, compared to $\sim 540 \mathrm{~nm}$ $(2.30 \mathrm{eV})$ for that of the $\mathrm{N}: \mathrm{TiO}_{2} \mathrm{NW}$ sample. We believe that the enhancement of the $\mathrm{N}$, Ta-coincorporated sample is likely because of fewer recombination centers due to charge compensation effects and suppression of the formation of an amorphous layer on the nanowires during the nitridation process. 


\section{EXPERIMENTAL METHODS}

Materials. All chemicals were purchased and used without further purification including titanium (IV) isopropoxide (TTIP) (98+ \%, Acros Organics), $\mathrm{HCl}$ (ACS Reagent Grade 36.5-38\%, MP), n-hexane (Extra dry, 96+\%, Acros Organics), titanium (IV) chloride, (99.0+ \%, Alfa Aesar), Ta precursor solution-Ta (V) isopropoxide (99.9\%, $10 \% \mathrm{w} / \mathrm{v}$ in isopropanol/n-hexane, Alfa Aesar), and ammonia (99.99\%, Matheson Trigas).

Solvothermal Synthesis. Fluorine-doped Tin Oxide (FTO) coated glass substrates were first cleaned by sonication in a mixture of ethanol and water for 30 minutes, subsequently rinsed by deionized (DI) water, and finally dried in an air stream. The FTO substrates were then seeded with a thin layer of $\mathrm{TiO}_{2}$ before growing the nanowire arrays by soaking in $0.025 \mathrm{M} \mathrm{TiCl}_{4}$ in $\mathrm{n}$-hexane for 30 minutes. They were then taken out, rinsed by ethanol, and finally annealed in air at $500{ }^{\circ} \mathrm{C}$ for 30 minutes. The seeded FTO substrates were then placed on the bottom of a Teflon lined autoclave (125 $\mathrm{mL}$, Parr Instrument), containing $50 \mathrm{~mL}$-hexane, $5 \mathrm{~mL} \mathrm{HCl}, 0.5 \mathrm{~mL}$ of $0.1 \mathrm{M} \mathrm{TiCl}_{4}$ in $\mathrm{n}$-hexane, $5 \mathrm{~mL}$ of titanium (IV) isopropoxide, and various amounts of Ta precursor solution (from $0.25-2.5 \mathrm{~mL}$ ). The solvothermal synthesis was conducted at $150{ }^{\circ} \mathrm{C}$ for 10 hours. After the reaction was completed and the autoclave naturally cooled down to room temperature, the $\mathrm{TiO}_{2}$ and $\mathrm{Ta}: \mathrm{TiO}_{2}$ nanowire films were taken out and cleaned by rinsing with copious amounts of ethanol and water.

Thermal treatments. To remove the contaminants and increase the crystallinity, the pristine $\mathrm{TiO}_{2}$ and $\mathrm{Ta}: \mathrm{TiO}_{2}$ nanowire samples were prepared by annealing the assolvothermally synthesized sample in air at $500{ }^{\circ} \mathrm{C}$ for 2 hours in a box oven. The nitridation process was performed using a tube furnace (MTI, OTF-1200x-80). The tube was first evacuated until the pressure inside the tube was below 1 Torr, and then filled 
with $\mathrm{NH}_{3}$ to atmospheric pressure. The flow of $\mathrm{NH}_{3}(30 \mathrm{~mL} /$ minute $)$ was controlled by a gas flow controller during the annealing period. The exhaust line was bubbled through a cup of water (the exhaust line exit was kept $\sim 5 \mathrm{~cm}$ below the water surface).

Material Characterizations. SEM was performed on a Zeiss field-emission SEM using a $10 \mathrm{kV}$ focus voltage. TEM and HRTEM were performed on a JEOL 2010F fieldemission TEM using a $200 \mathrm{kV}$ focus voltage. STEM, EDX line scan profile, and elemental mapping were performed on a Hitachi S-5500 equipped with STEM using 30 $\mathrm{kV}$ focus voltage. Grazing incidence X-ray diffraction (GIXRD) patterns were collected with a Bruker D8 diffractometer. The transmittance spectra were collected using a Cary 500 UV-vis-NIR spectrophotometer attached to a Labsphere DRA-CA-5500 integrating sphere. X-ray photoelectron spectroscopy (XPS) was performed on a Kratos Axis X-ray photoelectron spectrometer with scanning step of $0.1 \mathrm{eV}$ and dwell time of 2 seconds/step. The binding energy was calibrated using the $\mathrm{C} 1 \mathrm{~s}$ photoelectron peak at $284.5 \mathrm{eV}$ as a reference. The elemental percentages were calculated from XPS spectra using the CasaXPS computer program with specific relative sensitivity factors for the Kratos Axis XPS (Ti 2p: 2.001, O 1s: 0.78, and Ta 4f: 8.62).

Electrochemical and Photoelectrochemical (PEC) Characterizations. The PEC measurements were performed using a three-electrode electrochemical cell with the FTO supported nanowire arrays as the working electrode, a $\mathrm{Ag} / \mathrm{AgCl}$ (saturated $\mathrm{KCl}$ ) reference electrode, a platinum wire counter electrode, and $1 \mathrm{M} \mathrm{KOH}$ electrolyte $(\mathrm{pH}=$ 13.5). The working electrode with exposed area of $0.205 \mathrm{~cm}^{2}$ was illuminated from the back side (through the FTO substrate $-\mathrm{TiO}_{2}, \mathrm{Ta}^{\mathrm{TiO}}{ }_{2}$, and $\mathrm{N}, \mathrm{Ta}^{\mathrm{TiO}} \mathrm{Ti}_{2}$ nanowires interface) by a solar simulator (Newport, Model 9600, $150 \mathrm{~W}$ xenon lamp) equipped with an AM 1.5 G filter (Newport, Model 81094). The light intensity was measured as 100 $\mathrm{mW} / \mathrm{cm}^{2}$ using a thermopile detector with the spectrum response from 0.19 to $10.6 \mu \mathrm{m}$ 
(Newport, 818P-020-12). A CHI 660D electrochemical station was used for linear sweep voltammetry (I-V) and chronoamperometry (I-t) measurements.

Incident photon to current conversion efficiencies (IPCEs) were calculated from chronoamperometry measurements using a motorized monochrometer (Oriel Cornerstone $1301 / 8 \mathrm{~m})$. The monochrometer slit size was adjusted to $0.75 \mathrm{~mm} \times 2 \mathrm{~mm}$ providing monochromatic wavelengths with a bandwidth of $\sim 8 \mathrm{~nm}$ and a power density which could be adjusted from 197 to $705 \mu \mathrm{W} / \mathrm{cm}^{2}$ for wavelengths from 320 to $600 \mathrm{~nm}$. A typical light power density spectrum used for IPCE can be found in Figure 4.1. Light power was measured using a handheld optical power meter with a UV enhanced silicon photo-detector (Newport). IPCE values were calculated using the following equation: $\operatorname{IPCE}(\lambda)=\frac{1240 j_{p}(\lambda)}{\lambda E_{\lambda}(\lambda)}$

where $j_{p}(\lambda)$ is the measured photocurrent density $\left(\mathrm{mA} / \mathrm{cm}^{2}\right)$ and $E_{\lambda}(\lambda)$ is the incident light power density $\left(\mathrm{mW} / \mathrm{cm}^{2}\right)$ for each wavelength, $\lambda(\mathrm{nm})$.

The measured potentials vs. the $\mathrm{Ag} / \mathrm{AgCl}$ were converted to the reversible hydrogen electrode (RHE) scale via the Nernst equation:

$\mathrm{E}_{\mathrm{RHE}}=\mathrm{E}_{\mathrm{Ag} / \mathrm{AgCl}}+0.059 \mathrm{pH}+\mathrm{E}_{\mathrm{Ag} / \mathrm{AgCl}}^{\mathrm{o}}$

where $\mathrm{E}_{\mathrm{RHE}}$ is the converted potential vs. $\mathrm{RHE}, \mathrm{E}_{\mathrm{Ag} / \mathrm{AgCl}}$ is the experimental potential measured against the $\mathrm{Ag} / \mathrm{AgCl}$ reference electrode, and $\mathrm{E}_{\mathrm{Ag} / \mathrm{AgCl}}^{\mathrm{a}}=0.1976 \mathrm{~V}$ at $25^{\circ} \mathrm{C}$. 


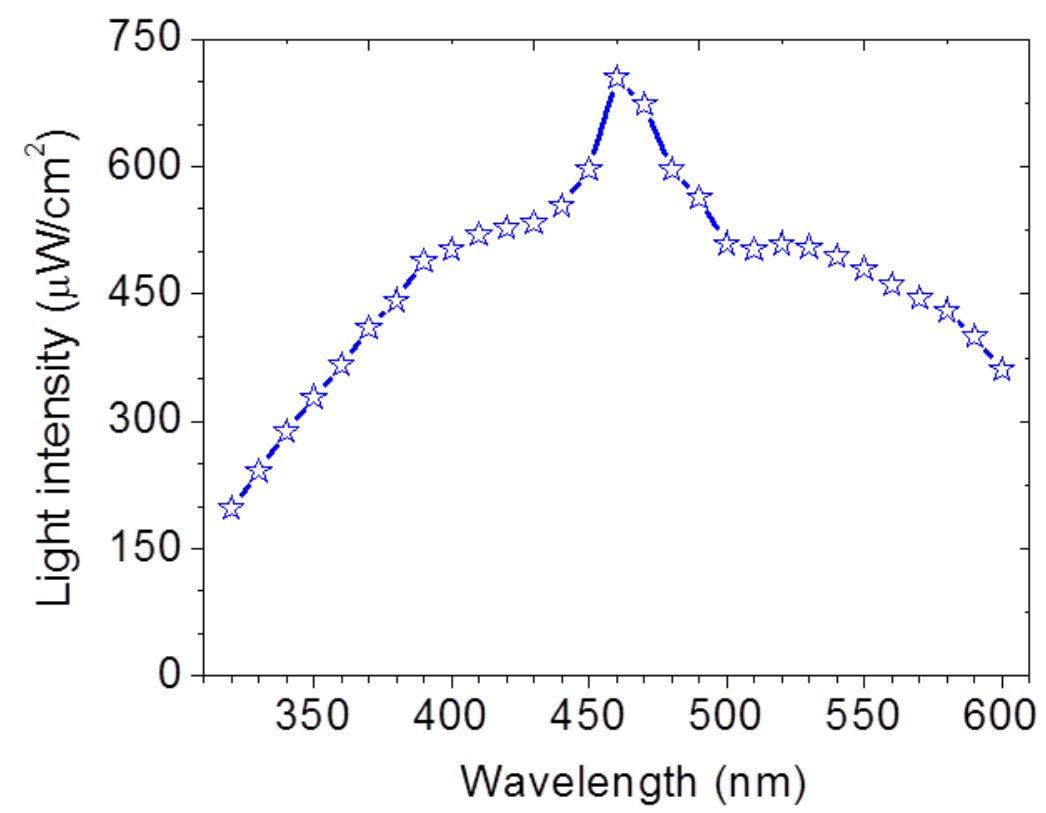

Figure 4.1. A typical incident light power density spectrum (from $320 \mathrm{~nm}-600 \mathrm{~nm}$ ) used for the IPCE measurements.

\section{RESULTS AND DISCUSIONS}

\section{Synthesis and Characterization of Ta-incorporated $\mathrm{TiO}_{2}\left(\mathrm{Ta}^{\mathrm{TiO}} \mathrm{T}_{2}\right)$ Nanowire arrays.}

The pristine $\mathrm{TiO}_{2}$ NWs were grown on fluorine-doped tin oxide (FTO) glass substrate using a method reported elsewhere ${ }^{21}$ with a slight change in the recipe; $\mathrm{TiCl}_{4}$ was added to the reaction solution to enhance the NW arrays' adherence to the FTO substrate. The feature sizes of $\mathrm{TiO}_{2} \mathrm{NW}$ arrays obtained with the addition of $\mathrm{TiCl}_{4}$ are almost the same , $\sim 5 \mathrm{~nm} .{ }^{21}$ However, the new recipe results in much shorter $\mathrm{TiO}_{2} \mathrm{NWs}$, $\sim 1.4 \mu \mathrm{m}$ compared to $4.4 \mu \mathrm{m}$ obtained without $\mathrm{TiCl}_{4}$. The $\mathrm{Ta}^{\mathrm{TiO}}{ }_{2} \mathrm{NW}$ arrays with various Ta incorporation levels are designated as $\mathrm{Ta}^{\mathrm{TiO}} \mathrm{TiO}_{2}-\mathrm{xxx}$ where $\mathrm{xxx}(\mathrm{xxx}=010-250)$ is the number of $10 \mu \mathrm{L}$ volumes of $10 \% \mathrm{w} / \mathrm{v}$ Ta $(\mathrm{V})$ isopropoxide in isopropanol $/ \mathrm{n}$ hexane solution added to the solvothermal reaction solution. Figure 4.2 shows the topview Scanning Electron Microscopy (SEM) images of as-synthesized $\mathrm{Ta}^{\mathrm{TiO}} \mathrm{Ti}_{2}$ nanowire 
arrays synthesized with various volumes of Ta precursor. The nanowire arrays consist of vertically aligned and densely packed nanowires with the feature sizes ranging from 5-20 nm. As mentioned above, the pristine $\mathrm{TiO}_{2}$ nanowires have similar tetragonal shapes and sizes as reported previously (synthesized using the slightly different recipe) (Figure 4.2a). ${ }^{21}$ Adding the Ta precursor solution significantly changes the morphology; the nanowires become bigger when we increase the amount of Ta precursor from 0.1 to 0.75 $\mathrm{mL}$. However adding even more Ta precursor $(1 \mathrm{~mL}-2.5 \mathrm{~mL})$ decreases the nanowire sizes and causes a change in the tetragonal cross-sectional shape. The length of the NWs (film thicknesses) are however unaffected with the addition of the Ta precursor. All of the samples have a thickness of $\sim 1.4 \mu \mathrm{m}$.

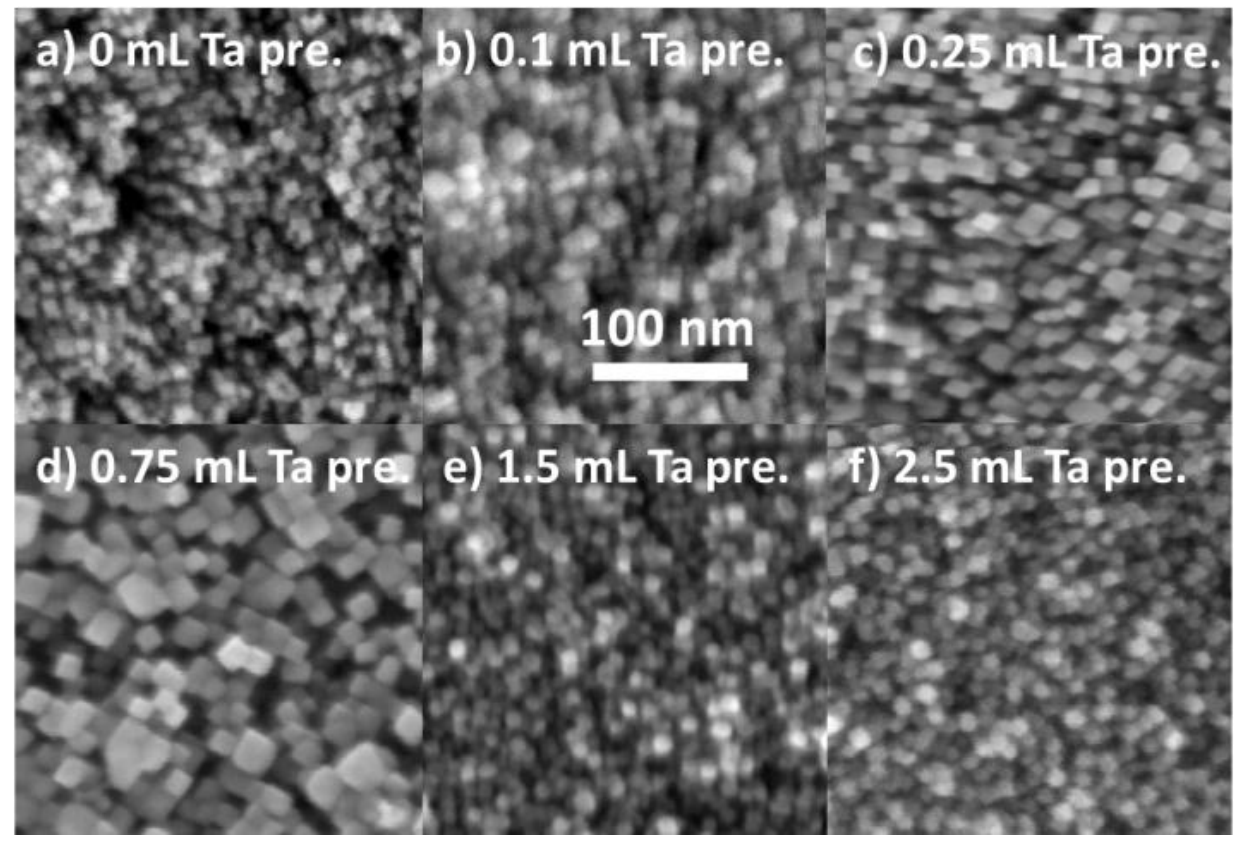

Figure 4.2. Top-view Scanning Electron Microscopy (SEM) images of $\mathrm{Ta}^{\mathrm{TiO}} \mathrm{Ti}_{2}$ nanowires synthesized with various amount of Ta precursor: (a) $0 \mathrm{~mL}$ (pristine $\mathrm{TiO}_{2}$ ), (b) $0.1 \mathrm{~mL}$, (c) $0.25 \mathrm{~mL}$, (d) $0.75 \mathrm{~mL}$, (e) $1.5 \mathrm{~mL}$, and (f) 2.5 $\mathrm{mL}$. The scale bar is applied for all the micrographs. 
In order to investigate the effects of Ta (V) isopropoxide and isopropanol on the morphology of the nanowires, we performed control experiments via the addition of $0.125 \mathrm{~mL}, 0.375 \mathrm{~mL}$, and $1.25 \mathrm{~mL}$ of pure isopropanol (equivalent to the amount of isopropanol in $0.25 \mathrm{~mL}, 0.75 \mathrm{~mL}$, and $2.5 \mathrm{~mL}$ of the Ta precursor) to the solvothermal reaction solution to grow pristine $\mathrm{TiO}_{2}$ nanowires. Interestingly, addition of isopropanol leads to the same vertically aligned nanowire morphology but with a bigger crosssectional dimension $\sim 10-15 \mathrm{~nm}$ (Figure 4.3). However, the feature size of the nanowires does not change with increasing amounts of isopropanol above $0.125 \mathrm{~mL}$. Therefore, we believe that the interaction of $\mathrm{Ta}(\mathrm{V})$ isopropoxide and isopropanol contribute to the morphology changes as observed in Figure 4.2.

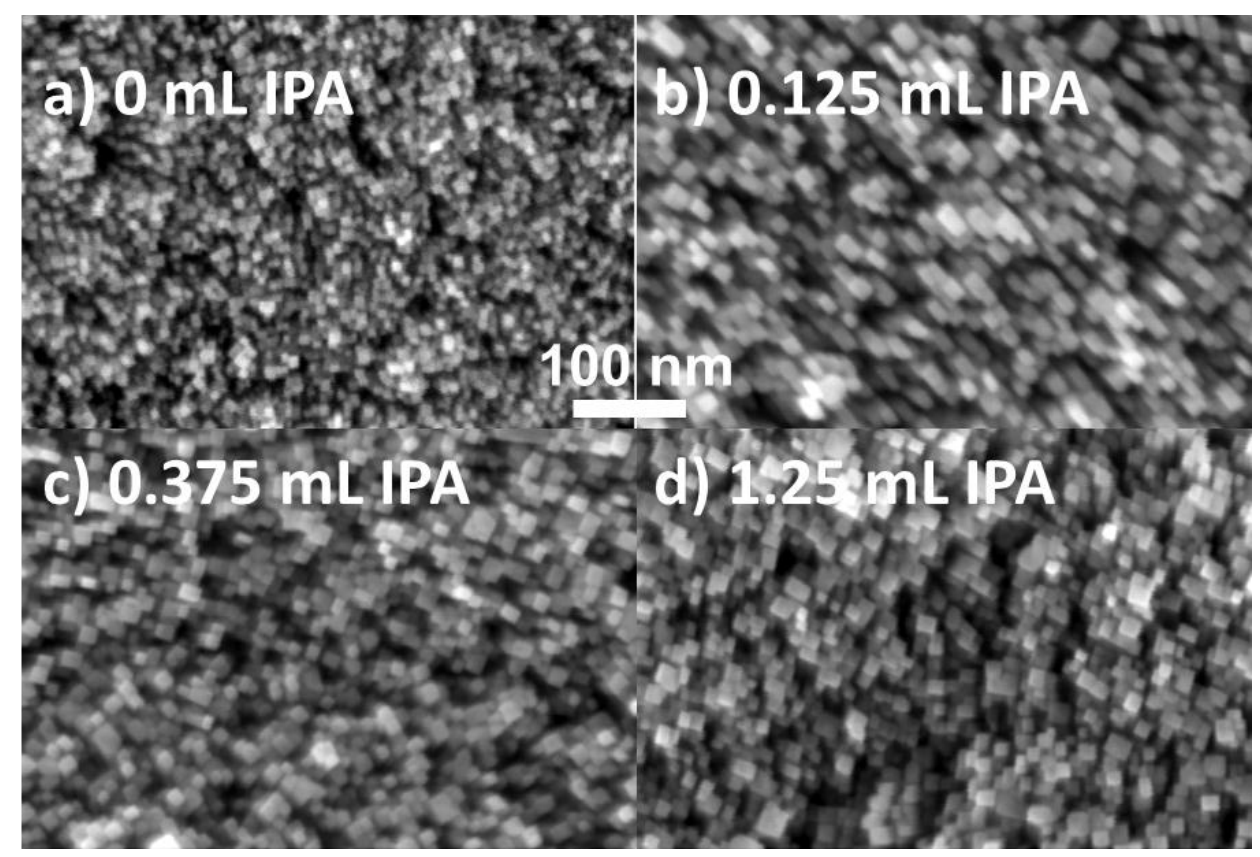

Figure 4.3. SEM images of $\mathrm{TiO}_{2}$ nanowire arrays synthesized with addition of isopropanol (IPA): (a) $0 \mathrm{~mL}$, (b) $0.125 \mathrm{~mL}$, (c) $0.375 \mathrm{~mL}$, and (d) $1.25 \mathrm{~mL}$. The scale bar is applicable for all micrographs. 
We employed X-ray Photoemission Spectroscopy (XPS) to investigate the chemical composition of the $\mathrm{Ta}: \mathrm{TiO}_{2}$ nanowires (Figure 4.4). As previously reported, $\mathrm{TiO}_{2}$ NW arrays were solvothermally grown via nonpolar solvent/hydrophilic solid substrate interfacial reaction mechanism in which Ti (IV) isopropoxide was hydrolyzed forming $\mathrm{TiO}_{2}{ }^{21,37}$ Hydrolyzation of $\mathrm{Ta}(\mathrm{V})$ isopropoxide forms $\mathrm{Ta}_{2} \mathrm{O}_{5}$, therefore we expect that $\mathrm{Ta}$ is incorporated into the $\mathrm{TiO}_{2}$ lattice as $\mathrm{Ta}^{5+}$. Indeed, the $\mathrm{Ta} 4 \mathrm{f}$ features at $26.2 \mathrm{eV}$ and $28.3 \mathrm{eV}$ (Figure 4.4a) of the Ta-modified $\mathrm{TiO}_{2}$ samples have been assigned to $\mathrm{Ta}^{5+}$, thus confirming our hypothesis. ${ }^{30}$ Figure $4.4 \mathrm{~b}$ shows the Ta atomic percentage determined by XPS in the $\mathrm{Ta}: \mathrm{TiO}_{2}$ nanowires synthesized with various amounts of $\mathrm{Ta}$ precursor. The Ta concentration increases with increasing Ta precursor as expected. The Ta concentration in the nanowires increases almost linearly from $0.11-0.29$ atomic \% with increasing Ta precursor from $0.25 \mathrm{~mL}$ to $0.75 \mathrm{~mL}$, but increases much faster from 0.61-3.48 atomic \% when increasing the Ta precursor amount from $1 \mathrm{~mL}$ to $2.5 \mathrm{~mL}$. In order to investigate the variation of Ta content in the nanowires synthesized with the same recipe, the Ta content was measured for different samples synthesized under the same conditions. The Ta content measured for 5 samples synthesized with addition of $0.75 \mathrm{~mL}$ of Ta precursors (samples $\mathrm{Ta}: \mathrm{TiO}_{2}-075$ ) is $0.26 \pm 0.048$ at.\%. 

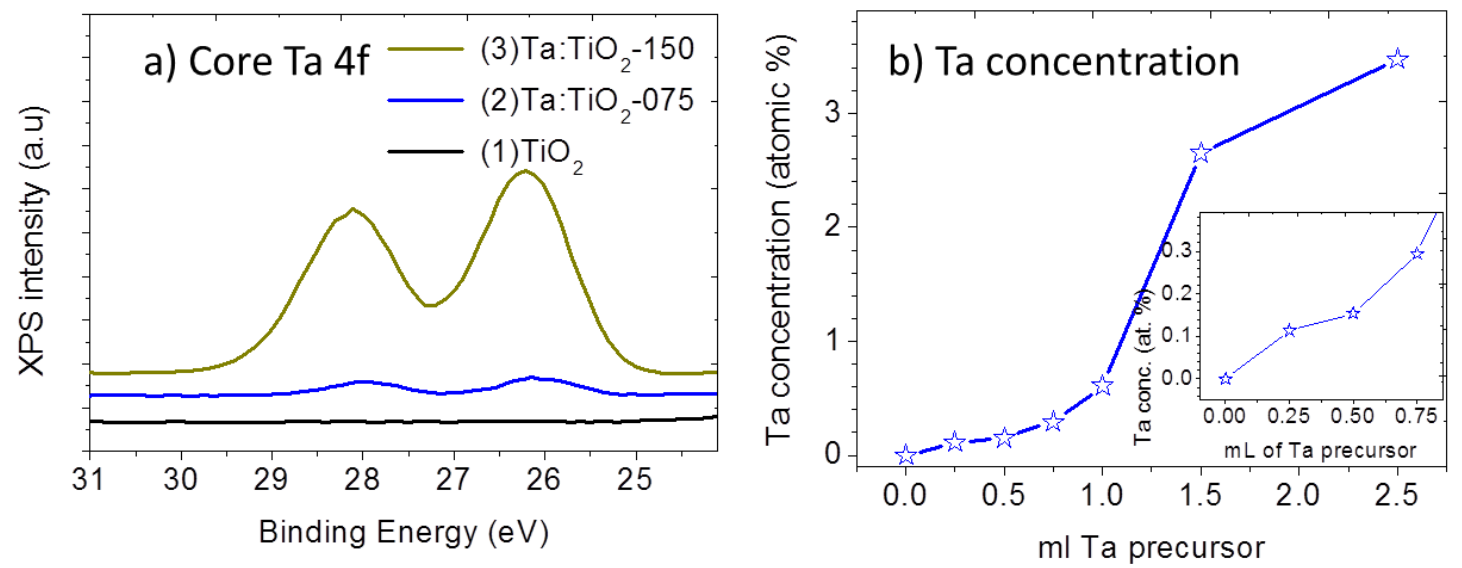

Figure 4.4. a) Core Ta $4 \mathrm{f} X P S$ spectra of $\mathrm{Ta}: \mathrm{TiO}_{2}$ nanowires synthesized with various amount of Ta precursor (1) $\mathrm{TiO}_{2}$, (2) $\mathrm{Ta}: \mathrm{TiO}_{2}-075$ (0.75 $\mathrm{mL}$ Ta precursor), and (3) $\mathrm{Ta}_{\mathrm{TiO}}-150$ (1.50 mL Ta precursor) and (b) atomic percentage of Ta in the Ta: $\mathrm{TiO}_{2}$ nanowires determined by XPS, the inset magnified the low Ta concentration region.

Figure 4.5a shows the grazing incidence angle X-ray diffraction (GIXRD) pattern of $\mathrm{Ta}: \mathrm{TiO}_{2}$ nanowires with various levels of Ta incorporation. Since the $\mathrm{Ta}: \mathrm{TiO}_{2} \mathrm{NWs}$ were grown on an FTO substrate, we performed GIXRD measurements to avoid interference from the $\mathrm{SnO}_{2}$ layer on the substrate. We did not observe any phase other than rutile (PDF\#97-003-1323) in all samples, even in the sample with high $\mathrm{Ta}$ concentration (sample Ta: $\mathrm{TiO}_{2}-150-2.65$ at. $\%$ of Ta). The XRD features of $\mathrm{Ta}: \mathrm{TiO}_{2}$ NWs are slightly narrower than that of pristine $\mathrm{TiO}_{2} \mathrm{NWs}$, indicating that grain sizes of Ta: $\mathrm{TiO}_{2} \mathrm{NWs}$ are bigger than that of pristine $\mathrm{TiO}_{2} \mathrm{NWs}$, which is in agreement with SEM measurements (Figure 4.1). 

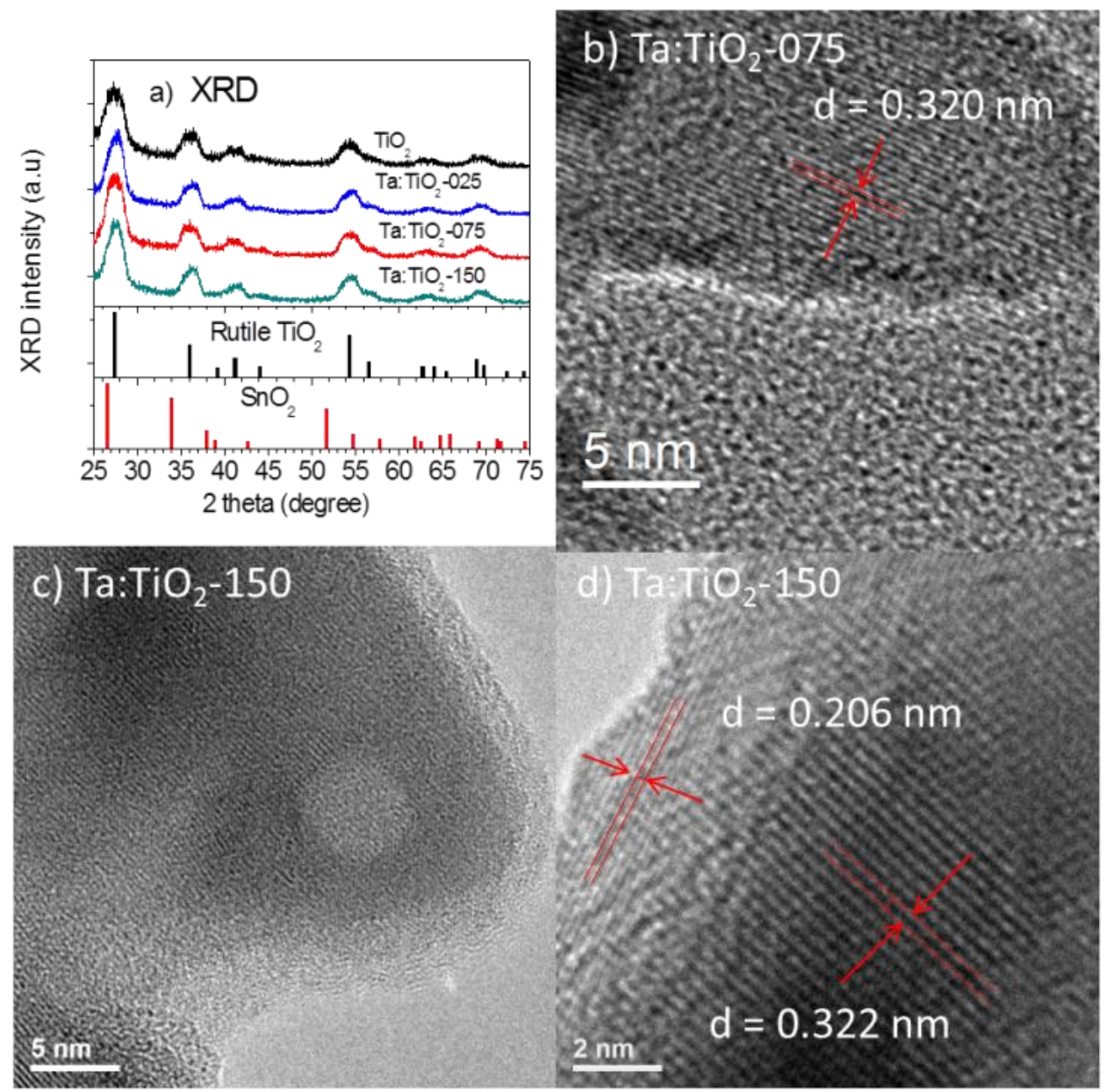

Figure 4.5. (a) Grazing incidence angle X-ray diffraction pattern of $\mathrm{Ta}^{\mathrm{T}} \mathrm{TiO}_{2}$ nanowires on $\mathrm{F}: \mathrm{SnO}_{2}$ coated substrates: $\mathrm{TiO}_{2}$ (black), Ta: $\mathrm{TiO}_{2}-025$ (blue), $\mathrm{Ta}_{\mathrm{TiO}}-075$ (red), and Ta:TiO $2-150$ (cyan) and HRTEM images of (b) $\mathrm{Ta}_{2} \mathrm{TiO}_{2}-075$, (c) and (d) $\mathrm{Ta}_{\mathrm{TiO}}-150$

High resolution transmission electron microscopy (HRTEM) was employed for further investigation of the structure of the Ta: $\mathrm{TiO}_{2}$ nanowires. HRTEM of $\mathrm{Ta}^{\mathrm{T}} \mathrm{TiO}_{2}-075$ nanowires (figure 4.5b) did not show a core/shell structure, indicating homogeneous incorporation of $\mathrm{Ta}$ at this low doping level. No significant change in the lattice was found after Ta incorporation as expected due to the comparable ionic radii (with VI coordination) of $\mathrm{Ti}^{4+}(0.061 \mathrm{~nm})$ and $\mathrm{Ta}^{5+}(0.064 \mathrm{~nm})$ ions. ${ }^{38}$ The interplanar d-spacing of 
(110) planes for the $\mathrm{Ta}: \mathrm{TiO}_{2}-075$ determined from HRTEM is $0.320 \mathrm{~nm}$, compared to $0.324 \mathrm{~nm}$ for that of the pristine $\mathrm{TiO}_{2} \mathrm{NW}$. The Ta: $\mathrm{TiO}_{2}-150 \mathrm{NWs}$, however, displayed a core/shell structure as shown in figure $4.5 \mathrm{c}$ and $4.5 \mathrm{~d}$. The $\mathrm{d}$-spacing for the outer shell is $0.206 \mathrm{~nm}$, thus indexing for the (210) plane. The d-spacing for the core is $0.322 \mathrm{~nm}$, indexing for the (110) plane. Arab et al. reported a solvothermal synthesis of branched Ta-incorporated $\mathrm{TiO}_{2}$ using titanium butoxide as $\mathrm{Ti}$ precursor and tantalum butoxide as Ta precursor. ${ }^{39}$ The authors reported changes in the surface roughness of the branches and believed that the differences in the rates of hydrolysis and condensation between $\mathrm{Ti}$ and $\mathrm{Ta}$ alkoxides would change the rate of nucleation of metal oxides, thus affecting the crystallinity and mechanism of growth of the nanowires. Feng et al. reported a solvothermal synthesis of homogenous Ta-doped $\mathrm{TiO}_{2}$ nanowires using $\mathrm{TaCl}_{5}$ as $\mathrm{Ta}$ precursor but did not report the Ta concentration. ${ }^{40}$
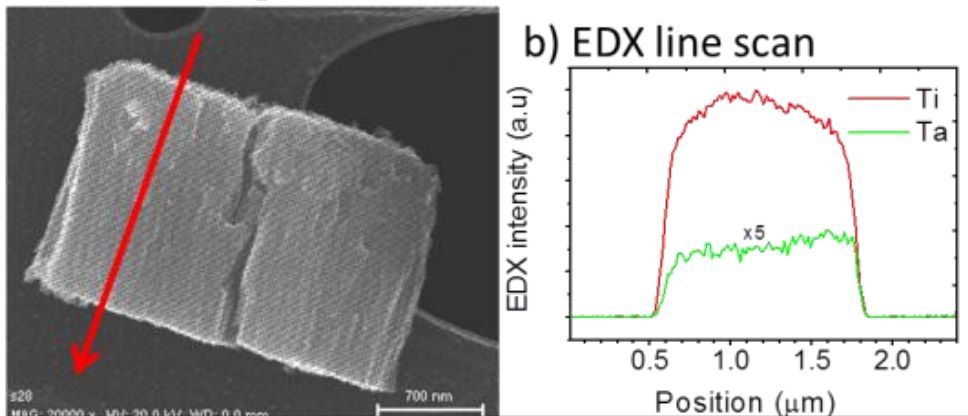

\section{c) $\mathrm{Ti}$}

d) $\mathrm{Ta}$

Figure 4.6. (a) SEM image of a chunk of $\mathrm{Ta}: \mathrm{TiO}_{2}-150$ nanowire arrays, (b) EDX line scan profile acquired along the NW arrays shown in Figure 4.4a, (c) and (d) Ti and Ta elemental mapping of the Ta: $\mathrm{TiO}_{2}-150 \mathrm{NW}$ chunks shown in Figure 4.4a. 
Figure 4.6b shows the energy-dispersive X-ray spectroscopy (EDX) line scan profile acquired along the length of a nanowire array as shown in Figure 4.6a, demonstrating that Ta is incorporated homogenously along the nanowire. Figure 4.6c and 4.6d show Ti and Ta elemental mapping of the nanowire array shown in Figure 4.6a, further confirming homogenous incorporation of Ta into the $\mathrm{TiO}_{2} \mathrm{NW}$ lattice.

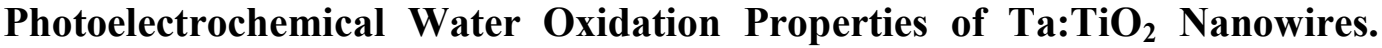
The photoelectrochemical characterization of $\mathrm{TiO}_{2}$ and $\mathrm{Ta}: \mathrm{TiO}_{2}$ NW samples was performed using a three-electrode electrochemical cell with the nanowire arrays as the working electrode, a $\mathrm{Ag} / \mathrm{AgCl}$ reference electrode, a Pt wire counter electrode, and $1 \mathrm{M}$ $\mathrm{KOH}$ electrolyte. A $150 \mathrm{~W}$ xenon lamp with an AM $1.5 \mathrm{G}$ filter was used as the light source, providing a light intensity of $100 \mathrm{~mW} / \mathrm{cm}^{2}$ (more details can be found in the experimental section). Before testing, the as-synthesized films were annealed in air at 500 ${ }^{\circ} \mathrm{C}$ for 2 hours to remove contaminants and improve the adherence of the NW arrays to the substrate. Figure $4.7 \mathrm{a}$ shows the photocurrent density at $1.23 \mathrm{~V}_{\mathrm{RHE}}$ of $\mathrm{Ta}: \mathrm{TiO}_{2}$ samples with Ta precursor volumes ranging from 0 to $2.5 \mathrm{~mL}$ (Ta incorporation levels ranging from 0 to 3.47 at. \%). In the low Ta incorporation range from $0-0.61$ at. \% (i.e. Ta precursor ranging from $0-1 \mathrm{~mL}$ ), the PEC performance increases as Ta concentration increases, reaching a maximum for a Ta concentration of 0.15 at. \% (volume of $\mathrm{Ta}$ precursor- $\mathrm{V}_{\mathrm{Ta}}=0.5 \mathrm{~mL}$ ); the PEC performance, however, decreases with increasing Ta concentration to 0.29 and 0.61 at. $\%\left(\mathrm{~V}_{\mathrm{Ta}}=0.75-1 \mathrm{~mL}\right)$. Figure $4.7 \mathrm{~b}$ shows linear sweep voltammetry (LSV) measurements of the pristine $\mathrm{TiO}_{2}$ and $\mathrm{Ta}: \mathrm{TiO}_{2}-050(0.15$ at. \% Ta) samples. The onset potentials of photocurrents of the pristine $\mathrm{TiO}_{2}$ and $\mathrm{Ta}: \mathrm{TiO}_{2}-50 \mathrm{NWs}$ are almost the same at around, $\sim 0.2 \mathrm{~V}_{\mathrm{RHE}}$, indicating that the flat band potential, thus the (quasi) Fermi level and the position of the conduction band (CB) edge does not shift with 
the incorporation of Ta. Indeed, both IPCE and UV-vis transmittance spectra (Figure 4.7c and 7d) indicate no change in the band gap of pristine $\mathrm{TiO}_{2}$ and $\mathrm{Ta}^{\mathrm{TiO}} \mathrm{TiO}_{2} \mathrm{NW}$ samples, thus any shift of the $\mathrm{CB}$ edge would have to be complemented with a shift of the valence band edge, which is unlikely. The $\mathrm{Ta}: \mathrm{TiO}_{2}-050$ sample shows a significant improvement in the photoactivity with the photocurrent reaches $0.44 \mathrm{~mA} / \mathrm{cm}^{2}$ at $1.23 \mathrm{~V}$ vs. reversible hydrogen electrode $\left(\mathrm{V}_{\mathrm{RHE}}\right)$, compared to that of $0.23 \mathrm{~mA} / \mathrm{cm}^{2}$ for the pristine $\mathrm{TiO}_{2}$ sample. As mentioned previously, no band gap change in any $\mathrm{Ta}^{\mathrm{TiO}} \mathrm{Ti}_{2} \mathrm{NW}$ sample was observed so we believe that the enhancement in the PEC performance of Ta: $\mathrm{TiO}_{2}$ nanowires is likely due to (1) an improvement in charge transfer properties, (2) faster kinetics for surface water oxidation, and (3) an increase in the cross-sectional feature sizes. Incorporation of $\mathrm{Ta}^{5+}$ into the $\mathrm{TiO}_{2}$ lattice can be considered as an n-type 'doping' method to improve the donor density and electron conductivity of $\mathrm{TiO}_{2} \cdot{ }^{40}$ Indeed, n-type 'doping' $\mathrm{TiO}_{2} \mathrm{NWs}$ via Sn incorporation ${ }^{41}$ or thermal treatment with hydrogen ${ }^{42}$ has been demonstrated to significantly improve the PEC performance. Continued increasing of the $\mathrm{Ta}^{5+}$ incorporation $(0.29-0.61$ at. \%) will reduce the depletion layer width due to the increase in donor density, thus lowering charge separation efficiency, which in turn reduces the photocurrent.

It is interesting that the photocurrent increases again at high Ta doping ( 2.65 and 3.47 at. \%), probably as the result of an enhancement in charge collection efficiency due to the unique core/shell structure as observed in HRTEM in Figure 4.5c and 4.5d. Hwang et al. reported an enhancement in PEC performance in core/shell structured $\mathrm{TiO}_{2}$ nanowires prepared by atomic layer deposition of a epitaxial rutile $\mathrm{TiO}_{2}$ layer on hydrothermally grown rutile $\mathrm{TiO}_{2}$ nanowires. ${ }^{43}$ The authors proposed that the ALD coating passivates surface states and increases surface area, thus improving the charge collection efficiency. 

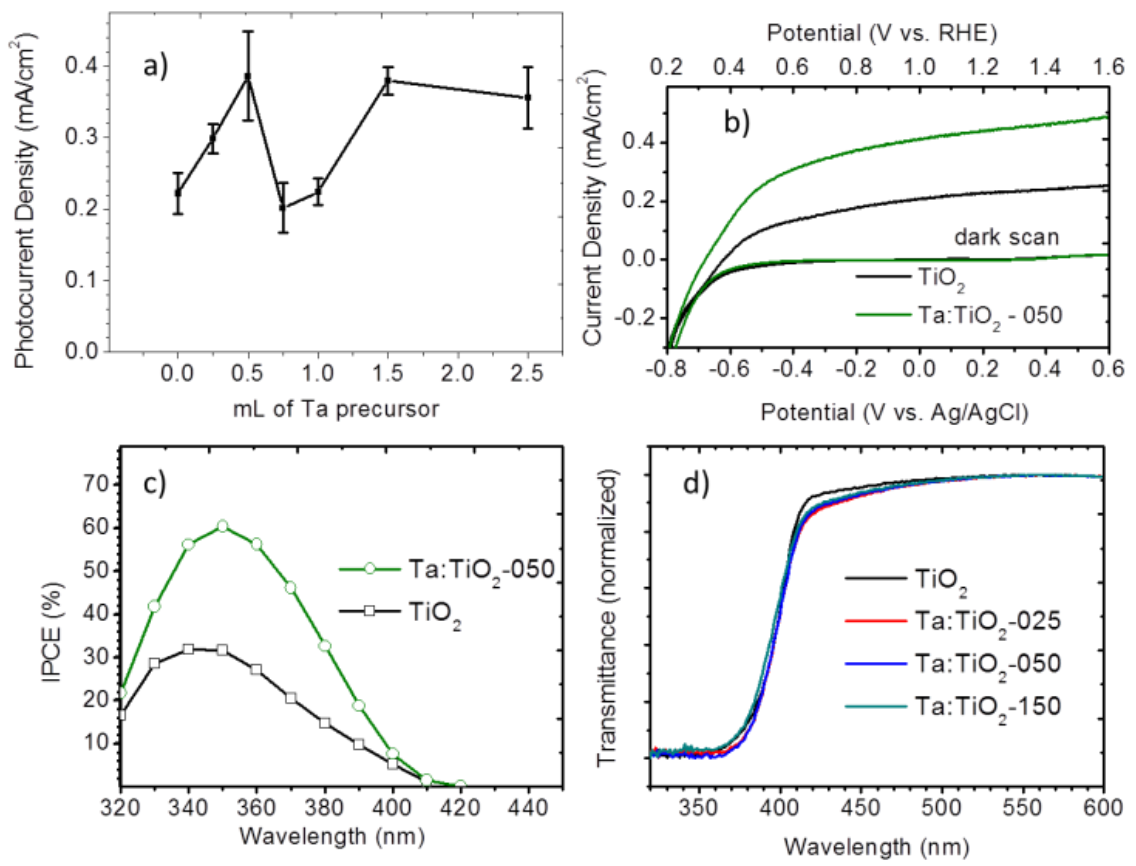

Figure 4.7. (a) Photocurrent density at $1.23 \mathrm{~V}_{\mathrm{RHE}}$ of pristine $\mathrm{TiO}_{2} \mathrm{NW}$ sample and $\mathrm{Ta}: \mathrm{TiO}_{2} \mathrm{NW}$ samples with various amount of Ta precursor, (b) linear sweep voltammetry (LSV) (scan rate of $25 \mathrm{mV} / \mathrm{s}$ ) of $\mathrm{TiO}_{2}$ (black) and $\mathrm{Ta}^{-\mathrm{TiO}_{2}-050}$ (green) NW samples, (c) IPCE spectra measured at 1.23 $\mathrm{V}_{\text {RHE }}$ and (d) UVvis transmittance spectra of $\mathrm{TiO}_{2} \mathrm{NW}$ sample and $\mathrm{Ta}: \mathrm{TiO}_{2} \mathrm{NW}$ samples. All the PEC measurements were conducted using a three-electrode electrochemical cell with a $\mathrm{Ag} / \mathrm{AgCl}$ reference electrode, a Pt wire counter electrode, and $1 \mathrm{M} \mathrm{KOH}$ electrolyte. A solar simulator (Oriel 96000) with an AM $1.5 \mathrm{G}$ filter with a light intensity of $100 \mathrm{~mW} / \mathrm{cm}^{2}$ was employed as the light source.

\section{Synthesis and Characterization of $\mathrm{N}$ and $\mathrm{Ta}$ co-incorporated $\mathrm{TiO}_{2}$ (N,}

Ta:TiO 2 Nanowire arrays. $\mathrm{N}, \mathrm{Ta}_{2} \mathrm{TiO}_{2}-\mathrm{Xxx} \mathrm{NWs}$ were synthesized by annealing the corresponding Ta: $\mathrm{TiO}_{2}$ - $\mathrm{xxx}$ NWs at $500{ }^{\circ} \mathrm{C}$ in $\mathrm{NH}_{3}$ flow $(30 \mathrm{~mL} / \mathrm{min})$ for 2 hours. For comparison, N-modified $\mathrm{TiO}_{2}\left(\mathrm{~N}: \mathrm{TiO}_{2}\right)$ samples were prepared by annealing the pristine $\mathrm{TiO}_{2} \mathrm{NW}$ sample in $\mathrm{NH}_{3}$ flow under the same conditions. 


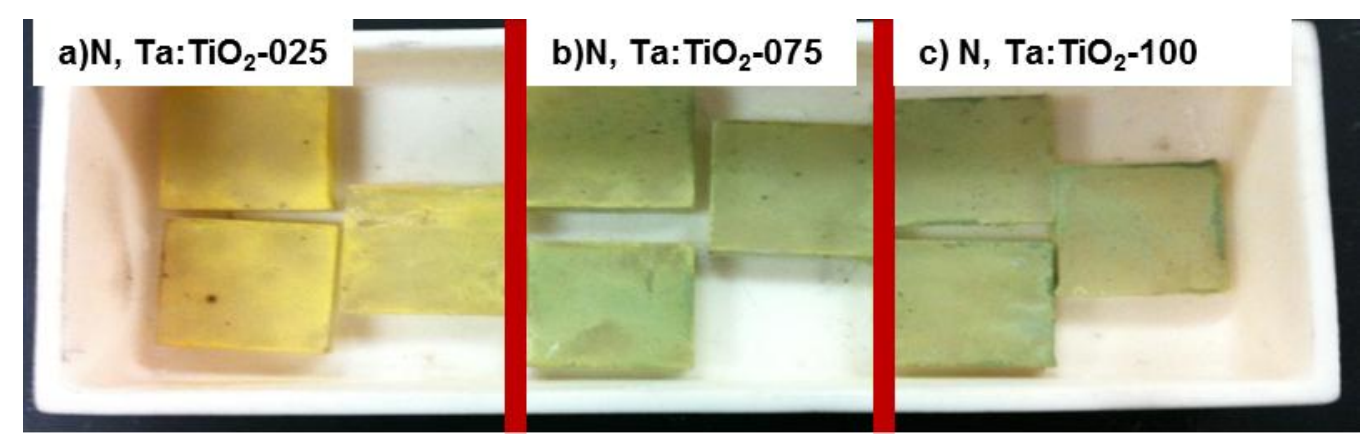

Figure 4.8. Digital images of $\mathrm{N}$, Ta-coincorporated $\mathrm{TiO}_{2}$ nanowire samples synthesized with various amount of Ta precursor (a) $0.25 \mathrm{~mL}$, (b) $0.75 \mathrm{~mL}$, and (c) 1.00 $\mathrm{mL}$.

After nitridation, the white color of $\mathrm{TiO}_{2}$ and $\mathrm{Ta}: \mathrm{TiO}_{2}$ samples turns to yellow for samples with Ta incorporation levels less than 0.15 at.\% (volume of Ta precursor less than $0.5 \mathrm{~mL}$ ) and green for samples with Ta incorporation levels greater than 0.15 at.\% (volume of Ta precursor greater than $0.5 \mathrm{~mL}$ ) (Figure 4.8). XRD indicated no crystal structure changes for any films; only the rutile phase was observed for all samples (Figure 4.9).

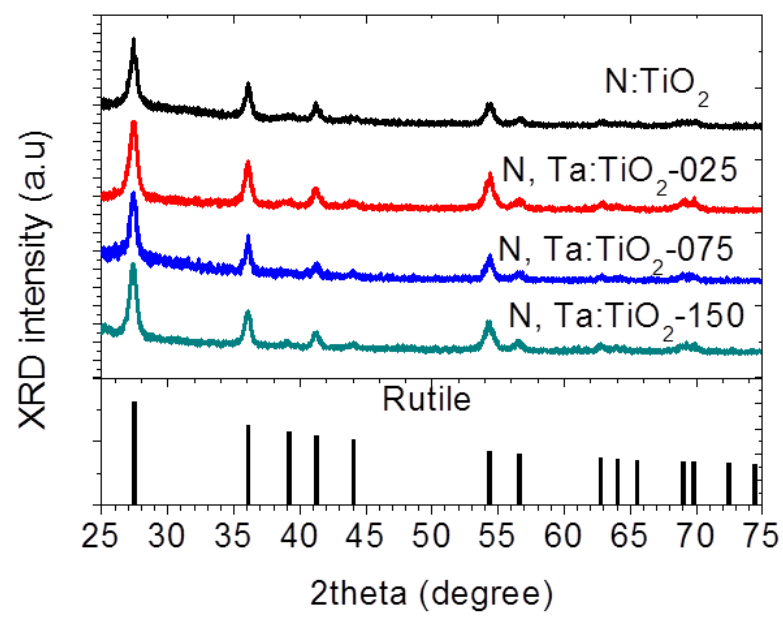

Figure 4.9. $\mathrm{XRD}$ of $\mathrm{N}: \mathrm{TiO}_{2}$ and $\mathrm{N}, \mathrm{Ta}: \mathrm{TiO}_{2}$ nanowire samples 
The cross section of the $\mathrm{N}: \mathrm{TiO}_{2} \mathrm{NWs}$ (mono-incorporation of $\mathrm{N}$ ) becomes larger and does not retain the sharp tetragonal shape (Figure 4.10a) of the as-synthesized pristine $\mathrm{TiO}_{2}$ NWs. On the other hand, Figure4. 6c indicates no changes in the cross section of the N, Ta: $\mathrm{TiO}_{2}-075$ sample (as well as other $\mathrm{N}$, Ta-coincorporated samples Figure 4.11) after nitridation.

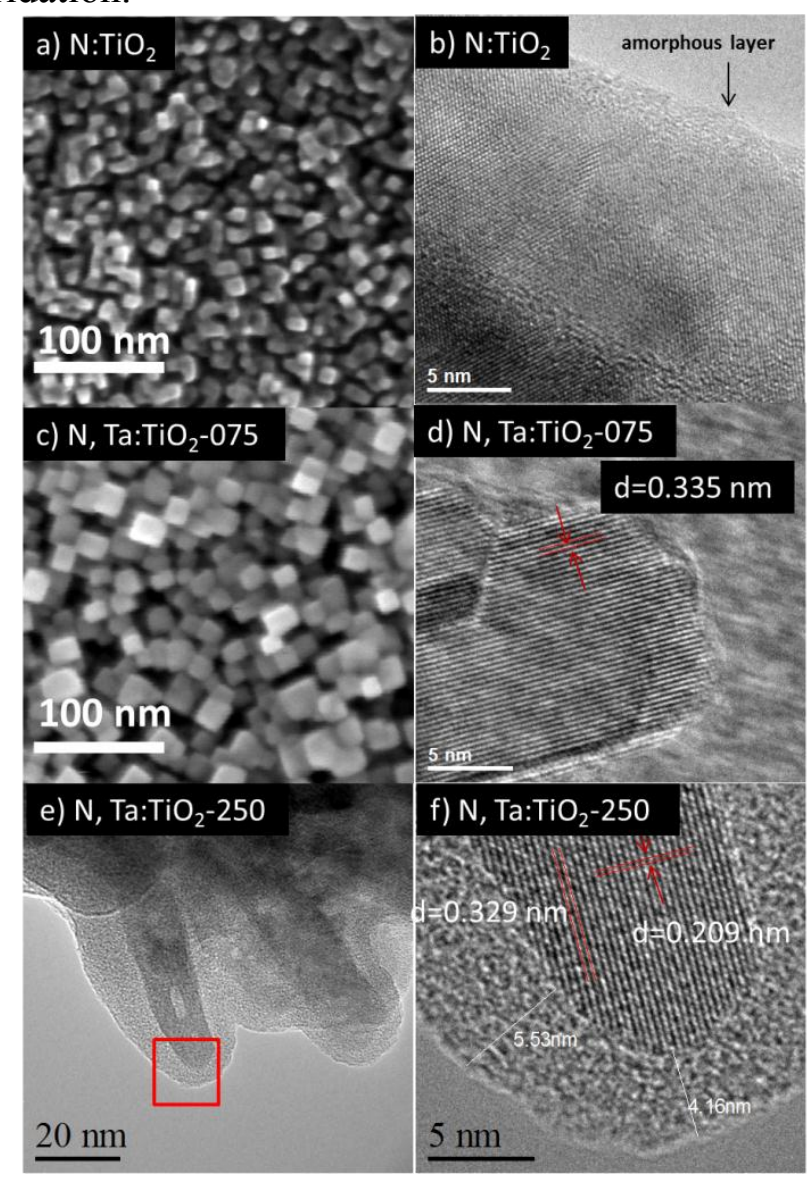

Figure 4.10. SEM images of (a) $\mathrm{N}: \mathrm{TiO}_{2} \mathrm{NW}$ and (c) $\mathrm{N}, \mathrm{Ta}_{\mathrm{TiO}} \mathrm{Ti}_{2}-075 \mathrm{NW}$ and HRTEM images of (b) $\mathrm{N}: \mathrm{TiO}_{2} \mathrm{NW}$, and (d) N,Ta: $\mathrm{TiO}_{2}-075 \mathrm{NW}$, (e) TEM images of $\mathrm{N}, \mathrm{Ta}: \mathrm{TiO}_{2}-250$ (NW) and (f) HRTEM images of N, Ta: $\mathrm{TiO}_{2}-250 \mathrm{NW}$ (the area on the red box on figure 10e) 
HRTEM images of the $\mathrm{N}: \mathrm{TiO}_{2} \mathrm{NW}$ (Figure 4.10a) indicates that an amorphous layer with a thickness of 1-2 $\mathrm{nm}$ (which probably causes the rounded shape of the nanowire) and a multi-domain structure were formed after nitriding the pristine $\mathrm{TiO}_{2}$ NWs. On the other hand, we did not observe the formation of an amorphous layer or multi-domain structure on the HRTEM image of N, Ta:TiO $2-075$ NWs (Figure 4.10d). The inter planar d-spacing of $\mathrm{N}, \mathrm{Ta}: \mathrm{TiO}_{2}-075$ was measured as $0.335 \mathrm{~nm}$, compared to $0.324 \mathrm{~nm}$ for pristine $\mathrm{TiO}_{2}$ indicating a lattice expansion due to incorporation of $\mathrm{Ta}$ and $\mathrm{N}$. This demonstrates that incorporating $\mathrm{Ta}^{5+}$ ions helps $\mathrm{N}$ inclusion into the $\mathrm{TiO}_{2}$ lattice without damaging the structure. In fact, Yin et al. predicted that Ta and $\mathrm{N}$ would exhibit a high binding energy $(1.92 \mathrm{eV})$, thus coincorporation of $\mathrm{Ta}$ and $\mathrm{N}$ overcomes the solubility of $\mathrm{N}$ in $\mathrm{TiO}_{2}$ lattices as well as improving the material quality over monoincorporation of N. ${ }^{12}$ It is interesting to note that the amorphous layer with a thickness $>$ $4.1 \mathrm{~nm}$ appears on $\mathrm{N}, \mathrm{Ta} \mathrm{TiO}_{2}-250$ nanowire sample (Figure 4.10e and 4.10f) which might explains for the low photoelectrochemical performance of this sample shown in a later section. We, however, have not figured out the reason for the formation of this amorphous layer. 


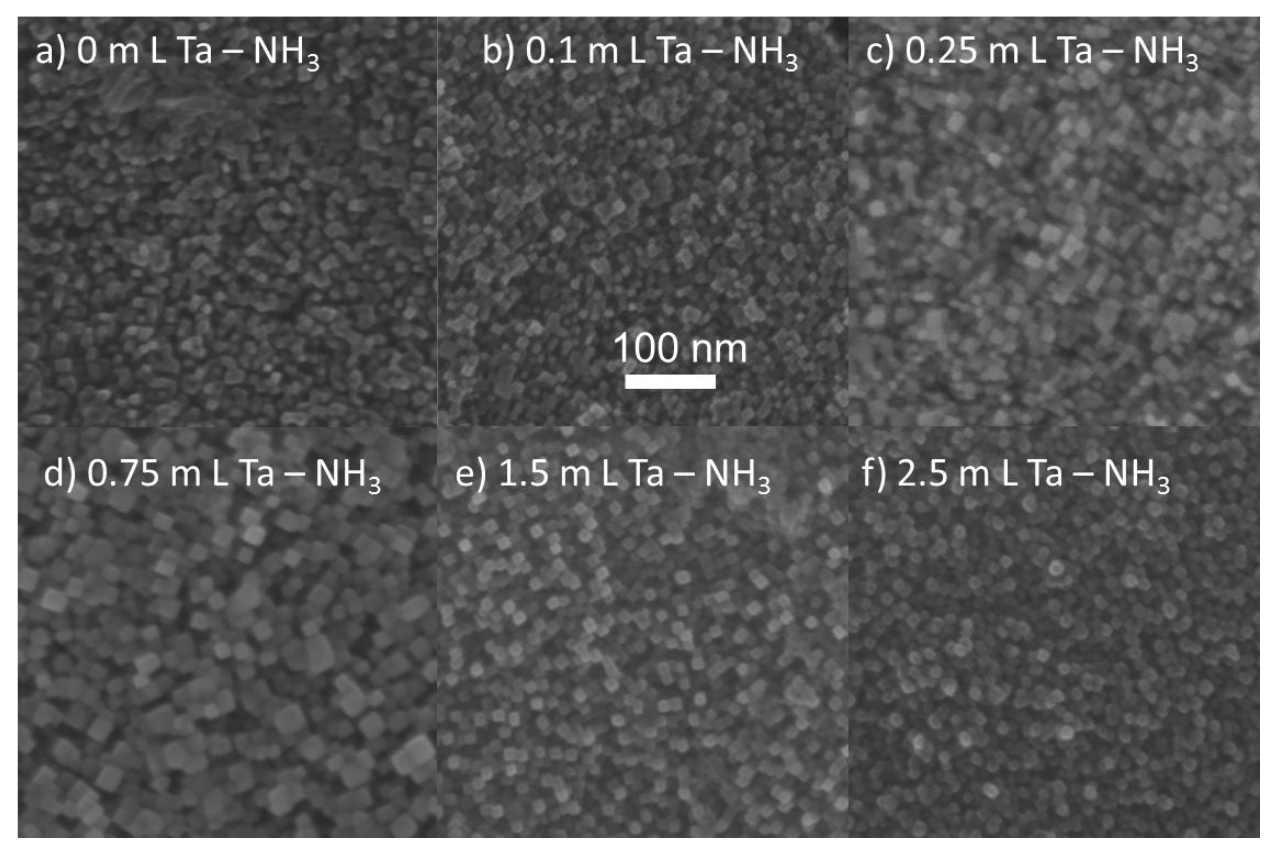

Figure 4.11. Top-view SEM images of $\mathrm{N}$, $\mathrm{Ta}: \mathrm{TiO}_{2}$ nanowires synthesized with various amount of Ta precursor: (a) $0 \mathrm{~mL}$ (pure $\mathrm{TiO}_{2}$ ), (b) $0.1 \mathrm{~mL}$, (c) $0.25 \mathrm{~mL}$, (d) $0.75 \mathrm{~mL}$, (e) $1.5 \mathrm{~mL}$, and (f) $2.5 \mathrm{~mL}$. The scale bar is applicable for all the micrographs.

XPS was also employed to determine the surface $\mathrm{N}$ content in the $\mathrm{N}: \mathrm{TiO}_{2}$ and $\mathrm{N}$, Ta: $\mathrm{TiO}_{2}$ samples (Figure 4.12). We only observed an $\mathrm{N}$ feature at $400 \mathrm{eV}$ (which is commonly assigned for molecular $\mathrm{N}_{2}$ adsorbed on the surface) for all samples including the pristine $\mathrm{TiO}_{2}$ nanowires. ${ }^{10,21} \mathrm{We}$ could not detect any $\mathrm{N}$ feature at $\sim 396 \mathrm{eV}$ which is assigned for substitutional $\mathrm{N}$ species, ${ }^{10}$ probably due to the resolution limit of the XPS instrument in our experiment, thus we could not estimate the concentration of $\mathrm{N}$ incorporated into the $\mathrm{TiO}_{2}$ lattice (note that the nitridation conditions used in the present work are less severe than that used in our previous reports ${ }^{21,24}$ ). 


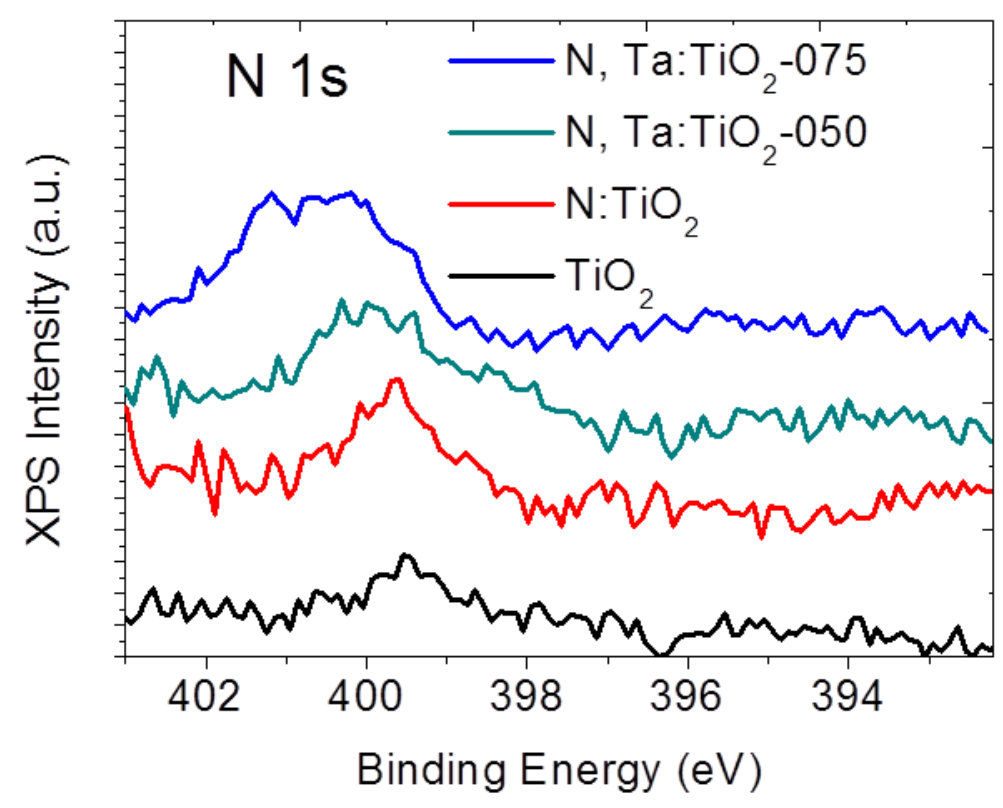

Figure 4.12. XPS spectra of core $\mathrm{N} 1 \mathrm{~s}$ for $\mathrm{TiO}_{2}$ (black), $\mathrm{N}: \mathrm{TiO}_{2}$ (red), $\mathrm{N}, \mathrm{Ta}: \mathrm{TiO}_{2}-050$ (cyan), and $\mathrm{N}, \mathrm{Ta}: \mathrm{TiO}_{2}-075$ (blue). The feature at $\sim 400 \mathrm{eV}$ is assigned for $\mathrm{N}$ species absorbed on the surface.

We, however, can observe the interaction of Ta and $\mathrm{N}$ in the core Ti $2 \mathrm{p}$ and core O 1s XPS spectra of $\mathrm{TiO}_{2}, \mathrm{~N}: \mathrm{TiO}_{2}$, and $\mathrm{N}$, Ta: $\mathrm{TiO}_{2}$ samples (figure 4.13). The Ti $2 \mathrm{p}$ feature at $458.85 \mathrm{eV}$ of $\mathrm{TiO}_{2} \mathrm{NWs}$ shifted to $458.55 \mathrm{eV}$ upon nitridation indicating an increase in the electron density around $\mathrm{Ti}^{4+}$ ions due to the substitution of $\mathrm{O}^{2-}$ ions by the more the negative $\mathrm{N}^{3-}$ ions. Cong et al. reported that the partial electron transformation from $\mathrm{N}$ to $\mathrm{Ti}$ causes an increase in the electron density around $\mathrm{Ti}$, thus lowering the binding energy of Ti $2 \mathrm{p} .{ }^{44}$ The similar phenomena were also reported by several other authors including Chen et al., Li et al., and Sathish et al. ${ }^{45-47}$ Increasing $\mathrm{Ta}^{5+}$ incorporation level shifts the Ti $2 \mathrm{p}$ feature back to higher binding energies of $458.75 \mathrm{eV}$ for $\mathrm{N}, \mathrm{Ta}: \mathrm{TiO}_{2}-050$ and $458.85 \mathrm{eV}$ for $\mathrm{N}, \mathrm{Ta}^{-} \mathrm{TiO}_{2}-075$ samples, respectively. A similar 
trend is observed for XPS core $\mathrm{O} 1 \mathrm{~s}$, confirming that $\mathrm{Ta}^{5+}$ acts as a charge compensation dopant for $\mathrm{N}^{3-}$.
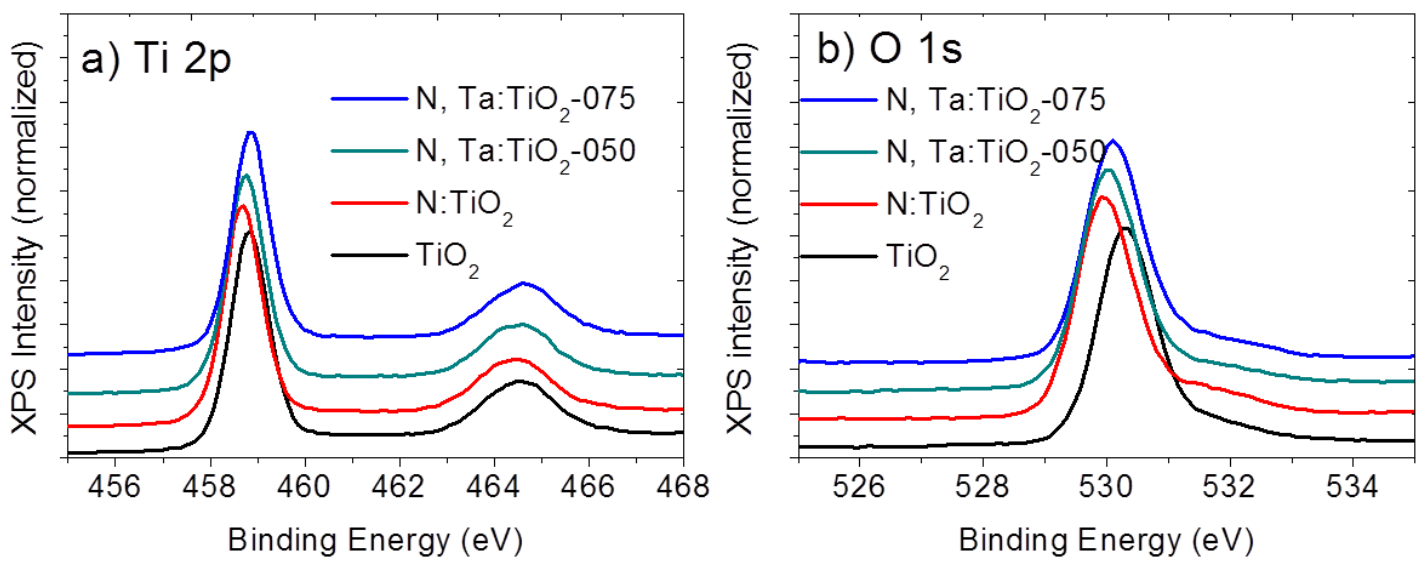

Figure 4.13. XPS spectra of (a) core $\mathrm{Ti} 2 \mathrm{p}$ and (b) core $\mathrm{O} 1 \mathrm{~s}$ for $\mathrm{TiO}_{2}$ (black), $\mathrm{N}: \mathrm{TiO}_{2}$ (red), N, Ta: $\mathrm{TiO}_{2}-050$ (cyan), and N, Ta: $\mathrm{TiO}_{2}-075$ (blue).

Figure $4.14 \mathrm{a}$ shows the AM $1.5 \mathrm{G}$ photocurrent of $\mathrm{N}, \mathrm{Ta}: \mathrm{TiO}_{2}$ samples with various Ta incorporation obtained by chronoamperometry measurements (CAM) at 1.23 $\mathrm{V}_{\mathrm{RHE}}$. The photocurrent increases with greater amounts of Ta precursor, reaching a maximum photocurrent of $0.55 \mathrm{~mA} / \mathrm{cm}^{2}$ with addition of $0.75 \mathrm{~mL}$ Ta precursor (corresponding to 0.3 at. \% Ta), then decreases when more Ta precursor is added. Figure

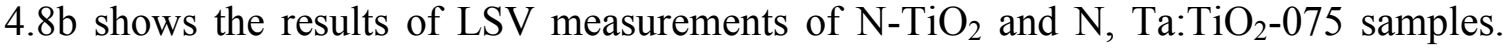
The onset potentials of the photocurrents are shifted to $0.4 \mathrm{~V}_{\mathrm{RHE}}$ for both samples, likely due to either a large band bending requirement for photogenerated electron and hole separation or slower surface kinetics as a result of incorporating $\mathrm{N}$ into the $\mathrm{TiO}_{2}$ and Ta: $\mathrm{TiO}_{2}$ lattice. $^{21}$ The N, Ta: $\mathrm{TiO}_{2}-075$ sample shows significant enhancement in PEC performance compared with $\mathrm{N}: \mathrm{TiO}_{2}$ samples both the in UV and visible region. The photocurrent of the $\mathrm{N}, \mathrm{Ta}: \mathrm{TiO}_{2}-075$ sample reaches $0.52 \mathrm{~mA} / \mathrm{cm}^{2}$ and $0.18 \mathrm{~mA} / \mathrm{cm}^{2}$ at 
1.23 $\mathrm{V}_{\mathrm{RHE}}$ under $\mathrm{AM} 1.5 \mathrm{G}$ and visible light $(>420 \mathrm{~nm}$ ) illumination, compared with 0.26 $\mathrm{mA} / \mathrm{cm}^{2}$ and $0.13 \mathrm{~mA} / \mathrm{cm}^{2}$ for that of the $\mathrm{N}-\mathrm{TiO}_{2}$ sample. Figure $4.14 \mathrm{c}$ shows the IPCE spectra measured at $1.23 \mathrm{~V}_{\mathrm{RHE}}$ for $\mathrm{N}, \mathrm{Ta}_{\mathrm{TiO}}-\mathrm{-075}$ and $\mathrm{N}: \mathrm{TiO}_{2}$ samples. The photocurrents obtained by integrating the calculated IPCE multiplied by the whole and the visible light range ( $>420 \mathrm{~nm}$ ) of the AM $1.5 \mathrm{G}$ solar energy flux ${ }^{48}$ is $0.55 \mathrm{~mA} / \mathrm{cm}^{2}$ and $0.16 \mathrm{~mA} / \mathrm{cm}^{2}$ for $\mathrm{N}, \mathrm{Ta}^{-} \mathrm{TiO}_{2}-075$ sample, and $0.28 \mathrm{~mA} / \mathrm{cm}^{2}$ and $0.09 \mathrm{~mA} / \mathrm{cm}^{2}$ for the $\mathrm{N}-$ $\mathrm{TiO}_{2}$ sample, respectively, which are in good agreement with the LSV and CAM measurements mentioned above. It is interesting to note that both the IPCE spectra and UV-vis transmittance spectra (figure 4.14d) demonstrate that the active spectra for N, Ta: $\mathrm{TiO}_{2}$ extends to $\sim 520 \mathrm{~nm}$ (corresponding to a photon energy of $2.38 \mathrm{eV}$ ), compared with $\sim 540 \mathrm{~nm}(2.30 \mathrm{eV})$ for that of $\mathrm{N}^{\mathrm{TiO}}{ }_{2}$. Yin et al. reported that since the atomic orbital energy of Ta $5 \mathrm{~d}$ is higher than that of Ti $3 \mathrm{~d}$, the conduction band of the N, Ta coincorporated anatase $\mathrm{TiO}_{2}$ upshifts $0.05 \mathrm{eV}$ compared to that of pristine anatase $\mathrm{TiO}_{2} \cdot{ }^{12}$

The enhancement in the PEC performance of the co-incorporated film compared to the mono-incorporated $\mathrm{N}: \mathrm{TiO}_{2}$ sample might not be due to better visible light absorption as demonstrated above but likely results from fewer recombination centers due to charge compensated co-incorporation. ${ }^{12,25,29}$ In addition, co-incorporation of Ta and $\mathrm{N}$ into $\mathrm{TiO}_{2} \mathrm{NWs}$ suppresses the formation of the amorphous layer observed on the $\mathrm{N}: \mathrm{TiO}_{2} \mathrm{NWs}$, thus likely better promoting hole extraction to the electrolyte. We noted that nitridation of the $\mathrm{TiO}_{2}$ nanowires that are highly incorporated with $\mathrm{Ta}$ (sample poor PEC N, Ta:TiO $2-250$ ) lead to formation of a thick amorphous layer (Figure 4.10e-f) thus lowering the PEC performance (Figure 4.14a). 

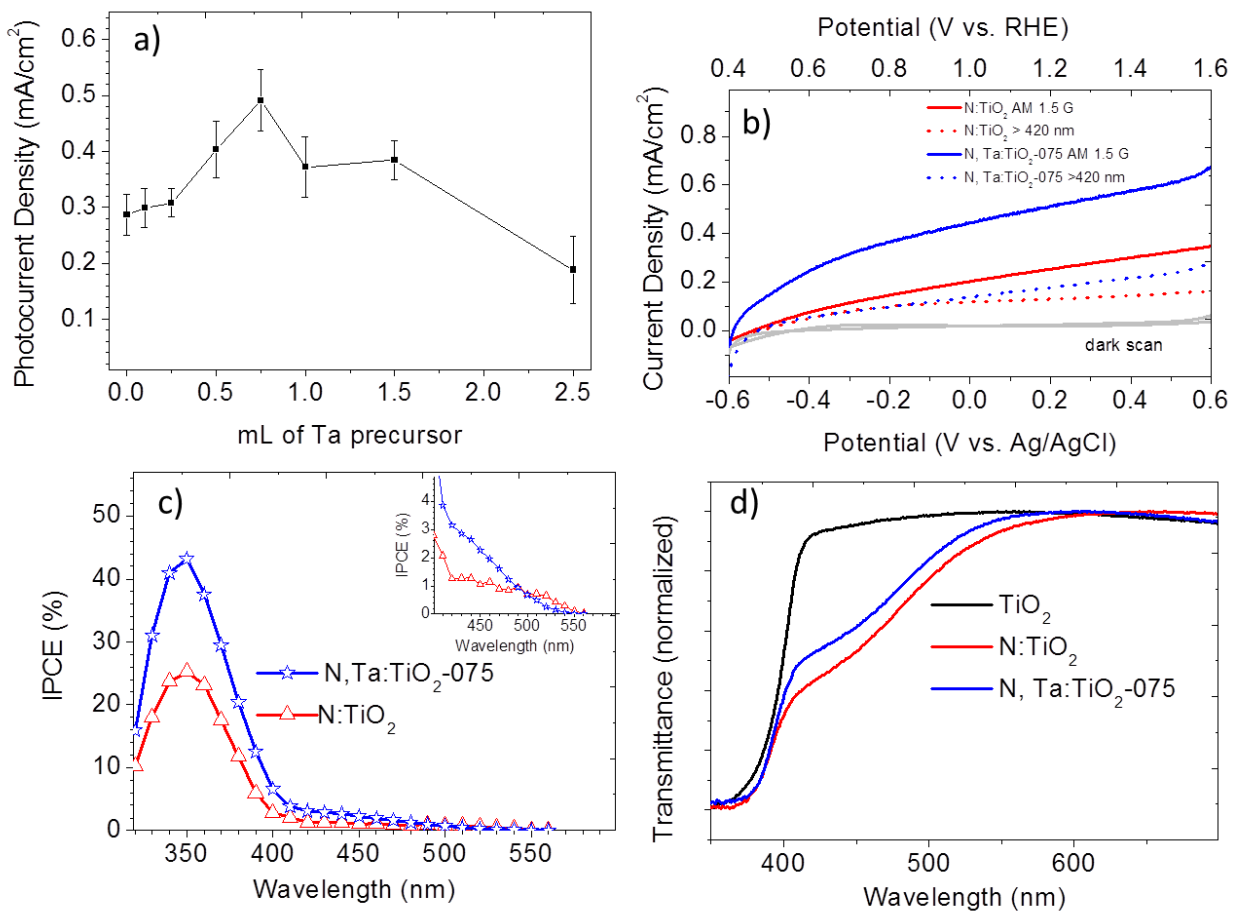

Figure 4.14. (a) Photocurrent density at $1.23 \mathrm{~V}_{\mathrm{RHE}}$ of $\mathrm{N}: \mathrm{TiO}_{2} \mathrm{NW}$ sample and $\mathrm{N}, \mathrm{Ta}: \mathrm{TiO}_{2}$ NW samples with various amount of Ta precursor, (b) LSV (scan rate of 25 $\mathrm{mV} / \mathrm{s}$ ) of $\mathrm{N}: \mathrm{TiO}_{2}$ (red) and $\mathrm{N}, \mathrm{Ta}: \mathrm{TiO}_{2}-075$ (blue) NW samples under AM $1.5 \mathrm{G}$ (solid line) and visible light (>420 nm) (dotted line), (c) IPCE spectra measured at $1.23 \mathrm{~V}_{\mathrm{RHE}}$ and (d) $\mathrm{UV}$-vis transmittance spectra of $\mathrm{N}: \mathrm{TiO}_{2} \mathrm{NW}$ sample and $\mathrm{N}, \mathrm{Ta}: \mathrm{TiO}_{2}-075 \mathrm{NW}$ samples. All the PEC measurements were conducted using a three-electrode electrochemical cell with a $\mathrm{Ag} / \mathrm{AgCl}$ reference electrode, a Pt wire counter electrode, and $1 \mathrm{M} \mathrm{KOH}$ electrolyte. A solar simulator (Oriel 96000) with an AM 1.5 G filter with a light intensity of $100 \mathrm{~mW} / \mathrm{cm}^{2}$ was employed as the light source. A UV filter blocking all wavelengths $<420 \mathrm{~nm}$ was used for visible light measurements.

The electrochemical impedance measurements on the pristine $\mathrm{TiO}_{2}, \mathrm{~N}: \mathrm{TiO}_{2}$, Ta: $\mathrm{TiO}_{2}-075$ and $\mathrm{N}, \mathrm{Ta}^{-} \mathrm{TiO}_{2}-075$ nanowire samples (Figure 4.15) show that the slope of the Mott-Schottky plot for N, Ta: $\mathrm{TiO}_{2}$ NW samples is substantially lower than that for other samples. However, due to the significant change in the morphology of the samples, 
it is difficult to comment on the change in the donor density due to the monoincorporation of $\mathrm{N}, \mathrm{Ta}$ and the coincorporation of Ta and $\mathrm{N}$.

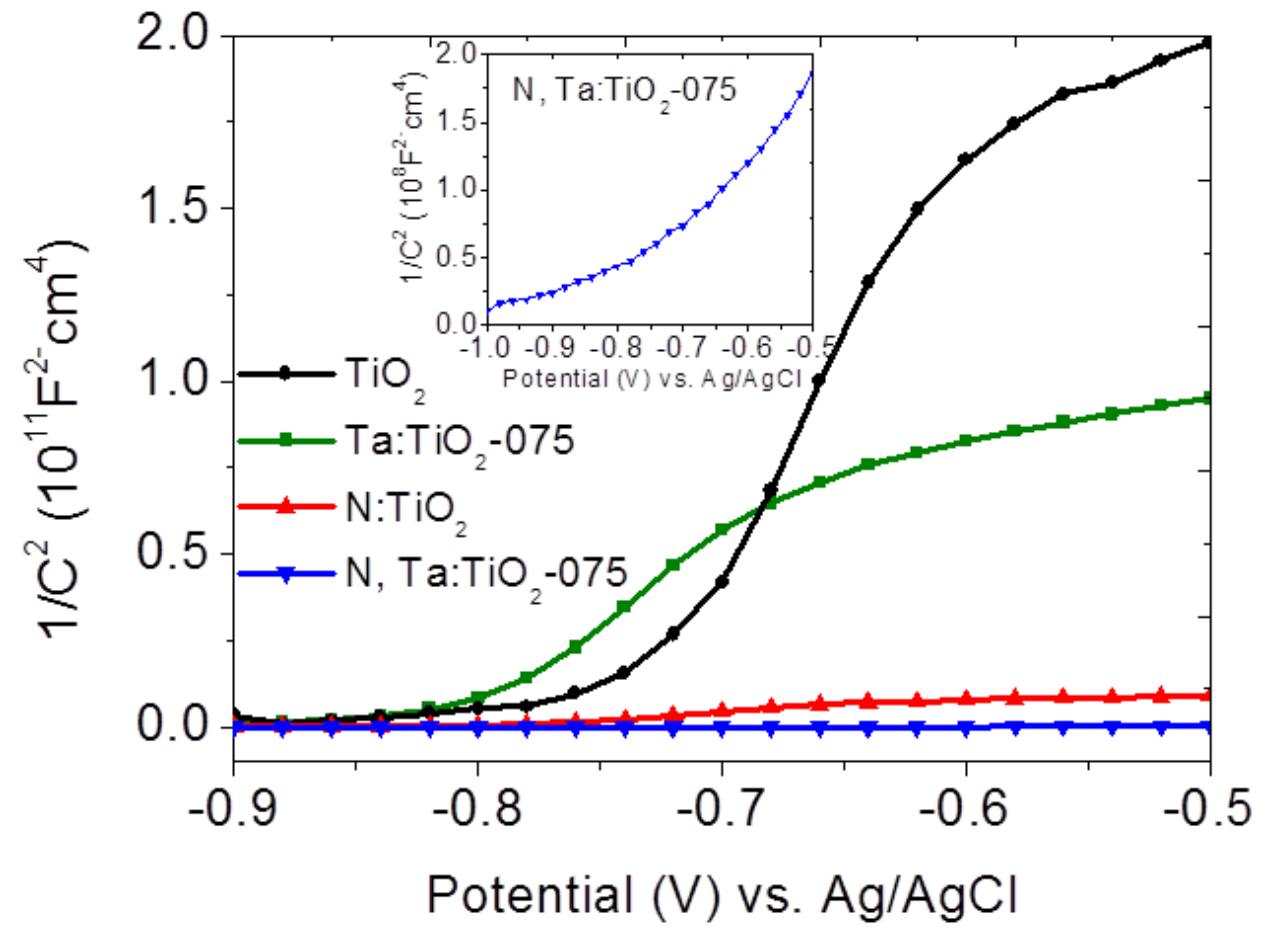

Figure 4.15. Mott-Schottky plots obtained at a frequency of $1 \mathrm{kHz}$ in the dark in $1 \mathrm{M}$ $\mathrm{KOH}$ electrolyte for the pristine $\mathrm{TiO}_{2}, \mathrm{Ta}_{\mathrm{TiO}}-075, \mathrm{~N}: \mathrm{TiO}_{2}$, and $\mathrm{N}$, Ta: $\mathrm{TiO}_{2}-075$ nanowires. The inset enlarges the Mott-Schottky plot for the N, $\mathrm{Ta}: \mathrm{TiO}_{2}-075$ nanowire samples.

\section{CONCLUSIONS}

In conclusion, we report the solvothermal synthesis of Ta-incorporated $\mathrm{TiO}_{2}$ nanowire arrays. The Ta incorporation level can be tuned from 0.11 to 3.5 atomic $\%$ by adjusting the volume of the Ta precursor. For low Ta concentrations $(<0.30$ at $\%)$, Ta was incorporated homogenously into the $\mathrm{TiO}_{2}$ nanowire. On the other hand, a core/shell structure was observed for high Ta incorporation levels (2.65 at. \%). We also report the synthesis of $\mathrm{N}$, Ta-coincorporated $\mathrm{TiO}_{2}$ nanowires arrays by nitridation of the Ta- 
incorporated $\mathrm{TiO}_{2} \mathrm{NW}$ arrays in $\mathrm{NH}_{3}$ flow at the relatively low temperature of $500{ }^{\circ} \mathrm{C}$. The IPCE and UV-vis transmittance spectra reveal that the active spectrum of N, Ta: $\mathrm{TiO}_{2}$ samples extends to $\sim 520 \mathrm{~nm}$, compared with $\sim 550 \mathrm{~nm}$ for the $\mathrm{N}-\mathrm{TiO}_{2}$ and $\sim 420 \mathrm{~nm}$ for pristine $\mathrm{TiO}_{2}$ and $\mathrm{Ta}: \mathrm{TiO}_{2}$ samples. The N,Ta:TiO 2 NW samples show significant enhancement in PEC performance both under AM 1.5 G and visible light $(>420 \mathrm{~nm})$ illumination. We speculate that coincorporation of $\mathrm{Ta}$ and $\mathrm{N}$ reduces charge recombination centers via charge compensation effects. In addition, coincorporation of Ta and $\mathrm{N}$ suppresses the formation of the amorphous layer during the nitridation process, thus improving hole extraction to the electrolyte and PEC performance. 


\section{REFERENCES}

(1) Gai, Y.; Li, J.; Li, S.-S.; Xia, J.-B.; Wei, S.-H. Phys. Rev. Lett. 2009, 102, 036402.

(2) Chen, X.; Mao, S. S. Chem. Rev. 2007, 107, 2891.

(3) Fujishima, A.; Honda, K. Nature 1972, 238, 37.

(4) Fujishima, A.; Zhang, X.; Tryk, D. A. Surf. Sci. Rep. 2008, 63, 515.

(5) Chen, X.; Liu, L.; Yu, P. Y.; Mao, S. S. Science 2011, 331, 746.

(6) Linsebigler, A. L.; Lu, G.; Yates, J. T. Chem. Rev. 1995, 95, 735.

(7) Bolton, J. R. Solar Energy 1996, 57, 37.

(8) Bolton, J. R.; Strickler, S. J.; Connolly, J. S. Nature 1985, 316, 495.

(9) Murphy, A. B.; Barnes, P. R. F.; Randeniya, L. K.; Plumb, I. C.; Grey, I. E.; Horne, M. D.; Glasscock, J. A. Int. J. Hydrogen Energy 2006, 31, 1999.

(10) Asahi, R.; Morikawa, T.; Ohwaki, T.; Aoki, K.; Taga, Y. Science 2001, 293, 269.

(11) Khan, S. U. M.; Al-Shahry, M.; Ingler, W. B. Science 2002, 297, 2243.

(12) Yin, W.-J.; Tang, H.; Wei, S.-H.; Al-Jassim, M. M.; Turner, J.; Yan, Y. Phys. Rev. B 2010, 82, 045106.

(13) Choi, J.; Park, H.; Hoffmann, M. R. J. Mater. Res. 2010, 25, 149.

(14) Umebayashi, T.; Yamaki, T.; Itoh, H.; Asai, K. J. Phys. Chem. Solids 2002, 63, 1909.

(15) Ohno, T.; Tanigawa, F.; Fujihara, K.; Izumi, S.; Matsumura, M. J. Photochem. Photobiol., A 1998, 118, 41.

(16) Chen, X. B.; Lou, Y. B.; Dayal, S.; Qiu, X. F.; Krolicki, R.; Burda, C.; Zhao, C. F.; Becker, J. J. Nanosci. Nanotechnol. 2005, 5, 1408.

(17) Choi, W. Y.; Termin, A.; Hoffmann, M. R. J. Phys. Chem. 1994, 98, 13669.

(18) Janisch, R.; Gopal, P.; Spaldin, N. A. J. Phys: Condes. Matter 2005, 17, R657.

(19) Litter, M. I.; Navio, J. A. J. Photochem. Photobiol., A 1996, 98, 171.

(20) Dvoranova, D.; Brezova, V.; Mazur, M.; Malati, M. A. Appl. Catal., B 2002, 37, 91.

(21) Hoang, S.; Guo, S.; Hahn, N. T.; Bard, A. J.; Mullins, C. B. Nano Lett. 2012, 12, 26.

(22) Park, J. H.; Kim, S.; Bard, A. J. Nano Lett. 2005, 6, 24.

(23) Umebayashi, T.; Yamaki, T.; Itoh, H.; Asai, K. Appl. Phys. Lett. 2002, 81, 454. 
(24) Hoang, S.; Berglund, S. P.; Hahn, N. T.; Bard, A. J.; Mullins, C. B. J. Am. Chem. Soc. 2012, 134, 3659.

(25) Long, R.; English, N. J. Chem. Phys. Lett. 2009, 478, 175.

(26) Zhu, W.; Qiu, X.; Iancu, V.; Chen, X.-Q.; Pan, H.; Wang, W.; Dimitrijevic, N. M.; Rajh, T.; Meyer, H. M.; Paranthaman, M. P.; Stocks, G. M.; Weitering, H. H.; Gu, B.; Eres, G.; Zhang, Z. Phys. Rev. Lett. 2009, 103, 226401.

(27) Breault, T. M.; Bartlett, B. M. J. Phys. Chem. C, 116, 5986.

(28) Gai, Y. Q.; Li, J. B.; Li, S. S.; Xia, J. B.; Yan, Y. F.; Wei, S. H. Phys. Rev. B 2009,80 .

(29) Ma, X. G.; Wu, Y.; Lu, Y. H.; Xu, J.; Wang, Y. J.; Zhu, Y. F. J. Phys. Chem. C 2011, 115, 16963.

(30) Obata, K.; Irie, H.; Hashimoto, K. Chem. Phys. 2007, 339, 124.

(31) Huang, J.; Wen, S.; Liu, J.; He, G. Journal of Natural Gas Chemistry 2012, 21, 302.

(32) Wang, W.; Lu, C.; Ni, Y.; Su, M.; Huang, W.; Xu, Z. Appl. Surf. Sci. 2012, 258, 8696.

(33) van de Krol, R.; Liang, Y. Q.; Schoonman, J. J. Mater. Chem. 2008, 18, 2311.

(34) Hahn, N. T.; Ye, H.; Flaherty, D. W.; Bard, A. J.; Mullins, C. B. ACS Nano 2010, 4, 1977.

(35) Mor, G. K.; Prakasam, H. E.; Varghese, O. K.; Shankar, K.; Grimes, C. A. Nano Lett. 2007, 7, 2356.

(36) Cho, I. S.; Chen, Z.; Forman, A. J.; Kim, D. R.; Rao, P. M.; Jaramillo, T. F.; Zheng, X. Nano Lett. 2011, 11, 4978.

(37) Feng, X.; Shankar, K.; Varghese, O. K.; Paulose, M.; Latempa, T. J.; Grimes, C. A. Nano Lett. 2008, 8, 3781.

(38) Shannon, R. D. Acta Crystallogr. Sect. A 1976, 32, 751.

(39) Arab, S.; Li, D. S.; Kinsinger, N.; Zaera, F.; Kisailus, D. J. Mater. Res. 2011, 26, 2653.

(40) Feng, X.; Shankar, K.; Paulose, M.; Grimes, C. A. Angew. Chem. Int. Ed. 2009, $48,8095$.

(41) Xu, M.; Da, P.; Wu, H.; Zhao, D.; Zheng, G. Nano Lett. 2012, 12, 1503.

(42) Wang, G.; Wang, H.; Ling, Y.; Tang, Y.; Yang, X.; Fitzmorris, R. C.; Wang, C.; Zhang, J. Z.; Li, Y. Nano Lett. 2011, 11, 3026.

(43) Hwang, Y. J.; Hahn, C.; Liu, B.; Yang, P. ACS Nano 2012, 6, 5060. 
(44) Cong, Y.; Zhang, J.; Chen, F.; Anpo, M. J. Phys. Chem. C 2007, 111, 6976.

(45) Chen, X.; Burda, C. J. Phys. Chem. B 2004, 108, 15446.

(46) Li, H.; Li, J.; Huo, Y. J. Phys. Chem. B 2006, 110, 1559.

(47) Sathish, M.; Viswanathan, B.; Viswanath, R. P.; Gopinath, C. S. Chem. Mater. $2005,17,6349$.

(48) http://rredc.nrel.gov/solar/spectra/am1.5/. 


\section{Chapter 5: Low Temperature Hydrothermal Synthesis of Vertically Aligned $\mathrm{TiO}_{2}$ Nanoplatelet Arrays for Solar Energy Conversion Applications}

\section{INTRODUCTION}

Titanium dioxide $\left(\mathrm{TiO}_{2}\right)$ is an abundant, low-cost, non-toxic, and photochemically stable metal oxide that has been widely used as a white pigment and sunscreen. ${ }^{1-4} \mathrm{TiO}_{2}$ is also a promising semiconductor material for various applications in photoelectrochemical (PEC) water splitting cells, organic pollutant photodegradation,

lithium-ion batteries, and dye sensitized solar cells (DSSCs). ${ }^{1,5-7} \mathrm{TiO}_{2}$ has a large band gap of $3.0 \mathrm{eV}$ for rutile and $3.2 \mathrm{eV}$ for anatase, therefore setting its theoretical maximum solar energy (AM $1.5 \mathrm{G}$ conditions) conversion efficiency at $2.2 \%{ }^{8}$ Since Fujishima and Honda discovered the photoelectrolysis of water using an n-type rutile $\mathrm{TiO}_{2}$ phoanode in 1972, ${ }^{1}$ numerous efforts have focused on improving the solar energy conversion efficiency of $\mathrm{TiO}_{2}$ materials via (1) reducing the band gap of $\mathrm{TiO}_{2}$ or sensitizing $\mathrm{TiO}_{2}$ with dye molecules to absorb visible light and (2) fabricating nanostructures of $\mathrm{TiO}_{2}$ to improve charge transport properties and to increase surface area for dye adsorption. 5, 6, 9-15 Incorporating $\mathrm{TiO}_{2}$ with nonmetal ions such as $\mathrm{C},{ }^{16} \mathrm{~N},{ }^{5,12}$ etc., and coincorporating $\mathrm{TiO}_{2}$ with metal and nonmetal ions ${ }^{17-19}$ have shown some successes in extending the optical absorption edge to the visible light region. Sensitization of $\mathrm{TiO}_{2}$ photoelectrodes with dye molecules for application in DSSCs has proven very efficient to convert visible light into electricity and has been the subject of extensive research since the discovery of O'Regan and Gräzel in $2001 .^{6}$

Besides enhancing optical absorption, it is equally important to improve the charge transport properties of $\mathrm{TiO}_{2} .^{11,}{ }^{20-22}$ In a PEC water splitting cell, holes 
photogenerated in $\mathrm{TiO}_{2}$ must diffuse to the electrode/electrolyte interface to participate in water oxidation, while photogenerated electrons must diffuse to the electrical contact then transport to the cathode to participate in water reduction. The hole diffusion length of $\mathrm{TiO}_{2}$ is $\sim 10 \mathrm{~nm},{ }^{23}$ significantly smaller than the optical path length required for light absorption (on order of $1 \mu \mathrm{m}$ ), therefore most photogenerated holes recombine before reaching electrolyte in a dense film of a sufficient thickness for light absorption. Recent work has focused on one dimensional nanostructures of $\mathrm{TiO}_{2}$ such as nanotubes, nanorods, nanowires etc., since these structures provide equivalent optical penetration depth to planar dense films but with less distance required for holes to diffuse to the interface (holes only need to diffuse across the radius of nanowires or the wall thickness of the nanotubes). ${ }^{11-14,} 20$ In addition to rapid charge transport properties, these nanostructures offer high surface area for dye adsorption which is essential for improving solar conversion efficiency in DSSCs. ${ }^{24,25}$

In the present study, we report a simple, scalable, low temperature hydrothermal synthesis of nanoplatelet arrays of rutile $\mathrm{TiO}_{2}$ with lengths of $\sim 130 \mathrm{~nm}$, widths of $\sim 5$ $\mathrm{nm}$, and heights (film thicknesses) of $\sim 1 \mu \mathrm{m}$ on fluorine doped tin oxide (FTO) coated glass substrates for photoanodes in PEC water oxidation and DSSC applications. We also demonstrate that this method can be applied for growing nanoplatelet arrays on various substrates including but not limited to Ti foil, glass, polyethylene terephthalate (PET) plastic, Si wafers, etc. The scalability, ease of synthesis, low cost (using low cost precursors $\mathrm{TiCl}_{3}, \mathrm{HCl}$, and $\left.\mathrm{H}_{2} \mathrm{O}\right)$, and low reaction temperature $\left(\sim 80{ }^{\circ} \mathrm{C}\right)$ are ideal for various applications, especially solar energy conversion. 


\section{EXPERIMENTAL SECTION}

Materials. All chemicals were purchased and used without further purification including $\mathrm{TiCl}_{3}(20 \%$ in $3 \% \mathrm{HCl}$ acid, Alfa Aesar), $\mathrm{HCl}$ (ACS Reagent Grade 36.5-38\%, MP), Di-tetrabutylammonium cis-bis(isothiocyanato)bis(2,2'-bipyridyl-4,4'dicarboxylato)ruthenium(II) aka. N719 dye (Sigma Aldrich), Idolyte AN-50 (Solaronix).

Hydrothermal Synthesis of $\mathrm{TiO}_{2}$ Nanoplatelet Arrays. Fluorine doped-Tin Oxide (FTO) coated glass substrates (with size of up to $3 \mathrm{~cm} \mathrm{x} 3 \mathrm{~cm}$ ) and other substrates were first cleaned by sonication in a mixture of ethanol and water for $30 \mathrm{~min}$, subsequently rinsed with deionized water, dried in an air stream and placed on the bottom of the $50 \mathrm{~mL}$ Pyrex glass vial reactor. In a typical hydrothermal growth procedure, the reaction solutions containing $10 \mathrm{~mL}$ of deionized water, $0.05-2.5 \mathrm{~mL}$ of $\mathrm{TiCl}_{3}$ solution (20\% in 3\% hydrochloric acid, Alfa Aesar), and 0-0.4 mL of $\mathrm{HCl}$ (ACS reagent grade 36.5-38\%, MP) were magnetically stirred for 30 minutes before being transferred into the Pyrex glass reactor. The hydrothermal growth was conducted at $80{ }^{\circ} \mathrm{C}$ for 2 to 10 hours in a box furnace. After the reaction was complete and the reactor was cooled down, the $\mathrm{TiO}_{2}$ nanoplatelet films were taken out and rinsed with copious amount of water. The $\mathrm{TiO}_{2}$ film deposited on the glass side of the FTO substrate was scraped off using a razor blade prior to further experimentation.

Post-treatments. The $\mathrm{TiO}_{2}$ nanoplatelets were then kept at $30{ }^{\circ} \mathrm{C}$ in a vacuum oven overnight, followed by ultraviolet/ozone treatment for 30 minutes to remove contaminants. Some of the samples were annealed in air at $450-550{ }^{\circ} \mathrm{C}$ in a box furnace for 30 minutes.

Material Characterizations. SEM was performed on a Zeiss field-emission SEM using a $10 \mathrm{kV}$ focus voltage. TEM and HRTEM were performed on a JEOL 2010F fieldemission TEM using a $200 \mathrm{kV}$ focus voltage. Grazing incidence X-ray diffraction 
(GIXRD) patterns were collected with a Bruker D8 diffractometer. The transmittance spectra were collected using a Cary 5000 UV-vis-NIR spectrophotometer. Photoluminescence spectra were acquired at room temperature using a FluoroLog 3 (Horiba Scientific) spectrofluorimeter. X-ray photoelectron spectroscopy (XPS) was performed on a Kratos Axis X-ray photoelectron spectrometer with a scanning step of 0.1 $\mathrm{eV}$ and a dwell time of 0.4 seconds/step. The binding energy was calibrated using the $\mathrm{C}$ 1s photoelectron peak at $284.5 \mathrm{eV}$ as a reference.

Electrochemical and Photoelectrochemical (PEC) Characterizations. The PEC measurements were performed using a three-electrode electrochemical cell with the FTO supported nanoplatelet array as the working electrode, a $\mathrm{Ag} / \mathrm{AgCl}$ (saturated $\mathrm{KCl}$ ) reference electrode, a platinum wire counter electrode, and $1 \mathrm{M} \mathrm{KOH}$ electrolyte $(\mathrm{pH}=$ 13.5). The working electrode with exposed area of $0.205 \mathrm{~cm}^{2}$ was illuminated from the back side (through the FTO substrate $-\mathrm{TiO}_{2}$ nanoplatelet interface) by a solar simulator (Newport, Model 9600, $150 \mathrm{~W}$ xenon lamp) equipped with an AM 1.5 G filter (Newport, Model 81094). The light intensity was measured as $100 \mathrm{~mW} / \mathrm{cm}^{2}$ using a thermopile detector with a spectrum response from 0.19 to $10.6 \mu \mathrm{m}$ (Newport, 818P-020-12). A CHI 660D electrochemical station was used for linear sweep voltammetry (I-V) and chronoamperometry (I-t) measurements.

Incident photon to current conversion efficiencies (IPCEs) were calculated from chronoamperometry measurements using a motorized monochromator (Oriel Cornerstone $1301 / 8 \mathrm{~m})$. The monochromator slit size was adjusted to $0.75 \mathrm{~mm}$ x $2 \mathrm{~mm}$ providing monochromatic wavelengths with a bandwidth of $\sim 8 \mathrm{~nm}$ and a power density which could be adjusted from 197 to $705 \mu \mathrm{W} / \mathrm{cm}^{2}$ for wavelengths from 320 to $800 \mathrm{~nm}$. A typical light power density spectrum used for IPCE can be found in Figure 5.1. Light 
power was measured using a handheld optical power meter with a UV enhanced silicon photo-detector (Newport). IPCE values were calculated using the following equation:

$$
\operatorname{IPCE}(\lambda)=\frac{1240 j_{p}(\lambda)}{\lambda E_{\lambda}(\lambda)}
$$

where $j_{p}(\lambda)$ is the measured photocurrent density $\left(\mathrm{mA} / \mathrm{cm}^{2}\right)$ and $E_{\lambda}(\lambda)$ is the incident light power density $\left(\mathrm{mW} / \mathrm{cm}^{2}\right)$ for each wavelength, $\lambda(\mathrm{nm})$.

The measured potentials $v s$. the $\mathrm{Ag} / \mathrm{AgCl}$ were converted to the reversible hydrogen electrode (RHE) scale via the Nernst equation

$$
\mathrm{E}_{\mathrm{RHE}}=\mathrm{E}_{\mathrm{Ag} / \mathrm{AgCl}}+0.059 \mathrm{pH}+\mathrm{E}_{\mathrm{Ag} / \mathrm{AgCl}}^{\mathrm{o}}
$$

where $\mathrm{E}_{\mathrm{RHE}}$ is the converted potential vs. RHE, $\mathrm{E}_{\mathrm{Ag} / \mathrm{AgCl}}$ is the experimental potential measured against the $\mathrm{Ag} / \mathrm{AgCl}$ reference electrode, and $\mathrm{E}_{\mathrm{Ag} / \mathrm{AgCl}}^{\mathrm{o}}=0.1976 \mathrm{~V}$ at $25^{\circ} \mathrm{C}$.

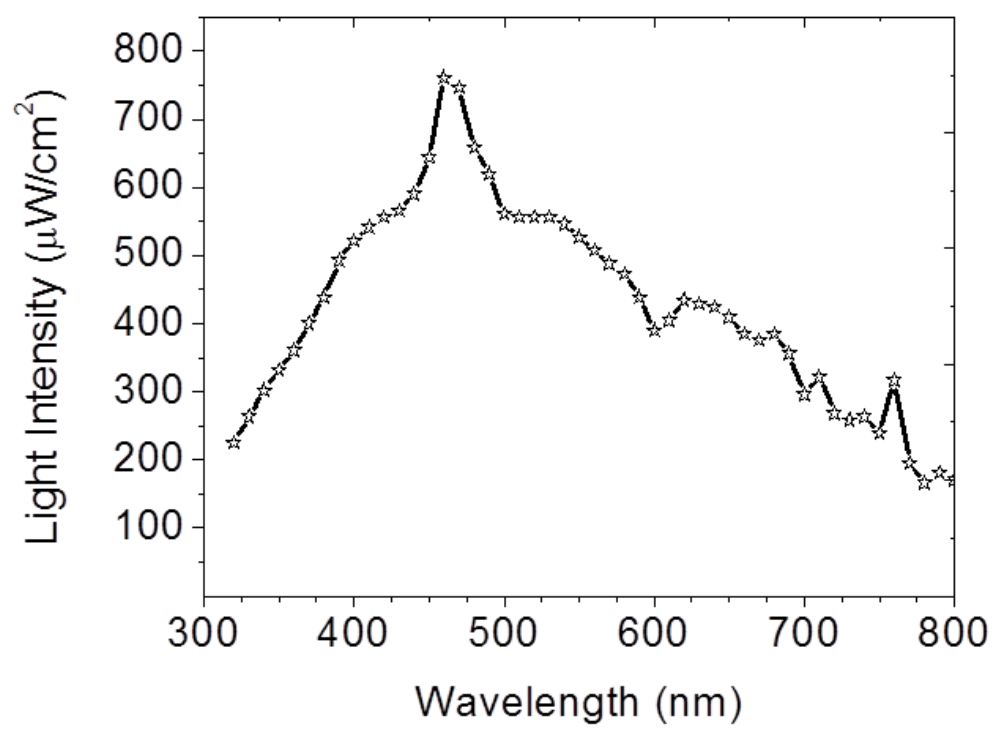

Figure 5.1. Typical light intensity for IPCE and EQE measurements 
Dye sensitized solar cell (DSSC) fabrication. The $\mathrm{TiO}_{2}$ nanoplatelet samples were immersed overnight in an ethanol solution containing $0.5 \mathrm{mM}$ N719 dye (ditetrabutylammonium cis-bis (isothiocyanato) bis (2,2'-bipyridyl-4,4'-dicarboxylato) ruthenium(II), Sigma Aldrich) for dye adsorption. Dye-sensitized $\mathrm{TiO}_{2}$ nanoplatelet arrays with an active area of $\sim 0.25-0.64 \mathrm{~cm}^{2}$ were assembled in a sandwich-type configuration with a Pt-coated FTO glass counter electrode (Solaronix) and a $25 \mu \mathrm{m}$ thick SX-1170 (Solaronix) spacer. The cells were filled with a commercial iodine/tri-iodine in acetonitrile based electrolyte (Iodolyte AN-50, Solaronix).

Dye sensitized solar cell characterizations. J-V measurements were obtained using a CHI 660D chemical station by independently applying external voltage to the cell and measuring the photocurrent. The electrochemical impedance spectroscopy of the DSSCs were obtained under AM 1.5 G illumination at open circuit potentials.

\section{RESULTS AND DISCUSSION}

Characterization of $\mathrm{TiO}_{2}$ Nanoplatelet Arrays. Figure 5.2a and b show the cross sectional view and top view scanning electron microscopy (SEM) images of a typical as-synthesized $\mathrm{TiO}_{2}$ nanoplatelet arrays on a FTO substrate, which were deposited at $80{ }^{\circ} \mathrm{C}$ for $3 \mathrm{~h}$ in $8 \mathrm{mM} \mathrm{TiCl}_{3}$ solution with $\mathrm{pH}$ of 0.85 . The $\mathrm{TiO}_{2}$ arrays consist of vertically aligned nanoplatelets with heights (film thicknesses) of $\sim 1 \mu \mathrm{m}$, lengths of $\sim$ $130 \mathrm{~nm}$, and widths $<5 \mathrm{~nm}$. The $\mathrm{TiO}_{2}$ nanoplatelet arrays can be classified as rutile $\mathrm{TiO}_{2}$ (JCPDS \#88-1875) with an enhancement in the exposure of the (101) facet, indicating that the nanoplatelets are well crystallized. The high resolution transmission electron microscopy (HRTEM) in Figure 5.1c indicates that the as-synthesized nanoplatelet is single crystalline, has a (110) interplanar d-spacing of $3.22 \AA$, and preferentially grows along the [001] direction. 


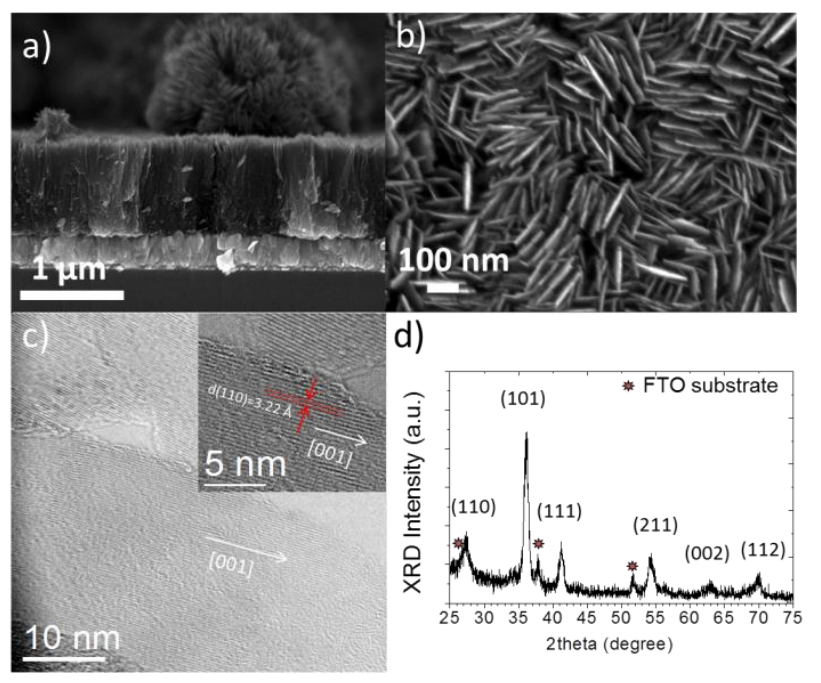

Figure 5.2. Single crystalline rutile $\mathrm{TiO}_{2}$ nanoplatelet arrays on FTO glass: (a) crosssectional and (b) top view SEM images, (c) HRTEM image; the inset shows lattice resolved HRTEM image, and (d) X-ray diffraction (XRD) pattern.

Figure 5.3a shows the XPS spectrum for core $\mathrm{Ti} 2 \mathrm{p}$ electrons from the $\mathrm{TiO}_{2}$ nanoplatelet sample. The Ti 2p3/2 and 2p1/2 XPS features at $458.4 \mathrm{eV}$ and $464.1 \mathrm{eV}$ respectively are assigned to $\mathrm{Ti}^{4+}$. Although, the $\mathrm{Ti}$ precursor is $\mathrm{Ti}^{3+}$ (in $\mathrm{TiCl}_{3}$ ), we observed only $\mathrm{Ti}^{4+}$ in the nanoplatelets. Figure $5.2 \mathrm{~b}$ shows the XPS spectrum of core O 1s which can be fitted by 2 curves peaking at $529.6 \mathrm{eV}$ and $531.3 \mathrm{eV}$ which can be assigned for surface $\mathrm{O}$ in $\mathrm{Ti}-\mathrm{O}$ and in $-\mathrm{OH}$ bonds respectively. ${ }^{26}$ 

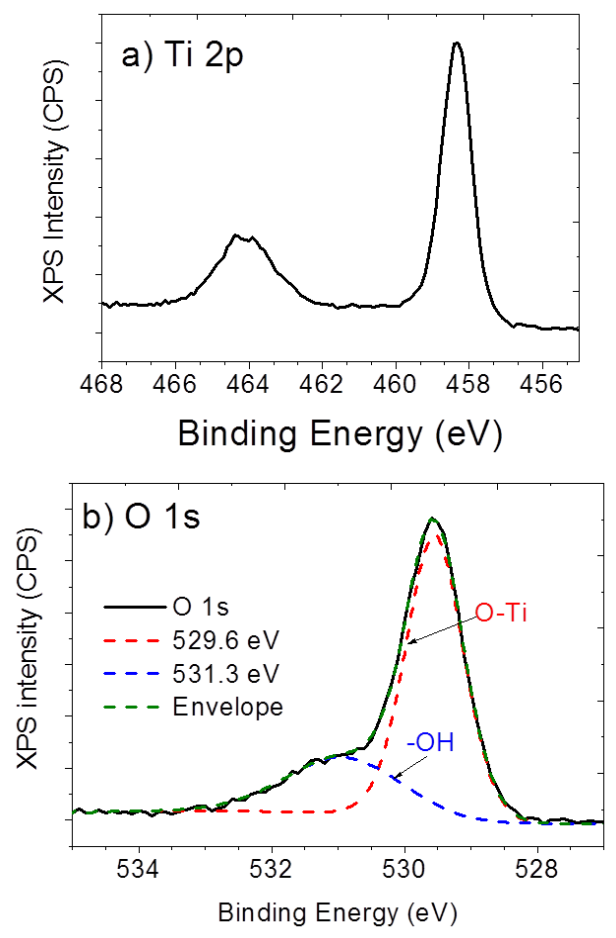

Figure 5.3. XPS spectra of (a) core Ti $2 p$ and (b) core $\mathrm{O}$ 1s and its fitting curves for $\mathrm{TiO}_{2}$ nanoplatelet arrays.

The morphology of the $\mathrm{TiO}_{2}$ films significantly changes with the acidity $(\mathrm{pH})$ of the reaction solution. Figure 5.4 shows the top-view SEM image of the $\mathrm{TiO}_{2}$ films obtained at different $\mathrm{pH}$ ranging from 1.2 to $0.66(\mathrm{pH}$ of the solution was adjusted by adding $0.05-0.3 \mathrm{~mL}$ of $\mathrm{HCl}$ solution to $10 \mathrm{~mL}$ of the reaction solution). We did not obtain any $\mathrm{TiO}_{2}$ deposition on the FTO substrate when the $\mathrm{pH}$ was out of this $\mathrm{pH}$ range. The $\mathrm{TiO}_{2}$ nanoplatelet morphology can only be obtained for $\mathrm{pH}$ in the range of $0.71-0.85$ (with addition of $0.2-0.25 \mathrm{~mL}$ of $\mathrm{HCl}$ solution). We observed an increase in the formation of a needle-like morphology when the $\mathrm{pH}$ was decreased to a value lower than 0.71 . In order to exclude the effect of changing the concentration of $\mathrm{Cl}^{-}$ions due to addition of different amounts of $\mathrm{HCl}$, we provided supplemental $\mathrm{Cl}^{-}$ion by adding various amounts of $\mathrm{NaCl}$ to the reaction solutions until the reaction solution is saturated with $\mathrm{NaCl}$. There 
is no change in the morphology of the $\mathrm{TiO}_{2}$ films with the addition of different amounts of $\mathrm{NaCl}$, thus confirming that the nanostructure of $\mathrm{TiO}_{2}$ films strongly depends on $\mathrm{pH}$ of the reaction solution but not on $\mathrm{Cl}^{-}$from the $\mathrm{HCl}$ solution.

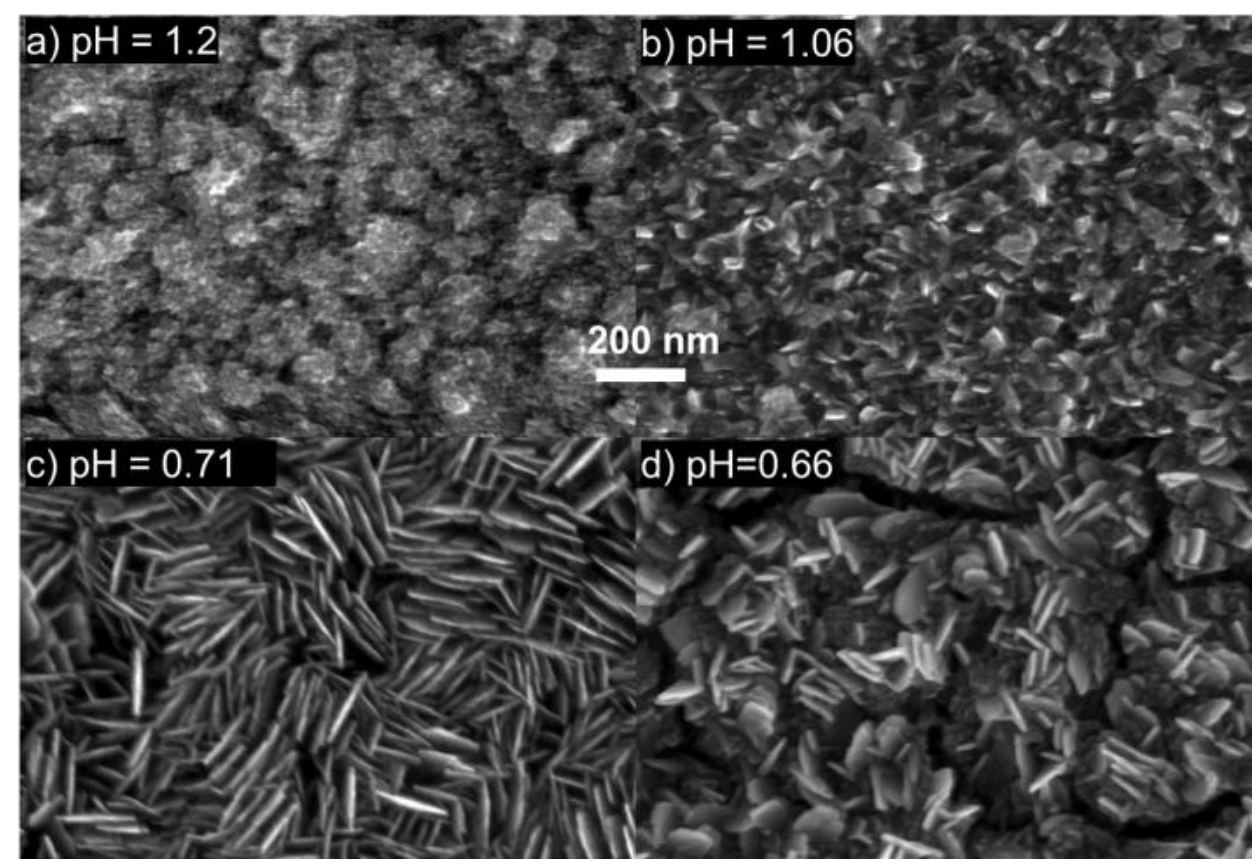

Figure 5.4. Top-view SEM images of $\mathrm{TiO}_{2}$ films obtained at various $\mathrm{pH}$ of the precursor solution: (a) $\mathrm{pH}=1.2$, (b) $\mathrm{pH}=1.06$, (c) $\mathrm{pH}=0.71$, and (d) $\mathrm{pH}=0.66$. The scale bar applies to all micrographs. We note that there is no $\mathrm{TiO}_{2}$ film obtained when $\mathrm{pH}$ of the precursor solution is smaller than 0.6 or larger than 1.2.

Hydrothermal/solvothermal grown one dimensional (1D) nanostructures of rutile $\mathrm{TiO}_{2}$ have received much attention since it demonstrates good performance for water photo-oxidation and DSSC applications. ${ }^{12-14}$ Typically the $\mathrm{TiO}_{2}$ nanowire arrays are hydrothermally/solvothermally grown using a Ti (IV) alkoxide such as titanium (IV) isopropoxide and titanium (IV) butoxide with or without $\mathrm{TiCl}_{4}$ as the titanium precursors. The growth of oriented $\mathrm{TiO}_{2}$ nanowires requires (1) slow hydrolysis of Ti precursors 
acquired by using a strong acidic medium and (2) capping agents/surfactants. ${ }^{14}$ Generally, the growth of 2D morphologies of rutile is not easy since it requires even slower reaction rates. ${ }^{27}$ Controlling the oxidation and hydrolysis of the Ti(III) precursor (such as $\mathrm{TiCl}_{3}$ ) is the key to obtaining the nanoplatelet morphology. Aoyama et al. ${ }^{27}$ investigated a 9-day chemical bath deposition of $\mathrm{TiO}_{2}$ nanosheets on glass substrates at room temperature using $0.1 \mathrm{M} \mathrm{TiCl}_{3}$ as the $\mathrm{Ti}$ precursor, reporting that the initial deposition started after 4 days, and then nanorod assembly started forming on the surface after 6 days. Finally, the formation of nanosheets from the nanorods started after 7 days. ${ }^{27}$ During $\mathrm{TiO}_{2}$ crystal growth, $\mathrm{Ti}^{\mathrm{III}}$ species were gradually oxidized by dissolved $\mathrm{O}_{2}$ to $\mathrm{Ti}^{\mathrm{IV}}$ species which were then hydrolyzed to form $\mathrm{TiO}_{2}$. Aoyama et al. also reported that when the initial $\mathrm{pH}$ was changed from 0.7 to 2 or the reaction temperature was increased from $25{ }^{\circ} \mathrm{C}$ to $40{ }^{\circ} \mathrm{C}$ to increase the reaction rate, needle-like morphologies or random aggregates were formed.

In our study, the growing process was facilitated by increasing reaction temperature to $80{ }^{\circ} \mathrm{C}$ but utilizing a much lower $\mathrm{TiCl}_{3}$ concentration $(8-40 \mathrm{mM})$ and low $\mathrm{pH}(0.60-1.2)$. Figure 5.5 shows the time-evolution growth of the $\mathrm{TiO}_{2}$ nanoplatelet arrays. The SEM image of the FTO substrate was included in Figure 5.5a for reference. We observed a $\mathrm{TiO}_{2}$ nanoplatelet crystal growth process similar to that reported by Aoyama and coworkers ${ }^{27}$ but on a much faster time scale. Initially, a $\mathrm{TiO}_{2}$ nuclei layer is slowly deposited on FTO substrate in the first 135 minutes (Figure 5.5b). After 150 minutes, $\mathrm{TiO}_{2}$ nano-needles were formed (Figure 5.5c) and quickly converted to nanoplatelets after 165 minutes as shown in Figure 5.4d (thickness of the film is $\sim 290$ $\mathrm{nm})$. The $\mathrm{TiO}_{2}$ nanoplatelets are then quickly grown, reaching a thickness of $\sim 1 \mu \mathrm{m}$ after 180 minutes (Figure 5.2a). 


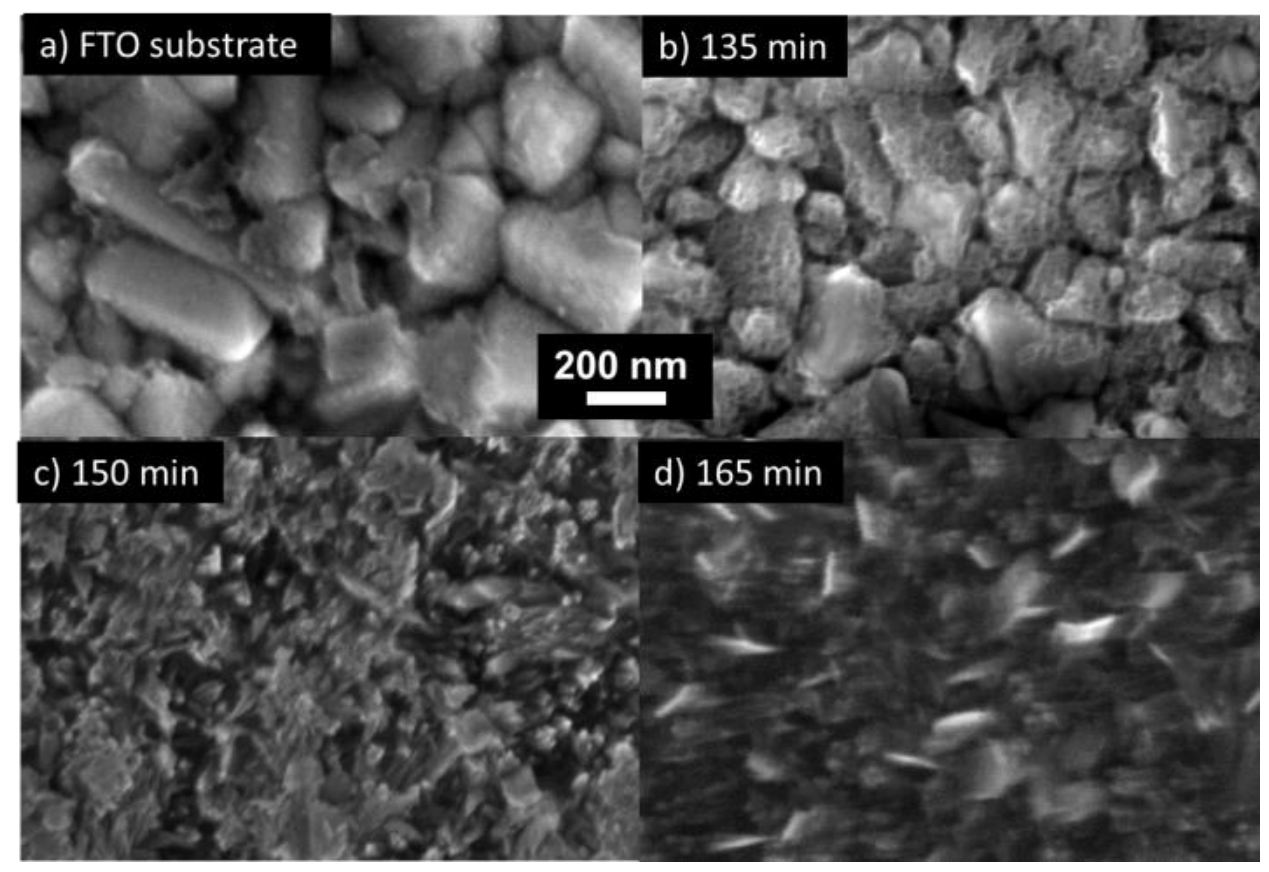

Figure 5.5. Top view SEM image of (a) FTO-coated glass substrate and time-evolution of $\mathrm{TiO}_{2}$ nanoplatelet growth: (b) after $135 \mathrm{~min}$, (c) after $150 \mathrm{~min}$, and (d) after $165 \mathrm{~min}$. The scale bar applies for all micrograph. See Figure 5.1b for the SEM image of the $\mathrm{TiO}_{2}$ film grown for $180 \mathrm{~min}$.

Prolonging the reaction duration from 3 hours to up to 10 hours does not increase the film thickness, but produces micron-size particles which consist of many nanoplaletlets (Figure 5.6) aggregating on the bottom of the reactor or on top of the films.

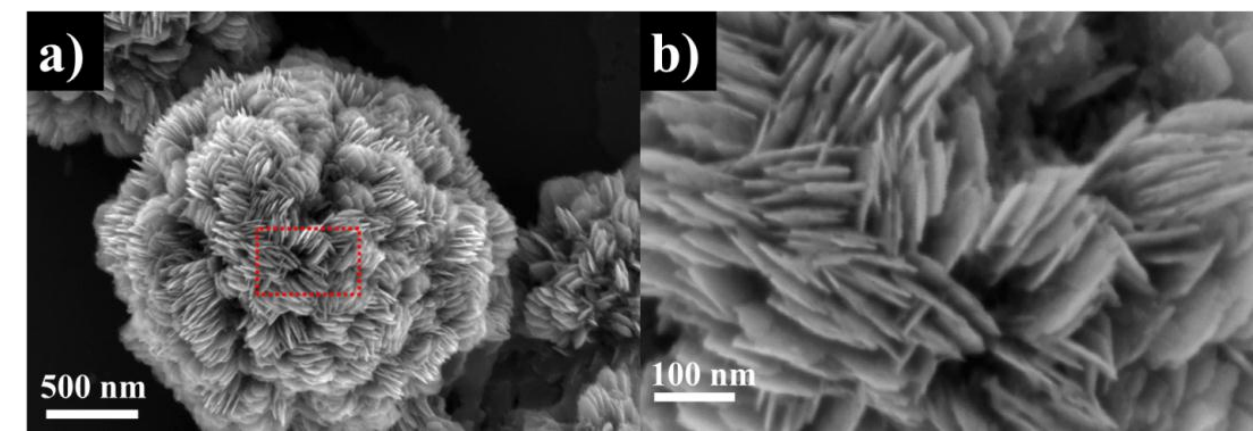

Figure 5.6. (a) SEM image of micron-size powder aggregating on the bottom of the reactor and (b) Higher magnification image of the area in the red box 
We did not observe a split of the nanosheets to nanofibers when prolonging the growing time of $\mathrm{TiO}_{2}$ nanosheet-arrays as reported by $\mathrm{Zhu}$ et al. when titanium (IV) isopropoxide was used as the Ti precursor. ${ }^{28} \mathrm{Zhu}$ et al. explained that this split is due to the increase in elastic strain stemming from the lattice mismatch between rutile $\mathrm{TiO}_{2}$ and the FTO substrate when the size of the $\mathrm{TiO}_{2}$ nanosheets increases. We have succeeded growing $\mathrm{TiO}_{2}$ nanoplatelet films on various substrates with different roughness and crystal structure such as glass, Ti foil, PET plastic, Si wafers etc. using the same recipe (Figure 5.7). We, therefore, believe that employing $\mathrm{TiCl}_{3}$ as the Ti precursor is the key in obtaining the nanoplatelet structure.

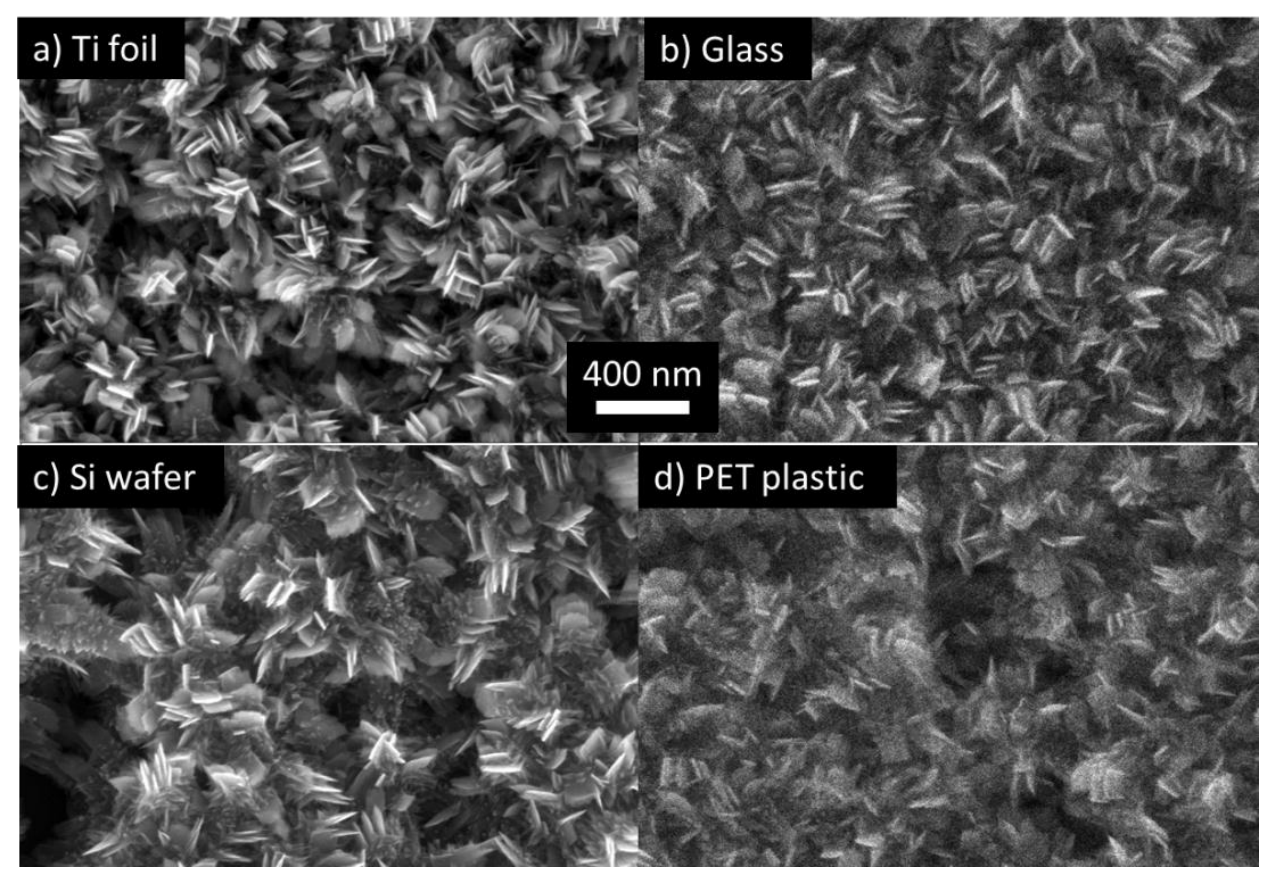

Figure 5.7. $\mathrm{SEM}$ images of $\mathrm{TiO}_{2}$ nanoplatelet grown on various substrates: (a) Ti foil, (b) glass, (c) Si wafer, and (d) polyethylene terephthalate (PET) plastic.

In order to investigate the effects of $\mathrm{TiCl}_{3}$ concentration, we prepared various $\mathrm{TiO}_{2}$ nanoplatelet arrays by adding $0.05-0.25 \mathrm{~mL}$ of $\mathrm{TiCl}_{3}$ solution to a reaction solution 
containing $10 \mathrm{~mL}$ of DI water and $0.2 \mathrm{~mL}$ of $\mathrm{HCl}$ to obtain concentrations of $\mathrm{TiCl}_{3}$ of from 8 to $40 \mathrm{mM}$. The $\mathrm{pH}$ of the reaction solution changes slightly when adding different volumes of $\mathrm{TiCl}_{3}$, reaching a $\mathrm{pH}$ of 0.91 with addition of $0.05 \mathrm{~mL}$ of $\mathrm{TiCl}_{3}$ solution and a $\mathrm{pH}$ of 0.70 with the addition of $0.25 \mathrm{~mL}$ of $\mathrm{TiCl}_{3}$ solution. As shown in figure 5.8 , the density of the nanoplatelets increases with the $\mathrm{TiCl}_{3}$ concentration. It is interesting to note that the thickness of the nanoplatelet arrays (the heights of the nanoplatelets) is almost the same although the shape of the nanoplatelets changes slightly with $\mathrm{TiCl}_{3}$ concentration which is probably due to the slight changes in $\mathrm{pH}$ of the precursor solution with the addition of different volumes of $\mathrm{TiCl}_{3}$ solution.

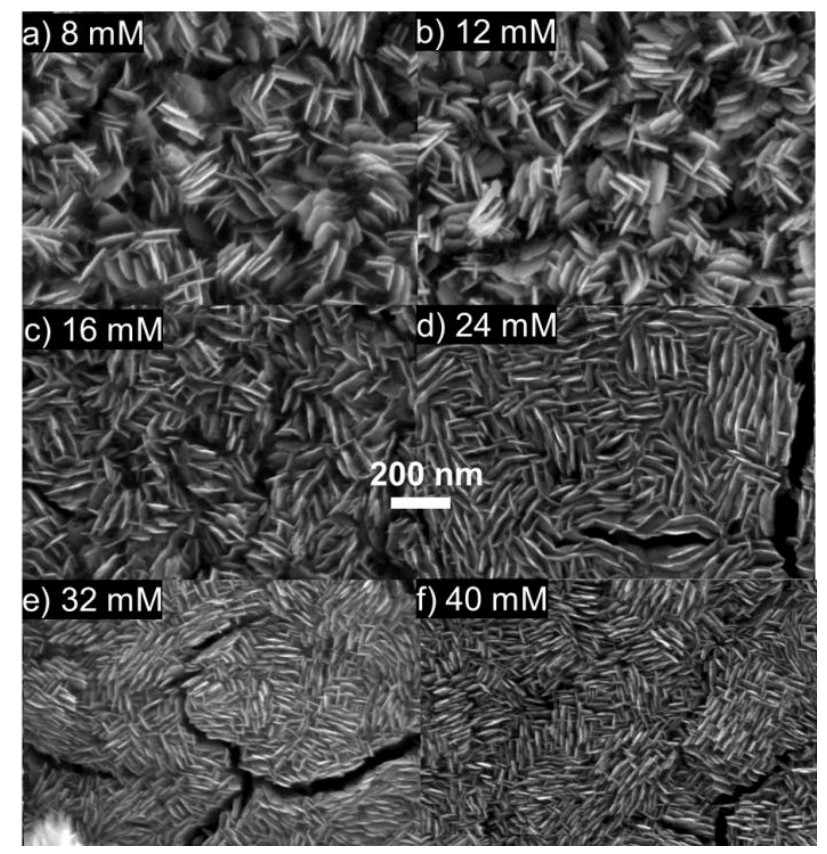

Figure 5.8. Top-view $\mathrm{SEM}$ images of $\mathrm{TiO}_{2}$ nanoplatelet arrays grown with various concentrations of $\mathrm{TiCl}_{3}$ solution: (a) $8 \mathrm{mM}$, (b) $12 \mathrm{mM}$, (c) $16 \mathrm{mM}$, (d) 24 $\mathrm{mM}$, (e) $32 \mathrm{mM}$, and (f) $40 \mathrm{mM}$. The scale bar is applied for all micrographs. Note that the $\mathrm{pH}$ of the reaction solution is slightly changed with the addition of different amounts of $\mathrm{TiCl}_{3}$ solution. 
Figure 5.9a shows the UV-vis absorbance spectra of a typical $\mathrm{TiO}_{2}$ nanoplatelet array with the absorption edge at $\sim 415 \mathrm{~nm}$, corresponding to a band gap of $3.0 \mathrm{eV}$, in agreement with the reported band gap value for rutile. ${ }^{2}$ Figure $5.9 \mathrm{~b}$ shows the photoluminescence (PL) spectra obtained using an excitation wavelength of $320 \mathrm{~nm}(3.88$ eV) at room temperature of a typical $\mathrm{TiO}_{2}$ nanoplatelet array. The PL from a semiconductor is a result of charge carrier recombination. ${ }^{29}$ Previous studies have shown that due to the indirect transition nature of $\mathrm{TiO}_{2}$, the $\mathrm{PL}$ response of bulk $\mathrm{TiO}_{2}$ is difficult to observe at room temperature (note that $\mathrm{TiO}_{2}$ has a direct band gap but is subjected to dipole-forbidden transitions ${ }^{26,30}$ ). We however observed a clear room temperature PL spectrum which can be fit by 3 Gaussian peaks at $402 \mathrm{~nm}(3.08 \mathrm{eV}), 440 \mathrm{~nm}(2.82 \mathrm{eV})$, and $486 \mathrm{~nm}(2.55 \mathrm{eV})$. Interestingly, the PL peak at $402 \mathrm{~nm}$ with a full width at half maximum (FWHM) of $50 \mathrm{~nm}$ coincides well with the band edge absorption shown in figure 5.9a and can thus be assigned as a band-to-band recombination. This band edge emission is very difficult to observe for indirect band gap semiconductors such as GaP and $\mathrm{TiO}_{2}$. There have been only few studies demonstrating the band-to-band emission for $\mathrm{TiO}_{2}$ ultrafine nanoparticles $(\sim 2 \mathrm{~nm}) .{ }^{31}$ The PL band centered at $440 \mathrm{~nm}$ is attributed to surface trap states. ${ }^{32}$ Finally the small peak at $486 \mathrm{~nm}$ is associated with surface oxygen vacancies since it originates from the charge transfer transition from $\mathrm{Ti}^{3+}$ to the oxygen anion in $\mathrm{TiO}_{6}{ }^{8-} \cdot 33$ 

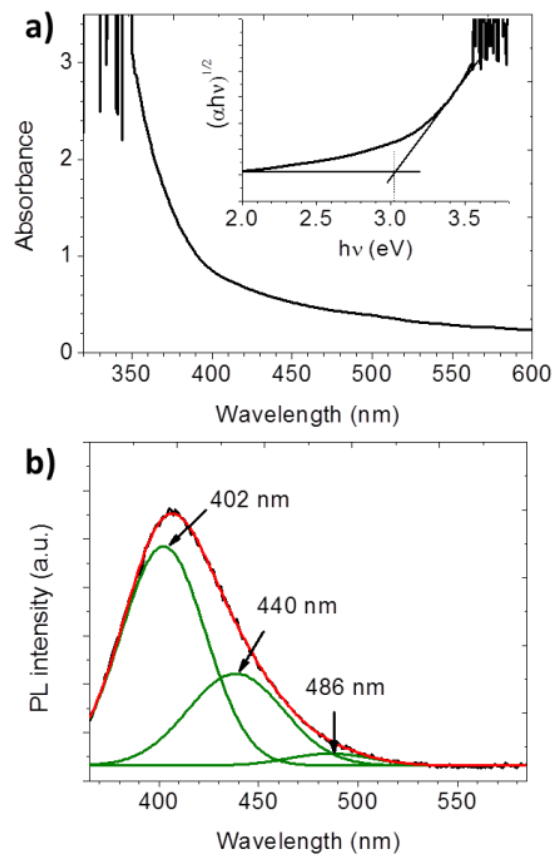

Figure 5.9. (a) UV-vis absorbance spectra of typical $\mathrm{TiO}_{2}$ nanoplatelet arrays. The inset shows the Tauc plot created for the absorbance values and (b) Photoluminescence emission spectrum (the black curve under the red curve which is the sum of the Gaussian fitted curves shown in green) from a typical $\mathrm{TiO}_{2}$ nanoplatelet film obtained at room temperature. The excitation wavelength is at $320 \mathrm{~nm}(3.88 \mathrm{eV})$.

\section{Photoelectrochemical Water Oxidation Performance of $\mathrm{TiO}_{2}$ Nanoplatelet}

Arrays. The PEC performance of the $\mathrm{TiO}_{2}$ films on FTO was measured using a threeelectrode electrochemical cell with the FTO supported $\mathrm{TiO}_{2}$ nanoplatelet array as the working electrode with exposed area of $0.2 \mathrm{~cm}^{2}$, a $\mathrm{Ag} / \mathrm{AgCl}$ reference electrode, a Pt wire counter electrode, and $1 \mathrm{M} \mathrm{KOH}$ electrolyte $(\mathrm{pH}=13.5)$. A solar simulator (Oriel 96000) coupled with an AM 1.5 G filter was used as the light source with light intensity of 100 $\mathrm{mW} / \mathrm{cm}^{2}$ measured by a thermopile detector (Newport $818 \mathrm{P}-020-12$ ). Incident photon to current conversion efficiencies (IPCEs) were calculated from chronoamperometry measurements using a motorized monochromator (Oriel Cornerstone 130 1/8 m). The monochromator slit size was adjusted to $0.75 \mathrm{~mm}$ x $2 \mathrm{~mm}$ providing monochromatic 
wavelengths with a bandwidth of $\sim 5 \mathrm{~nm}$ and a power density which could be adjusted from 165 to $760 \mu \mathrm{W} / \mathrm{cm}^{2}$ for wavelengths from 320 to $800 \mathrm{~nm}$. Light power was measured using a handheld optical power meter with a UV enhanced silicon photodetector (Newport). IPCE values were calculated using the following equation:

$\operatorname{IPCE}(\lambda)=\frac{1240 j_{p}(\lambda)}{\lambda E_{\lambda}(\lambda)}$

where $j_{p}(\lambda)$ is the measured photocurrent density $\left(\mathrm{mA} / \mathrm{cm}^{2}\right)$ and $E_{\lambda}(\lambda)$ is the incident light power density $\left(\mathrm{mW} / \mathrm{cm}^{2}\right)$ for each wavelength, $\lambda(\mathrm{nm})$.

The measured potentials vs. saturated $\mathrm{Ag} / \mathrm{AgCl}$ were converted to the reversible hydrogen electrode (RHE) scale via the Nernst equation:

$\mathrm{E}_{\mathrm{RHE}}=\mathrm{E}_{\mathrm{Ag} / \mathrm{AgCl}}+0.059 \mathrm{pH}+\mathrm{E}_{\mathrm{Ag} / \mathrm{AgCl}}^{\mathrm{o}}$

where $\mathrm{E}_{\mathrm{RHE}}$ is the converted potential vs. RHE, $\mathrm{E}_{\mathrm{Ag} / \mathrm{AgCl}}$ is the experimental potential measured against $\mathrm{Ag} / \mathrm{AgCl}$ reference electrode, and $\mathrm{E}_{\mathrm{Ag} / \mathrm{AgCl}}^{\mathrm{o}}=0.1976 \mathrm{~V}$ at 25 ${ }^{\circ} \mathrm{C}$.

Before testing, the as-synthesized films were annealed in air at $550{ }^{\circ} \mathrm{C}$ for 30 minutes to improve crystallinity and adherence of the $\mathrm{TiO}_{2}$ nanoplatelet array to the $\mathrm{SnO}_{2}$ layer. Figure 5.11a shows the linear sweep voltammetry under intermittent illumination for a typical $\mathrm{TiO}_{2}$ nanoplatelet array synthesized with a $16 \mathrm{mM} \mathrm{TiCl}_{3}$ precursor solution at $\mathrm{pH}$ of 0.71 . The onset potential is at $-0.8 \mathrm{~V}$ vs $\mathrm{Ag} / \mathrm{AgCl}\left(0.2 \mathrm{~V}_{\mathrm{RHE}}\right)$, in good agreement with the flat band potential determined from the Mott-Schottky plot (Figure 5.10). 


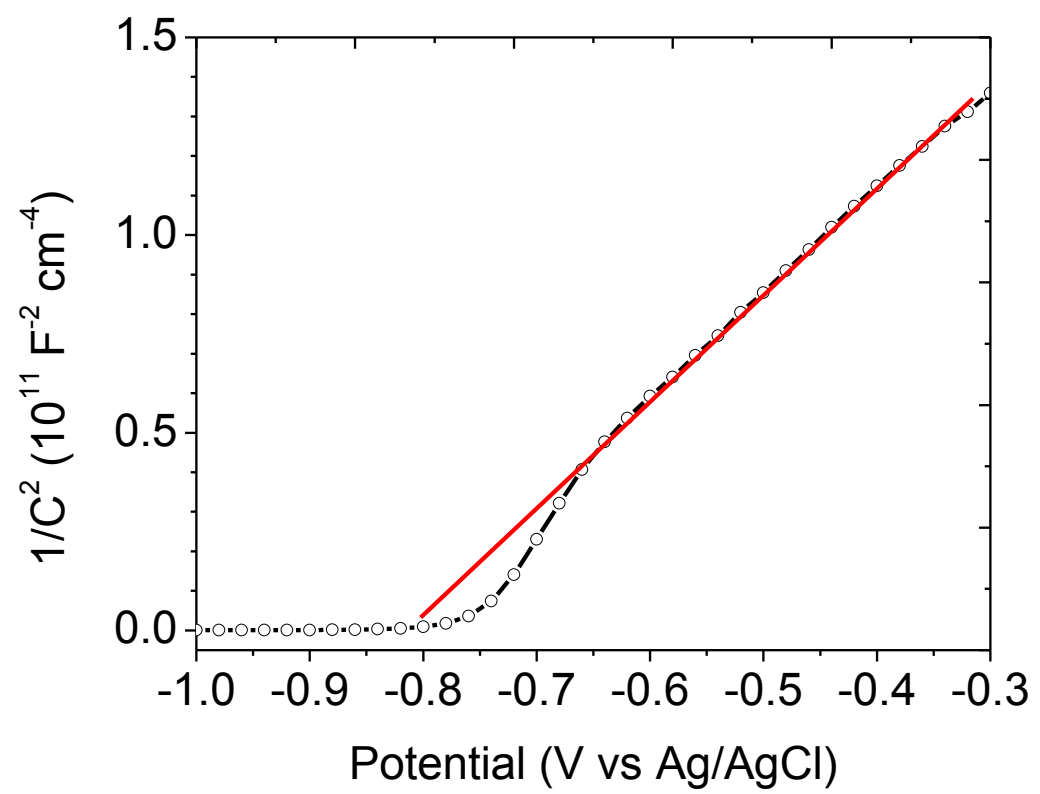

Figure 5.10. Mott-Schottky plot obtained in the dark in $1 \mathrm{M} \mathrm{KOH}$ electrolyte for a typical $\mathrm{TiO}_{2}$ nanoplatelet sample.

It is interesting that the photocurrent increases sharply with applied bias, reaching the saturated photocurrent at an exceptionally low potential of $-0.6 \mathrm{~V}$ vs $\mathrm{Ag} / \mathrm{AgCl}(0.4 \mathrm{~V}$ vs $\mathrm{RHE}$ ), compared to $-0.25 \mathrm{~V}$ vs. $\mathrm{Ag} / \mathrm{AgCl}$ for the single crystalline $\mathrm{TiO}_{2}$ rutile nanowire array photoanode reported by Feng et al. ${ }^{13}$ and compared to $0.5-1 \mathrm{~V}$ vs $\mathrm{Ag} / \mathrm{AgCl}$ for nanoparticle-based $\mathrm{TiO}_{2}$ photoanodes. ${ }^{34}$ This indicates excellent charge separation characteristics resulting from a high degree of crystallinity and a unique morphology that enables vectorial charge transfer (photo-generated holes just need to diffuse one-half of the lateral dimension of the nanoplatelet and photo-generated electrons can transport to the back contact without scattering at grain boundaries ${ }^{21}$ ). Figure 5.11b shows the IPCE spectrum for the $\mathrm{TiO}_{2}$ nanoplatelet photoanode in $1 \mathrm{M}$ $\mathrm{KOH}$ at $1.2 \mathrm{~V}_{\mathrm{RHE}}$. The IPCE onset is at $\sim 410 \mathrm{~nm}$, in good agreement with a band gap of $3.0 \mathrm{eV}$ as measured above. The IPCE values are high ( $\geq 40 \%)$ over a range of 330-380 
$\mathrm{nm}$, reaching a maximum of $57 \%$ at $350 \mathrm{~nm}$ indicative high light absorption and good charge separation characteristics.

Figure 5.11c shows the PEC performance at $1.2 \mathrm{~V}_{\mathrm{RHE}}$ for the $\mathrm{TiO}_{2}$ nanoplatelet films grown at various values of $\mathrm{pH}$. The $\mathrm{TiO}_{2}$ films obtained at $\mathrm{pH}$ of 0.6 and $\mathrm{pH} \geq 1.06$ are very thin, thus showing very poor PEC performance due to poor light absorption. The average thickness of $\mathrm{TiO}_{2}$ films obtained at $\mathrm{pH}$ of 0.66 is $\sim 600 \mathrm{~nm}$, compared to $\sim 1 \mu \mathrm{m}$ for the films obtained at $\mathrm{pH}$ of 0.71 and 0.85 , thus absorbing fewer photons and exhibiting lower photocurrents. The $\mathrm{TiO}_{2}$ nanoplatelet films obtained at $\mathrm{pH}$ of 0.71 demonstrates better PEC performance than the films grown at $\mathrm{pH}$ of 0.85 , although both films have quite similar morphology and thickness. We are unable to obtain exclusive evidence to explain this phenomenon. We hypothesize that changing $\mathrm{pH}$ might affect the initial nucleation rate and affect the aggregation at the base of the nanoplatelets which inhibits the diffusion of electrolyte deep into the $\mathrm{TiO}_{2}$ nanoplatelet array (which cannot be observed by conventional SEM). 

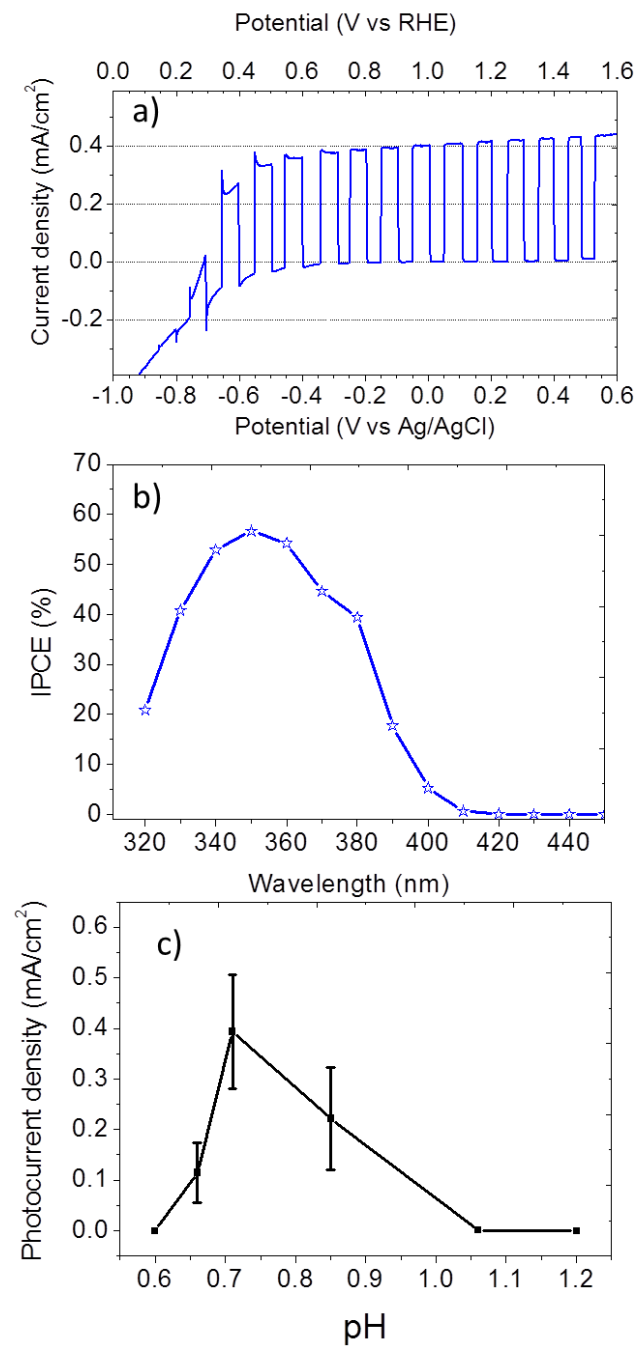

Figure 5.11. (a) Linear sweep voltammetry under intermittent AM 1.5 G illumination and (b) IPCE spectrum at $1.2 \mathrm{~V}_{\mathrm{RHE}}$ for a typical $\mathrm{TiO}_{2}$ nanoplatelet film synthesized with a $16 \mathrm{mM} \mathrm{TiCl}_{3}$ precursor solution at $\mathrm{pH}$ of 0.71 . (c) PEC performance at $1.2 \mathrm{~V}_{\mathrm{RHE}}$ of $\mathrm{TiO}_{2}$ films synthesized at various $\mathrm{pH}$. All measurements were conducted using 3-electrode electrochemical cell with a $\mathrm{Ag} / \mathrm{AgCl}$ reference electrode, a $\mathrm{Pt}$ wire counter electrode, and $1 \mathrm{M} \mathrm{KOH}$ electrolyte.

Dye sensitized solar cell performance of $\mathrm{TiO}_{2}$ nanoplatelet arrays. Prior to testing the performance for dye sensitized solar cell (DSSC), the as-hydrothermally synthesized $\mathrm{TiO}_{2}$ nanoplatelet samples were kept at $30{ }^{\circ} \mathrm{C}$ in a vacuum oven overnight to 
evaporate residue water, followed by UV/ozone treatment for 30 minutes to remove contaminants. Some of the films denoted as annealed- $\mathrm{TiO}_{2}$ nanoplatelets were annealed in air at $450{ }^{\circ} \mathrm{C}$ for 30 minutes. The $\mathrm{TiO}_{2}$ nanoplatelet arrays were then immersed overnight in an ethanol solution of $0.5 \mathrm{mM}$ N719 dye (di-tetrabutylammonium cis-bis (isothiocyanato) bis (2,2'-bipyridyl-4,4'-dicarboxylato) ruthenium(II), Sigma Aldrich) for dye adsorption. Dye-sensitized $\mathrm{TiO}_{2}$ nanoplatelet arrays with an active area of $\sim 0.25$ $0.64 \mathrm{~cm}^{2}$ were assembled in a sandwich-type configuration with a Pt-coated FTO glass counter electrode (Solaronix) and a $25 \mu \mathrm{m}$ thick SX-1170 (Solaronix) spacer. The cells were filled with a commercial iodine/tri-iodine in acetonitrile based electrolyte (Iodolyte AN-50, Solaronix).

Figure 5.12a shows the J-V characteristics and photoconversion efficiency of a typical dye sensitized, "as-hydrothermally synthesized" $\mathrm{TiO}_{2}$ nanoplatelet sample (no thermal post-treatment) under AM 1.5 G illumination. The photoconversion efficiency is $1.28 \%$ with an open circuit potential $\left(\mathrm{V}_{\mathrm{oc}}\right)$ of $0.68 \mathrm{~V}$, short circuit current density $\left(\mathrm{J}_{\mathrm{sc}}\right)$ of $2.92 \mathrm{~mA} \mathrm{~cm}^{-2}$, and a fill factor $(\mathrm{FF})$ of $64 \%$. This is quite promising performance for a $\mathrm{TiO}_{2}$ film that does not require thermal post-treatment. As we mentioned in the previous section, we were able to grow the nanoplatelet arrays on various types of substrates (including PET plastic). The as-synthesized $\mathrm{TiO}_{2}$ nanoplatelets are already crystallized and are thus ready to be used for DSSC application. This ability is especially useful for DSSC applications requiring flexible substrates which are normally polymer based materials and cannot handle the high temperatures that might be required in posttreatment processes.

The annealed- $\mathrm{TiO}_{2}$ nanoplatelets show significant improvement in DSSC performance (Figure 5.12a) with an overall photoconversion efficiency of $3.7 \%, \mathrm{~V}_{\text {oc }}$ of $0.76 \mathrm{~V}, \mathrm{~J}_{\mathrm{sc}}$ of $7.66 \mathrm{~mA} \mathrm{~cm}{ }^{-2}$, and $\mathrm{FF}$ of $64 \%$. Figure $5.12 \mathrm{~b}$ shows the external quantum 
efficiencies (EQE) of the annealed $\mathrm{TiO}_{2}$ nanoplatelet sample measured under short-circuit conditions. The photocurrent obtained by integrating the calculated EQE multiplied by AM 1.5 G solar energy flux is $7.55 \mathrm{~mA} / \mathrm{cm}^{2}$ which is in good agreement with the measured $\mathrm{J}_{\mathrm{sc}}$ value $\left(7.66 \mathrm{~mA} \mathrm{~cm}^{-2}\right)$.
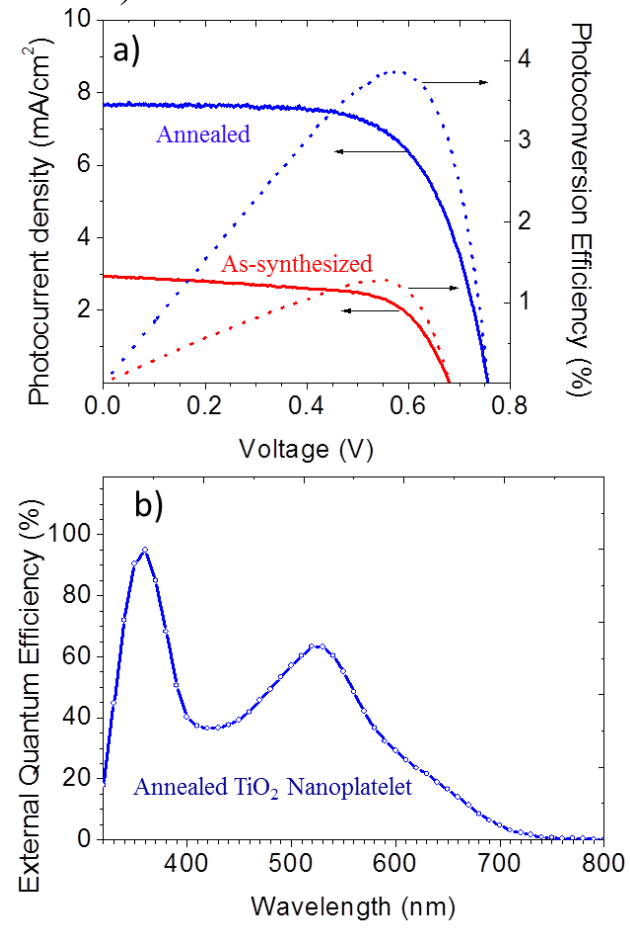

Figure 5.12. (a) Photocurrent density (solid line) and photoconversion efficiency (dotted line) of the DSSCs made of as-synthesized $\mathrm{TiO}_{2}$ nanoplatelets (red) and annealed $\mathrm{TiO}_{2}$ nanoplatelets (blue) under AM 1.5 G illumination (100 $\mathrm{mW} / \mathrm{cm}^{2}$ ); (b) External quantum efficiency of the DSSC made of annealed $\mathrm{TiO}_{2}$ nanoplatelets.

Figure 5.13 shows the electrochemical impedance spectroscopy (EIS) spectra obtained under AM 1.5 G illumination at $\mathrm{V}_{\text {oc }}$ of the DSSCs made of as-synthesized (red) and annealed (blue) $\mathrm{TiO}_{2}$ nanoplatelet samples. Both spectra show 2 semi-circles, of which the smaller and larger semicircles are attributed to the charge transfer at the counter electrode $(\mathrm{CE}) /$ electrolyte interface and the $\mathrm{TiO}_{2} /$ dye/electrolyte interface, 
respectively. The sheet resistance (Rs) of the substrates and the electrolyte, charge transfer resistance of the $\mathrm{CE}(\mathrm{R} 1)$, resistance at the $\mathrm{TiO}_{2} /$ dye/electrolyte interface (R2), and constant phase elements (CPE 1 and CPE 2) were analyzed using Z-view software with an equivalent circuit shown in the inset of Figure 5.13. Both cells have similar Rs of $\sim 11.5 \Omega$ and $\mathrm{R} 1$ of $\sim 1.8 \Omega$ as expected due to the use of the same counter electrode and electrolyte. It is interesting that the cell made of as-synthesized $\mathrm{TiO}_{2}$ nanoplatelets exhibits a higher value for $\mathrm{R} 2$ of $\sim 43 \Omega$ compared to $\mathrm{R} 2$ of $\sim 17 \Omega$ for the annealed $\mathrm{TiO}_{2}$ nanoplatelets. Normally, the increase in R2 indicates a better barrier for the backtransferring of electrons from $\mathrm{TiO}_{2}$ to the electrolyte, thus improving the DSSC performance. ${ }^{35}$ However, we observed lower performance for the as-synthesized $\mathrm{TiO}_{2}$ nanoplatelets cell. We propose that since the as-synthesized $\mathrm{TiO}_{2}$ film did not undergo thermal treatment, there are still some hydroxyl $(-\mathrm{OH})$ groups on the $\mathrm{TiO}_{2}$ nanoplatelet surfaces and probably moisture and oxygen trapped into the nanoplatelet arrays that could introduce adverse effects regarding N719 dye adsorption and/or degrade the N719 dye. The products of N719 dye degradation might be pyridine derivatives which are not effective for photon conversion but could absorb on the $\mathrm{TiO}_{2}$ surface thus inhibiting electron back transfer from $\mathrm{TiO}_{2}$ to the electrolyte. Jo et al. reported similar phenomena with the performance of their DSSCs decreasing with increasing the N719 dye coating temperature. $^{35}$ The authors explained that the degradation of N719 dye at high temperature produces pyridine derivatives which act as a barrier for electron back scattering. 


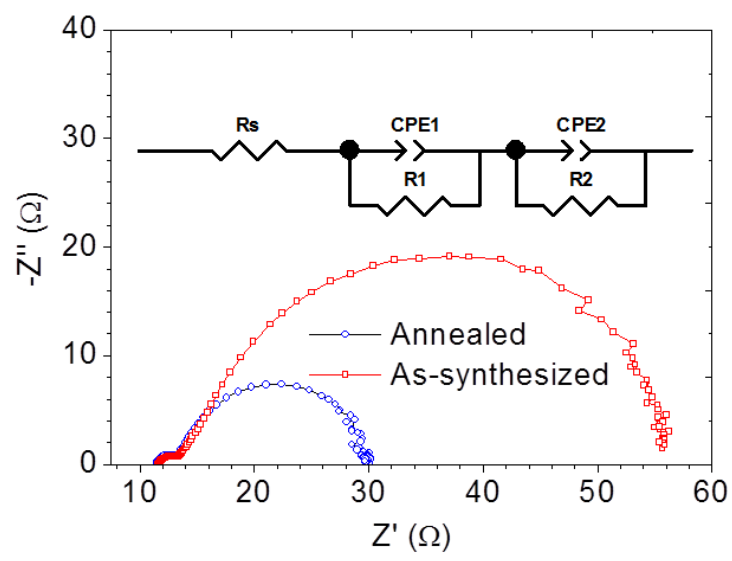

Figure 5.13. Electrical impedance spectroscopy (EIS) for DSSCs made of as-synthesized (red line) and annealed (blue line) $\mathrm{TiO}_{2}$ nanoplatelets. The inset demonstrates the equivalent circuit of the cell consisting of the counter electrode $(\mathrm{CE}) /$ redox electrolyte interface and the $\mathrm{TiO}_{2} /$ dye/redox electrolyte interface, where R1 and R2 are the respective resistances, CPE1 and CPE2 are the respective constant phase elements, and Rs is the sheet resistance of FTO, Pt-coated FTO substrates and the resistance of electrolyte.

\section{CONCLUSIONS}

In conclusion, we report a facile, scalable, low cost, and low temperature $\left(80{ }^{\circ} \mathrm{C}\right)$ hydrothermal synthesis of single crystalline $\mathrm{TiO}_{2}$ rutile nanoplatelet arrays on FTO and various substrates including Ti foil, glass, PET plastic, and Si substrates. The nanoplatelet arrays consist of vertically aligned nanoplatelets with heights (film thicknesses) of up to 1 $\mu \mathrm{m}$, lengths up to $130 \mathrm{~nm}$, and widths $\leq 5 \mathrm{~nm}$. The growth of the nanoplatelet arrays is sensitive to the acidity and $\mathrm{TiCl}_{3}$ concentration of the precursor solution. We believe that controlling the oxidation and hydrolysis of $\mathrm{Ti}^{3+}$ by using a low $\mathrm{TiCl}_{3}$ concentration $(8-40$ $\mathrm{mM})$ and low $\mathrm{pH}(0.71-0.85)$ is the key to obtaining the nanoplatelet morphology. We also demonstrate the application of $\mathrm{TiO}_{2}$ nanoplatelet arrays for water photo-oxidation and DSSC applications. As a photoanode for PEC water photo-oxidation, the $\mathrm{TiO}_{2}$ 
nanoplatelet sample demonstrated excellent charge separation characteristics with a saturated photocurrent under AM $1.5 \mathrm{G}$ illumination of $\sim 0.4 \mathrm{~mA} / \mathrm{cm}^{2}$ was reached at an exceptionally low bias of $-0.6 \mathrm{~V}$ vs $\mathrm{Ag} / \mathrm{AgCl}\left(0.4 \mathrm{~V}_{\mathrm{RHE}}\right)$, compared to $-0.25 \mathrm{~V}$ vs. $\mathrm{Ag} / \mathrm{AgCl}$ for a single crystalline $\mathrm{TiO}_{2}$ rutile nanowire array photoanode. ${ }^{13}$ Dye sensitized solar cells assembled using $\mathrm{N} 719$ dye sensitized- $\mathrm{TiO}_{2}$ nanoplatelet arrays show promising performance with photoconversion efficiencies of $1.28 \%$ for as-synthesized and $3.7 \%$ for annealed $\mathrm{TiO}_{2}$ nanoplatelets. 


\section{REFERENCES}

1. Fujishima, A.; Honda, K., Electrochemical Photolysis of Water at a Semiconductor Electrode. Nature 1972, 238, (5358), 37-38.

2. Chen, X.; Mao, S. S., Titanium Dioxide Nanomaterials: Synthesis, Properties, Modifications, and Applications. Chem. Rev. 2007, 107, (7), 2891-2959.

3. Fujishima, A.; Zhang, X.; Tryk, D. A., $\mathrm{TiO}_{2}$ photocatalysis and related surface phenomena. Surf. Sci. Rep. 2008, 63, (12), 515-582.

4. Linsebigler, A. L.; Lu, G.; Yates, J. T., Photocatalysis on $\mathrm{TiO}_{2}$ Surfaces: Principles, Mechanisms, and Selected Results. Chem. Rev. 1995, 95, (3), 735-758.

5. Asahi, R.; Morikawa, T.; Ohwaki, T.; Aoki, K.; Taga, Y., Visible-light photocatalysis in nitrogen-doped titanium oxides. Science 2001, 293, (5528), 269-271.

6. O'Regan, B.; Gratzel, M., A low-cost, high-efficiency solar cell based on dyesensitized colloidal $\mathrm{TiO}_{2}$ films. Nature 1991, 353, 737.

7. Lin, Y.-M.; Abel, P. R.; Flaherty, D. W.; Wu, J.; Stevenson, K. J.; Heller, A.; Mullins, C. B., Morphology Dependence of the Lithium Storage Capability and Rate Performance of Amorphous $\mathrm{TiO}_{2}$ Electrodes. J. Phys. Chem. C 2011, 115, (5), 2585-2591.

8. Murphy, A. B.; Barnes, P. R. F.; Randeniya, L. K.; Plumb, I. C.; Grey, I. E.; Horne, M. D.; Glasscock, J. A., Efficiency of solar water splitting using semiconductor electrodes. Int. J. Hydrogen Energy 2006, 31, (14), 1999-2017.

9. Cho, I. S.; Chen, Z.; Forman, A. J.; Kim, D. R.; Rao, P. M.; Jaramillo, T. F.; Zheng, X., Branched $\mathrm{TiO}_{2}$ Nanorods for Photoelectrochemical Hydrogen Production. Nano Lett. 2011, 11, (11), 4978-4984.

10. Hoang, S.; Berglund, S. P.; Hahn, N. T.; Bard, A. J.; Mullins, C. B., Enhancing Visible Light Photo-oxidation of Water with $\mathrm{TiO}_{2}$ Nanowire Arrays via Cotreatment with $\mathrm{H}_{2}$ and $\mathrm{NH}_{3}$ : Synergistic Effects between $\mathrm{Ti}^{3+}$ and N. J. Am. Chem. Soc. 2012, 134, (8), 3659-3662.

11. Mor, G. K.; Shankar, K.; Paulose, M.; Varghese, O. K.; Grimes, C. A., Enhanced photocleavage of water using titania nanotube arrays. Nano Lett. 2005, 5, (1), 191-195.

12. Hoang, S.; Guo, S.; Hahn, N. T.; Bard, A. J.; Mullins, C. B., Visible Light Driven Photoelectrochemical Water Oxidation on Nitrogen-Modified $\mathrm{TiO}_{2}$ Nanowires. Nano Lett. 2012, 12, (1), 26-32.

13. Feng, X.; Shankar, K.; Varghese, O. K.; Paulose, M.; Latempa, T. J.; Grimes, C. A., Vertically Aligned Single Crystal $\mathrm{TiO}_{2}$ Nanowire Arrays Grown Directly on Transparent Conducting Oxide Coated Glass: Synthesis Details and Applications. Nano Lett. 2008, 8, (11), 3781-3786. 
14. Liu, B.; Aydil, E. S., Growth of Oriented Single-Crystalline Rutile TiO2 Nanorods on Transparent Conducting Substrates for Dye-Sensitized Solar Cells. J. Am. Chem. Soc. 2009, 131, (11), 3985-3990.

15. Ye, M.; Xin, X.; Lin, C.; Lin, Z., High Efficiency Dye-Sensitized Solar Cells Based on Hierarchically Structured Nanotubes. Nano Lett. 2011, 11, (8), 3214-3220.

16. Park, J. H.; Kim, S.; Bard, A. J., Novel carbon-doped TiO2 nanotube arrays with high aspect ratios for efficient solar water splitting. Nano Lett. 2006, 6, (1), 24-28.

17. Hoang, S.; Guo, S.; Mullins, C. B., Co-incorporation of $\mathrm{N}$ and $\mathrm{Ta}$ into $\mathrm{TiO}_{2}$ Nanowires for Visible-light Driven Photoelectrochemical Water Oxidation. $J$. Phys. Chem. C 2012, 116, (44), 23283-23290.

18. Yin, W.-J.; Tang, H.; Wei, S.-H.; Al-Jassim, M. M.; Turner, J.; Yan, Y., Band structure engineering of semiconductors for enhanced photoelectrochemical water splitting: The case of $\mathrm{TiO}_{2}$. Phys. Rev. B 2010, 82, (4), 045106.

19. Gai, Y.; Li, J.; Li, S.-S.; Xia, J.-B.; Wei, S.-H., Design of Narrow-Gap $\mathrm{TiO}_{2}$ : A Passivated Codoping Approach for Enhanced Photoelectrochemical Activity. Phys. Rev. Lett. 2009, 102, (3), 036402.

20. van de Krol, R.; Liang, Y. Q.; Schoonman, J., Solar hydrogen production with nanostructured metal oxides. J. Mater. Chem. 2008, 18, (20), 2311-2320.

21. Kamat, P. V., Meeting the Clean Energy Demand: Nanostructure Architectures for Solar Energy Conversion. J. Phys. Chem. C 2007, 111, (7), 2834-2860.

22. Wang, G.; Wang, H.; Ling, Y.; Tang, Y.; Yang, X.; Fitzmorris, R. C.; Wang, C.; Zhang, J. Z.; Li, Y., Hydrogen-Treated $\mathrm{TiO}_{2}$ Nanowire Arrays for Photoelectrochemical Water Splitting. Nano Lett. 2011, 11, (7), 3026-3033.

23. Salvador, P., Hole diffusion length in $\mathrm{n}-\mathrm{TiO}_{2}$ single crystals and sintered electrodes: Photoelectrochemical determination and comparative analysis. J. Appl. Phys. 1984, 55, (8), 2977-2985.

24. Feng, X.; Zhu, K.; Frank, A. J.; Grimes, C. A.; Mallouk, T. E., Rapid Charge Transport in Dye-Sensitized Solar Cells Made from Vertically Aligned SingleCrystal Rutile $\mathrm{TiO}_{2}$ Nanowires. Angew. Chem. Int. Ed. 2012, 51, (11), 2727-2730.

25. Zhu, K.; Frank, A. J., Converting light to electrons in oriented nanotube arrays used in sensitized solar cells. MRS Bull. 2011, 36, (6), 446-452.

26. Yu, J.-G.; Yu, H.-G.; Cheng, B.; Zhao, X.-J.; Yu, J. C.; Ho, W.-K., The Effect of Calcination Temperature on the Surface Microstructure and Photocatalytic Activity of $\mathrm{TiO}_{2}$ Thin Films Prepared by Liquid Phase Deposition. J. Phys. Chem. $B$ 2003, 107, (50), 13871-13879.

27. Aoyama, Y.; Oaki, Y.; Ise, R.; Imai, H., Mesocrystal nanosheet of rutile TiO2 and its reaction selectivity as a photocatalyst. CrystEngComm 2012, 14, (4), 1405-1411. 
28. Zhu, H.; Yang, J.; Feng, S.; Liu, M.; Zhang, J.; Li, G., Growth of $\mathrm{TiO}_{2}$ nanosheetarray thin films by quick chemical bath deposition for dye-sensitized solar cells. Appl. Phys. A 2011, 105, (3), 769-774.

29. Liqiang, J.; Yichun, Q.; Baiqi, W.; Shudan, L.; Baojiang, J.; Libin, Y.; Wei, F.; Honggang, F.; Jiazhong, S., Review of photoluminescence performance of nanosized semiconductor materials and its relationships with photocatalytic activity. Sol. Energy Mater. Sol. Cells 2006, 90, (12), 1773-1787.

30. Daude, N.; Gout, C.; Jouanin, C., Electronic band structure of titanium dioxide. Phys. Rev. B 1977, 15, (6), 3229-3235.

31. Pan, D.; Zhao, N.; Wang, Q.; Jiang, S.; Ji, X.; An, L., Facile Synthesis and Characterization of Luminescent $\mathrm{TiO}_{2}$ Nanocrystals. Adv. Mater. 2005, 17, (16), 1991-1995.

32. Liu, J.; Li, J.; Sedhain, A.; Lin, J.; Jiang, H., Structure and Photoluminescence Study of TiO2 Nanoneedle Texture along Vertically Aligned Carbon Nanofiber Arrays. J. Phys. Chem. C 2008, 112, (44), 17127-17132.

33. Yu, J. C.; Yu; Ho; Jiang; Zhang, Effects of F- Doping on the Photocatalytic Activity and Microstructures of Nanocrystalline TiO2 Powders. Chem. Mater. 2002, 14, (9), 3808-3816.

34. Oliva, F. Y.; Avalle, L. a. B.; Santos, E.; Cámara, O. R., Photoelectrochemical characterization of nanocrystalline $\mathrm{TiO}_{2}$ films on titanium substrates. $J$. Photochem. Photobiol., A 2002, 146, (3), 175-188.

35. Jo, Y.; Jung, C.-1.; Lim, J.; Kim, B. H.; Han, C.-H.; Kim, J.; Kim, S.; Kim, D.; Jun, Y., A novel dye coating method for $\mathrm{N} 719$ dye-sensitized solar cells. Electrochim. Acta 2012, 66, (0), 121-125. 


\section{Chapter 6: Concluding Remarks and Future Research}

\section{OVERVIEW OF COMPLETED WORK}

In the previous chapters, we have discussed the solvo/hydrothermal synthesis methods and characterizations of single crystalline $\mathrm{TiO}_{2}$ nanowires and nanoplatelets on fluorine-doped tin oxide (FTO) coated glass substrates for photoelectrochemical (PEC) applications. These solvo/hydrothermal synthesis methods employ low cost precursors, simple set-up and provide high yield and high quality materials, thus are amenable to large-scale applications. These nanostructured $\mathrm{TiO}_{2}$ materials have shown excellent charge transport properties and thus PEC performance. We have also demonstrated a number of strategies to further improve the $\mathrm{PEC}$ performance of $\mathrm{TiO}_{2}$ including optimization of charge transport properties and light absorption via controlling the material compositions and employing water oxidation co-catalysts.

In chapter 2, we employed a solvothermal synthesis to grow single crystalline $\mathrm{TiO}_{2}$ nanowires on FTO with exceptionally small feature sizes of only $\sim 5 \mathrm{~nm}$. The morphology of the film can be controlled by manipulating synthesis parameters such as reaction temperature, Ti precursors and solvents, seeding methods etc. We have shown that the small feature sizes of the nanowires promote $\mathrm{N}$ diffusion into $\mathrm{TiO}_{2}$ lattice, thus allowing significant amount of $\mathrm{N}$ incorporating into $\mathrm{TiO}_{2}$ nanowires via nitridation in $\mathrm{NH}_{3}$ flow at a relatively low temperature. The active spectra of $\mathrm{N}$-incorporated $\mathrm{TiO}_{2}$ nanowires extends to $\sim 520 \mathrm{~nm}(2.4 \mathrm{eV})$, compared to $420 \mathrm{~nm}$ for the pristine $\mathrm{TiO}_{2}$ nanowires, the PEC performance however decreases with $\mathrm{N}$ incorporation probably due to a decreased oxidative power of photogenerated holes. Employing cobalt water oxidation catalyst systems facilitates water oxidation and passivates surface states on the $\mathrm{N}$-modified $\mathrm{TiO}_{2}$ nanowires, thus enhancing the PEC performance. 
In chapter 3, we demonstrated a novel strategy to improve visible light photooxidation properties of $\mathrm{TiO}_{2}$ nanowires involving hydrogenation and nitridation cotreatment. The active spectrum of the cotreated- $\mathrm{TiO}_{2}$ nanowires extends to $570 \mathrm{~nm}$, compared to $550 \mathrm{~nm}$ for the nitrided $\mathrm{TiO}_{2}$ nanowires and $420 \mathrm{~nm}$ for the pristine $\mathrm{TiO}_{2}$ nanowires. Employing electron paramagnetic resonance spectroscopy and X-ray photon emission spectroscopy, we revealed the concentration of $\mathrm{Ti}^{3+}$ species in the bulk of the $\mathrm{TiO}_{2}$ following hydrogenation and nitridation cotreatment $\left(\mathrm{H}, \mathrm{N}: \mathrm{TiO}_{2}\right)$ is considerably higher than that of the sample treated solely with ammonia. We proposed that the reversible electron transfer from $\mathrm{Ti}^{3+}$ to $\mathrm{N}$ dopant increases the electron density around $\mathrm{N}$ dopant, thus increasing Coulombic repulsion between $\mathrm{N}$ states and $\mathrm{O}$ states in the valence band of the $\mathrm{H}, \mathrm{N}: \mathrm{TiO}_{2}$ sample. Due to the greater Coulombic repulsion, the $\mathrm{N}$ states in the $\mathrm{H}, \mathrm{N}: \mathrm{TiO}_{2}$ sample have higher energy than that of the $\mathrm{N}$-modified $\mathrm{TiO}_{2}$ sample, thus enabling excitation with photons of longer wavelength.

In chapter 4, we presented a solvothermal synthesis route to incorporate Ta with concentration ranging from 0.11 to 3.47 atomic $\%$ into $\mathrm{TiO}_{2}$ nanowires. High resolution transmission electron microscopy (HRTEM) indicate homogeneous incorporation of Ta at low doping level ( 0.61 atomic \%). However, we observed a core/shell structure at high doping level $\left(\sim 2.65\right.$ atomic \%). $\mathrm{N}$ and $\mathrm{Ta}$ coincorporated $\mathrm{TiO}_{2}$ nanowires $(\mathrm{N}$, $\mathrm{Ta}: \mathrm{TiO}_{2}$ ) were prepared via nitridation of Ta-incorporated $\mathrm{TiO}_{2}$ nanowires at a relatively low temperature $\left(500{ }^{\circ} \mathrm{C}\right)$. The $\mathrm{N}, \mathrm{Ta}^{\mathrm{T}} \mathrm{TiO}_{2}$ samples demonstrate an enhanced PEC performance compared to the $\mathrm{N}$-incorporated $\mathrm{TiO}_{2}$ sample both in the $\mathrm{UV}$ and visible light region. We believe that the enhancement shown by the $\mathrm{N}, \mathrm{Ta}_{\mathrm{TiO}} \mathrm{Tamples}_{2}$ is due to fewer recombination centers from charge compensation effects and suppression of the formation of an amorphous layer on the nanowires during the nitridation process. 
In chapter 5, we demonstrated a hydrothermal synthesis of vertically aligned $\mathrm{TiO}_{2}$ nanoplatelet arrays on fluorine-doped tin oxide coated glass substrates and their applications for photoelectrochemical (PEC) water splitting and dye sensitized solar cells. The $\mathrm{TiO}_{2}$ arrays consisting of single crystal rutile nanoplatelets with heights (film thicknesses) of up to $1 \mu \mathrm{m}$, lengths of up to $130 \mathrm{~nm}$, and widths of $\sim 5 \mathrm{~nm}$ were grown via controlling oxidation and hydrolysis of $\mathrm{TiCl}_{3}$ at low $\mathrm{pH}(0.71-0.85)$ and low $\mathrm{TiCl}_{3}$ concentration $(8-40 \mathrm{mM})$. The morphology of the $\mathrm{TiO}_{2}$ nanoplatelet arrays can be controlled by manipulating reaction parameters such as reaction time, $\mathrm{pH}$ of solution, and Ti precursor concentration. As a photoanode for water oxidation in a PEC water splitting cell, the $\mathrm{TiO}_{2}$ nanoplatelets show excellent charge separation characteristics with a saturated photocurrent in $1 \mathrm{M} \mathrm{KOH}$ electrolyte under AM $1.5 \mathrm{G}$ illumination of $\sim 0.4$ $\mathrm{mA} / \mathrm{cm}^{2}$ reached at an exceptionally low bias of $-0.6 \mathrm{~V}$ vs $\mathrm{Ag} / \mathrm{AgCl}(0.4 \mathrm{~V}$ vs. reversible hydrogen electrode). Dye sensitized solar cells assembled using N719 dye sensitized$\mathrm{TiO}_{2}$ nanoplatelet arrays also show promising performance with photoconversion efficiencies of $1.28 \%$ for as-synthesized (no thermal post-treatment) and $3.7 \%$ for annealed $\mathrm{TiO}_{2}$ nanoplatelets. We also demonstrated that the $\mathrm{TiO}_{2}$ nanoplatelet arrays can be grown on various substrates including but not limited to Ti foil, glass, Si, and polyethylene terephthalate plastic. The synthesis method requires only low cost precursors $\left(\mathrm{TiCl}_{3}, \mathrm{HCl}\right)$, low reaction temperature $\left(80{ }^{\circ} \mathrm{C}\right)$, and easily scales up, thus ideal for various applications, especially for solar energy conversions.

\section{ONGOING AND FUTURE WORK}

As we discussed, an efficient photocatalyst semiconducting material for the PEC water splitting must satisfy stringent requirements such as a narrow band gap and high optical absorption coefficient to absorb a large fraction of the sunlight spectrum, an 
appropriate electronic band structure with band edges straddling the water redox potential, efficient charge transport properties, high photo-stability in an aqueous environment, and low cost. Unfortunately, no known single material has been discovered that satisfies all of these requirements. Figure 6.1 demonstrates various strategies to improve the PEC water splitting activity. ${ }^{1}$ To design materials, improving light absorbance and charge transport properties are two of the main approaches.

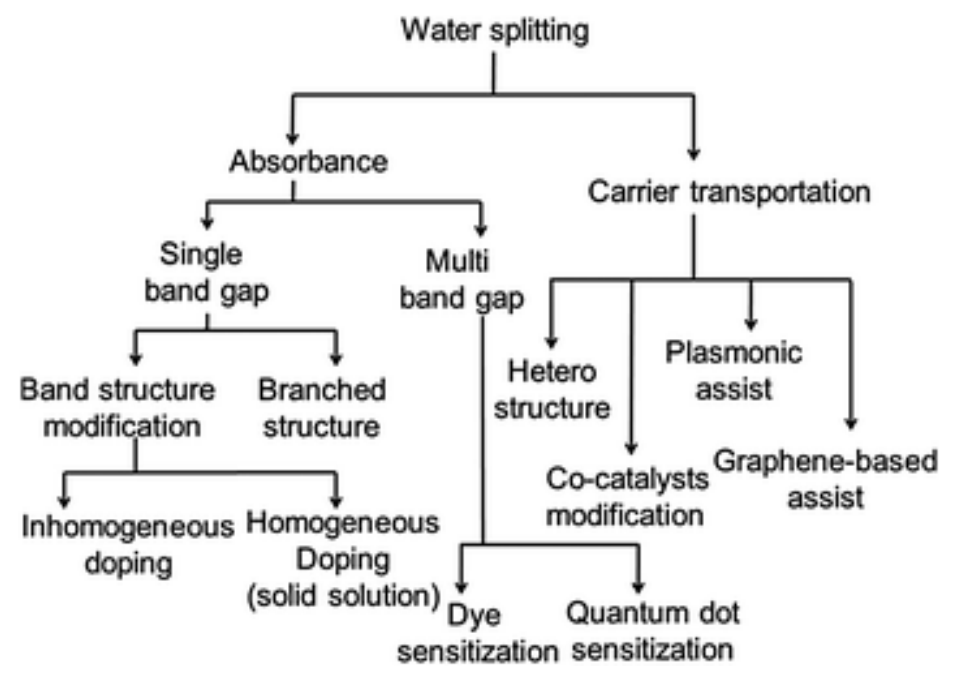

Figure 6.1. Various approaches for material design for water splitting application.

We are continuing studies on optimization the PEC performance of $\mathrm{TiO}_{2}$ materials via improving both absorbance and charge transport properties. In particular, we are currently working on the synthesis and characterizations of $\mathrm{Nb}$-incorporated $\mathrm{TiO}_{2}$ hierarchical microspheres which consist of many nanowires for water photo-oxidation and dye sensitized solar cell applications. The incident-photon-to-current conversion efficiency (IPCE) spectra of dye sensitized solar cells employing the $\mathrm{TiO}_{2}$ hierarchical microspheres (Figure 6.2) indicates efficient light harvesting properties probably due to light scattering and light trapping by the unique morphology. 

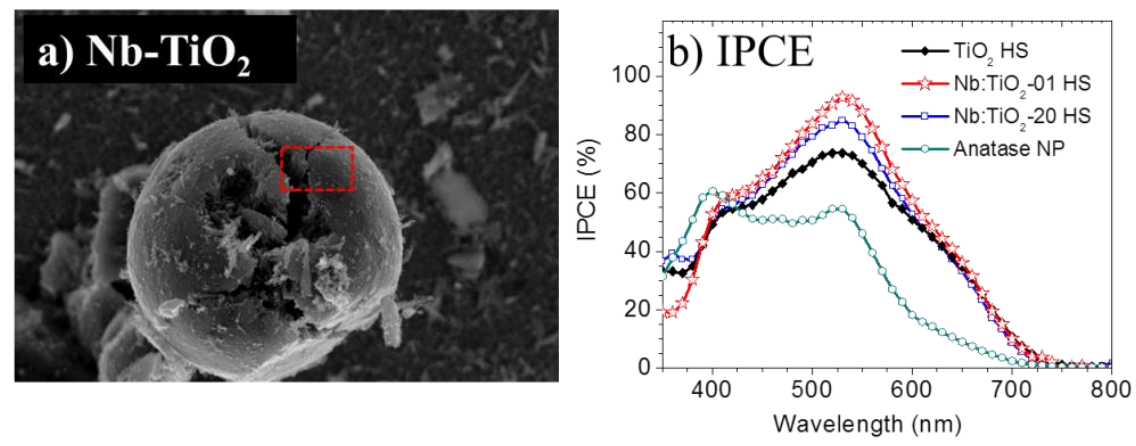

Figure 6.2. (a) Scanning electron micrograph of a $\mathrm{Nb}$-incorporated $\mathrm{TiO}_{2}$ hierarchical microsphere (HS), (b) incident-photon-to-current conversion efficiency (IPCE) spectra of dye sensitized solar cells employing $\mathrm{TiO}_{2}$ anatase nanoparticles (cyan), $\mathrm{TiO}_{2} \mathrm{HS}$ (black) and $\mathrm{Nb}$-incorporated $\mathrm{TiO}_{2}$ materials (blue and red).

We have recently initiated a project involving preparation of $\mathrm{TiO}_{2}$ and reduced graphene oxide nanocomposites for water splitting application. Employing solvol/hydrothermal synthesis, nanostructured $\mathrm{TiO}_{2}$ or transitional metal ( $\mathrm{Ta}, \mathrm{Nb}, \mathrm{W}$ etc.) incorporated $\mathrm{TiO}_{2}$ materials will be deposited on to a reduced graphene oxide arrays grown on fluorine-doped tin oxide (FTO) coated glass substrate. The nanocomposites will be further annealed in $\mathrm{NH}_{3}$ or $\mathrm{C}_{2} \mathrm{H}_{4}$ flow at an elevated temperature for incorporation of $\mathrm{N}$ or $\mathrm{C}$ that allow enhanced visible light excitations. The reduced graphene oxide scaffold acts as the electron channels, thus enabling faster electron transfer and minimizing photogenerated electron-hole recombination. ${ }^{2}$ We believe that the nanocomposites are also promising for dye sensitized solar cell applications.

In addition, we would like to propose some other directions for design $\mathrm{TiO}_{2}$ materials including (1) development of a 'soft' method for inclusion of N, C, etc, (2) development of titanate-based nanostructured photocatlysts emplying our reported $\mathrm{TiO}_{2}$ nanostructures. 
Develop a 'soft' method for incorporation of anion such as N, C, S etc. Anion incorporation seems to be more effective that cation incorporation in enhancing the visible light absorbance of $\mathrm{TiO}_{2}$. However, the general method for anion incorporation is annealed $\mathrm{TiO}_{2}$ materials in the anion-containing environment (for example $\mathrm{NH}_{3}$ for $\mathrm{N}$ incorporation). This method normally creates nonhomogeneous 'doping' and defects. Employing the anion-containing precursor in solvo/hydrothermal growth might provide milder conditions to modify $\mathrm{TiO}_{2}$ materials.

Develop titanate-based nanostructured photocatalysts which have a lower band gap than $\mathrm{TiO}_{2}$ such as bismuth titanium oxides (e.gBi $\left.{ }_{12} \mathrm{TiO}_{20}{ }^{3}\right)$. The energy level of $\mathrm{Bi} 6 \mathrm{~s}$ is close to but higher than $\mathrm{O} 2 \mathrm{p}$, thus allowing hybridization between $\mathrm{Bi} 6 \mathrm{~s}$ and $\mathrm{O} 2 \mathrm{p}$ orbitals to form a new valence band and narrow the band gap. Bismuth titanates can be prepared via hydrothermal reactions of our $\mathrm{TiO}_{2}$ nanowires, nanoplatelets, and hierarchical microspheres with Bi precursors. 


\section{REFERENCES}

(1) Chen, H. M.; Chen, C. K.; Liu, R.-S.; Zhang, L.; Zhang, J.; Wilkinson, D. P. Chem. Soc. Rev. 2012, 41, 5654.

(2) Williams, G.; Seger, B.; Kamat, P. V. ACS Nano 2008, 2, 1487.

(3) Murugesan, S.; Smith, Y. R.; Subramanian, V. J. Phys. Chem. Lett. 2010, 1,1631 . 


\section{Bibliography}

1. http://rredc.nrel.gov/solar/spectra/am1.5/.

2. Abe, R.; Higashi, M.; Domen, K., Facile Fabrication of an Efficient Oxynitride TaON Photoanode for Overall Water Splitting into $\mathrm{H}_{2}$ and $\mathrm{O}_{2}$ under Visible Light Irradiation. J. Am. Chem. Soc. 2010, 132, (34), 11828-11829.

3. Anpo, M.; Che, M.; Fubini, B.; Garrone, E.; Giamello, E.; Paganini, M., Generation of superoxide ions at oxide surfaces. Top. Catal. 1999, 8, (3), 189198.

4. Arab, S.; Li, D. S.; Kinsinger, N.; Zaera, F.; Kisailus, D., Solvothermal synthesis of a highly branched Ta-doped $\mathrm{TiO}_{2}$. J. Mater. Res. 2011, 26, (20), 2653-2659.

5. Asahi, R.; Morikawa, T.; Ohwaki, T.; Aoki, K.; Taga, Y., Visible-light photocatalysis in nitrogen-doped titanium oxides. Science 2001, 293, (5528), 269271.

6. Asahi, R.; Taga, Y.; Mannstadt, W.; Freeman, A. J., Electronic and optical properties of anatase $\mathrm{TiO}_{2}$. Phys. Rev. B 2000, 61, (11), 7459.

7. Bard, A. J.; Fox, M. A., Artificial Photosynthesis-Solar Splitting of Water to Hydrogen and Oxygen. Acc. Chem. Res. 1995, 28, (3), 141-145.

8. Batzill, M.; Morales, E. H.; Diebold, U., Influence of Nitrogen Doping on the Defect Formation and Surface Properties of $\mathrm{TiO}_{2}$ Rutile and Anatase. Phys. Rev. Lett. 2006, 96, (2), 026103.

9. Beranek, R.; Neumann, B.; Sakthivel, S.; Janczarek, M.; Dittrich, T.; Tributsch, H.; Kisch, H., Exploring the electronic structure of nitrogen-modified $\mathrm{TiO}_{2}$ photocatalysts through photocurrent and surface photovoltage studies. Chem. Phys. 2007, 339, (1-3), 11-19.

10. Bolton, J. R., Solar photoproduction of hydrogen: A review. Solar Energy 1996, 57, (1), 37-50.

11. Bolton, J. R.; Strickler, S. J.; Connolly, J. S., Limiting and realizable efficiencies of solar photolysis of water. Nature 1985, 316, (6028), 495-500.

12. Breault, T. M.; Bartlett, B. M., Lowering the Band Gap of Anatase-Structured $\mathrm{TiO}_{2}$ by Coalloying with $\mathrm{Nb}$ and $\mathrm{N}$ : Electronic Structure and Photocatalytic Degradation of Methylene Blue Dye. J. Phys. Chem. C 116, (10), 5986-5994.

13. Burda, C.; Lou, Y.; Chen, X.; Samia, A. C. S.; Stout, J.; Gole, J. L., Enhanced Nitrogen Doping in TiO2 Nanoparticles. Nano Lett. 2003, 3, (8), 1049-1051.

14. Chen, H. M.; Chen, C. K.; Liu, R.-S.; Zhang, L.; Zhang, J.; Wilkinson, D. P., Nano-architecture and material designs for water splitting photoelectrodes. Chem. Soc. Rev. 2012, 41, (17), 5654-5671. 
15. Chen, X.; Burda, C., Photoelectron Spectroscopic Investigation of NitrogenDoped Titania Nanoparticles. J. Phys. Chem. B 2004, 108, (40), 15446-15449.

16. Chen, X.; Burda, C., The Electronic Origin of the Visible-Light Absorption Properties of C-, N- and S-Doped $\mathrm{TiO}_{2}$ Nanomaterials. J. Am. Chem. Soc. 2008, 130, (15), 5018-5019.

17. Chen, X.; Liu, L.; Yu, P. Y.; Mao, S. S., Increasing Solar Absorption for Photocatalysis with Black Hydrogenated Titanium Dioxide Nanocrystals. Science 2011, 331, (6018), 746-750.

18. Chen, X.; Mao, S. S., Titanium Dioxide Nanomaterials: Synthesis, Properties, Modifications, and Applications. Chem. Rev. 2007, 107, (7), 2891-2959.

19. Chen, X. B.; Lou, Y. B.; Dayal, S.; Qiu, X. F.; Krolicki, R.; Burda, C.; Zhao, C. F.; Becker, J., Doped semiconductor nanomaterials. J. Nanosci. Nanotechnol. 2005, 5, (9), 1408-1420.

20. Cho, I. S.; Chen, Z.; Forman, A. J.; Kim, D. R.; Rao, P. M.; Jaramillo, T. F.; Zheng, X., Branched $\mathrm{TiO}_{2}$ Nanorods for Photoelectrochemical Hydrogen Production. Nano Lett. 2011, 11, (11), 4978-4984.

21. Choi, J.; Park, H.; Hoffmann, M. R., Combinatorial doping of $\mathrm{TiO}_{2}$ with platinum $(\mathrm{Pt})$, chromium $(\mathrm{Cr})$, vanadium $(\mathrm{V})$, and nickel $(\mathrm{Ni})$ to achieve enhanced photocatalytic activity with visible light irradiation. J. Mater. Res. 2010, 25, (1), 149-158.

22. Choi, W. Y.; Termin, A.; Hoffmann, M. R., The role of metal-ion dopants in quantum-sized $\mathrm{TiO}_{2}$ - Correlation between photoreactivity and charge carrier recombination dynamics. J. Phys. Chem. 1994, 98, (51), 13669-13679.

23. Cong, Y.; Zhang, J.; Chen, F.; Anpo, M., Synthesis and Characterization of Nitrogen-Doped TiO2 Nanophotocatalyst with High Visible Light Activity. $J$. Phys. Chem. C 2007, 111, (19), 6976-6982.

24. Di Valentin, C.; Finazzi, E.; Pacchioni, G.; Selloni, A.; Livraghi, S.; Czoska, A. M.; Paganini, M. C.; Giamello, E., Density Functional Theory and Electron Paramagnetic Resonance Study on the Effect of Nâ’'F Codoping of TiO2. Chem. Mater. 2008, 20, (11), 3706-3714.

25. Diwald, O.; Thompson, T. L.; Zubkov, T.; Walck, S. D.; Yates, J. T., Photochemical Activity of Nitrogen-Doped Rutile $\mathrm{TiO}_{2}(110)$ in Visible Light. $J$. Phys. Chem. B 2004, 108, (19), 6004-6008.

26. Dvoranova, D.; Brezova, V.; Mazur, M.; Malati, M. A., Investigations of metaldoped titanium dioxide photocatalysts. Appl. Cat. B 2002, 37, (2), 91-105.

27. Emeline, A. V.; Sheremetyeva, N. V.; Khomchenko, N. V.; Ryabchuk, V. K.; Serpone, N., Photoinduced Formation of Defects and Nitrogen Stabilization of 
Color Centers in N-Doped Titanium Dioxide. J. Phys. Chem. C 2007, 111, (30), 11456-11462.

28. Feng, X.; Shankar, K.; Paulose, M.; Grimes, C. A., Tantalum-Doped Titanium Dioxide Nanowire Arrays for Dye-Sensitized Solar Cells with High Open-Circuit Voltage. Angew. Chem. Int. Ed. 2009, 48, (43), 8095-8098.

29. Feng, X.; Shankar, K.; Varghese, O. K.; Paulose, M.; Latempa, T. J.; Grimes, C. A., Vertically Aligned Single Crystal $\mathrm{TiO}_{2}$ Nanowire Arrays Grown Directly on Transparent Conducting Oxide Coated Glass: Synthesis Details and Applications. Nano Lett. 2008, 8, (11), 3781-3786.

30. Fujishima, A.; Honda, K., Electrochemical Photolysis of Water at a Semiconductor Electrode. Nature 1972, 238, (5358), 37-38.

31. Fujishima, A.; Zhang, X. T.; Tryk, D. A., $\mathrm{TiO}_{2}$ photocatalysis and related surface phenomena. Surf. Sci. Rep. 2008, 63, (12), 515-582.

32. Gai, Y.; Li, J.; Li, S.-S.; Xia, J.-B.; Wei, S.-H., Design of Narrow-Gap TiO 2 : A Passivated Codoping Approach for Enhanced Photoelectrochemical Activity. Phys. Rev. Lett. 2009, 102, (3), 036402.

33. Gai, Y. Q.; Li, J. B.; Li, S. S.; Xia, J. B.; Yan, Y. F.; Wei, S. H., Design of shallow acceptors in $\mathrm{ZnO}$ through compensated donor-acceptor complexes: A density functional calculation. Phys. Rev. B 2009, 80, (15).

34. Hahn, N. T.; Ye, H.; Flaherty, D. W.; Bard, A. J.; Mullins, C. B., Reactive Ballistic Deposition of $\square-\mathrm{Fe}_{2} \mathrm{O}_{3}$ Thin Films for Photoelectrochemical Water Oxidation. ACS Nano 2010, 4, (4), 1977-1986.

35. Hoang, S.; Berglund, S. P.; Hahn, N. T.; Bard, A. J.; Mullins, C. B., Enhancing Visible Light Photo-oxidation of Water with $\mathrm{TiO}_{2}$ Nanowire Arrays via Cotreatment with $\mathrm{H}_{2}$ and $\mathrm{NH}_{3}$ : Synergistic Effects between $\mathrm{Ti}^{3+}$ and N. J. Am. Chem. Soc. 2012, 134, (8), 3659-3662.

36. Hoang, S.; Guo, S.; Hahn, N. T.; Bard, A. J.; Mullins, C. B., Visible Light Driven Photoelectrochemical Water Oxidation on Nitrogen-Modified $\mathrm{TiO}_{2}$ Nanowires. Nano Lett. 2012, 12, (1), 26-32.

37. Huang, J.; Wen, S.; Liu, J.; He, G., Band gap narrowing of TiO2 by compensated codoping for enhanced photocatalytic activity. J. Nat. Gas Chem. 2012, 21, (3), 302-307.

38. Hwang, Y. J.; Hahn, C.; Liu, B.; Yang, P., Photoelectrochemical Properties of $\mathrm{TiO}_{2}$ Nanowire Arrays: A Study of the Dependence on Length and Atomic Layer Deposition Coating. ACS Nano 2012, 6, (6), 5060-5069.

39. Irie, H.; Washizuka, S.; Yoshino, N.; Hashimoto, K., Visible-light induced hydrophilicity on nitrogen-substituted titanium dioxide films. Chem. Commun. 2003, (11), 1298-1299. 
40. Irie, H.; Watanabe, Y.; Hashimoto, K., Nitrogen-Concentration Dependence on Photocatalytic Activity of $\mathrm{TiO}_{2}-\mathrm{xN}_{\mathrm{x}}$ Powders. J. Phys. Chem. B 2003, 107, (23), 5483-5486.

41. Janisch, R.; Gopal, P.; Spaldin, N. A., Transition metal-doped $\mathrm{TiO}_{2}$ and $\mathrm{ZnO}$ present status of the field. J. Phys.: Condens. Matter 2005, 17, (27), R657-R689.

42. Kanan, M. W.; Nocera, D. G., In Situ Formation of an Oxygen-Evolving Catalyst in Neutral Water Containing Phosphate and $\mathrm{Co}^{2+}$. Science 2008, 321, (5892), 1072-1075.

43. Kay, A.; Cesar, I.; Grätzel, M., New Benchmark for Water Photooxidation by Nanostructured $\square-\mathrm{Fe}_{2} \mathrm{O}_{3}$ Films. J. Am. Chem. Soc. 2006, 128, (49), 15714-15721.

44. Khan, S. U. M.; Al-Shahry, M.; Ingler, W. B., Efficient photochemical water splitting by a chemically modified n- $\mathrm{TiO}_{2}$ Science 2002, 297, (5590), 2243-2245.

45. Lan, M.; Peng, X.; Hong, S.; Pei-Nan, W.; Weidian, S., First-principles calculation of $\mathrm{N}: \mathrm{H}$ codoping effect on energy gap narrowing of $\mathrm{TiO}_{2}$. Appl. Phys. Lett. 2007, 90, 171909.

46. Leary, R.; Westwood, A., Carbonaceous nanomaterials for the enhancement of $\mathrm{TiO}_{2}$ photocatalysis. Carbon 2011, 49, (3), 741-772.

47. Li, H.; Li, J.; Huo, Y., Highly Active $\mathrm{TiO}_{2} \mathrm{~N}$ Photocatalysts Prepared by Treating $\mathrm{TiO}_{2}$ Precursors in $\mathrm{NH}_{3}$ /Ethanol Fluid under Supercritical Conditions. J. Phys. Chem. B 2006, 110, (4), 1559-1565.

48. $\quad$ Lindgren, T.; Lu, J.; Hoel, A.; Granqvist, C. G.; Torres, G. R.; Lindquist, S. E., Photo electrochemical study of sputtered nitrogen-doped titanium dioxide thin films in aqueous electrolyte. Sol. Energy Mater. Sol. Cells 2004, 84, (1-4), 145157.

49. Linsebigler, A. L.; Lu, G.; Yates, J. T., Photocatalysis on $\mathrm{TiO}_{2}$ Surfaces: Principles, Mechanisms, and Selected Results. Chem. Rev. 1995, 95, (3), 735-758.

50. Litter, M. I.; Navio, J. A., Photocatalytic properties of iron-doped titania semiconductors. J. Photochem. Photobiol. A 1996, 98, (3), 171-181.

51. Livraghi, S.; Paganini, M. C.; Giamello, E.; Selloni, A.; Di Valentin, C.; Pacchioni, G., Origin of Photoactivity of Nitrogen-Doped Titanium Dioxide under Visible Light. J. Am. Chem. Soc. 2006, 128, (49), 15666-15671.

52. Long, R.; English, N. J., Band gap engineering of (N, Ta)-codoped $\mathrm{TiO}_{2}$ : A firstprinciples calculation. Chem. Phys. Lett. 2009, 478, (4-6), 175-179.

53. Ma, X. G.; Wu, Y.; Lu, Y. H.; Xu, J.; Wang, Y. J.; Zhu, Y. F., Effect of Compensated Codoping on the Photoelectrochemical Properties of Anatase $\mathrm{TiO}_{2}$ Photocatalyst. J. Phys. Chem. C 2011, 115, (34), 16963-16969. 
54. Meinan, L.; Hongxia, W.; Cheng, Y.; Geoffrey, W.; John, B., One-step synthesis of titanium oxide with trilayer structure for dye-sensitized solar cells. Appl. Phys. Lett. 2011, 98, 133113.

55. Mi, L.; Zhang, Y.; Wang, P.-N., First-principles study of the hydrogen doping influence on the geometric and electronic structures of N-doped TiO2. Chem. Phys. Lett. 2008, 458, (4-6), 341-345.

56. Miyauchi, M.; Ikezawa, A.; Tobimatsu, H.; Irie, H.; Hashimoto, K., Zeta potential and photocatalytic activity of nitrogen doped $\mathrm{TiO}_{2}$ thin films. PCCP 2004, 6, (4), 865-870.

57. Mor, G. K.; Prakasam, H. E.; Varghese, O. K.; Shankar, K.; Grimes, C. A., Vertically oriented Ti-Fe-O nanotube array films: Toward a useful material architecture for solar spectrum water photoelectrolysis. Nano Lett. 2007, 7, (8), 2356-2364.

58. Murphy, A. B.; Barnes, P. R. F.; Randeniya, L. K.; Plumb, I. C.; Grey, I. E.; Horne, M. D.; Glasscock, J. A., Efficiency of solar water splitting using semiconductor electrodes. Int. J. Hydrogen Energy 2006, 31, (14), 1999-2017.

59. Murugesan, S.; Smith, Y. R.; Subramanian, V., Hydrothermal Synthesis of $\mathrm{Bi}_{12} \mathrm{TiO}_{20}$ Nanostrucutures Using Anodized $\mathrm{TiO}_{2}$ Nanotubes and Its Application in Photovoltaics. J. Phys. Chem. Lett. 2010, 1, (10), 1631-1636.

60. Nakamura, R.; Tanaka, T.; Nakato, Y., Mechanism for visible light responses in anodic photocurrents at $\mathrm{N}$-doped $\mathrm{TiO}_{2}$ film electrodes. J. Phys. Chem. B 2004, 108, (30), 10617-10620.

61. Napoli, F.; Chiesa, M.; Livraghi, S.; Giamello, E.; Agnoli, S.; Granozzi, G.; Pacchioni, G.; Di Valentin, C., The nitrogen photoactive centre in N-doped titanium dioxide formed via interaction of $\mathrm{N}$ atoms with the solid. Nature and energy level of the species. Chem. Phys. Lett. 2009, 477, (1ậ€"3), 135-138.

62. Obata, K.; Irie, H.; Hashimoto, K., Enhanced photocatalytic activities of Ta, N codoped $\mathrm{TiO}_{2}$ thin films under visible light. Chem. Phys. 2007, 339, (1-3), 124-132.

63. Ohno, T.; Tanigawa, F.; Fujihara, K.; Izumi, S.; Matsumura, M., Photocatalytic oxidation of water on $\mathrm{TiO}_{2}$-coated $\mathrm{WO}_{3}$ particles by visible light using Iron(III) ions as electron acceptor. J. Photochem. Photobiol. A 1998, 118, (1), 41-44.

64. Ohsawa, T.; Henderson, M. A.; Chambers, S. A., Epitaxial Growth and Orientational Dependence of Surface Photochemistry in Crystalline $\mathrm{TiO}_{2}$ Rutile Films Doped with Nitrogen. J. Phys. Chem. C 2010, 114, (14), 6595-6601.

65. Pan, H.; Zhang, Y.-W.; Shenoy, V. B.; Gao, H., Effects of H-, N-, and (H, N)Doping on the Photocatalytic Activity of $\mathrm{TiO}_{2}$. J. Phys. Chem. C 2011, 115, (24), 12224-12231. 
66. Park, J. H.; Kim, S.; Bard, A. J., Novel carbon-doped $\mathrm{TiO}_{2}$ nanotube arrays with high aspect ratios for efficient solar water splitting. Nano Lett. 2006, 6, (1), 24-28.

67. Russo, S. P.; Grey, I. E.; Wilson, N. C., Nitrogen/hydrogen codoping of anatase: A DFT study. J. Phys. Chem. C 2008, 112, (20), 7653-7664.

68. Salvador, P., Hole diffusion length in $\mathrm{n}-\mathrm{TiO}_{2}$ single crystals and sintered electrodes: Photoelectrochemical determination and comparative analysis. J. Appl. Phys. 1984, 55, (8), 2977-2985.

69. Sathish, M.; Viswanathan, B.; Viswanath, R. P.; Gopinath, C. S., Synthesis, Characterization, Electronic Structure, and Photocatalytic Activity of NitrogenDoped $\mathrm{TiO}_{2}$ Nanocatalyst. Chem. Mater. 2005, 17, (25), 6349-6353.

70. Serpone, N., Is the Band Gap of Pristine $\mathrm{TiO}_{2}$ Narrowed by Anion- and CationDoping of Titanium Dioxide in Second-Generation Photocatalysts? J. Phys. Chem. B 2006, 110, (48), 24287-24293.

71. Shannon, R. D., Revised effective ionic-radii and systematic studies of interatomic distances in halides and chalcogenides. Acta Crystallographica Section A 1976, 32, 751-767.

72. Shao, F.; Sun, J.; Gao, L.; Yang, S.; Luo, J., Template-Free Synthesis of Hierarchical $\mathrm{TiO}_{2}$ Structures and Their Application in Dye-Sensitized Solar Cells. ACS Appl. Mater. Interfaces 2011, 3, (6), 2148-2153.

73. Takahashi, I.; Payne, D. J.; Palgrave, R. G.; Egdell, R. G., High resolution X-ray photoemission study of nitrogen doped $\mathrm{TiO}_{2}$ rutile single crystals. Chem. Phys. Lett. 2008, 454, (4-6), 314-317.

74. Tang, J.; Cowan, A. J.; Durrant, J. R.; Klug, D. R., Mechanism of $\mathrm{O}_{2}$ Production from Water Splitting: Nature of Charge Carriers in Nitrogen Doped Nanocrystalline $\mathrm{TiO}_{2}$ Films and Factors Limiting $\mathrm{O}_{2}$ Production. J. Phys. Chem. C 2011, 115, (7), 3143-3150.

75. Teleki, A.; Pratsinis, S. E., Blue nano titania made in diffusion flames. PCCP 2009, 11, (19), 3742-3747.

76. Torres, G. R.; Lindgren, T.; Lu, J.; Granqvist, C. G.; Lindquist, S. E., Photoelectrochemical study of nitrogen-doped titanium dioxide for water oxidation. J. Phys. Chem. B 2004, 108, (19), 5995-6003.

77. Umebayashi, T.; Yamaki, T.; Itoh, H.; Asai, K., Band gap narrowing of titanium dioxide by sulfur doping. Appl. Phys. Lett. 2002, 81, (3), 454-456.

78. Umebayashi, T.; Yamaki, T.; Itoh, H.; Asai, K., Analysis of electronic structures of $3 \mathrm{~d}$ transition metal-doped $\mathrm{TiO}_{2}$ based on band calculations. J. Phys. Chem. Solids 2002, 63, (10), 1909-1920. 
79. van de Krol, R.; Liang, Y. Q.; Schoonman, J., Solar hydrogen production with nanostructured metal oxides. J. Mater. Chem. 2008, 18, (20), 2311-2320.

80. Wang, G.; Wang, H.; Ling, Y.; Tang, Y.; Yang, X.; Fitzmorris, R. C.; Wang, C.; Zhang, J. Z.; Li, Y., Hydrogen-Treated $\mathrm{TiO}_{2}$ Nanowire Arrays for Photoelectrochemical Water Splitting. Nano Lett. 2011, 11, (7), 3026-3033.

81. Wang, J.; Tafen, D. N.; Lewis, J. P.; Hong, Z.; Manivannan, A.; Zhi, M.; Li, M.; $\mathrm{Wu}, \mathrm{N}$., Origin of Photocatalytic Activity of Nitrogen-Doped $\mathrm{TiO}_{2}$ Nanobelts. $J$. Am. Chem. Soc. 2009, 131, (34), 12290-12297.

82. Wang, W.; Lu, C.; Ni, Y.; Su, M.; Huang, W.; Xu, Z., Preparation and characterization of visible-light-driven N-F-Ta tri-doped $\mathrm{TiO}_{2}$ photocatalysts. Appl. Surf. Sci. 2012, 258, (22), 8696-8703.

83. Williams, G.; Seger, B.; Kamat, P. V., $\mathrm{TiO}_{2}$-Graphene Nanocomposites. UVAssisted Photocatalytic Reduction of Graphene Oxide. ACS Nano 2008, 2, (7), 1487-1491.

84. Xu, M.; Da, P.; Wu, H.; Zhao, D.; Zheng, G., Controlled Sn-Doping in $\mathrm{TiO}_{2}$ Nanowire Photoanodes with Enhanced Photoelectrochemical Conversion. Nano Lett. 2012, 12, (3), 1503-1508.

85. Ye, H.; Park, H. S.; Bard, A. J., Screening of Electrocatalysts for Photoelectrochemical Water Oxidation on W-Doped $\mathrm{BiVO}_{4}$ Photocatalysts by Scanning Electrochemical Microscopy. J. Phys. Chem. C 2011, 115, (25), 1246412470 .

86. Yin, W.-J.; Tang, H.; Wei, S.-H.; Al-Jassim, M. M.; Turner, J.; Yan, Y., Band structure engineering of semiconductors for enhanced photoelectrochemical water splitting: The case of $\mathrm{TiO}_{2}$. Phys. Rev. B 2010, 82, (4), 045106.

87. Zhu, W.; Qiu, X.; Iancu, V.; Chen, X.-Q.; Pan, H.; Wang, W.; Dimitrijevic, N. M.; Rajh, T.; Meyer, H. M.; Paranthaman, M. P.; Stocks, G. M.; Weitering, H. H.; Gu, B.; Eres, G.; Zhang, Z., Band Gap Narrowing of Titanium Oxide Semiconductors by Noncompensated Anion-Cation Codoping for Enhanced Visible-Light Photoactivity. Phys. Rev. Lett. 2009, 103, (22), 226401. 


\section{Vita}

Son Thanh Hoang was born in Bac Giang, Vietnam. In 2001, he graduated from HUS High School for Gifted Students in Chemistry in Hanoi, Vietnam, and enrolled in the Honor Program for Talented Students at the Hanoi University of Science (HUS) with a major in Chemistry. While attending HUS, Son conducted undergraduate research under the guidance of Professor Ha Cao The. Son finished his undergraduate work and was awarded his Bachelor of Science degree in Chemistry in May 2005. In 2007, Son received Vietnam Education Foundation's fellowship and enrolled in the Chemical Engineering doctoral program at the University of Texas at Austin where he began his graduate research under the guidance of Professor C. Buddie Mullins.

Email address: hson83@gmail.com

This dissertation was typed by the author. 